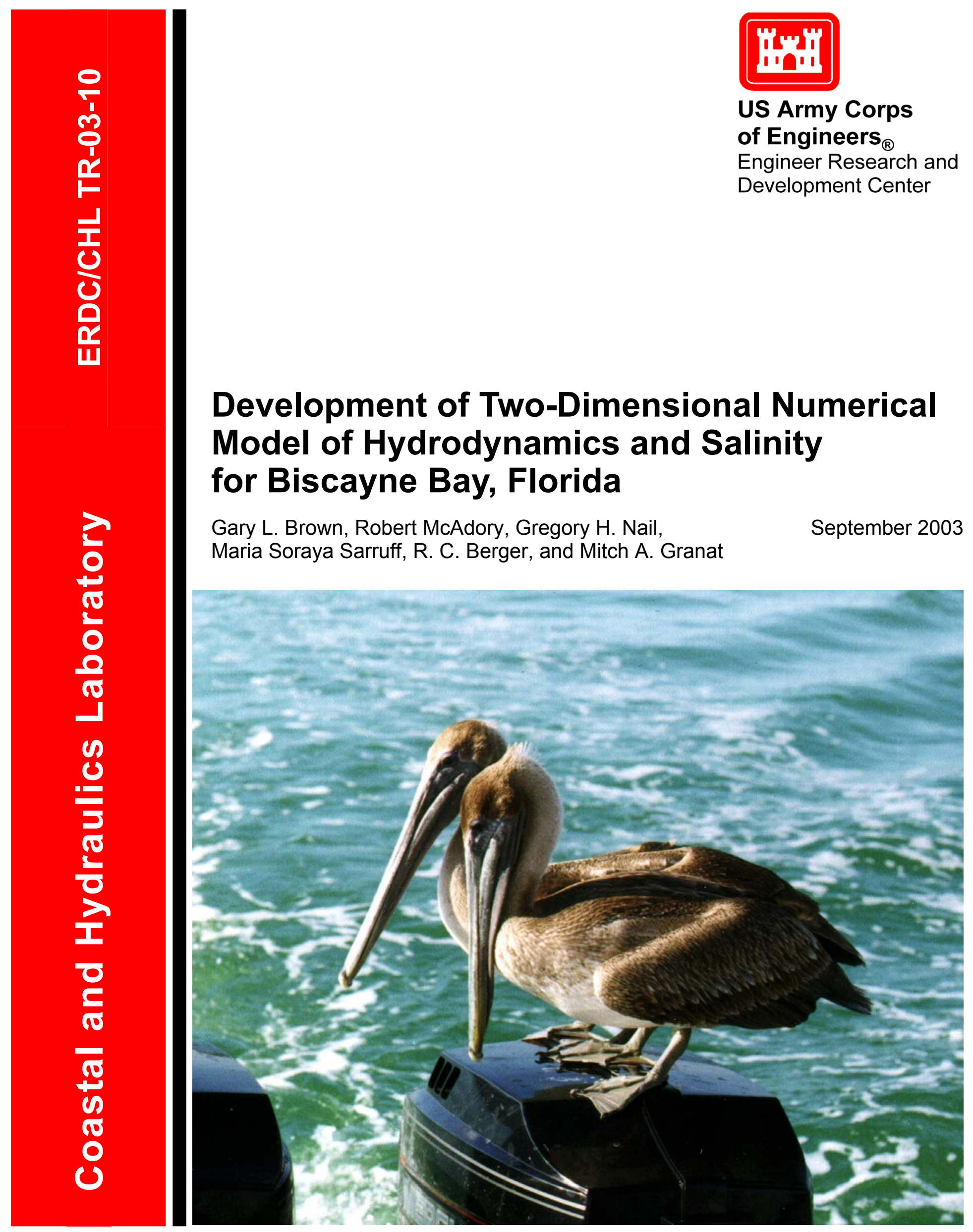

Approved for public release; distribution is unlimited. 


\section{Development of Two-Dimensional Numerical Model of Hydrodynamics and Salinity for Biscayne Bay, Florida}

Gary L. Brown, Robert McAdory, Gregory H. Nail, Maria Soraya Sarruff, R. C. Berger

Coastal and Hydraulics Laboratory

U.S. Army Engineer Research and Development Center

3909 Halls Ferry Road

Vicksburg, MS 39180-6199

Mitch A. Granat

U.S. Army Engineer District, Jacksonville

P.O. Box 4970

Jacksonville, FL 32232-0019

Final report

Approved for public release; distribution is unlimited

Prepared for U.S. Army Engineer District, Jacksonville P.O. Box 4970

Jacksonville, FL 32232-0019 
ABSTRACT: This report documents the development of a verified 2-D numerical model of the hydrodynamics and salinity of Biscayne Bay, FL. The computer code employed for this study was TABS-MDS (multidimensional sediment) (formerly called RMA10-WES). The model was calibrated and verified against an extensive set of hydrodynamic and salinity field data collected in a previous effort performed by the U.S. Army Engineer Research and Development Center, Coastal and Hydraulics Laboratory, in conjunction with the Biscayne National Park. This report discusses general characteristics of the Biscayne Bay system, model development, model boundary condition, and calibration and verification results.

DISCLAIMER: The contents of this report are not to be used for advertising, publication, or promotional purposes. Citation of trade names does not constitute an official endorsement or approval of the use of such commercial products. All product names and trademarks cited are the property of their respective owners. The findings of this report are not to be construed as an official Department of the Army position unless so designated by other authorized documents. 


\section{Contents}

Conversion Factors Non-SI to SI Units of Measurement.................................. vi

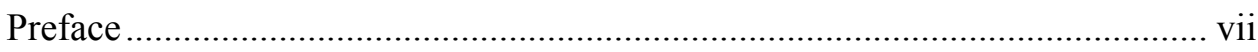

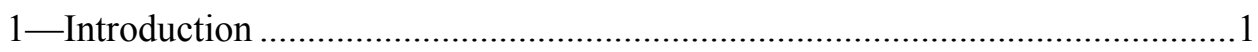

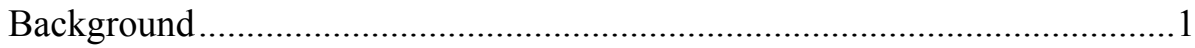

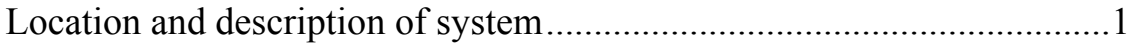

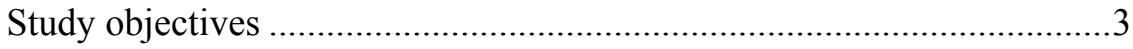

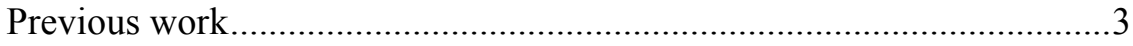

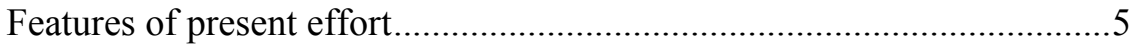

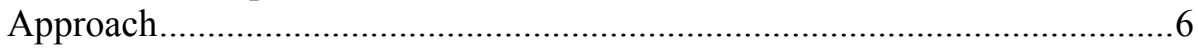

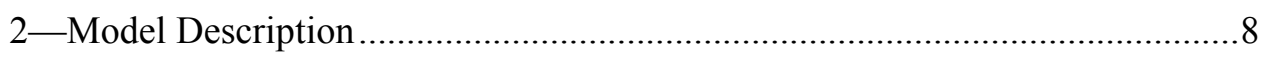

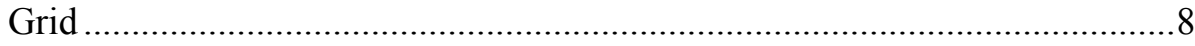

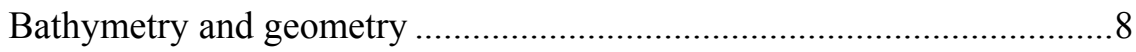

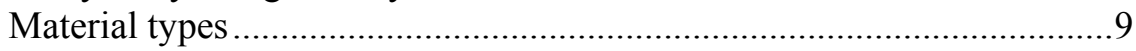

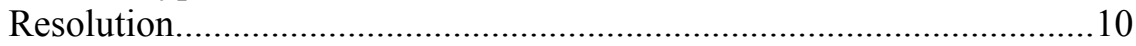

Model Boundary Conditions and Initial Conditions ....................................10

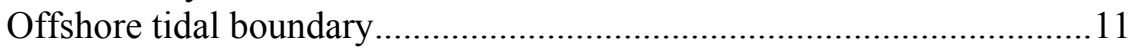

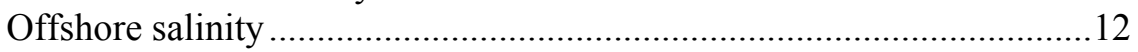

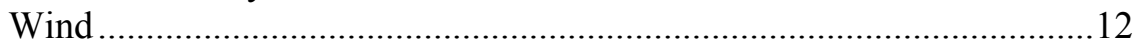

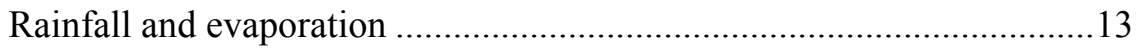

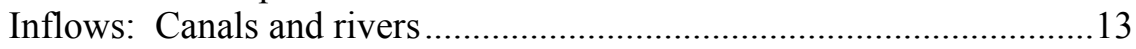

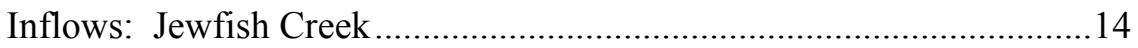

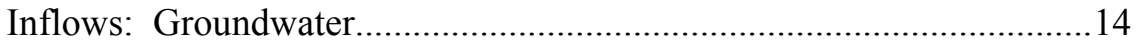

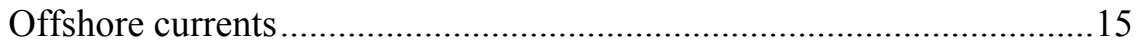

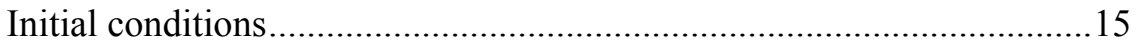

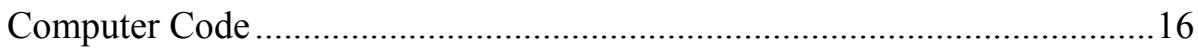

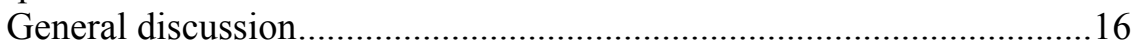

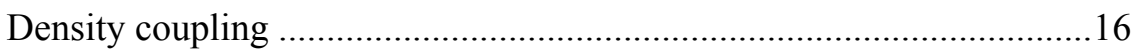

Modeling of intermittently wetted regions ............................................16

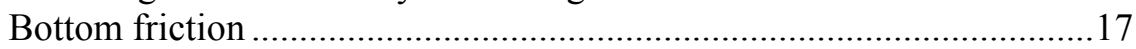

Horizontal turbulent mixing and diffusion .......................................... 17

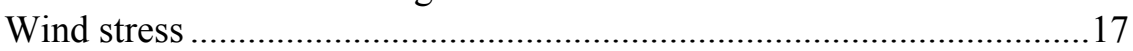

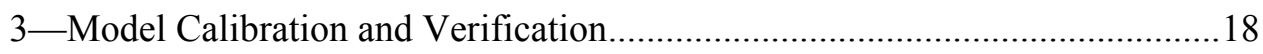

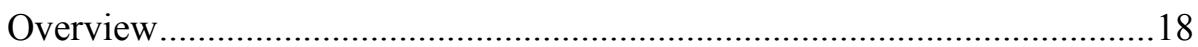

Prototype Data ...................................................................................... 18

Biscayne National Park/Coastal and Hydraulics Laboratory data...........18 


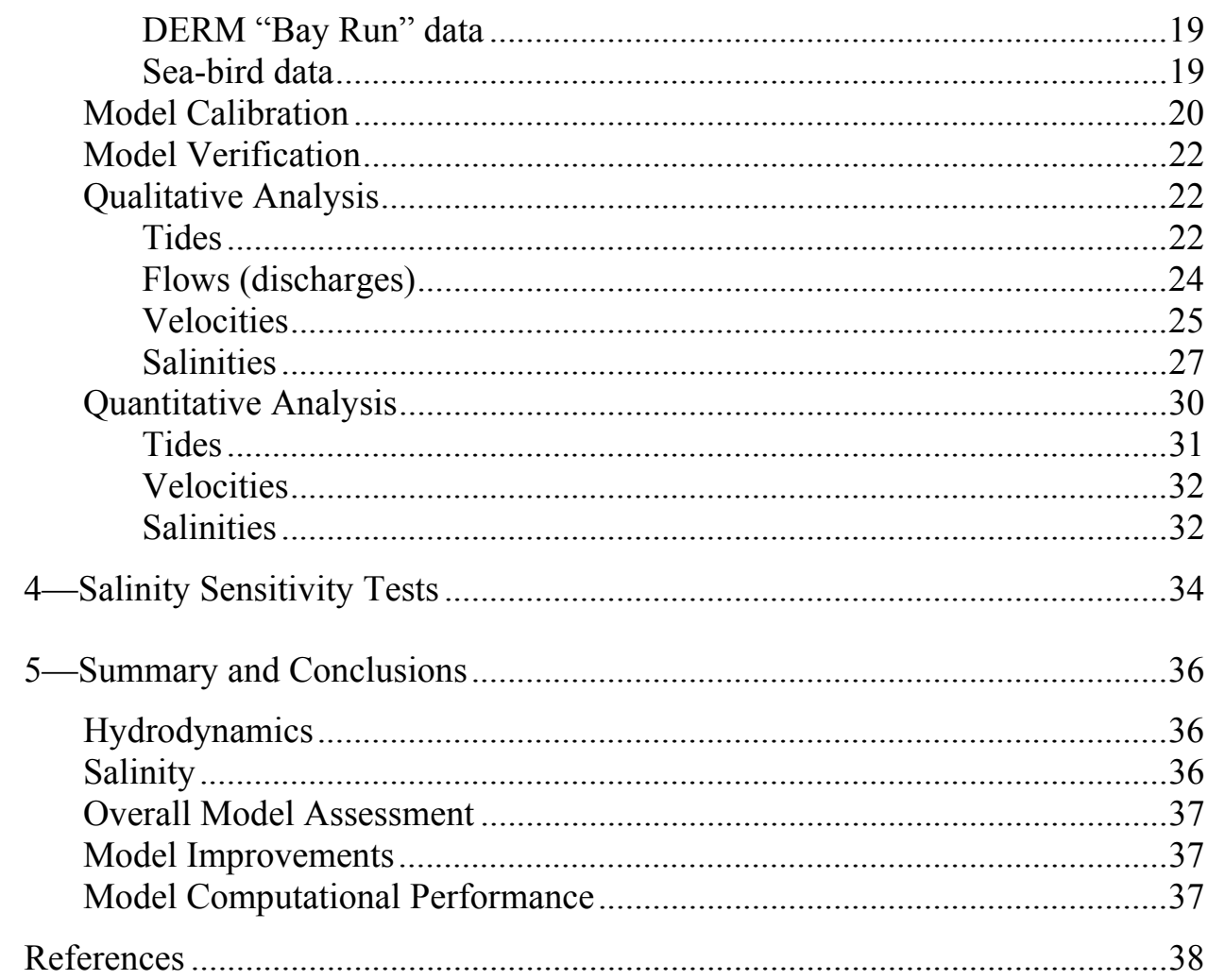

Figures 1-25

Plates 1-85

Appendix A:

SF 298

\section{List of Tables}

Table 1. Major Material Types and Descriptions ....................................9

Table 2. Salinity at Fowey Rocks and Alina’s Reef................................12

Table 3. Estimated Error in Flow Prediction at Biscayne Bay Structures......................................................................... 14

Table 4. Calibrated Parameters for Biscayne Bay...............................21

Table 5. Variance Ellipse Statistics .......................................................26

Table 6. Statistics for Water-Surface Elevation Comparisons:

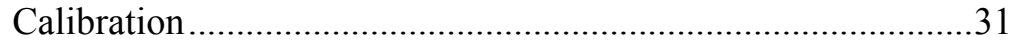

Table 7. Statistics for Water-Surface Elevation Comparisons:

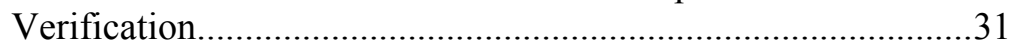


Table 8. Statistics for Velocity Comparisons: Calibration ........................32

Table 9. Statistics for Velocity Comparisons: Verification.......................33

Table 10. Statistics for Salinity Comparison .............................................33

Table 11. Comparison of Sensitivity to Baseline Run ...............................35 


\section{Conversion Factors Non-SI to SI Units of Measurement}

Non-SI units of measurement used in this report can be converted to SI units as follows:

\begin{tabular}{||l|l|l||}
\hline \hline Multiply & By & To Obtain \\
\hline \hline cubic feet & 0.02831685 & cubic meters \\
\hline degrees (angle) & 0.1745329 & radians \\
\hline feet & 0.3048 & meters \\
\hline gallons (U.S. liquid) & 0.003785412 & cubic meters \\
\hline inches & 25.4 & millimeters \\
\hline miles (U.S. statute) & 1.609347 & kilometers \\
\hline square feet & 0.09290304 & square meters \\
\hline square inches & 0.00064516 & square meters \\
\hline
\end{tabular}




\section{Preface}

The model development investigation reported herein was conducted by the Coastal and Hydraulics Laboratory (CHL), U.S. Army Engineer Research and Development Center (ERDC) Vicksburg, MS. CHL's participation was under the sponsorship of the U.S. Army Engineer District, Jacksonville, and their partners: the Miami-Dade County Department of Environmental Resources Management (DERM), Biscayne National Park (BNP), and the South Florida Water Management District (SFWMD). CHL contributions were under the management of Messrs. Michael Choate and Mitch Granat, Jacksonville District.

The work was performed under the general supervision of Mr. Thomas W. Richardson, Director, CHL, Dr. William D. Martin, Deputy Director, CHL, and Dr. Robert McAdory, Chief, Tidal Hydraulics Branch (THB). Mr. Gary Brown, THB, Dr. Greg Nail, THB, and Dr. McAdory wrote this report with Ms. Maria Soraya Sarruff and Dr. R. C. (Charlie) Berger, THB, providing significant contributions to the substance of the report. Mr. Jose A. Sanchez, U.S. Army Engineer District, Vicksburg, developed the initial numerical grid and performed initial testing of the grid, and Dr. Keu W. Kim and Mr. Alex Carrillo, THB, contributed to development of the model. The report benefited from the careful reading of Ms. Gwen Burzycki, DERM, Mr. Earl Edris, CHL, Ms. Debbie Fulcher, CHL, and Mr. Granat. Comments and discussions with Mr. Richard Curry, BNP, Mr. Tim McIntosh, Dr. Susan Markley, and Ms. Sue Alspach, DERM, Messrs. Rick Alleman and Matt Davis, SFWMD, and Mr. David Schmidt, Jacksonville District, were also helpful. The comments and discussions provided by outside technical reviewers, Dr. Zaki Moustafa, SFWMD, and the Individual Independent Technical Review (IITR) Committee were extremely helpful. The IITR was composed of Dr. Bill Boicourt, University of Maryland, Dr. Don Hansen, Atlantic Oceanographic and Meteorological Laboratory and University of Miami, FL, Dr. John Headland, Moffat and Nichol Engineers, Dr. John Klinck, Old Dominion University, and Dr. Gerald Orlub, University of California at Davis. Comments and assistance from Dr. Jeffery P. Holland, Director, Information Technology Laboratory and Dr. William H. McAnally, retired, CHL, were also very valuable.

COL James R. Rowan, EN, was Commander and Executive Director of ERDC. Dr. James R. Houston was Director. 


\section{Introduction}

\section{Background}

Biscayne Bay, near Miami, FL, is a popular tourist destination, an important commercial fishing resource, and a valuable habitat for several endangered species of flora and fauna. Therefore, the U. S. Army Engineer District, Jacksonville, as well as local sponsors and partners such as the Miami-Dade Department of Environmental Resource Management (DERM), Biscayne National Park (BNP), and the South Florida Water Management District (SFWMD) are interested in developing data sets and numerical models that can aid in the study and management of Biscayne Bay circulation, salinity, and water quality. For this purpose, the U. S. Army Engineer Research and Development Center (ERDC), Coastal and Hydraulics Laboratory (CHL), was tasked with developing a physics based numerical model of Biscayne Bay.

The study of circulation, salinity, and water quality patterns in a system such as Biscayne Bay is a complex issue. Physical processes that impact the water quality within the system vary both spatially and temporally. Factors that determine circulation and salinity patterns in the system include: the bathymetry and geometry of the navigation channels, interconnecting canals and inlets; astronomical tide-induced currents; wind-induced currents; freshwater inflow; rainfall and evaporation; and vertical density gradients resulting from salinity stratification. This numerical model study was proposed and undertaken primarily to develop numerical modeling tools to aid in the further assessment of the impact of these and other features on the system. Particular emphasis was placed on the use of the tools to assess the impact of changing freshwater inflows on the hydrodynamics and salinity of the bay. The companion field data collection effort is discussed by McAdory et al. (2002).

\section{Location and description of system}

Biscayne Bay is a shallow, subtropical marine lagoon, with substantial estuarine characteristics along the western shoreline. It is located along the southeast coast of Florida. Biscayne Bay is about 60 miles $^{1}$ long and a maximum of about 8 miles wide. The bay extends from Jewfish Creek in Barnes Sound in the south to Dumfoundling Bay in the north. The Florida mainland bounds the

\footnotetext{
1 Units of measurement cited in this report are in non-SI units. A table of factors for converting non-SI to SI units of measurement is presented on $\mathrm{p}$. vi.
} 
bay on the west, and the eastern boundary is formed by a string of, primarily, coral islands and shallow, vegetated mud banks from Key Largo in the south to Miami Beach in the north. A location map of Biscayne Bay is shown in Figure 1. Figure 2 gives the locations of various significant land and water features within the bay. Fresh water enters the bay primarily through 16 man-made coastal salinity control structures, which allow a controlled release of surface-water runoff via a system of drainage canals and levees. Additional fresh water is contributed directly through rainfall and groundwater flows.

In terms of hydrodynamics, the bay can be divided into three distinct regions: the northern, middle, and southern reaches. The northern reach (North Bay) extends northward from Rickenbacker Causeway, a bridge linking Key Biscayne with the city of Miami, to Dumfoundling Bay. Man-made channels, dredged areas, and man-made islands characterize this northern portion of the bay. The circulation in this area is not affected significantly by the wind. Instead, the various channels and canals guide the tidal exchange with the Florida Straits through several inlets. Government Cut on the south and Bakers Haulover Inlet on the north are two of the main direct connections of North Bay with the offshore area. The area in North Bay between Government Cut and Bakers Haulover Inlet is characterized by the existence of a tidal node (or standing wave) where little horizontal excursion due to tidal forcing is observed.

The central reach of the bay (Central Bay) extends from Card Sound northward to Rickenbacker Causeway. The central portion of Biscayne Bay is exposed to direct tidal exchange with the Florida Straits through the Safety Valve, a natural, shallow inlet approximately 8 miles wide and bounded by Key Biscayne on the north and the Ragged Keys and Elliott Key on the south. Central Bay is characterized by large expanses of shallow, open water. Consequently, the wind speed and direction, along with the tide, have a strong effect on the currents in this region.

The southern reach of Biscayne Bay (South Bay) is formed by Card Sound, Barnes Sound, and adjacent waters, which experience direct tidal exchange with the Florida Straits through a series of natural inlets into Card Sound. These inlets include Angelfish Creek, Broad Creek, and Caesar Creek (known as the ABC's). Barnes Sound is isolated from direct ocean tidal influence. This southern portion of the bay exhibits a complicated pattern of tidal exchange and wind-driven currents. Water can enter and leave this area through any of the several mentioned natural inlets exchanging with the Florida Straits to the east, to the Central Bay to the north, or through Jewfish Creek to Florida Bay to the south. Several small connections from Manatee Bay to Long Sound in Florida Bay also exist through culverts under U.S. Highway 1.

The present day salinity of Biscayne Bay is governed by the addition of small volumes, compared to the tidal prism, of fresh water from various sources (primarily canals, rainfall, and groundwater) combined with the influence of tidal exchange with the Florida Straits through various inlets and channels and winddriven circulation. In general, the isohalines tend to align themselves in a northsouth direction, with the fresher water remaining closer to the western shoreline. The north-south alignment changes with inflow patterns, usually seasonally, with the isohalines shifting seaward or landward, depending on the amount of fresh 
water present. Local conditions of rainfall and groundwater additions, as well as the occurrence of extreme meteorological events (such as the landfall of a major hurricane) also affect the distribution of salinity in the bay.

In the past, the bay proper was fresher than it is today, with the higher isohalines farther from the western boundary than is now the case. However, channelization and impoundment of overland freshwater flows, together with the creation of Bakers Haulover Inlet and the expansion of Government Cut, have resulted in a significant increase in the average salinity of the system. Bellmund et al. (1999) and Cantillo et al. (2000) provide good discussions of the bay.

Although there is evidence that Biscayne Bay experiences local intermittent stratification, particularly in the vicinity of the canal mouths, the system is believed to be largely well mixed, primarily the result of the influence of wind mixing (Alleman et al. 1995).

\section{Study objectives}

The goals of this effort were to develop a two-dimensional (2-D) finite element (FE) hydrodynamic and salinity transport model and to use the model to characterize the response of the bay system salinity and circulation to various freshwater discharge scenarios. This report documents efforts toward the development of this verified 2-D numerical model. Results of the scenario experiments using the model will be reported in a later publication. The hydrodynamic and salinity results derived from the use of this verified numerical model can be used, together with additional water quality models, to simulate the environmental impacts of various proposed changes to the regulation of freshwater discharge to the system.

\section{Previous work}

This effort is not the first attempt at developing a 2-D computational hydrodynamic and salinity transport model of Biscayne Bay. Although several earlier models were developed, the report by Fatt and Wang (1987) stands as a major source of information about other previous models, as well as their own.

Fatt and Wang (1987) describe the results of using an FE model to simulate salinity transport in Biscayne Bay. Results from an earlier FE hydrodynamic model, Wang and Connor (1975), were used to drive this salinity transport model. The Wang and Connor hydrodynamic model was verified and documented by Wang (1978). Fatt and Wang's salinity transport results were then compared against synoptic field measurements collected by the National Park Service (Fatt and Wang 1987). These data were collected from August through October 1985. Of interest are not only the results of the salinity transport modeling, but the analysis of the hydrodynamic and constituent transport characteristics of the bay in general. 
The FE mesh used by Fatt and Wang for constituent transport was identical to that on which the hydrodynamic results were computed. It has quadratic, triangular elements and covers the area from Rickenbacker Causeway south to the Card Bank. The western boundary is land while the eastern boundary is along the various inlets, including Safety Valve, Bear Cut, Caesar's Creek, etc. A total of 287 elements were used. The algorithm by which the salinity values were computed involved a hybrid Eulerian-Lagrangian scheme whereby the transport equation was decomposed into convective and diffusive equations, solved separately, and the results summed.

The boundary conditions prescribed to the Fatt and Wang salinity transport model were those at the canal mouths and along the inlets exchanging with the Florida Straits. The salinity value assigned to nodes along ocean inlet boundary locations was chosen based on salinity data gathered at Adams Key and Markers 1/1A. Salinity values at the canal mouth locations were assigned using a reduction factor, which compensates for the mixing of fresh and salt water that occurs in the canals upstream of the bay. A separate reduction factor was estimated for each canal mouth, using a trial-and-error calibration procedure. This procedure has the advantage of compensating for any vertical mixing which may occur in the canals, thereby mitigating some of the impact of using a vertically averaged model to simulate locally stratified flow. However, the procedure suffers from being calibrated to a narrow range of discharge rates and durations, and therefore each reduction factor is only applicable when the canals are flowing at similar discharges and under similar circumstances to the ones for which the reduction factors were calculated (Fatt and Wang 1987). Rainfall data were used as a model input, but evaporation and groundwater flows were considered of little consequence and therefore not included in the Fatt and Wang model.

The salinity transport model was run for the period October 20 through 25, 1985 , using selected hydrodynamic solution fields to drive it. Comparisons were made between model simulations and field measurements with contour plots of salinity. Overall, the model was able to predict the same general pattern of salinity distribution as shown by the field measurements. The salinity contours are aligned primarily in a north-south direction, with some local closure around the canal mouths along the western shoreline.

Also of interest in the Fatt and Wang (1987) study are the field data. Their analysis of the synoptic salinity measurements, at some 48 stations throughout the central bay, reveals some interesting facts. Most readings were taken at low or high tide, at three locations in the water column (bottom, middle, surface). An analysis was made of the freshwater discharge (six canal mouths) versus salinity at nearby stations. The expected response is an increase in discharge to be followed by a decrease in measured salinity. Fatt and Wang report that this was not always the case. For instance, the August 1985 data showed the opposite response for five of the six canal mouths. Sudden drops in salinity, which were not preceded by increases in discharge, are also reported. These apparently uncorrelated or counterintuitive trends in salinity values are of interest. Similar phenomena were observed during the present study. This is thought to be a consequence of wind-driven circulation or, possibly, localized rainfall and/or local stratification. 
Fatt and Wang concluded that their FE salinity transport model successfully reproduced bay salinity distribution patterns, mixing and transport, in a general way. The predicted salinities were generally lower than those obtained from field measurements. They suggested that this error could be a result of the fact that evaporation is not included in their model. They also pointed out that a primary source of error in their analysis was the uncertainty of the salinity at model boundaries.

The Wang model was recently discussed in the 1999 Florida Bay Science Conference, Key Largo, FL. The model now includes Barnes Sound and Card Sound. Calculations have been made for salinity and compared with the DERM Bay Run data. However, since these latest results have not yet been published, any further discussion of this model, including its underlying assumptions and efficacy in describing Biscayne Bay hydrodynamics and salinity, is not possible.

Cofer-Shabica and Wang (1989) further analyzed the canal discharge and salinity data from the Fatt and Wang (1987) study, principally that of the Mowry Canal (corresponding to the discharge through S-20F in the present study). They attribute at least some of the seemingly unexplained rises and falls in salinity to the discontinuous and highly localized rainfall patterns. Evidence is presented that strongly indicates the presence of fresher water remaining trapped along the western shore, in the vicinity of the Mowry Canal. Finally, among other things, they concluded that leakage through the S-20F structure does not occur. They suggest it is reasonable to extend this conclusion to the other structures.

A study by Sengupta, Lee, and Miller (1978) describes a three-dimensional (3-D) finite difference model of Biscayne Bay. Their model was developed in two versions, one for sediment transport and the other for constituent transport (without density coupling). The model was not extended to salinity transport. The hydrodynamics were run for April 15, 1975, and results compared to some statistical norms of time series water-surface elevation and surface currents. Although the results look reasonable, the short time duration and coarse grid make it difficult to learn much that is relevant to the present study.

\section{Features of present effort}

Although each of the models previously discussed has merit, there are several features unique to the model presented in this report that make it suitable for the evaluation of freshwater impacts on Biscayne Bay. These include:

a. The inclusion of South Bay and North Bay in the model domain.

$b$. The extension of the ocean boundary eastward from the Safety Valve to a point several miles offshore, thereby minimizing the impact of boundary effects on the model results (especially salinity results).

c. High grid resolution, especially in the nearshore.

d. The simultaneous inclusion of groundwater inflow, rainfall/evaporation, and wind in the boundary forcing. 
e. The direct application of freshwater inflows at the canals mouths (as opposed to inflows with salinities calibrated to a narrow range of inflow values).

f. The availability of continuous, yearlong, hydrodynamic, and salinity data at several locations throughout the bay, for use in calibrating and verifying the model.

\section{Approach}

The general approach used in this numerical effort was to develop a computational mesh, establish appropriate boundary conditions, and employ a digital computer code, all of which constitute the model proper. This model was then used to compute numerical results that were compared to hydrodynamic field data for a given time period (for this study, September 1997 through October 1997). An iterative process of computation of results, comparison with field data, model parameter adjustment, and recalculation and recomparison was then undertaken. This cyclic process, referred to as model calibration, was continued until the model results and hydrodynamic field data matched as well as possible within the constraints of the modeling process. These constraints refer, primarily, to the calibration practice of adjusting model parameters only within their uncertainties or accepted ranges of variability for the 2-D physics-based numerical modeling attempted. Then, the model was run for an additional time period (for this study, November 1997 through June 1998) during which no model parameters were adjusted. The results of this run were also compared to field data (both hydrodynamic and salinity). This procedure is referred to as model verification. Results of the calibration and verification runs were evaluated, and additional sensitivity experiments of various kinds were also undertaken to determine the sensitivity of the model to uncertainties in various boundary forcings. Such a physics-based numerical model, which does not depend on continual adjustment of its parameters, may then be run to assess the impacts of various planned actions with confidence that the physics implied by the planned action is responsible for differences between base and plan conditions.

The computer code employed for this study is TABS-MDS (multidimensional sediment) (formerly called RMA10-WES), a Galerkin based finite element algorithm designed to obtain numerical solutions to one-dimensional (1-D), 2-D, and/or 3-D unsteady free surface flows. (See King 1988; Appendix A herein.) The model code and modeling approach are out growths of the TABS-MD modeling system (Thomas and McAnally 1990). The model boundary conditions were taken primarily from data gathered in Biscayne Bay during the 1997 and 1998 BNP/CHL field data collection effort (McAdory et al. 2002), Fowey Rocks data (see http://www.noaa.gov), and SFWMD canal discharges (McAdory et al. 2002). The digitized representation, or computational mesh, was developed early in this study and circulated for comments among the study sponsors. Over time, the mesh was improved in response to comments and additional data received.

In conducting this study, particular emphasis has been placed on duplicating the physics of the system, rather than merely trying to duplicate the system response, as given by the field data. In other words, the range over which a given 
model parameter was adjusted was constrained by the requirement that the parameter value should represent a realistic estimate of the corresponding prototype value (see prior discussion). This approach is necessary if the resulting model is to be a predictive tool. It minimizes the likelihood of achieving a good result for the wrong reasons, a potential hazard if model parameters are tuned to force a desired outcome without regard to the physical sensibility of the parameter values. Also, focusing on the physics can reveal problems with the initial modeling assumptions and/or boundary conditions that might otherwise go unnoticed or unrecognized. As will be discussed and argued in the remainder of this report, the developed 2-D numerical model reproduces the system hydrodynamics and salinity values and characteristics well, thus lending itself to use as a physics-based, predictive tool for assessing the response of the Biscayne Bay system to changes in forcings of proposed improvements to the system. 


\section{Model Description}

\section{Grid}

\section{Bathymetry and geometry}

A previously developed FE mesh was further modified for the purposes of this study. The existing mesh was developed and circulated among the study sponsors early in the project. This existing mesh was generated by utilizing published National Oceanographic and Atmospheric Administration (NOAA) charts with bathymetry in feet below mean lower low water (mllw). All open water regions delineated in the NOAA charts were included in the grid. Although there are some regions along the western shoreline (particularly in the southern part of the domain) that have intermittently wetted coastal marshes that are not represented in the grid, they were determined to be either too small or too poorly defined to be included in the grid at this time. As these areas are studied in greater detail at a later time, these intermittently wetted areas can be defined and included through either of two wetting and drying algorithms available in the model code. Portions of the current model already include the possibility of wetting and drying. See discussion later in this chapter.

A graphical user interface (GUI), the Surface-Water Modeling System (SMS) (Environmental Modeling Research Laboratory 2000), was used to place node points along the landform boundaries and interior open water sections of Biscayne Bay. SMS is an elaboration of the FastTABS (BYU 1994) visualization system pre- and post-processing interface. Each node is identified separately and has an assigned bed elevation at that location. The nodes are connected together to form triangular or rectangular elements. The TABS-MDS code uses an unstructured representation of the system geometry. Thus, the placement of the nodes need not be in a Cartesian arrangement. This unstructured FE approach then allows the modeler to accommodate the irregular shapes of islands, inlets, and shorelines and include higher resolution only where needed.

The previously developed mesh of Biscayne Bay, used at the start of this study, contained 22,458 nodes and 8,068 elements. Modifications were made to the previously existing mesh. Among these were: (a) the inclusion of elements for all canals, extending up to the structures; (b) finer resolution along an offshore reef and several other areas; (c) slight relocations and reassignments of bathymetry to several nodes along the western shoreline; (d) the addition of two small channels connecting Manatee Bay and Barnes Sound through Main Key and Short Key; and (e) removal of a few minor errors in node to node 
connectivity. The resulting FE mesh used in this study has 24,527 nodes and 8,536 elements. For completion, this mesh is shown in its entirety in Figure 3. Figures 4, 5, and 6 show magnified views of the northern, central, and southern portions of the mesh, respectively.

\section{Material types}

The TABS-MDS model allows the user to group together elements that share a common characteristic. This grouping is called a material type. Material types provide a way of assigning values of model parameters to the various regions of the mesh without having to assign parameters to each element individually. The model parameters assigned by material type are Manning's $\mathrm{n}$ (bed friction) and the horizontal turbulent mixing parameters. These and other modeling concepts are discussed more in Appendix A. Figure 6 shows the Biscayne Bay mesh with the major material types highlighted. Table 1 lists these material types, together with a brief description of the regions of the mesh they represent. Figure 7 shows the material types of Biscayne Bay. These material type groupings were developed in consultation with study partners and through use of the DERM "Bottom Communities of Biscayne Bay" map (DERM 1983). ${ }^{1}$ A description of the numerical values of parameters assigned to the model by material type is presented later in this chapter.

\begin{tabular}{||l|l||}
\hline \multicolumn{2}{|l||}{\begin{tabular}{l||} 
Table 1 \\
Major Material Types and Descriptions
\end{tabular}} \\
\hline \hline Material Type & Description \\
\hline \hline 1 & Offshore, smooth bed \\
\hline 2 & Middle Bay, grass beds \\
\hline 3 & Card Bank, grass beds \\
\hline 4 & South Bay, inlets \\
\hline 5 & Offshore reefs \\
\hline 6 & Little Card Sound, grass beds \\
\hline 7 & Card Sound, grass beds \\
\hline 8 & North Bay, inlets (Including Government Cut and Bakers Haulover Inlet) \\
\hline 10 & Canals \\
\hline 11 & Middle Bay, western shoreline \\
\hline 12 & Barnes Sound and Manatee Bay, grass beds \\
\hline 13 & Cutter Bank \\
\hline 14 & South and Southeast Bay, southwest of Elliott Key \\
\hline 15 & Featherbed Bank, Ragged Keys, and Soldier Key \\
\hline 16 & North Bay, west of Virginia Key \\
\hline 17 & North Bay, Julia Tuttle Causeway to Bakers Haulover Inlet \\
\hline 18 & North Bay, South of Julia Tuttle Causeway \\
\hline 19 & Shoals, Julia Tuttle Causeway to Bakers Haulover Inlet \\
\hline 20 & Offshore Boundary \\
\hline \hline
\end{tabular}

1 Miami-Dade Department of Environmental Resources Management. (1983). "Bottom communities of Biscayne Bay" Map, Published in Cooperation with: State of Florida Department of Environmental Regulation, United States Department of the Interior, National Park Service, Miami, FL. 


\section{Resolution}

The surface areas of the elements in the mesh vary over several orders of magnitude, from as small as $1 \times 10^{4} \mathrm{ft}^{2}$ to as large as $3 \times 10^{7} \mathrm{ft}^{2}$. Locations where velocity and/or salinity gradients are expected to be high are highly resolved, as are regions of special interest to the study (such as the western shore). In regions where gradients are expected to be small, or where there is less interest in resolving the local current/salinity field (such as in the offshore), the resolution is coarser. The unstructured nature of the finite element mesh allows this approach to be taken. The mesh for Biscayne Bay was developed by taking full advantage of this capability.

\section{Model Boundary Conditions and Initial Conditions}

The TABS-MDS model requires initial and boundary conditions, as well as a number of modeling parameters, to be specified via input files. The governing equations for hydrodynamics require that either water-surface elevation or velocity (or flow rate) be specified at all nodes along open boundaries (i.e., boundaries other than land boundaries). In addition to these necessary conditions, the Biscayne Bay model was driven with additional inputs, including applied wind stress, rainfall/evaporation, and applied groundwater. At the land boundaries, TABS-MDS imposes a slip condition, forcing the velocity to be parallel to the shoreline. That is, the velocity magnitude is solved for, while the velocity direction is forced to be tangent to the land boundary.

To solve for salt transport, it is necessary to impose salinity boundary conditions. For Biscayne Bay, a salt concentration was specified along the offshore boundary for all flow into the model domain. The concentration of flow exiting the model domain through the offshore boundary was not specified. (To specify the concentration of flow exiting the model in this way would be physically nonsensical because the salinity of the near boundary water that will be pushed out of the ocean boundary is intended to be determined by the internal dynamics of the model.) The concentration was specified for all inflows to the system, as well as for rainfall/evaporation and groundwater.

The unsteady nature of the Biscayne Bay problem necessitates that a timestepping procedure be used, so that the boundary conditions can be changed for each new time-step. Hence, for Biscayne Bay, all the applied boundary conditions were given as time series. In this way a simulation of the entire bay was performed. The influences of changes in the applied boundary conditions with respect to time were propagated throughout the model domain via the numerical solution of the governing equations. Removing these boundaries, particularly the ocean salinity and tidal boundaries, far from the area of interest (i.e., the Bay proper) minimizes the pegging of bay salinities and water levels by the specified boundary values. This allows the values of salinity and water level, for instance, in the area of interest to be shaped by the modeled physics. Initial conditions are also necessary for the modeled physical parameters. To assign initial conditions for the model, an initial solution field is generated for both the hydrodynamics and the salinity. 
The entire set of boundary conditions assembled for the calculations discussed in this report was 12 months long, spanning the time from August 1997 through July 1998. However, no rainfall or evaporation data were available for August 1997 or July 1998 (rainfall data were also unavailable for September 1997, but for this month an estimate of the rainfall was taken from raw pan evaporation data, which record net precipitation). Since rainfall and evaporation are considered significant parameters in the Biscayne Bay system, it was not considered suitable to include these months in the simulation without these data. Therefore, the entire period of simulation consists of the 10-month period extending from September 1997 through June 1998. The hydrodynamic model was calibrated with the September through October 1997 data, and verified against the November 1997 through June 1998 data. No calibration was figured for the salinity (see Chapter 3). The salinity was permitted to spin up through September 1997 and was verified against the October 1997 through June 1998 data.

\section{Offshore tidal boundary}

The time series of water-surface elevations used along the offshore boundary was extrapolated from measured water-surface elevations at Gauge 9 conductivity, temperature, and depth recorder No. 9 (CTD9) of the BNP/CHL data set. The signal from CTD9 was modified such that it matched the measured signal at the Virginia Key National Ocean Service (NOS) station (No. 8723214), located at the Rosenstiel School of Marine and Atmospheric Science (RSMAS) for the calibration time interval. The Virginia Key station was used because the National Geodetics vertical datum (NGVD29) is well established at this station. The Virginia Key station data were not used in place of the CTD9 water-surface elevation data because the CTD9 data provided the more complete data set for the entire data collection period. The following adjustments were made to the CDT9 data to establish a match with the Virginia Key data:

Phase shift $=-45 \mathrm{~min}$

Vertical offset $=+0.7 \mathrm{ft}$ (including $0.67 \mathrm{ft}$ for adjustment from mllw to NGVD29)

Signal amplification $=27$ percent $($ amplitude multiplied by 1.27$)$

The phase shift accounts for the time of travel from the model boundary to the modeled position of the Virginia Key station. The vertical offset ensures the model data are appropriate at the Virginia Key station. And the signal amplification accounts for deamplification of the tidal signal as it moves toward the coast. It was found that by making these adjustments to the CTD9 data, TABS-MDS consistently reproduced the tide signal at the NOS Virginia Key station through the calibration period. The model and field data for the calibration period are shown for water-surface elevation in Plates 1-15. Virginia Key data are given in Plate 15. The time series generated for the model is given in 30-min increments, which corresponds to the length of the time-step used in the simulation. 


\section{Offshore salinity}

The salinity along the ocean boundary was specified as a constant value for each month within the data set. To establish the monthly values to be applied to the offshore boundary, data were examined from two different locations: the Fowey Rocks Lighthouse, located about $4 \frac{1}{2}$ miles east of Soldier Key, and the BNP gauge at Alina's Reef, located about 3 miles east of Card Sound (Figure 8). Both data sets are shown in Figure 9. Examination of the data reveals trends that appear to indicate instrument fouling at the Fowey Rocks gauge. The evidence for this is the periodic appearance of a gradual downward trend in salinity, followed by a sudden increase that corresponds, in time, to the maintenance of the gauge. Such behavior is indicative of gauge fouling. Because of this apparent fouling of the Fowey Rocks data, the monthly averaged Alina's Reef data were used as the ocean salinity boundary condition (Figure 9 and Table 2).

\begin{tabular}{|c|c|c|}
\hline \multicolumn{3}{|c|}{$\begin{array}{l}\text { Table } 2 \\
\text { Salinity at Fowey Rocks and } \\
\text { Alina's Reef }\end{array}$} \\
\hline Month & $\begin{array}{l}\text { Alina's Reef } \\
\text { Average (all } \\
\text { data) }\end{array}$ & $\begin{array}{l}\text { Fowey Rocks } \\
\text { Average (all } \\
\text { data) } \\
\end{array}$ \\
\hline Sept. 97 & 34.9 & 35.1 \\
\hline Oct. 97 & 35.4 & 35.8 \\
\hline Nov. 97 & 35.7 & 35.2 \\
\hline Dec. 97 & 35.4 & 35.0 \\
\hline Jan. 98 & 35.9 & 34.6 \\
\hline Feb. 98 & 35.7 & 33.7 \\
\hline Mar. 98 & 35.9 & 33.8 \\
\hline Apr. 98 & 36.6 & 34.7 \\
\hline May 98 & 36.6 & 35.8 \\
\hline June 98 & 34.9 & 35.2 \\
\hline
\end{tabular}

\section{Wind}

The wind applied to the model was based on data from the BNP/CHL gauge located at the Convoy Point station. Wind values were applied over the entire bay portion of the computational domain, with the value updated at 30-min. intervals. Wind values were not applied over the ocean portions of the model domain. Qualitative comparisons of the Convoy Point wind data with wind data taken at the NOAA gauge at Fowey Rocks suggest that the dominant wind direction is relatively homogeneous in the area of the bay, with the biggest overall difference being a decrease in velocity magnitude from the Fowey Rocks station to the Convoy Point station. Smith also reached this conclusion and provided quantitative comparisons, finding the Fowey Rocks-Convoy Point velocity magnitudes to be in the ratio 1.45 (McAdory et al. 2002). The Convoy Point wind speed data for the entire simulation period are shown in Figure 10.

The raw Convoy Point data were manipulated to account for differences in magnitude due to height of collection and the near land location of the Convoy Point station. The raw data were corrected to the standard $10-\mathrm{m}$ height above the water using the factor 1.16 (Hsu 1988). These height corrected data were then used to calculate wind stress on the water surface in North Bay, South Bay (Card and Barnes Sounds), and along the western shoreline in Central Bay using the formulation of $\mathrm{Wu}$ (1980). This application was made assuming these areas are relatively sheltered as compared with the main Central Bay area. To account for higher wind velocity magnitudes over the open water of Central Bay, half the factor relating the Fowey Rocks ocean wind data to the Convoy Point nearshore wind data was applied, namely 1.225 (Figure 11). 


\section{Rainfall and evaporation}

Rainfall and evaporation data were taken from the weather station at Convoy Point. These values were applied over the entire model domain, with the values updated at 30-min. intervals. The spatial distribution of rainfall and evaporation in Biscayne Bay can be significantly heterogeneous, especially in the summer months, when storms tend to be intense and localized. Use of a set of uniform rainfall and evaporation data from a station located in the system, e.g., the Convoy Point station, means that the data are assumed, in the large, to be representative of the system. Spatially varying data can be incorporated into the model, when available, as desired. Figures 12 and 13 show rainfall and evaporation for the entire simulation period.

\section{Inflows: Canals and rivers}

Freshwater inflows from the various canals and rivers that flow into Biscayne Bay are regulated by 16 structures. Figure 8 shows the locations of these structures. These structures are managed by the SFWMD (Van Horn 1996). Rating curves, developed by SFWMD and the U. S. Army Corps of Engineers (USACE), exist for each of these structures (Swain et al. 1997), and revised curves were developed by Swain et al. (1997). Since the integration of these new curves into the SFWMD canal flow data sets was not complete at the time of this study, sponsors recommended use of the earlier rating curves (Imru 2001). In any case, flow data used in the modeling effort were flows provided to CHL by the SFWMD (McAdory et al. 2002). These flows were generated by SFWMD from the DBHYDRO database (available from SFWMD) using the existing rating curves to generated flow hydrographs for each structure. For use in the modeling, the hydrographs were averaged over 30-min. intervals, and the resulting values were applied as inflows to the model. Checks were made to ensure that this 30-min averaging did not change the net flow into the bay.

There is significant uncertainty concerning the accuracy of the rating curves, particularly for extreme events. The coefficients used for these curves are based on logarithmic regression analyses of data that represent limited ranges of flow (Swain et al. 1997). Since several of the events that occur during the period of record exceed these ranges, it is uncertain whether or not the coefficients can be trusted in these high flow cases. This question is the subject of ongoing investigation at the SFWMD. In a recent report, personnel at the SFWMD supply estimates of the absolute percent error in the prediction of the flow at each of the structures (Imru 2001). The errors reported for the SFWMD/USACE rating curves are given in Table 3.

The hydrographs of each of the 16 structures for the entire simulation period, as used in the modeling effort, are given in Plates 1 through 8 . The salinity of these inflows was specified as 0.0 . Although some small values of salinity may occur upstream of the structures, it was assumed that flow of any significant duration would flush this trace salinity from the canals. Finally, negative flow values were set to zero in the modeling effort. Since the canal structures are specifically designed to avoid such flows, these apparent flows are considered to be an artifact of the telemetric process. 


\begin{tabular}{|l|l||}
\hline $\begin{array}{l}\text { Table 3 } \\
\text { Estimated Error in Flow Prediction at Biscayne Bay Structures }\end{array}$ \\
\hline \hline Salinity Control Structure & $\begin{array}{l}\text { Absolute Percent Error in Flow Estimate for } \\
\text { SFWMD/COE Rating Curves }\end{array}$ \\
\hline \hline S-29 & 19 \\
\hline G-58 & No data \\
\hline S-28 & 29 \\
\hline S-27 & 23 \\
\hline S-26 & 38 \\
\hline S-25B & 9 \\
\hline S-25 & No data \\
\hline G-93 & 20 \\
\hline S-22 & 9 \\
\hline S-123 & 12 \\
\hline S-21 & 24 \\
\hline S-21A & 22 \\
\hline S-20G & 29 \\
\hline S-20F & 50 \\
\hline S-20 & 24 \\
\hline S-197 & 17 \\
\hline
\end{tabular}

\section{Inflows: Jewfish Creek}

Jewfish Creek is a small inlet connecting Barnes Sound to Blackwater Sound. For this model study, it was treated as a flow boundary. Flow and salinity data were available for Jewfish Creek throughout the period of simulation. However, intermittent gaps in the data record exist. To fill these gaps, synthetic data were generated, based on a simple correlation between watersurface elevation data from Manatee Bay (CTD1) and the flow at Jewfish Creek for periods when flow data exist. Since the volume of flow passing through Jewfish Creek is small relative to the tidal exchange in Barnes Sound, and since the salinity is similar to the salinity found in Barnes Sound, the error introduced into the hydrodynamic and salinity modeling by using synthetic data to fill gaps in the data record is assumed to be negligible. For reasons similar to those discussed for the offshore salinity boundary, salinity for inflow, only, into Barnes Sound through Jewfish Creek was specified. These salinity values were based on field data taken at Jewfish Creek. Figure 14 shows the Jewfish Creek hydrograph and salinity for the entire simulation period as used in the modeling effort.

\section{Inflows: Groundwater}

The groundwater inflow was taken directly from model results generated by the U. S. Geological Survey (USGS) (Langevin 2001). The groundwater inflow was applied in the following locations: along the western shoreline of Biscayne Bay north of structure S-123 (this includes approximately 21 miles of shoreline); along the western shoreline of Biscayne Bay south of structure S-123 (this includes approximately 26 miles of shoreline); in the Miami River; and in the 
Coral Gables Canal. Figure 15 shows these locations. The groundwater inflow was distributed as follows:

a. $\quad 37.5$ percent was applied along the shoreline north of S-123.

b. 12.5 percent was applied along the shoreline south of S-123.

c. 25.0 percent was applied in the Miami River.

d. 25.0 percent was applied in the Coral Gables Canal.

No groundwater was applied during September 1997. However, September 1997 is a spin-up month for the model salinity; this omission was assumed to have negligible impact on the modeling results for subsequent months of simulating. This assumption is reinforced by the small amount of groundwater inflow when compared with the September 1997 canal inflows. The groundwater was assigned a salinity of 17.5 , again based on the model results of the USGS (Langevin 2001). The groundwater inflows applied to the model for the entire simulation period (except September 1997) are given in Figure 16.

\section{Offshore currents}

Offshore currents are considered an important mechanism for sweeping away low salinity water from Biscayne Bay. To simulate these offshore sweeping currents, and thus allow for their effects to be realized in the area of interest (i.e., in the bay), a north-south slope was placed on the ocean boundary of the computational domain. This slope generates offshore currents that simulate the effects, in the bay, of the actual offshore currents. This is particularly the case in terms of sweeping Biscayne Bay water that exits the bay away from its exit point. The sweeping-current-inducing slope of the offshore area was varied in time according to the direction of the winds. The induced sweeping currents thus vary from northerly to southerly in direction, depending on the offshore wind direction. The predominant direction, as evidenced by the wind, is toward the north. The result is a sweeping current with the proper order of magnitude for both current direction and current magnitude. This result is sufficient to account, in the bay, for sweeping effects outside of the bay at the level of this modeling effort.

\section{Initial conditions}

The initial conditions for the hydrodynamics were generated by the model. The model was used to solve for a steady state solution for Biscayne Bay, and this solution was used as the initial condition field for velocities and depth. The initial conditions for salinity were interpolated from field data. Salinity values were extracted from the BNP/CHL data set, and these were used, together with a 2-D interpolation scheme, to generate an initial salinity field for the entire model domain. 


\section{Computer Code}

\section{General discussion}

The numerical model used for this study is TABS-MDS. TABS-MDS is a Galerkin-based FE solution for unsteady open channel flow and sediment transport. The model is based on RMA10, a code originally developed by Ian King of Resource Management Associates (King 1988) under contract to the Corps. The CHL version of the model has been modified to such an extent that, to avoid confusion, the CHL version has been assigned the name TABS-MDS.

The code is capable of simulating hydrodynamics in 1-D, 2-D and/or 3-D modes. It solves conservation of fluid mass equations, horizontal momentum equations, and equations of state (for the determination of density as a function of salinity, temperature, and/or suspended sediment), and convection/diffusion equations. To improve computational efficiency, the hydrostatic assumption is implemented. This assumption implies that vertical accelerations are negligible. This approximation is valid, and widely used, in estuarine application of model codes.

TABS-MDS is both unstructured and implicit. An unstructured code maximizes the ability to resolve complicated shoreline or other geometry, and an implicit code allows the time-step length to be largely unconstrained by the grid resolution and local velocities. These are generally needed for generating accurate representations of estuarine systems with complicated shorelines and dramatic spatial differences in velocity, such as is found in Biscayne Bay. For more details concerning the TABS-MDS model, consult Appendix A.

\section{Density coupling}

For this study, TABS-MDS was run in 2-D vertically averaged mode. By definition, this eliminates the possibility of modeling salinity or velocity stratified profiles in the bay. However, coupling the density in a 2-D calculation does permit the inclusion of horizontal density gradient effects, which are the dominant density gradient contribution in well-mixed systems. This density coupling was enabled for this study.

\section{Modeling of intermittently wetted regions}

TABS-MDS is equipped with a feature that permits the water and salt mass storage in intermittently wetted regions of the domain (e.g., marshes, shoals, etc.) to be accounted for in the calculation. This feature is called marsh porosity, as was originally proposed by Roig (1995). The marsh porosity method distributes the water in a partially submerged element over the entire element, thereby creating a thin layer of water submerging 100 percent of the surface area of the element. This method conserves both mass and momentum. Since the distribution of water over each element is likely different than the distribution observed in the field, the friction loss across a marsh porosity element may be different in the model than in the field. Therefore, if marsh porosity elements are located in a 
region of the mesh where momentum conservation is important, care must be exercised in the selection and calibration of friction parameters for these elements. For more information on marsh porosity, consult Roig (1995).

For Biscayne Bay, marsh porosity was activated in the mesh at any node for which the depth is $0.5 \mathrm{ft}$ or less. There are several areas of the mesh where this is a possibility. The shallowest depths in Biscayne Bay occur at Card Bank and the shoals in the North Bay (material types 3 and 19 (Table 1 and Figure 7)). The bed elevations in these regions get as high as $-0.8 \mathrm{ft}$, referenced to mllw. Therefore, any time the water-surface elevation (relative to mllw) is less than $-9 \mathrm{~cm}$ $(-0.3 \mathrm{ft})$ in these regions, marsh porosity will become active (i.e., these regions will be effectively dry). This means that, although marsh porosity may be intermittently activated in these regions, it is never active for an extended duration. As mentioned earlier in this chapter, further application of marsh porosity wetting and drying can be added to other areas of the modeled bay, such as the western areas, as desired for future model applications.

\section{Bottom friction}

Bottom friction in TABS-MDS is represented with a modified form of Manning's equation. This modification is intended to correct for depth dependence in the calculation of bottom friction. For more on this method, consult Appendix A.

\section{Horizontal turbulent mixing and diffusion}

Horizontal turbulent mixing and diffusion are represented in TABS-MDS by the method of Smagorinsky (1963). This method, originally developed for atmospheric models, has been widely used in hydrodynamic models (Hamrick 1992). Given the appropriate choice of coefficients, this method has demonstrated the capacity to model sub-grid scale dissipation in hydrodynamic systems (Speziale 1998). Details of the implementation of the Smagorinsky method into the Biscayne Bay model are given in the calibration section of Chapter 3. For more details on the Smagorinsky method, consult Appendix A.

\section{Wind stress}

The $\mathrm{Wu}$ formulation (Wu 1980) is used to calculate wind stress on the bay water surface. This method is assumed to be adequate given the estimates of wind velocity used. 


\section{Model Calibration and Verification}

\section{Overview}

Calibration refers to the process of running a simulation for a given period of record and adjusting selected parameters to match the model results to the field data. Verification refers to the process of running a simulation for a period of record other than the one used for calibration and comparing model simulation results and field data without adjusting any parameters. As previously stated in Chapter 1, the hydrodynamics were calibrated with data from September through October 1997, and verified against data from November 1997 through June 1998. The salinity was not calibrated; that is, no further adjustments were made to model parameters, beyond what adjustments were made for the hydrodynamic calibration, to alter the salinity results. Salinity calculations were permitted to spin up through September 1997, and then the salinity was verified against data from October 1997 through June 1998.

\section{Prototype Data}

The following is a brief discussion of the prototype data. For more detailed information, consult McAdory et al. (2002).

\section{Biscayne National Park/Coastal and Hydraulics Laboratory data}

This is an extensive data set, and the main one used for this study. It consists of four major parts: water-surface elevation data, salinity data, velocity data, and flow, or discharge, data.

Water-surface elevation data. These data were collected at 12 CTD monitoring gauges located throughout the model domain. The gauges were attached to the bed and floated in the water column with submerged buoys, which placed the sensors approximately $1 \mathrm{ft}$ from the bed. Data were collected synoptically at 11 CTD locations from June 1997 to June 1998 and from January to June 1998 for the CTD10 in the mouth of the Miami River. A data record was recorded every $15 \mathrm{~min}$. Each data record consisted of time, temperature, depth, $\mathrm{pH}$, dissolved oxygen, and conductivity. Figure 17 shows the locations of these gauges. 
Salinity data. Salinity data were calculated internally to each CTD from the measured conductivity and temperature values at each CTD and stored internally for later retrieval for the same period of record that the water-surface elevation data were collected. Therefore, salinity data were also collected approximately $1 \mathrm{ft}$ from the bed. Water-surface elevation and salinity values were recorded independently, however, so data gaps in one of these quantities may not be present in the other.

Velocity data. Velocity data were collected at five locations in the bay, using bottom mounted Acoustic Doppler Profiling (ADP) instruments. At each gauge, the velocities were reported at multiple depths. This was done by dividing the water column into 11.8 in. sections, or "bins," and measuring the velocity in each bin (note that the bottom 23.6 in. of the water column are unmeasured because of limitations of the instrument). Measurements were taken every 15 min. Figure 17 shows the locations of these instruments.

Note that, although velocity data were collected at ADP4, the depth sensor was not recording properly, and therefore the locations of each velocity measurement within the water column were impossible to determine. Since the method of depth averaging employed for this study depends on knowing the locations within the water column of each velocity measurement, it was decided to omit the data from ADP4 from consideration in this study.

Flow data. Flow data were collected with Acoustic Doppler Current Profilers (ADCP) mounted aboard vessels. Two separate data sets were gathered, one in October and one in February. Each data set consists of 27 transects, each sampled for approximately $9 \mathrm{hr}$. Figure 18 depicts the locations of these transects. Note that Transect 24 was not taken in the February collection period.

\section{DERM “Bay Run” data}

The DERM Bay Run water quality data are salinity data (and a number of other parameters) collected over multiple sites in Biscayne Bay (DERM various). One measurement is taken per month, and each measurement consists of at least two readings at different depths in the water column, yielding an instantaneous local salinity profile. The readings always consist of at least one reading at the water surface, and one reading at a depth of $3.3 \mathrm{ft}$. If the local water depth at the sampling site is greater than $3.6 \mathrm{ft}$ at the time of the reading, then a third sample is taken at the bottom. The locations of these sampling points are given in Figures 19 through 21.

\section{Sea-bird data}

Periodically, the BNP/CHL gauges were serviced and replaced. Each time this occurred for the CTD locations, a hand-held salinity gauge was lowered over the side of the vessel, and a salinity profile was recorded. Because of limitations of the instrument, however, this profile never includes a salinity measurement in 
the upper $3.3 \mathrm{ft}$ of the water column. A Sea-Bird instrument was used for this profiling (McAdory 2002).

\section{Model Calibration}

The hydrodynamic model was calibrated over the time period from September through October 1997. The model was run with a time-step of $0.5 \mathrm{hr}$, giving approximately 25 time-steps per tidal cycle. The tide signals at the 12 CTD locations were compared to the model results at the CTD locations in the model, and adjustments were made to the friction parameters in the model. Velocity and discharge calculations were then compared to field data and further, more refined adjustments were made to the model friction.

The eddy viscosities in the model were adjusted during the period of calibration, but only for the purposes of achieving numerical stability. As was stated in Chapter 2, the eddy viscosity in the Biscayne Bay study was controlled by the Smagorinsky method (Smagorinsky 1963). In TABS-MDS, there are actually two quantities that control the eddy viscosity when using the Smagorinsky method. The first quantity is the Smagorinsky parameter, which is adjusted with the Smagorinsky coefficient. The second is a minimum allowable eddy viscosity parameter. This value is used to supply the model with sufficient diffusion to ensure stability. At each computational point and at each time-step, the model calculates both values of eddy viscosity (one with the Smagorinsky parameter and the other with the minimum allowable eddy viscosity parameter) and selects the maximum of the two for the value it uses. A value of 0.05 was selected for the Smagorinsky coefficient, which is in the range of accepted values typically used in estuarine systems (Speziale 1998). Then, a nominal initial estimate of the minimum eddy viscosity parameter was selected. The model was allowed to run, and local instabilities were eliminated by adjusting the minimum eddy viscosity parameter until the instabilities were corrected. Since the minimum eddy viscosity parameter can be applied by material type, this adjustment could be done locally, without elevating the global value of the minimum eddy viscosity. In some cases, when only a few elements were manifesting the instability, a new material type was created to allow the minimum eddy viscosity parameter to be adjusted for those elements only. This method of adjustment ensured that the minimum eddy viscosity that was applied to the model was just sufficient to prevent numerical instabilities from occurring.

Although the wind speed/stress was not calibrated, the model and field tide and velocity data for October were filtered to remove the tidal signal, and the remaining wind-induced signals were compared. This is discussed further in the "Qualitative Analysis" section later in this chapter.

No calibration was performed for the salinity modeling. The horizontal diffusion coefficients were determined by the same process used to adjust the eddy viscosity. That is, a value of 0.05 was selected for the Smagorinsky coefficient, a nominal minimum diffusion parameter was selected, and the minimum diffusion parameter was adjusted until any numerical instabilities were eliminated. Hence, as with the eddy viscosity, the only adjustments applied to diffusion were for the purposes of achieving numerical stability. 
Table 4 is a summary of the final modeling parameters that resulted from the calibration process. For each material type, Table 4 lists the following: Manning's n, the time-averaged eddy viscosity, and the time-averaged diffusion coefficient. The time-averaged values are averaged over the month of October 1997, but averaging over any month in the simulation period will yield similar results for these parameters. Note that the extremely high value of eddy viscosity for material type 20 was applied to ensure stability along the offshore boundary. It has little effect on the mixing in the rest of the model.

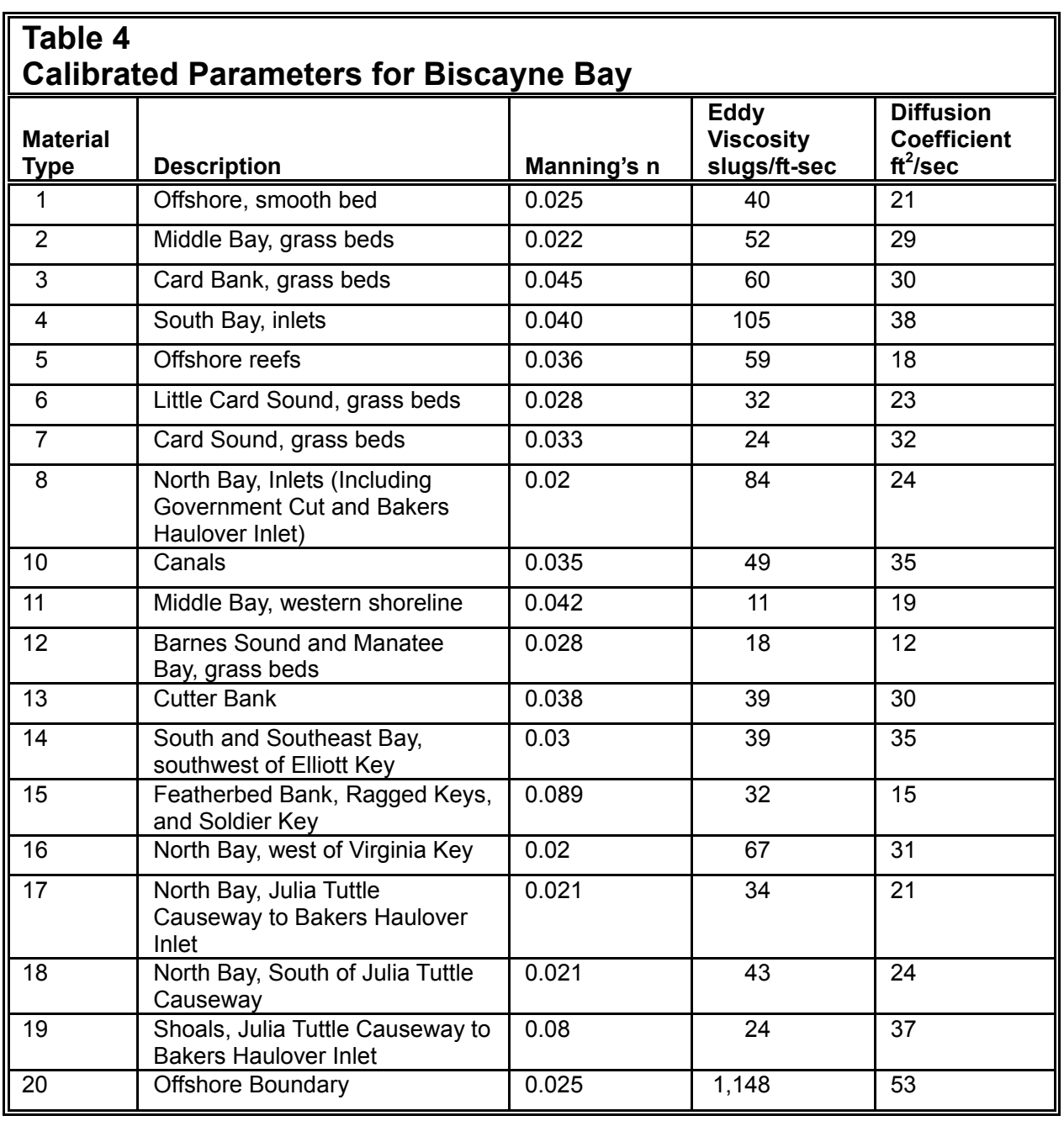

The Manning's $n$ values given here are typical for the types of bottom cover observed in Biscayne Bay (Chow 1959). Of note are the extremely high Manning's $n$ values for material types 15 and 19. Material type 15 represents coral and other subgrid-scale roughness features in the immediate vicinity of Ragged Keys and Soldier Key, as well as a shallow seagrass community at Featherbed Bank. Material type 19 represents a seagrass community in very shallow water. Although the Manning's n values assigned here are very high, they do not exceed the range given by Chow. 


\section{Model Verification}

After calibration was complete, a verification simulation was conducted as follows: the model was run for the full 10 months of the simulation period, with the final 8 months (November 1997 through June 1998) used for hydrodynamic verification, and the final 9 months (October 1997 through June 1998) used for salinity verification. The model was run with a time-step of $0.5 \mathrm{hr}$. An initial salinity field was assigned to the model based on field data collected at the 12 BNP/CHL gauges. The model was allowed to run through September 1997 to ensure that the model had reached a state of dynamic equilibrium similar to that expected in the field. This process is called spin-up. In a tidal system, hydraulic properties propagate at the speed of the tidal wave, and hence reach a spin-up state rapidly, usually in a few tidal cycles. Properties that travel with the speed of a water particle, such as salinity, take a much longer time to spin up. Thus, when salinity is considered, longer spin-up times, on the order of 100 tidal cycles, are not uncommon.

Figure 22 is a plan view of the velocity field for a typical ebb tide at Government Cut. The contours are contours of salinity. Note the offshore current, which is induced by the applied slope along the offshore boundary (as noted in Chapter 2). This current is responsible for the observed deflection to the north of the ebb flow through Government Cut. Figure 23 is a plan view of the salinity contours for April 15, 1998, observed at maximum ebb.

\section{Qualitative Analysis}

\section{Tides}

Plots of the model and field tides at the $12 \mathrm{BNP} / \mathrm{CHL}$ CTDs for the calibration period are given in Plates 9 through 15, and the tides for the verification period are given in Plates 16 through 22. Both the model and field tidal signals have been averaged over time, and the mean values have been removed. This was done to more easily compare the tidal amplitude in both data sets. Plates 23 through 32 contain data that has been filtered to remove the tidal signals. (All signals with a period less than $36 \mathrm{hr}$ were removed). This was done to compare the effects of wind on the water-surface elevation in the model and the field (subtidal effects). The analysis was conducted for the months of October 1997, and February and April 1998. However, since the results were largely the same for both February and April, only the October and April plots are given in this report. The analysis was conducted for CDTs $1,3,4,6,8,9$, and 11 . In addition, Plates 27 and 32 give the difference between stations 1 and 3, and stations 6 and 9. This was done to remove the contribution of the wind signal imposed at the boundary, so the response of the model to wind forcing can be more readily observed.

The plots of the difference between stations 6 and 9 in Plates 27 and 32 include the east-west wind component to illustrate the dependence of the observed response of the water surface on the wind (since CTD6 is essentially 
due west of CTD9, the east-west component of the wind is appropriate for this purpose).

The agreement between model and field is generally good. There are several instances, however, where the model and field differ in either tidal amplitude or the response of the signal to wind. There are several possible explanations for this, including:

a. Errors in modeling the effects of wind, including errors in local wind speed specification.

$b$. Errors in the field data, especially drift induced by meter fouling.

c. Errors in friction specification in the model, especially with respect to the potential for seasonal changes in friction due to seagrass growth and dieoff.

d. Errors inherent in modeling assumptions, such as the assumption of spatially uniform rainfall or temporally and spatially invariant atmospheric pressure.

The response of the water surface to the wind is much greater in April than in October. Therefore, some of the discrepancies observed in the April data were not as apparent during the calibration period (October). follows:

An overview of the water-surface elevation data at each gauge is given as

CTD1: The signal at this gauge is significantly damped by friction as the tide propagates through Card Sound and Barnes Sound and into Manatee Bay. Subtidal signals are readily apparent in these data. The model predicts the tidal amplitude adequately. Plate 28 appears to show that the response of the model to the wind is too great at CTD1. However, this elevated response has actually propagated in from CTD3. Plate 32 demonstrates that the net model response of the water-surface elevation to the wind from CTD3 to CTD1 is close to the field response. The elevated response propagating in from CTD3 is likely a consequence of applying the tidal data at CTD9 as the boundary condition across the entire offshore boundary.

CTD2: The response at CTD2 is similar to that observed at CTD1.

CTD3: The tidal signal amplitude in the model at this gauge is consistently greater than the amplitude of the field signal. Additionally, Plate 28 shows that the response to the wind is significantly greater than that observed in the field, as is mentioned in the discussion of CTD1. Both of these discrepancies are likely consequences of applying the tidal data at CTD9 as the boundary condition across the entire offshore boundary.

CTD4: The tidal amplitude in the model and field are in good agreement at this gauge. Plate 28 shows that the wind-induced response in the model and the field is in good agreement, with some increased response in the model during high-wind events. 
CTD5: The signal in the field at this gauge appears to have been influenced by some type of local interference. There is a tendency for the field signal to truncate the troughs of the tidal signal. This may be the result of some error in the processing of the raw field data. As of the publication of this report, this possibility is still being investigated. Apart from this aberration, which occurs throughout much of the record, the model signal at CTD5 matches well with the field signal.

CTD6: These data for this gauge correspond well with the field. Of note is a significant deviation between the model and field observed in October.

However, this deviation is due to an instance of meter fouling which was left uncorrected (McAdory 2002) and hence, does not imply modeling error. The wind-induced response matches well with the field. The field response observed toward the end of the month is merely the meter fouling mentioned previously. Also, Plate 32 indicates that the model predicts the water-surface slope across the bay reasonably well.

CTD7: The agreement between model and field is generally good for this gauge.

CTD8: The agreement at this gauge is similar to that observed at CTD7. Plate 30 indicates that the response to of the model to the wind is also well represented.

CTD9: The agreement is quite good here, which should be expected since the signal at this gauge was used to drive the model boundary. Plate 30 shows excellent agreement between the model and field, indicating that the decision to omit wind stress from the ocean (to avoid artificially magnifying the wind response) was justified.

CTD10: The agreement between model and field is generally good for this gauge.

CTD11: The agreement between model and field at this gauge is good. Plate 31 indicates that the response of the model to the wind is also in good agreement with the field.

CTD12: The agreement between model and field at this gauge is generally good. The observed difference in mean elevation in June is a consequence of meter fouling which was left uncorrected (McAdory 2002).

\section{Flows (discharges)}

Plots of comparisons between the model and the field flows for the calibration period are given in the Plates 33 through 45, and for the verification period are given in Plates 46 through 58. In general, flood tide is defined as positive flow, and ebb tide is defined as negative flow. For the most part, the agreement between the model and field is good, especially at the major transects, where the largest volume exchanges occur $(1-3,5-8,10-16,20,26)$. However, there are some significant discrepancies. The flow at Transect 20 (Atlantic Intracoastal 
Waterway (AIWW) at Dodge Island Bridge) is somewhat out of phase for both October and February. This may be a real phase problem, or it may be an error in data processing. The agreement at Transects 2 (Angelfish Creek) is suspect in February. However, the total volume of exchange with Biscayne Bay through Transects 2, 3 (Broad Creek), and 4 (Old Rhodes Key to Swan Key) appears to be similar in the model and the field.

There are significant discrepancies observed in the smaller flows. These could be a consequence of any of several factors which are as follows:

a. The high volume of unobserved flow slipping past along the boundary of the transect (as compared to the volume captured by the transect). This is a consequence of the crudeness of the shoreline resolution at extremely small scales.

$b$. The low resolution of the model for these flows (often these transects are only one element wide).

c. The low velocities of these flows, resulting in less dominant advection and hence, more erratic flows.

\section{Velocities}

Plates 59 and 60 give the surface, middle, and bottom X-velocity component for each of the ADPs, filtered to remove the tidal signal (i.e., periods less than $36 \mathrm{hr}$ ). The east-west wind is included in the plots to demonstrate the influence of the wind on the velocities. Although these plots show significant differences in the response of each portion of the water column to the wind, the direction of the response is generally the same throughout the water column. This indicates that a depth-averaged representation of the velocities is a valid means of reducing the data without losing significant information about the behavior of the velocities.

Note that, in all of these velocity plots, the surface velocity tends to respond the least to the wind forcing. This is counterintuitive and could indicate an error in the ADP data, or in the reduction of these data. However, since no errors have been identified as of the publication of this report, these data are accepted as is.

To get an estimate of the depth-averaged velocity at each meter (for purposes of model comparison), a weighted average of the velocity profile is calculated. Since the bottom 23.6 in. of the water column are unmeasured, a logarithmic velocity profile is assumed in this region, with the velocity measured in the first bin (the near bottom bin) used to specify the velocity at the top of the profile. Similarly, the unmeasured portion of the water column near the surface is assumed to travel at the same velocity as the velocity in the near surface bin.

To express the velocity vector data set as a scalar data set, a dominant direction of flow was identified for each ADP. The $\mathrm{X}$ and $\mathrm{Y}$ data from both the model and field were used to generate variance ellipse statistics. These statistics yield the magnitude and direction of the maximum and minimum variances of the velocity data. The dominant direction of flow, maximum standard deviation (taken from the maximum variance), minimum standard deviation, and the ratio 
of the standard deviations (maximum to minimum) for each depth-averaged ADP data record are given in Table 5. The ratio of the standard deviations indicates the degree of uniformity in the direction of the velocities; a high ratio indicates that the velocities oscillate along a nearly constant path, whereas a low ratio indicates that the velocities oscillate along multiple paths. Hence, high ratios indicate confined flow, and low ratios indicate unconfined flow.

\begin{tabular}{||l|l|l|l|l||}
\hline $\begin{array}{l}\text { Table 5 } \\
\text { Variance Ellipse Statistics }\end{array}$ \\
\hline \hline ADP & $\begin{array}{l}\text { Dominant Direction of Flow } \\
\text { (degrees ccw from the } \\
\text { positive x-axis) }\end{array}$ & $\begin{array}{l}\text { Maximum } \\
\text { Standard } \\
\text { Deviation } \\
\text { ft/sec }\end{array}$ & $\begin{array}{l}\text { Minimum } \\
\text { Standard } \\
\text { Deviation } \\
\text { ft/sec }\end{array}$ & $\begin{array}{l}\text { Standard } \\
\text { Deviation } \\
\text { Ratio }\end{array}$ \\
\hline \hline ADP1 MODEL & 42.32 & 0.29 & 0.172 & 1.69 \\
\hline ADP1 FIELD & 2.21 & 0.352 & 0.198 & 1.78 \\
\hline & & & & \\
\hline ADP2 MODEL & 82.8 & 0.27 & 0.061 & 4.44 \\
\hline ADP2 FIELD & 68.55 & 0.319 & 0.235 & 1.36 \\
\hline & & & & \\
\hline ADP3 MODEL & 23.48 & 0.696 & 0.145 & 4.81 \\
\hline ADP3 FIELD & 18.92 & 0.5 & 0.206 & 2.43 \\
\hline & & & & \\
\hline ADP5 MODEL & 48.03 & 0.801 & 0.023 & 35.02 \\
\hline ADP5 FIELD & 39.71 & 0.676 & 0.163 & 4.14 \\
\hline \hline
\end{tabular}

The meters were active throughout the entire period of record. ADP1, however, was inactive, from September through December 1997. Therefore, there are no data at ADP1 for the calibration period.

The velocities at ADP's 2, 3, and 5 are plotted over the calibration period in Plates 61 and 62. The plots of the velocities over the verification period are plotted in Plates 63 and 64. For each plot, the dominant directions taken from Table 5 are used to determine a flow axis. Each velocity measurement is then projected onto the flow axis, and the sign of the projection is used to determine whether the flow is positive or negative. Plates 65 through 71 contain data which have been filtered to remove the tidal signals (all signals with a period less than $36 \mathrm{hr}$ were removed). This was done to compare the effects of wind on the velocities in the model and the field. The analysis was conducted for the months of October 1997 and February and April 1998. However, since the results were largely the same for both February and April, only the October and April plots are given in this report. For these plots, the velocity components were plotted (i.e., $\mathrm{X}$ and $\mathrm{Y}$ velocity).

Some comments concerning the velocities at each ADP meter are given below.

ADP1: The model appears to simulate the tidal velocity amplitudes with reasonable accuracy. Plate 68 indicates that the model is in good agreement with the field response to the wind. Note that Table 5 gives a dominant direction of 
flow for the field that has a greater east-west component than the model. Since the wind-induced currents are well represented in the model, this difference in the dominant direction of flow is likely a difference in the direction of the tidal excursion. This difference may be due to a local subgrid-scale geometric feature in the field that is not resolved in the model.

ADP2: The model appears to simulate the tidal velocity amplitudes with reasonable accuracy. However, Plates 65 and 69 show that the wind response in the model and the field are in the opposite directions, and of drastically different magnitudes. A possible explanation for this can be inferred from Figure 24. This is a plot of the residual velocities in the Central Bay, averaged over April 15 and 16,1998 . Note that, in the vicinity of ADP2, the model predicts a residual recirculation current. If the location of the meter in the field is different than the model, or if the local geometry and/or mixing as represented in the model are slightly different, then the residual current observed in the model could reverse direction to correspond with the field.

ADP3: The amplitude of the tidal velocity is greater in the model than in the field. This is surprising because the measured flow through the Safety Valve, which is located just east of ADP3, correlates extremely well with that given in the field (see Transect 8, Plates 36 and 49). Therefore, this effect is likely local. The wind-induced current at ADP3 corresponds well with that observed in the field (Plates 66 and 70).

ADP5: The tidal velocities in the model at this meter correspond extremely well to those observed in the field. The wind-induced currents are also in good agreement with the wind-induced currents in the field (Plates 67 and 71).

\section{Salinities}

The salinity plots at the $12 \mathrm{BNP} / \mathrm{CHL}$ CTDs are given for the verification period in Plates 72 through 77. These plates also contain selected plots of DERM Bay Run salinity data for Bay Run gauges with are in close proximity to the BNP/CHL CTDs.

In general, the model and field are in good agreement with respect to salinity. However, where discrepancies exist, they are likely the result of any of several factors. These factors are (in order of likely significance):

a. Inaccurate values of local wind strength applied in the model.

$b$. Inaccurate or erroneous estimates of the inflow rates at the coastal structures.

c. Insufficient or excessive currents in the offshore to sweep away lowsalinity water.

d. Errors in the estimation of the offshore salinity boundary condition.

$e$. Locally stratified conditions in the bay (since the gauges are near the bed, locally stratified conditions, if and when they exist, would tend to 
make the observed values higher than the depth averaged value given in the model).

f. Errors in the estimation of the evaporation rate.

g. The lack of any tidal wetlands resolved in the grid, which would supply an additional evaporation sink for fresh water.

A discussion of each gauge follows:

CTD1: The model reasonably predicts the field measurement for much of the verification period. However, the model exceeds the field value by as much as 3 to 4 from December through March. This may be due to the excessive wind response in the tide propagating in from the offshore boundary, as observed at CTD3 (see "Tides" section). Note that a large storm event recorded in early February is manifest in both the model and in the field. The model tends to underpredict the amplitude of the salinity signal, possibly indicating excessive turbulent mixing in the model. However, Table 4 indicates an average diffusion coefficient for the material type in Manatee Bay (material type 12) of $12 \mathrm{ft}^{2} / \mathrm{s}$, which is relatively small.

CTD2: This gauge is influenced by flow at S-20. There is a large flow event recorded at S-20 in September. The flow rate recorded for this event reaches $900 \mathrm{cfs}$, which exceeds the Special Project Flood for this structure (750 cfs) (Swain et al. 1997). This may indicate an error in the estimate of this flow. The model tends to overestimate the salinity in February and March, possibly because of the influence of excessive wind response in the tide (see the discussion of CTD1). In May, the salinity in the field climbs to two (2) to three (3) parts per thousand (ppt) greater than salinity than the model predicts. This increase in salinity is also observed at CTD4, CTD5, and CTD6. This rapid increase in salinity in the bay is the result of minimal inflow from the coastal structures, combined with a prevailing onshore wind. The model predicts the trend well, but tends to slightly underpredict the rate of increase in the salinity.

CTD3: The model is within 1 to 2 ppt of the field for much of the record, with a 3- to 4-ppt difference through October and November. Note that there is some slight stratification observed in the Seabird data during this period, which may explain some of the discrepancy.

CTD4: These data at this gauge are plotted together with data from two of the DERM Bay Run stations: BB41, located about 1.5 miles south of CTD4, and BB38, located about 2.5 miles northeast of CTD4. The model and field are in good agreement for most of the record, with a departure of 2 to 3 ppt occurring in April and May (see discussion of CTD2). The DERM Bay Run data show some intermittent stratification in the region. Of note is stratification observed at BB41 in early February, which corresponds to a major flood event. This event is also observed in the model data.

CTD5: Although the magnitude of the salinity for the model and field are often different, the pattern of the salinity response is well represented in the model. This response is largely due to the influence of wind and the inflows at the nearby canals. It is noteworthy that this region of the bay exhibits high 
horizontal salinity gradients. Therefore, the value of salinity recorded at nearby locations can be significantly different. Also, the observed error in the predicted inflow for the nearby coastal structures (i.e., S-20F, S-20G, S-21, and S-21A) is relatively high (Table 3 ). Therefore, errors in the salinity can be partially attributed to errors in the estimate of the inflows in the canals.

These data at this gauge are plotted together with data from the DERM Bay Run station MI01, which is located in the mouth of Military Canal. It is noteworthy that S-20G is rarely flowing though the simulation period (Plate 2). Therefore, the high stratification observed at MI01 is likely the result of flows through the other nearby canals. Although the Seabird data indicate little stratification, the shallow depth at this gauge (average depth is $2.9 \mathrm{ft}$ ) makes the measurement of a salinity profile with the seabird device difficult (the Seabird measurement excludes the upper $3 \mathrm{ft}$ of the water column). Hence, the Seabird measurement at this gauge is not helpful in determining the degree of local stratification at CTD5.

CTD6: These data at this gauge are plotted together with data from the DERM Bay Run station BB39A, which is located within a few hundred feet of CTD6. The salinity at CTD6 is generally in good agreement with the field, both with respect to average salinity and salinity amplitude. However, the model tends to overpredict the salinity amplitude during January through March. There is some local stratification observed at BB39A. This gauge is also influenced by inflows from S-20F, S-20G, S21-A, and S-21, although to a lesser extent than is CTD5.

CTD7: This gauge is located within 2 miles of S-123. It is plotted together with data from the DERM Bay Run stations CD01A, which is located within a few hundred feet of CTD7, and BB36, which is about 3 miles east of CTD7. In general, the agreement between the model and field is good, except that the model tends to overpredict salinity through December and January by about 3 to 4 ppt. The effects of the February storm event are manifest in both the model and the field. Note that, toward the end of the period of record, CD01A records persistent high stratification, whereas the Seabird gauge records none. Since CD01A is located nearby CTD7, this points to the possibility that the Seabird gauge is not recording local stratification. If this is true, it may be because the freshwater lens is too close to the surface to be measured by the Seabird gauge. Note also the large salinity difference between CD01A and BB36, which are separated by about 3 miles. These differences demonstrate the high horizontal salinity gradients near the western shoreline. This is especially evident from April through June.

CTD8: This gauge is located in the mouth of Canal 2, which is controlled by S-22 (Plate 4). This gauge is plotted together with data from Bay Run station BB34, which is located within a few hundred feet of CTD8. The model and field are in close agreement for the entire period of record. It is noteworthy that, although the Seabird data evidences little or no stratification, the BB34 data record persistent stratification throughout the period of record. This is further evidence to support the hypothesis that the Seabird gauge is not measuring the fresher water at the surface. There is particularly strong stratification observed at the time of the rainfall event in February. 
CTD9: This gauge agrees reasonably well with the field, although the amplitude of the signal is generally smaller than that observed in the field. The salinity at this gauge is largely a reflection of the value specified at the offshore boundary. Therefore, the close agreement at this gauge tends to support the validity of the choice of the salinity boundary condition for the offshore boundary.

CTD10: This gauge is plotted together with several nearby DERM Bay Run stations. CTD10 is located near the mouth of the Miami River. The model agrees well with the field, in both mean salinity and salinity tidal amplitude. DERM Bay Run station MR01 is located in the mouth of the Miami River, and hence, records significant stratification throughout the period of record. There is evidence of meter fouling in the field data toward the end of June.

CTD11: This gauge agrees well with the field. There is evidence of meter fouling in the field data toward the end of June.

CTD12: Although the agreement between model and field at CTD12 is generally good, there is a significant drop in model salinity observed in early December and in early February. There is a high flow record at S-28 that occurs in these time frames, and hence, errors in the estimate of flow at this location, and this could influence CTD12. Also, there is relatively high stratification observed at the local DERM Bay Run stations and in the Seabird data at these times, which could contribute to the discrepancy.

\section{Quantitative Analysis}

Statistical analysis of the model and field data is given with four statistics: mean error (ME), mean absolute error (MAE), root mean square error (RMS), and index of agreement $(d)$. The index of agreement is a descriptive measure of predictive success. It gives a value between 0 and 1, with 1 indicating perfect agreement. Since it is a relative measure of modeling success, and it is bounded (between 0 and 1), it is also useful for making cross-comparisons between models (Willmott 1982).

Letting $O$ and $P$ be the observed and predicted values of a quantity $N$, the following expressions result:

$$
\begin{aligned}
& \mathrm{ME}=\frac{1}{N} \sum_{n=1}^{N}\left(O_{n}-P_{n}\right) \\
& \mathrm{MAE}=\frac{1}{N} \sum_{n=1}^{N}\left|O_{n}-P_{n}\right| \\
& \mathrm{RMS}=\sqrt{\frac{1}{N} \sum_{n=1}^{N}\left(O_{n}-P_{n}\right)^{2}}
\end{aligned}
$$




$$
d=1-\left[\frac{\sum_{n=1}^{N}\left(P_{n}-O_{n}\right)^{2}}{\sum_{n=1}^{N}\left(\left|P_{n}-\bar{O}\right|+\left|O_{n}-\bar{O}\right|\right)^{2}}\right]
$$

\section{Tides}

Table 6 contains a statistical analysis of the water-surface elevation data for the calibration period, and Table 7 contains the same analysis for the verification period. Values are also given for the NOS gauge at Virginia Key. Note that the model and field data were averaged, and their mean values removed. Therefore, the mean error is always given as 0 .

\begin{tabular}{||l|l|l|l|l||}
\hline \hline \multicolumn{5}{||l}{$\begin{array}{l}\text { Table } 6 \\
\text { Statistics for Water-Surface Elevation Comparisons: Calibration }\end{array}$} \\
\hline \hline CTD Gauge & ME, ft & MAE, $\mathrm{ft}$ & RMS, ft & $\boldsymbol{d}$ \\
\hline \hline 1 & 0 & 0.181 & 0.23 & 0.917 \\
\hline 2 & 0 & 0.157 & 0.198 & 0.936 \\
\hline 3 & 0 & 0.174 & 0.215 & 0.936 \\
\hline 4 & 0 & 0.132 & 0.165 & 0.982 \\
\hline 5 & 0 & 0.257 & 0.321 & 0.932 \\
\hline 6 & 0 & 0.263 & 0.324 & 0.938 \\
\hline 7 & 0 & 0.128 & 0.161 & 0.987 \\
\hline 8 & 0 & 0.114 & 0.14 & 0.99 \\
\hline 9 & 0 & 0.088 & 0.107 & 0.995 \\
\hline 10 & No Data & No Data & No Data & No Data \\
\hline 11 & 0 & 0.173 & 0.208 & 0.984 \\
\hline 12 & 0 & 0.214 & 0.252 & 0.975 \\
\hline NOS & 0 & 0.136 & 0.166 & 0.987 \\
\hline \hline
\end{tabular}

\section{Table 7}

Statistics for Water-Surface Elevation Comparisons: Verification

\begin{tabular}{||l|l|l|l|l|}
\hline \hline CTD Gauge & ME, ft & MAE, ft & RMS, ft & $\boldsymbol{d}$ \\
\hline \hline 1 & 0 & 0.171 & 0.212 & 0.895 \\
\hline 2 & 0 & 0.151 & 0.189 & 0.924 \\
\hline 3 & 0 & 0.149 & 0.194 & 0.935 \\
\hline 4 & 0 & 0.165 & 0.207 & 0.969 \\
\hline 5 & 0 & 0.184 & 0.231 & 0.96 \\
\hline 6 & 0 & 0.123 & 0.155 & 0.984 \\
\hline 7 & 0 & 0.128 & 0.159 & 0.986 \\
\hline 8 & 0 & 0.16 & 0.204 & 0.979 \\
\hline 9 & 0 & 0.092 & 0.116 & 0.994 \\
\hline 10 & 0 & 0.179 & 0.245 & 0.979 \\
\hline 11 & 0 & 0.155 & 0.19 & 0.987 \\
\hline 12 & 0 & 0.197 & 0.234 & 0.978 \\
\hline NOS & 0 & 0.121 & 0.153 & 0.99 \\
\hline
\end{tabular}


The agreement between the model and field is very high. This is evident in the values given for the index of agreement, which are very close to 1 . The best agreement is at CTD9 and Virginia Key, which is not surprising since data at CTD9 were used to drive the offshore boundary, and the NOS gauge is located nearby. The worst agreement occurs at CTD Gauges 1 through 3 and Gauge 5. The errors at Gauges 1 through 3 are likely propagated in from the offshore boundary, which was specified according to the tide recorded at CTD9, located further to the north. Note that the error shown for CTD5 may be exaggerated because of the truncation of the troughs in the field record that was discussed in the "Qualitative Analysis" section.

A harmonic analysis was performed on the water-surface elevation data. The analysis was done over the month of May 1998 because there exists field data at all the gauges for this month. The tidal signal was filtered to remove all signals with a period less than $3 \mathrm{hr}$ and greater than $35 \mathrm{hr}$. The signal was then analyzed for six constituents: $\mathrm{M} 2, \mathrm{~S} 2, \mathrm{~N} 2, \mathrm{~K} 2, \mathrm{~K} 1$, and $\mathrm{O} 1$. The results are given in Plates 78 through 85 . Plates 78 through 84 compare the tidal constituent amplitudes. These confirm that the M2 constituent is the dominant component of the tide. Plate 85 gives the phase lag of the constituents, relative to CTD9. For convenience, the average phase lag is calculated for the semidiurnal components (M2, S2, N2, K2) and the diurnal components $(\mathrm{K} 1, \mathrm{O} 1)$. The agreement in amplitude and phase is generally good. The worst agreement appears at CTD3. This may result from the fact that the tide data at CTD9 were used as a model boundary condition across the entire offshore boundary. Note that, although the phase lag is especially poor for the diurnal components at CTD3, there is very little tidal energy associated with the diurnal components.

\section{Velocities}

A statistical analysis of the velocity data for the calibration period is given in Table 8, and Table 9 contains the same analysis for the verification period. These tables contain the same statistics that are given in Tables 6 and 7 for the water-surface elevations. The statistics bear out the qualitative analysis: the best agreement between model and field is at ADP5, the worst is at ADP2.

\section{Salinities}

A statistical summary of the salinity data at the BNP/CHL gauges is given in Table 10. The summary contains the same statistics as those given for the watersurface elevations and velocities. Although the mean difference in salinity at

\begin{tabular}{||l|l|l|l|l||}
\hline \multicolumn{4}{||l||}{$\begin{array}{l}\text { Table } 8 \\
\text { Statistics for Velocity Comparisons: Calibration }\end{array}$} \\
\hline \hline ADP & ME, ft/sec & MAE, ft/sec & RMS, ft/sec & $\boldsymbol{d}$ \\
\hline \hline 1 & No Data & No Data & No Data & No Data \\
\hline 2 & -0.026 & 0.185 & 0.253 & 0.842 \\
\hline 3 & -0.016 & 0.269 & 0.334 & 0.924 \\
\hline 5 & -0.028 & 0.138 & 0.184 & 0.984 \\
\hline \hline
\end{tabular}




\begin{tabular}{|c|c|c|c|c|}
\hline \multicolumn{5}{|c|}{$\begin{array}{l}\text { Table } 9 \\
\text { Statistics for Velocity Comparisons: Verification }\end{array}$} \\
\hline ADP & ME (ft/sec) & MAE (ft/sec) & RMS (ft/sec) & $d$ \\
\hline 1 & "-0.006 & 0.179 & 0.258 & $\overline{0.879}$ \\
\hline 2 & -0.041 & 0.275 & 0.35 & 0.714 \\
\hline 3 & -0.032 & 0.208 & 0.272 & 0.954 \\
\hline 5 & -0.036 & 0.17 & 0.246 & 0.973 \\
\hline
\end{tabular}

\begin{tabular}{|c|c|c|c|c|}
\hline CTD Gauge & ME, ppt & MAE, ppt & RMS, ppt & $d$ \\
\hline 1 & 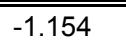 & "1.528 & 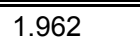 & "0.657 \\
\hline 2 & 0.119 & 1.927 & 2.304 & 0.594 \\
\hline 3 & 1.607 & 2.225 & 2.922 & 0.496 \\
\hline 4 & 0.177 & 1.517 & 1.858 & 0.812 \\
\hline 5 & 3.643 & 4.166 & 4.967 & 0.886 \\
\hline 6 & -0.396 & 2.271 & 2.922 & 0.931 \\
\hline 7 & -1.105 & 1.963 & 2.562 & 0.867 \\
\hline 8 & 0.612 & 1.264 & 1.677 & 0.94 \\
\hline 9 & -0.154 & 0.847 & 1.398 & 0.718 \\
\hline 10 & -1.2 & 2.345 & 3.784 & 0.639 \\
\hline 11 & 0.406 & 1.103 & 2.232 & 0.794 \\
\hline 12 & 1.806 & 2.496 & 3.624 & 0.501 \\
\hline
\end{tabular}

CTD5 is relatively high, this gauge also exhibits a high index of agreement. This is because of the ability of the model to predict the general behavior of the salinity in the field. CTD Gauges 1 through 3 yield a low index of agreement. This is a result of the low variability of the salinity signal over time, combined with the tendency for the model to overpredict the salinity in the middle of the simulation. The gauges in the North Bay show higher values of mean absolute error than of mean error, indicating the dominance of salinity amplitude differences, or the lack of a persistent trend in overprediction or underprediction. 


\section{Salinity Sensitivity Tests}

Five tests were conducted to determine the sensitivity of the model salinity to variations in the boundary conditions. The tests were designed to reflect a conservative estimate of the degree of uncertainty in the model boundary forcings. The tests are as follows:

a. Test A: Sensitivity to the imposed offshore current was investigated by eliminating the offshore boundary slope.

b. Test $B$ : Sensitivity to the evaporation rate was investigated by increasing the evaporation rate by a factor of 1.5 .

c. Test $C$ : Sensitivity to errors in the estimates of the flows at the structures was investigated by reducing the amount of flow at each structure by either

(1) One-half the error given in Table 3, or

(2) 10 percent, whichever is larger.

d. Test $D$ : Sensitivity to the offshore salinity boundary condition was investigated by increasing the specified boundary condition by $1 \mathrm{ppt}$.

e. Test $E$ : Sensitivity to the wind speed (and hence wind stress) was investigated by increasing the wind speed by a factor of 1.2 .

The results of these sensitivity tests are given in Figure 25. The figure shows the mean absolute value of the change in salinity at each CTD gauge because of each sensitivity test. The most significant impact results from the increase in wind speed (Test E). This impact is most evident along the western shoreline of Biscayne Bay, at CTDs 5, 6, 7, and 8. The reduction in the inflow rates at the coastal structures (Test $\mathrm{C}$ ) has a significant impact on the salinity at CTDs 5 and 6 , where the flows at structures S-20F, S20-G, S21, and S-21A have a dramatic influence. The increased evaporation (Test B) has a significant impact in South and Central Biscayne Bay. The elimination of the offshore current (Test A) has the greatest impact at CTD3. The increased offshore salinity (Test D) has the greatest impact in the North Bay.

Table 11 gives the vector sum of the mean absolute differences in salinity for the five sensitivity tests. This is given together with the mean absolute error in salinity at each of the gauges for the verification run. If the difference between these two values is positive (i.e., if the vector sum of sensitivity differences is greater than the mean absolute error), we can assume that the error in the model 


\begin{tabular}{||l|l|l|l||}
\hline \hline $\begin{array}{l}\text { Table 11 } \\
\text { Comparison of Sensitivity to Baseline Run }\end{array}$ \\
\hline \hline \\
CTD Gauge & $\begin{array}{l}\text { Vector Sum of } \\
\text { Sensitivity } \\
\text { Differences }\end{array}$ & $\begin{array}{l}\text { MAE for Baseline } \\
\text { Model Run }\end{array}$ & Difference \\
\hline \hline 1 & 1.43 & 1.53 & $\mathbf{- 0 . 1 0}$ \\
\hline 2 & 1.55 & 1.93 & $\mathbf{- 0 . 3 7}$ \\
\hline 3 & 1.53 & 2.23 & $\mathbf{- 0 . 7 0}$ \\
\hline 4 & 1.71 & 1.52 & 0.19 \\
\hline 5 & 3.48 & 4.17 & $\mathbf{- 0 . 6 8}$ \\
\hline 6 & 2.94 & 2.27 & 0.67 \\
\hline 7 & 1.91 & 1.96 & $\mathbf{- 0 . 0 6}$ \\
\hline 8 & 1.79 & 1.26 & 0.53 \\
\hline 9 & 1.14 & 0.85 & 0.29 \\
\hline 10 & 1.45 & 2.35 & $\mathbf{- 0 . 9 0}$ \\
\hline 11 & 1.45 & 1.10 & 0.34 \\
\hline 12 & 1.27 & 2.50 & $\mathbf{- 1 . 2 3}$ \\
\hline
\end{tabular}

is within the bounds of the error in the applied boundary conditions. Table 11 shows several negative differences, which are given in bold type. However, all of these differences (except for CTD12) are less than 1ppt, and given the fact that the sensitivity tests were conducted with conservative estimates of the error in the applied boundary conditions, these negative differences do not indicate conclusively that the model is performing inadequately at any of the gauges. The performance of the model at CTD12 is of concern, but it may be that this results from errors in the estimate of the inflow at S-28 (p 25), and that applying the conservative estimate of one-half the measured error in the inflow may have been inadequate. 


\section{Summary and Conclusions}

\section{Hydrodynamics}

Tides: The model successfully reproduces the observed tidal signal in the Central and North Bay, with respect to both the tidal and subtidal (i.e., winddriven) response. The tidal signal is well represented in the South Bay, but the wind-driven response is excessive in the model. This appears to result from the application of the measured tidal signal at CTD9 as the offshore boundary condition. Although this boundary specification is valid in the North and Central Bay, it propagates an exaggerated wind response into the South Bay.

Flows: The model adequately reproduces the observed flows across the ADCP transects. Although there are some discrepancies, most of these are across transects with relatively small flow rates.

Velocities: The model successfully reproduces the observed velocity signal, both tidal and subtidal, at ADPs 3 and 5. The subtidal signal is well represented at ADP1, but the dominant direction of the tidal excursion in the model is more northerly than the field, by about $40 \mathrm{deg}$. The tidal signal is adequately represented at ADP2, but the subtidal velocities are in the opposite directions in the model and the field. This is likely a consequence of the fact that ADP2 is located in a residual return current in the model, and the local configuration of this current could be different in the field.

Also, subtidal analysis of the surface, middepth, and bottom velocities for ADPs 1, 2, 3, and 5 reveals that, although the response to the wind is different at different depths, the entire water column generally responds in the same direction. This serves as further justification for the validity of depth averaging, and hence, the use of a 2-D depth-averaged model for Biscayne Bay.

\section{Salinity}

The model adequately reproduces the observed field salinity. There are some significant discrepancies between the model and the field, but sensitivity tests conducted to determine the sensitivity of the model to applied boundary conditions tend to indicate that the error in the model is (a) within the bounds of the uncertainty in the boundary conditions, or (b) exceeds these bounds, but by an insignificant amount, especially considering that the bounds of the boundary uncertainty were chosen conservatively. 


\section{Overall Model Assessment}

The model is sufficiently well-calibrated for use in conducting base versus plan simulations to assess the impact of various freshwater distribution scenarios on the salinities in Biscayne Bay.

\section{Model Improvements}

Some suggested improvements include:

a. A thorough investigation of the inflow rates at the canals.

$b$. The implementation of an ocean boundary condition generated by a coastal ocean model (such as ADCIRC) with the effects of wind included.

c. A field investigation of the average wind speed and direction in the various parts of Biscayne Bay. This might consist of a program of synoptic wind data collection in several different locations, using the same type of equipment mounted at the same elevation above the water surface.

d. The resolution of coastal wetlands into the grid.

\section{Model Computational Performance}

The model was run on two separate systems: a DEC-Alpha workstation with four processors running in parallel, and the Silicon Graphics O3K system, using eight processors running in parallel. For a 10 -month simulation with one-halfhour time-steps, the Dec-Alpha required approximately 6.5 days to complete the run, and the $\mathrm{O} 3 \mathrm{~K}$ required approximately 1.2 days to complete the run. 


\section{References}

Alleman, R. W., Bellmund, S. A., Black, D. W., Formati, S. E., Gove, C. A., and Gulick, L. K. (1995). "Surface Water Improvement and Management Plan for Biscayne Bay: Technical supporting document and appendices" South Florida Water Management District.

Bellmund, S., Browder, J., and Alspach, S. (1999). Issue paper on freshwater flows to Biscayne Bay for the Alternative Evaluation Team, February 5, 1999. First author is at Biscayne National Park, Homestead, FL.

Brigham Young University (BYU). (1994). FastTABS 3.0 hydrodynamic modeling reference manual. Engineering Graphics Laboratory, Provo, Utah.

Cantillo, A. Y., Hale, K., Collins, E., Pikula, L., and Caballero, R. (2000). "Biscayne Bay: Environmental history and annotated bibliography," NOAA Technical Memorandum NOS NCCOS CCMA 145 and bibliographic files.

Chow, V. T. (1959). Open channel hydraulics. McGraw-Hill, New York.

Christensen, B. A. (1970). "Manning's n for cast-in-place concrete pipe; Discussions by Bent A. Christensen, and R. Sakthivadivel, S. Seetharaman and M.V. Somasundaram," Journal of the Hydraulics Division, Proceedings of the American Society of Civil Engineers, 96(HY3).

Cofer-Shabica, S. V., and Wang, J. D. (1989). "The effects of freshwater canal discharges on salinities in Biscayne National Park," Proceedings of Sixth Symposium on Coastal and Ocean Management/ASCE, July 11-14, 1989, Charleston, SC.

Environmental Modeling Research Laboratory. (2000). SMS 7.0, Tutorials, Brigham Young University, Provo, UT.

Fatt, J. C., and Wang, J. D. (1987). "Canal discharge impacts on Biscayne Bay salinities, Biscayne National Park," United States Department of the Interior Report SER-89, Boulder, CO.

Hamrick, J. M. (1992). "A three-dimensional environmental fluid dynamics computer code: Theoretical and computational aspects," Special Report No. 317, Applied Marine Science and Ocean Engineering, Virginia Institute of Marine Science. 
Henderson-Sellers, B. (1984). Engineering limnology. Pitman Advanced Publishing, Boston, 81-91.

Hsu, S. A. (1988). Coastal meteorology. Academic Press, New York.

Imru, M. (2001). "Considerations for implementation of new flow rating for coastal structures discharging into Biscayne Bay," December 2000, South Florida Water Management District, West Palm Beach, FL.

King, I. P. (1988). "A finite element model for three-dimensional hydrodynamic systems," prepared by Resource Management Associates, Lafayette, CA, for U.S. Army Corps of Engineers, Waterways Experiment Station, Vicksburg, MS.

\section{CA.}

. (1993). "RMA10,” Resource Management Associates, Lafayette,

Langevin, C. D. (2001). "Simulation of ground-water discharge to Biscayne Bay, Southeastern Florida," Water-Resources Investigations Report 00-4251, United States Geological Survey, Tallahassee, FL.

McAdory R. T., Pratt, T. C., Hebler, M. T., Fagerburg, T. L., and Curry, R. (2002). "Biscayne Bay field data," Technical Report ERDC/CHL TR-02-8, U.S. Army Engineer Research and Development Center, Vicksburg, MS.

Mellor, G. L., and Yamada, T. (1982). "Development of a turbulence closure model for geophysical fluid problems," Reviews of Geophysics and Space Physics 20(4), 851-875.

Roig, L. C. (1995). "Mathematical theory and numerical methods for the modeling of wetland hydraulics." Proceedings, water resources engineering, 1995 First International Conference, San Antonio, Texas, August 14 - 18, 1995, American Society of Civil Engineers, New York, 249-253.

Sengupta, S., Lee, S. S., and Miller, H. P. (1978). "Three-dimensional numerical investigations and wind-induced transport processes in Biscayne Bay," Sea Grant Bulletin No. 39, University of Miami.

Smagorinsky, J. (1963). "General circulation experiments with the primitive equations." Monthly Weather Review 93, 99-165.

Speziale, C. G. (1998). "Turbulence modeling for time-dependent RANS and VLES: A review," AIAA Journal, 36(2), 173-184.

Swain, E. D., Kapadia, A., Koné, S. D. E., Mtunda, D., and Tillis, G. M.. (1997). "Determining discharge coefficient ratings for coastal structures in Dade County Florida," Water Resources Investigations Report 97-4079, U.S. Geological Survey, Tallahassee, FL. 
Thomas, T. G., and Williams, J. R. R. (1995). "Large eddy simulation of a symmetric trapezoidal channel at a Reynolds number of 430,000," Journal of Hydraulic Research, 33(6), 825-830.

Thomas, W. A., and McAnally, W. H., Jr. (1990). "User's manual for the generalized computer program system: Open-channel flow and sedimentation, TABS-2," U.S. Army Engineer Waterways Experiment Station, Vicksburg, MS.

Van Horn, S. (1996). "A hydrometeorologic monitoring network metadata report," WRE No. 344, Resource Assessment Division, Water Resource Evaluation Department, South Florida Water Management District, West Palm Beach, FL.

Wang, J. D., and Connor, J. J. (1975). "Mathematical modeling of near coastal circulation," Report No. 200, Ralph M. Parsons Laboratory for Water Resources and Hydromechanics, Massachusetts Institute of Technology, R75-19.

Wang, J. D. (1978). "Verification of finite element hydrodynamic model CAFÉ," Verification of mathematical and physical models in hydraulic engineering." Proceedings of the $26^{\text {th }}$ annual hydraulics engineering specialty conference, August 9-11, University of Maryland, College Park, MD.

Willmott, C. J. (1982). "Some comments on the evaluation of model performance," Bulletin of the American Meteorological Society 63(11), $1309-1310$.

Wu, J. (1980). "Wind stress coefficients over sea-surface near neutral conditions - a revisit," Journal of Physical Oceanography 10, 727-740. 


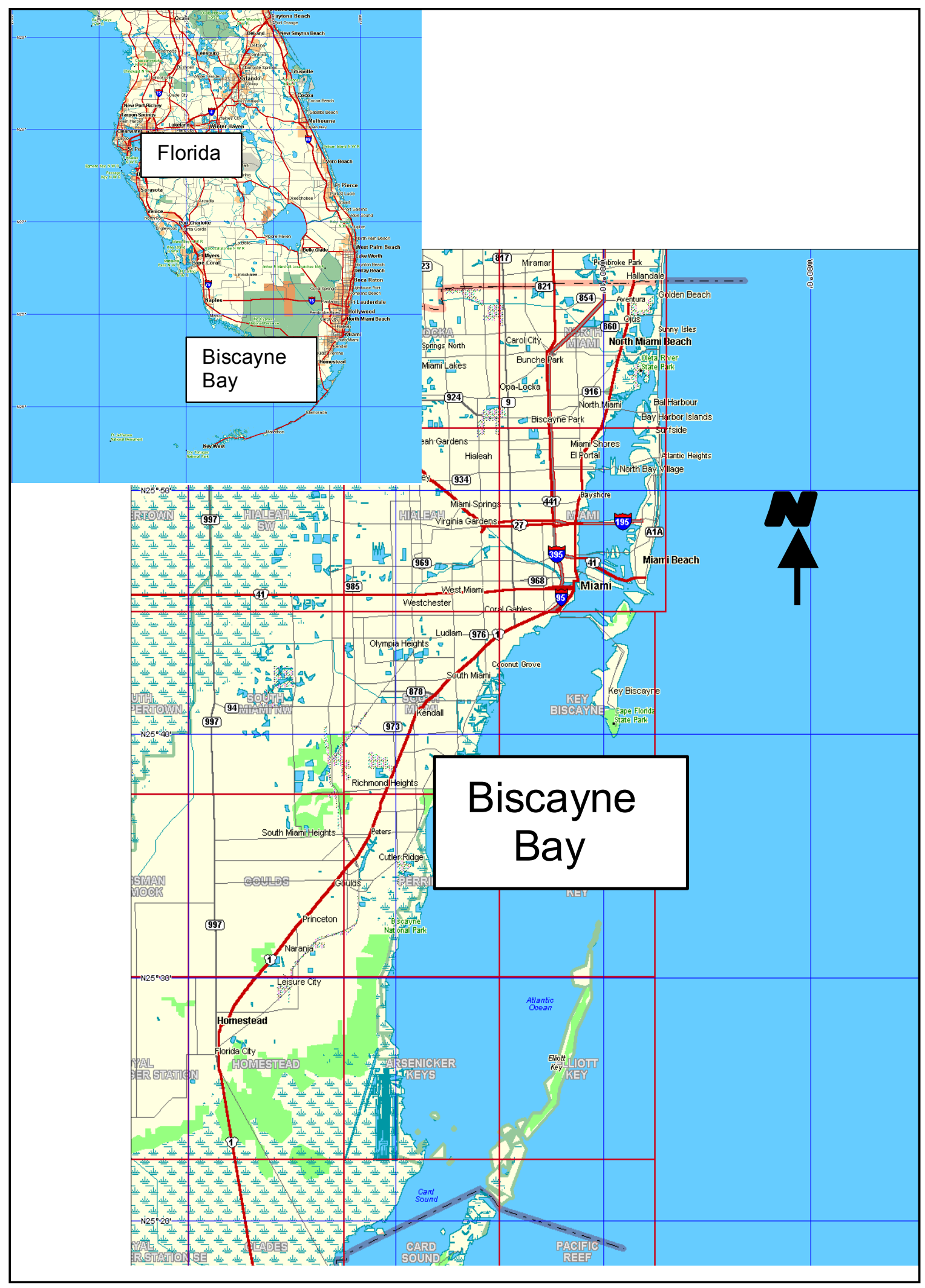

Figure 1. Biscayne Bay location maps 


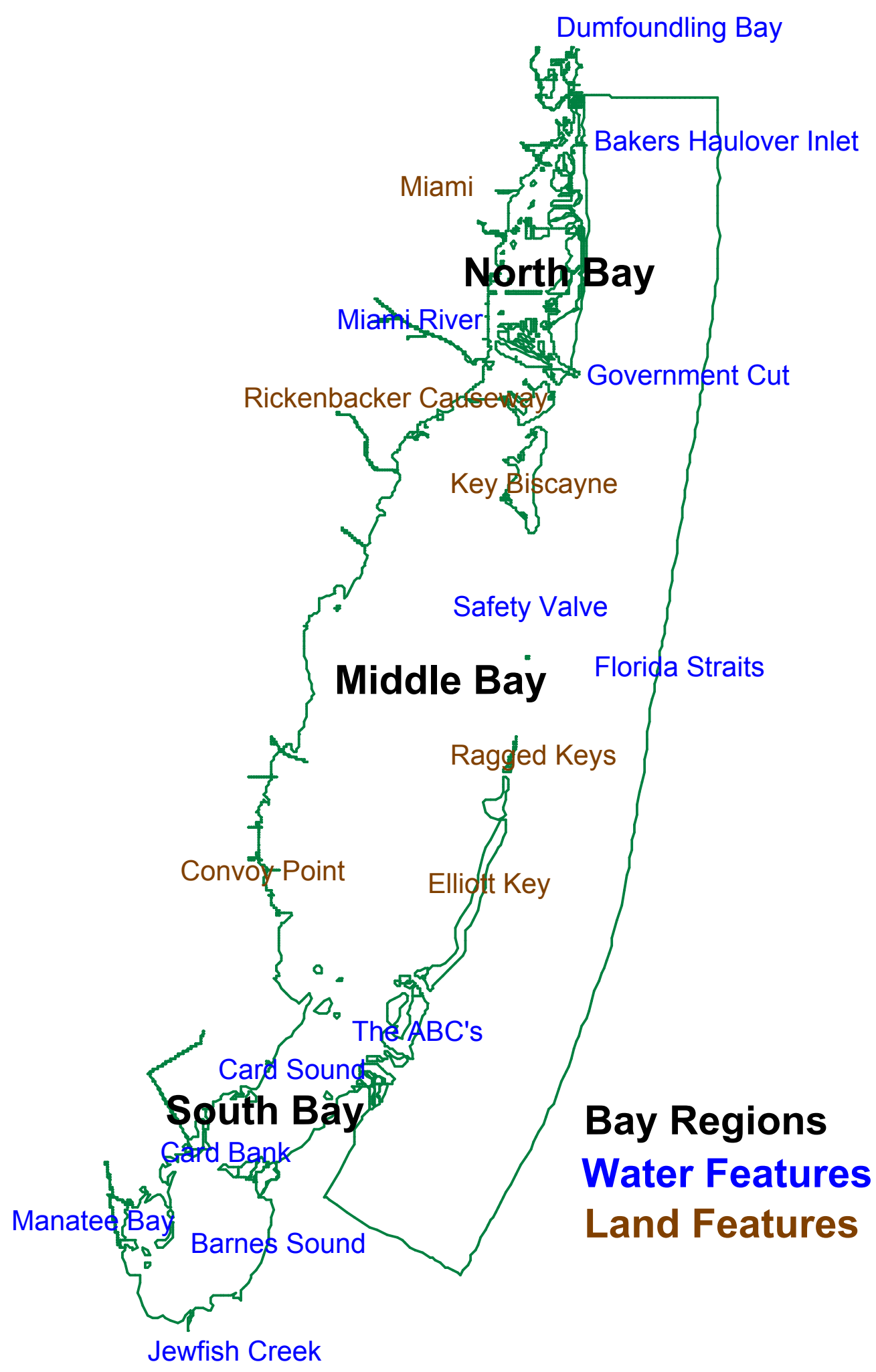

Figure 2. Feature map of Biscayne Bay 


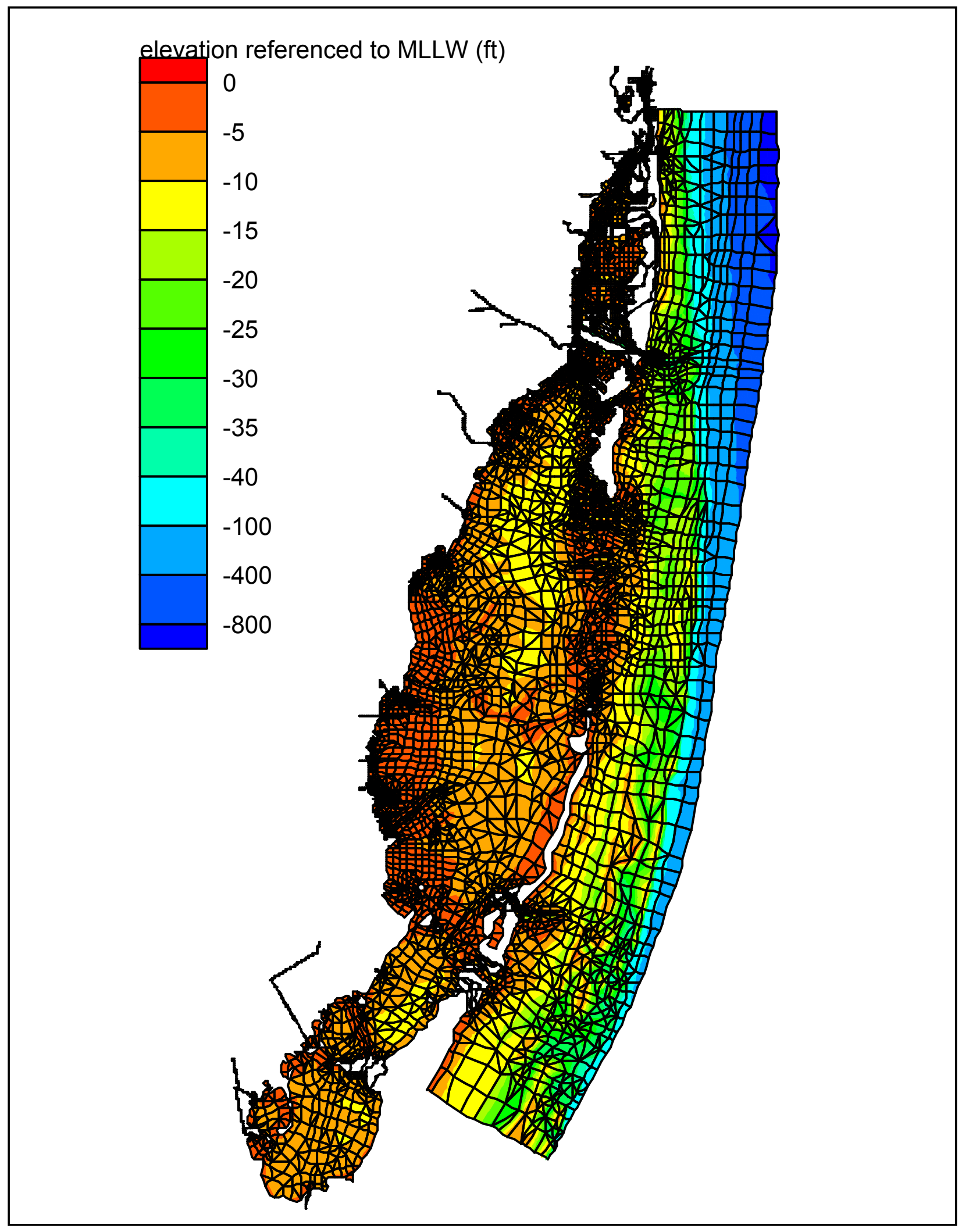

Figure 3. The FE mesh 


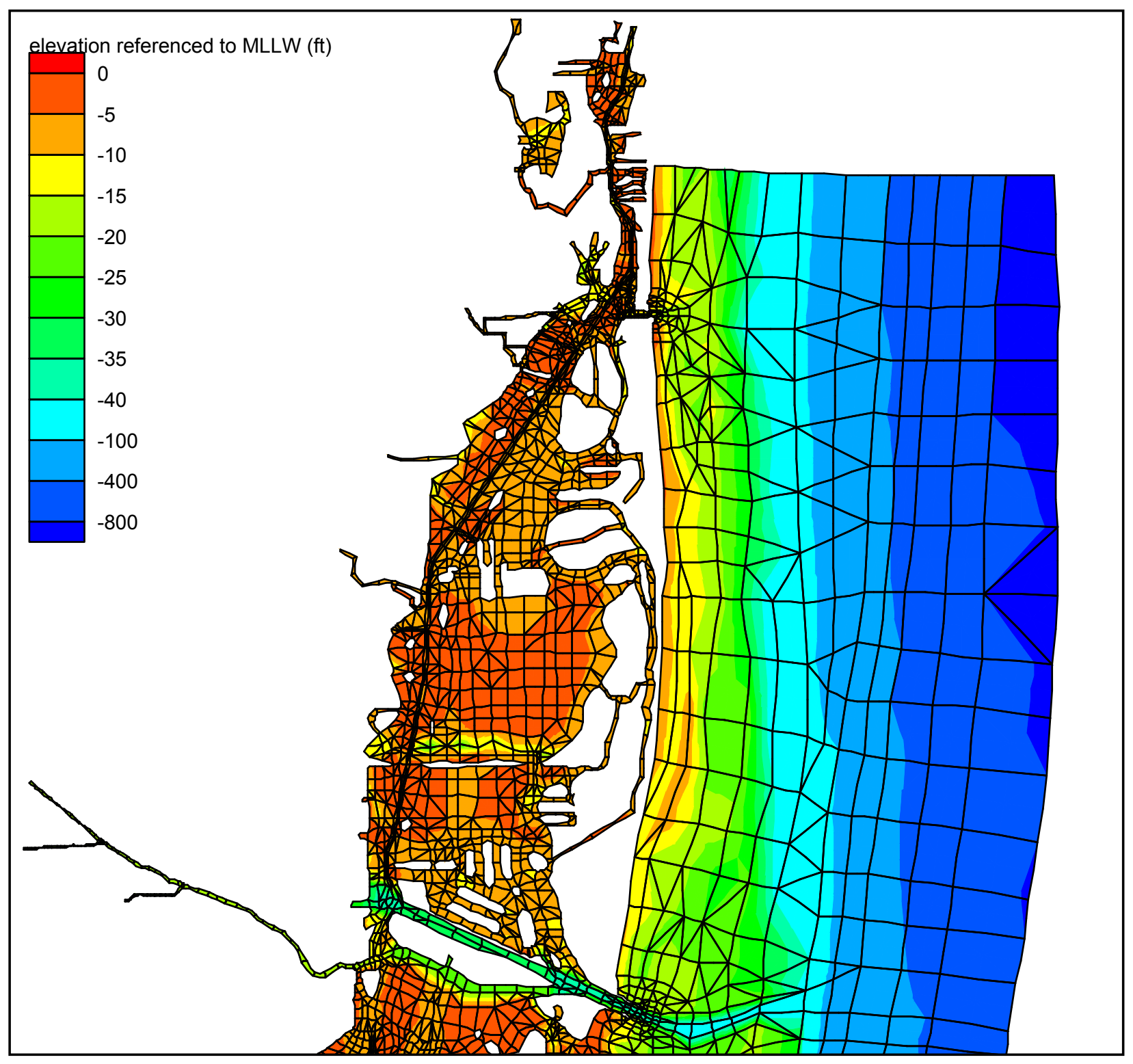

Figure 4. The northern mesh showing North Bay 


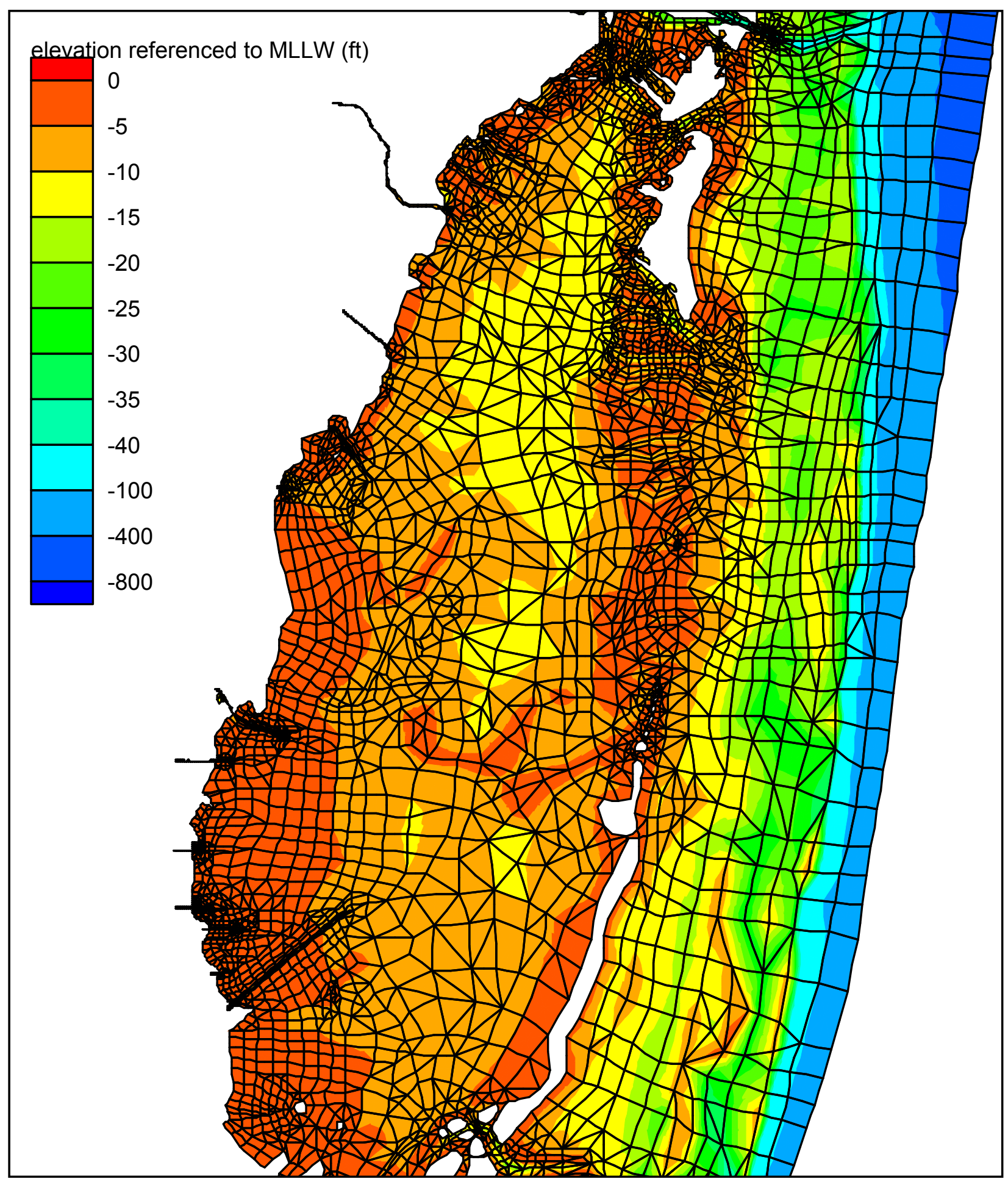

Figure 5. The middle mesh, showing Middle Bay 


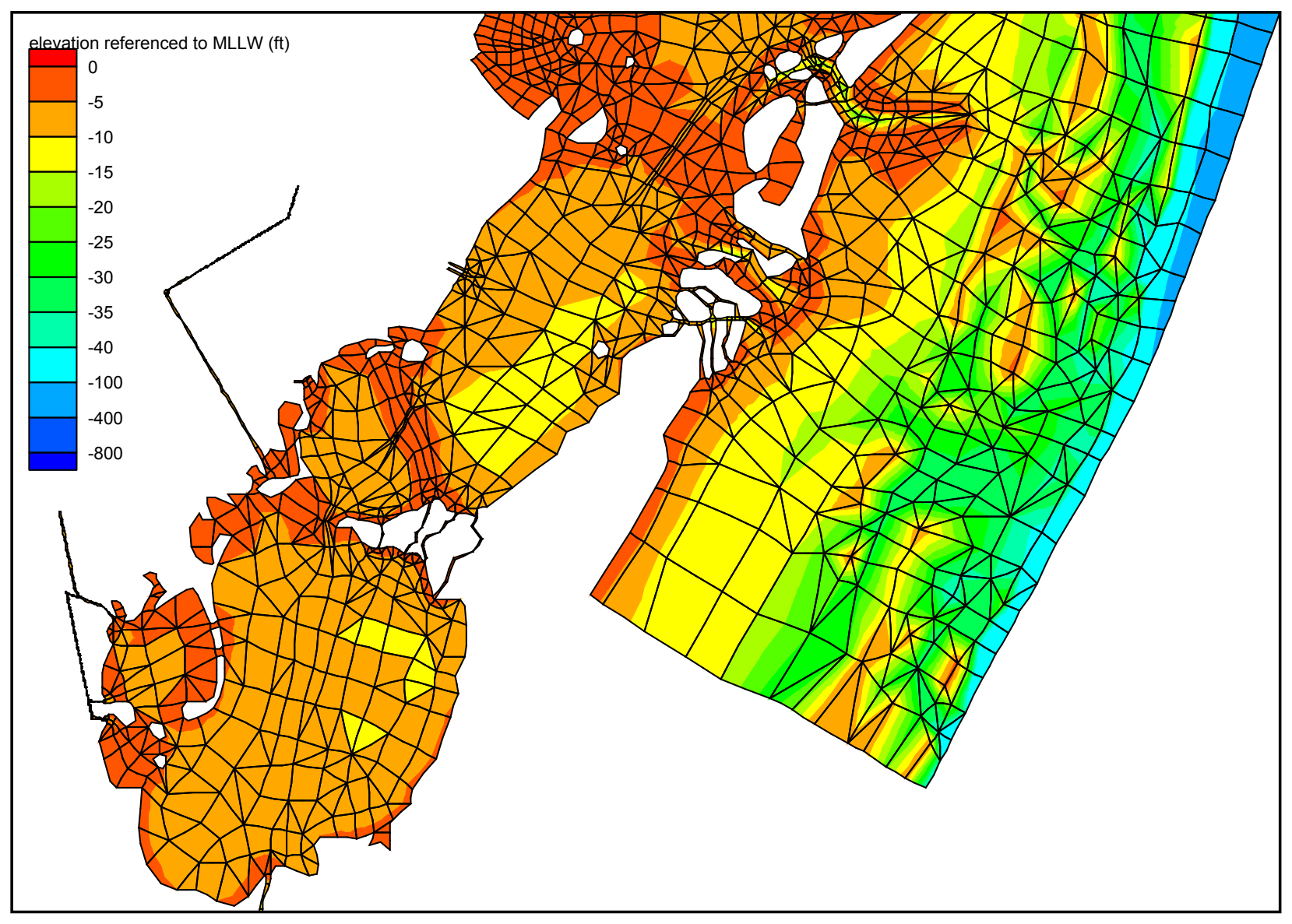

Figure 6. The southern mesh, showing South Bay 


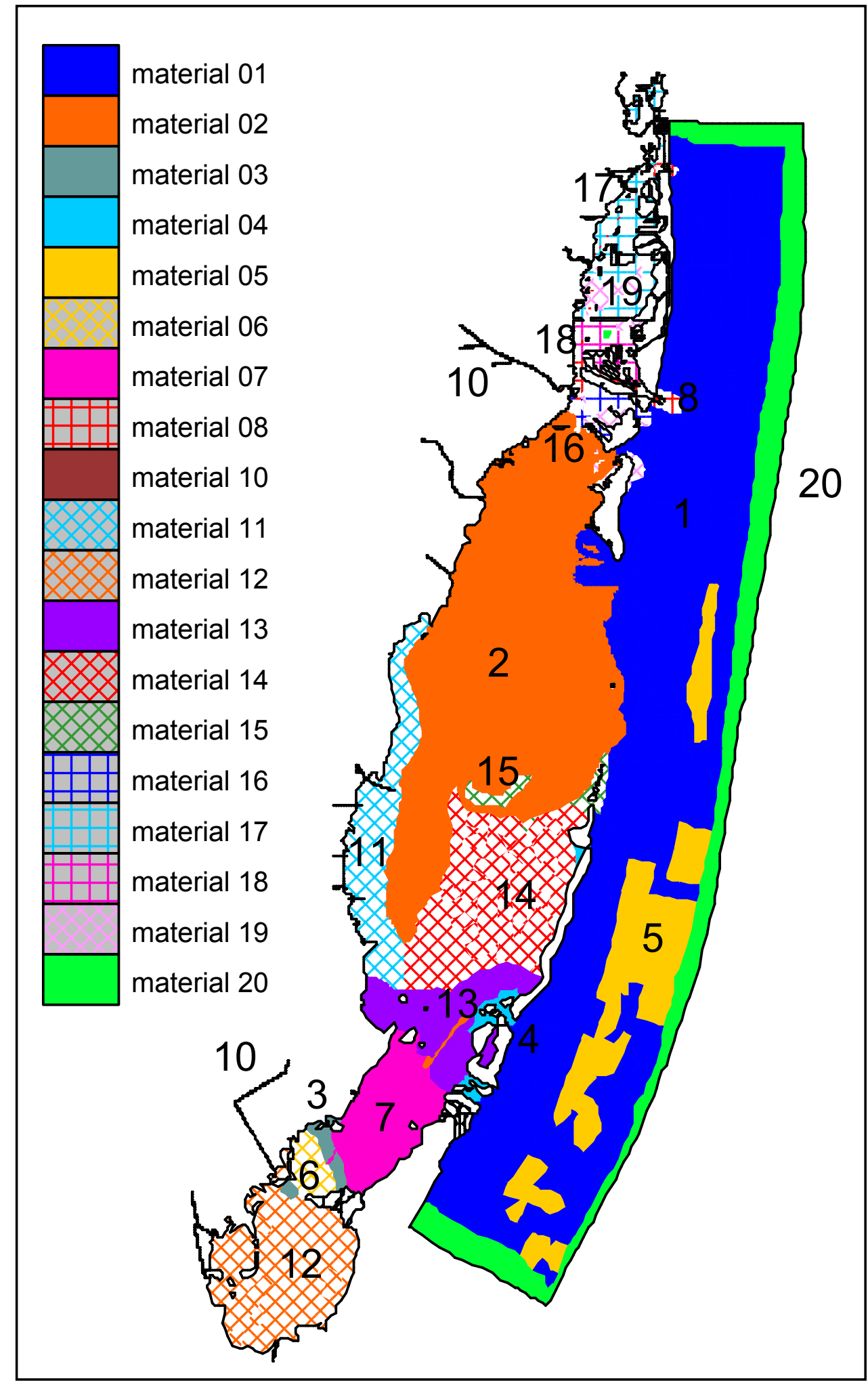

Figure 7. Material types for Biscayne Bay (as described in Table 1) 


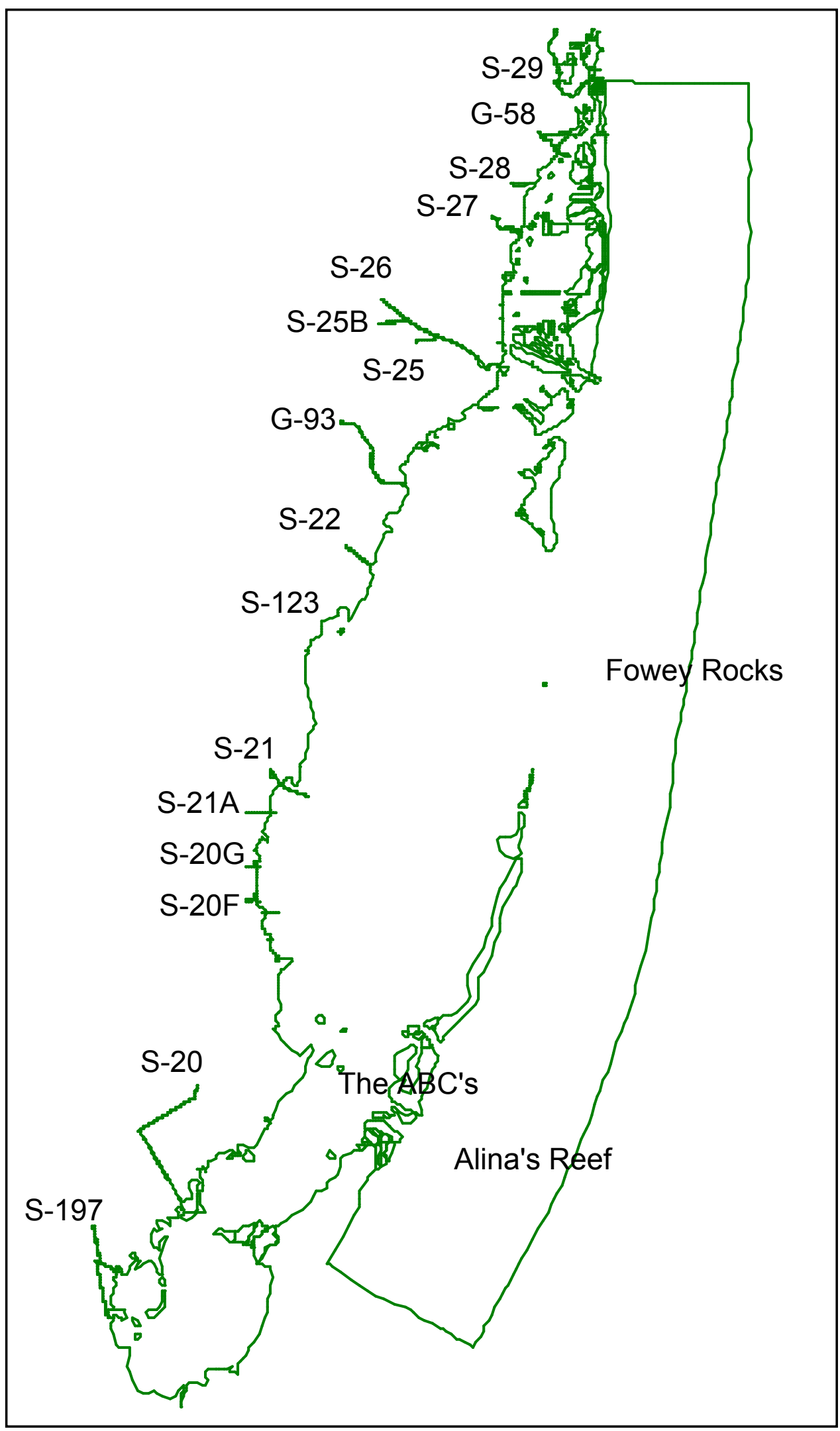

Figure 8. Location of salinity control structures and offshore salinity gauges for Biscayne Bay 


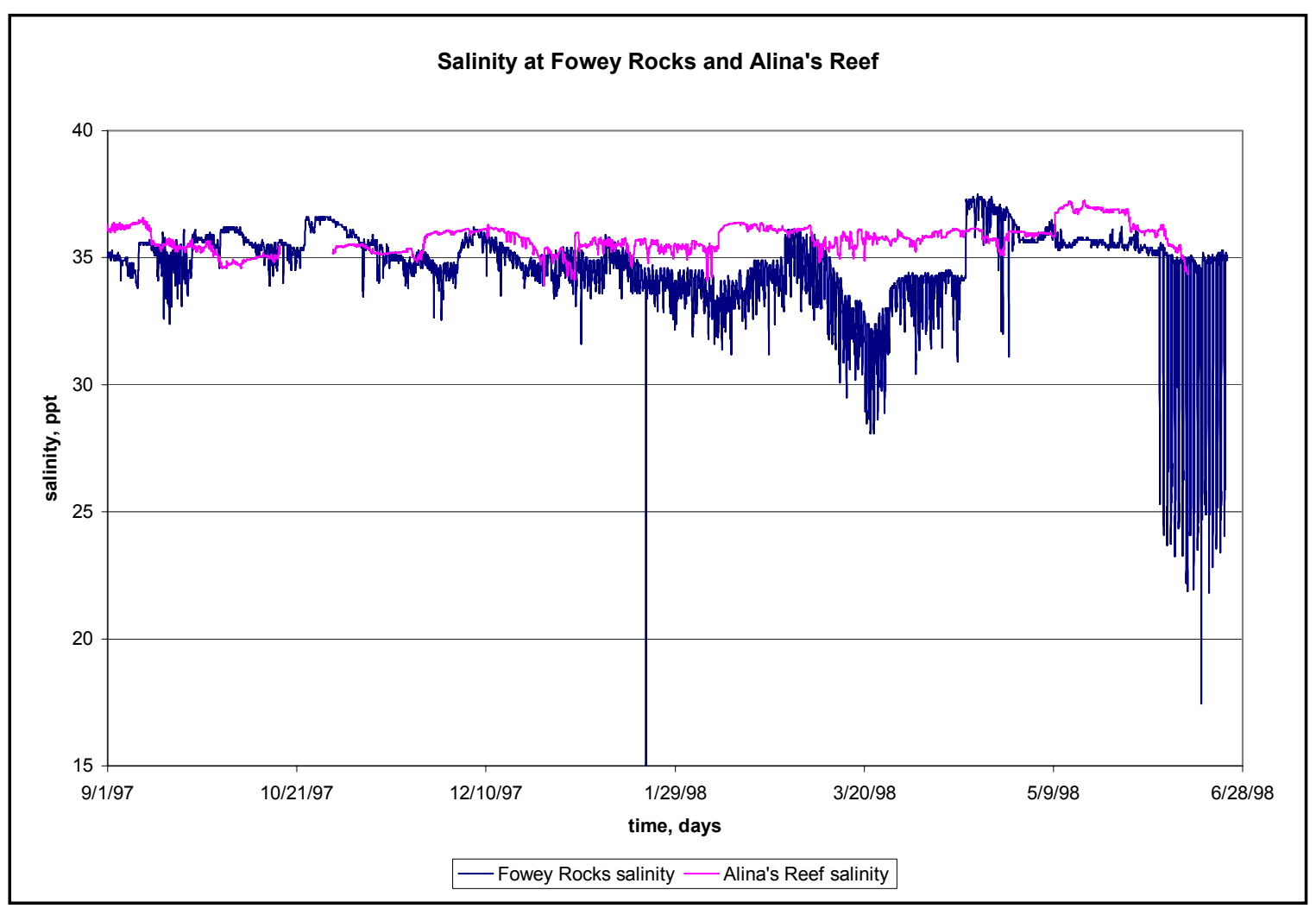

Figure 9. Salinity at Fowey Rocks and Alina's Reef

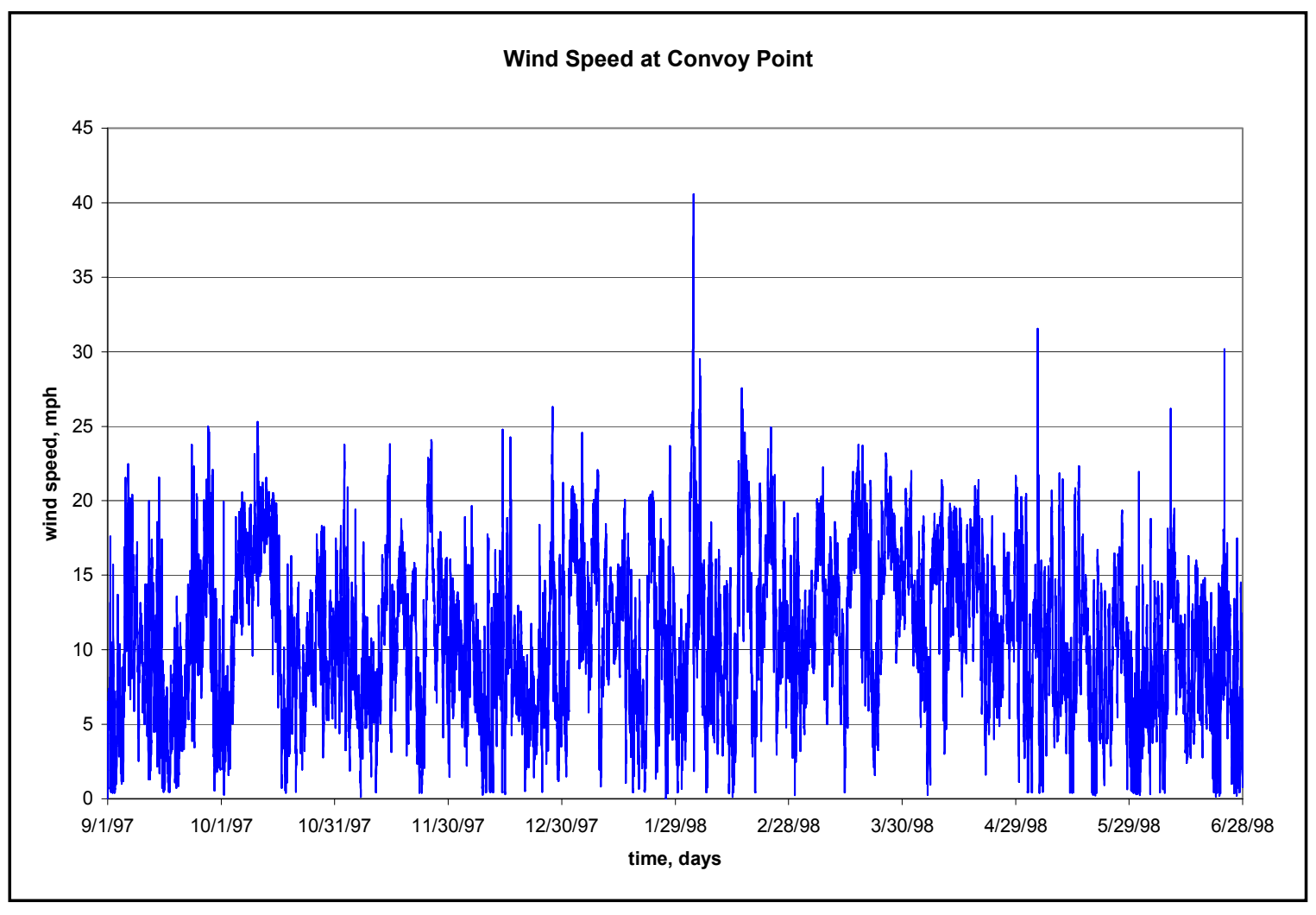

Figure 10. Wind speed at Convoy Point 


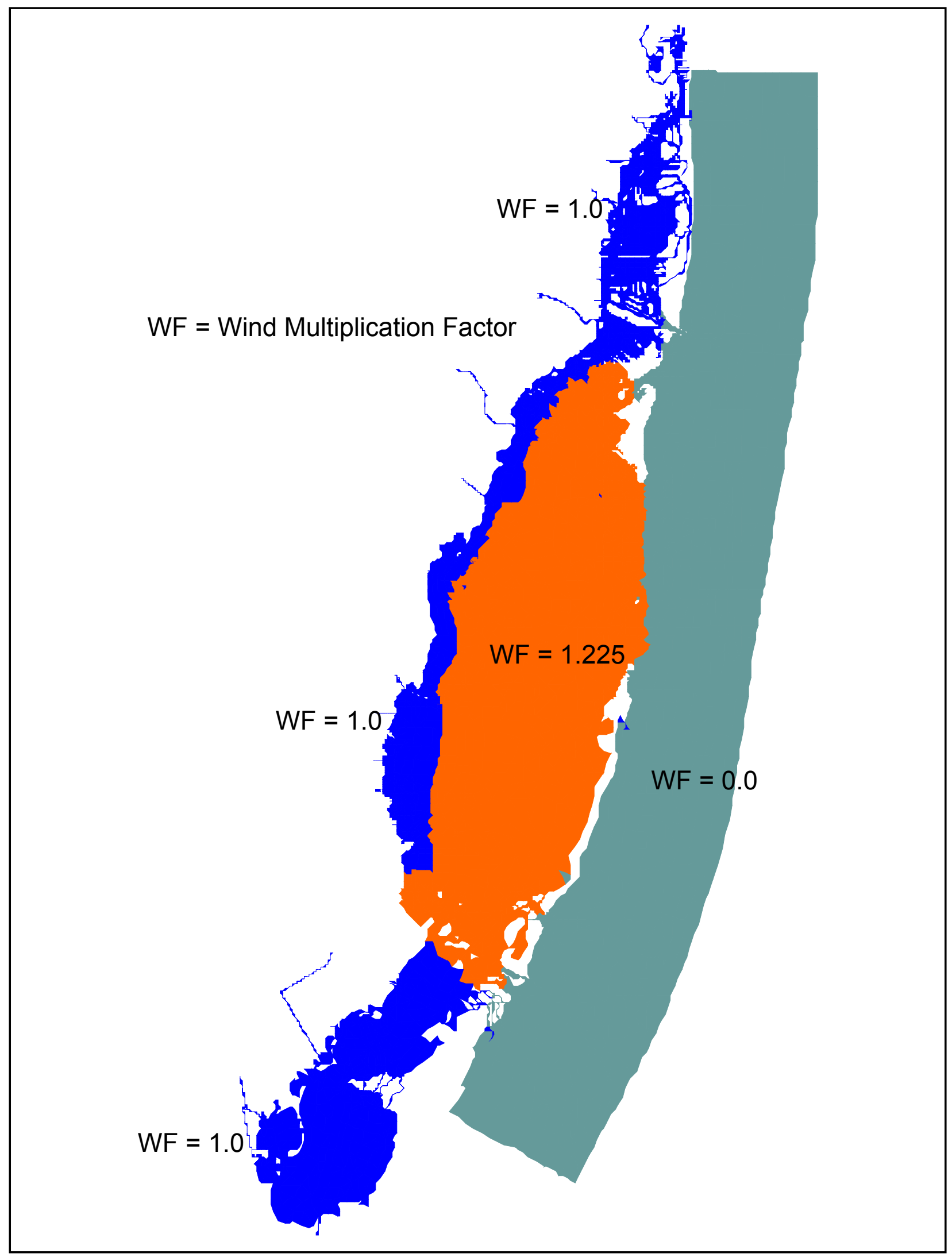

Figure 11. Wind multiplication factors for Biscayne Bay 


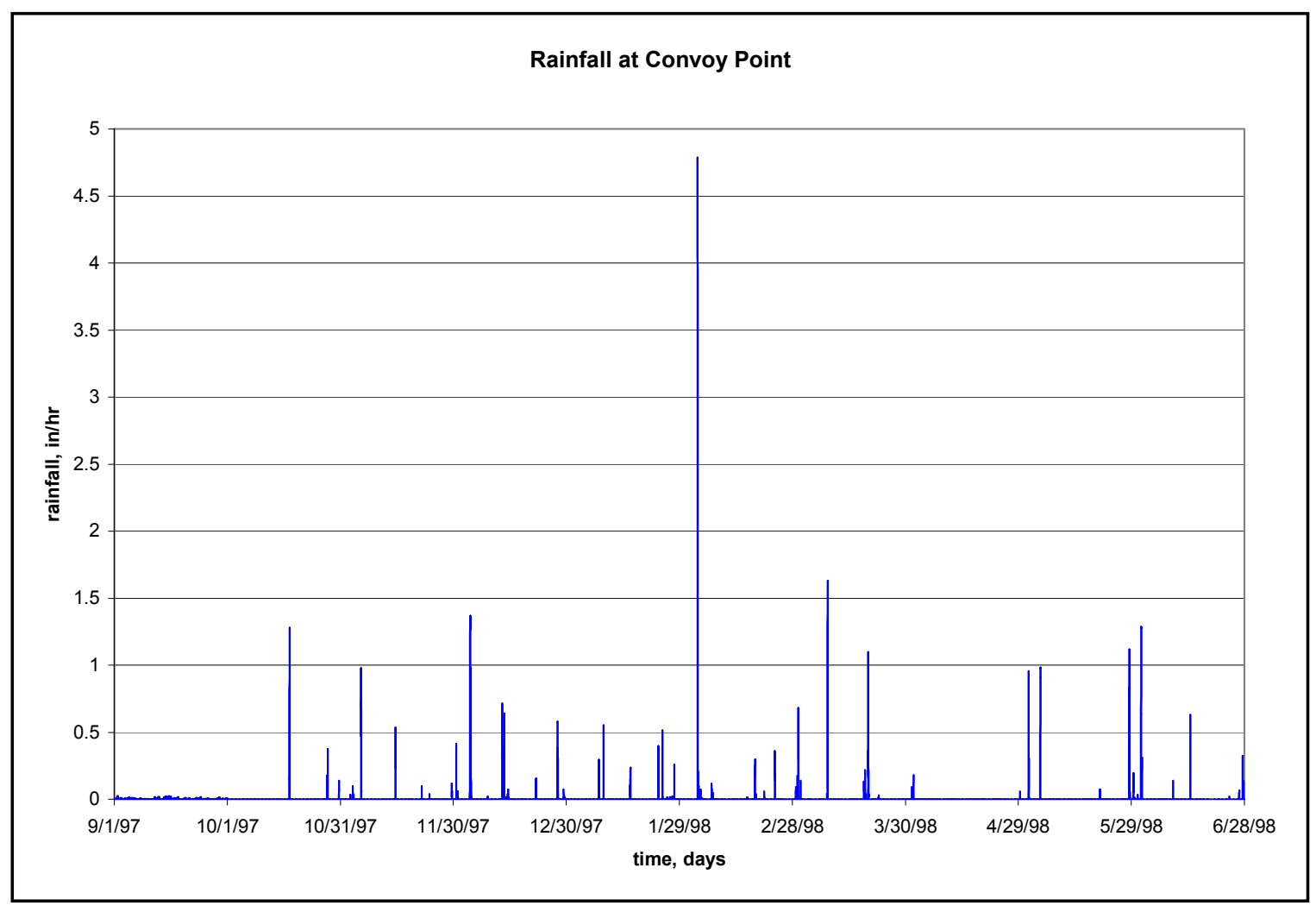

Figure 12. Rainfall at Convoy Point

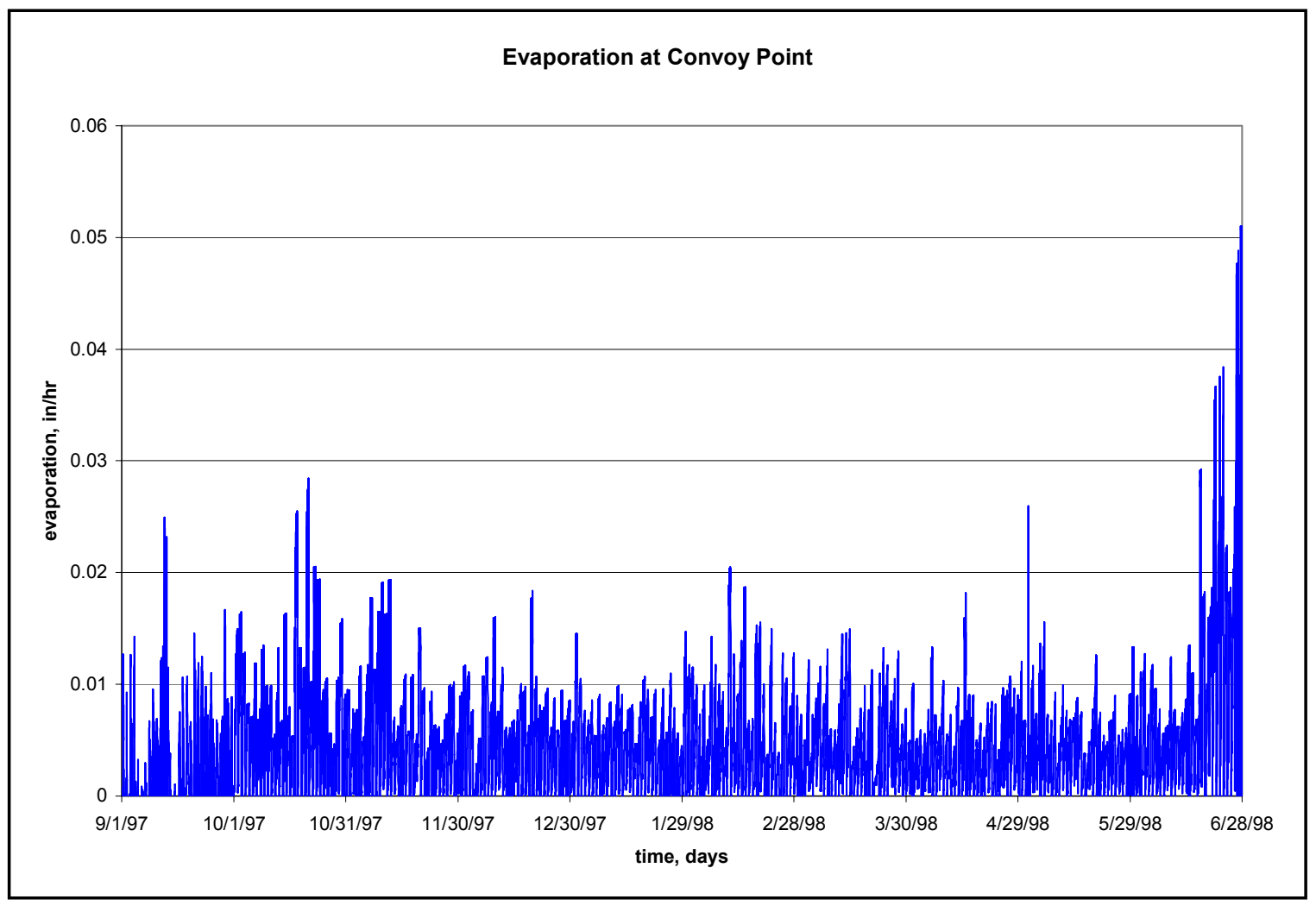

Figure 13. Evaporation at Convoy Point 


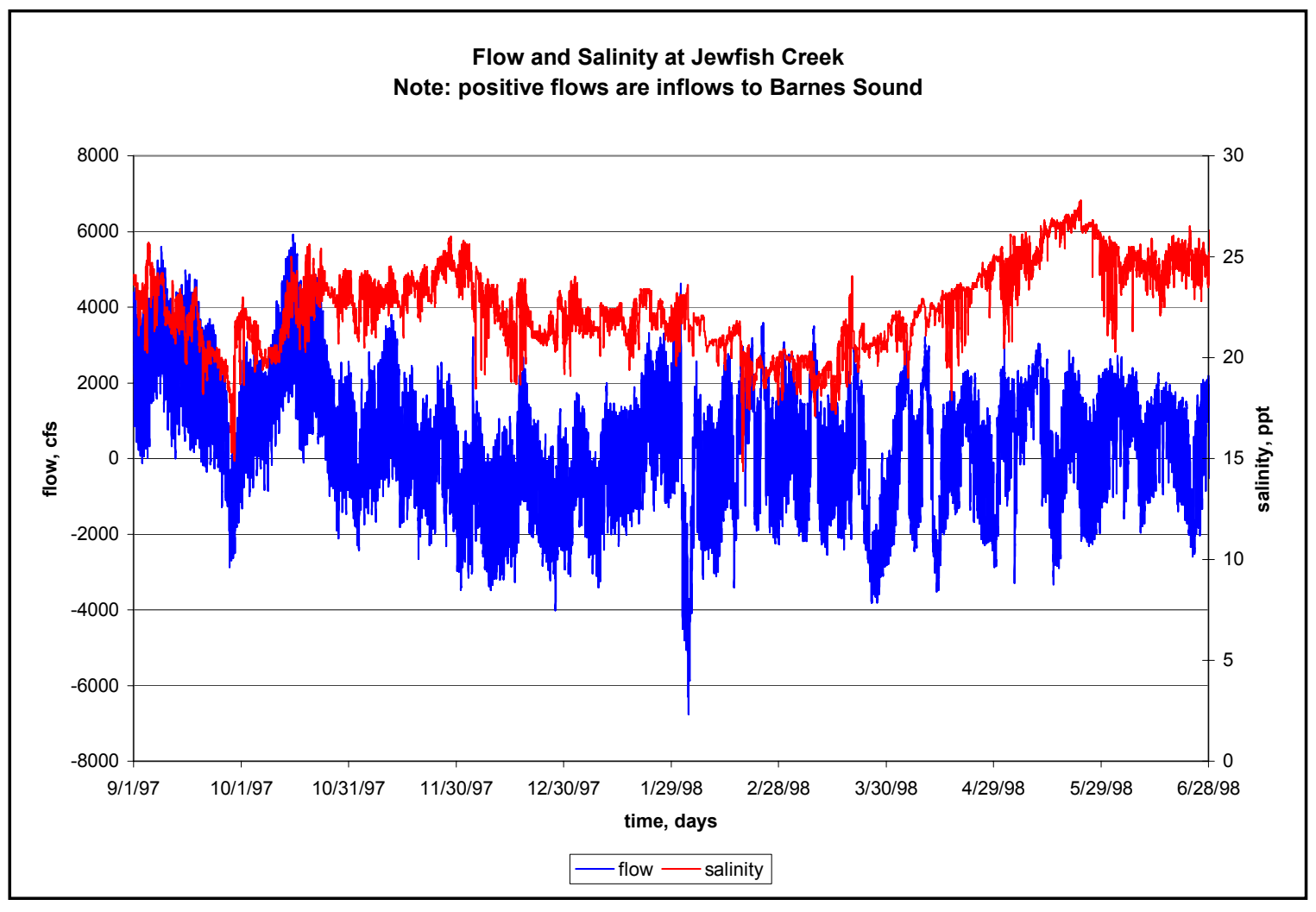

Figure 14. Flow and salinity at Jewfish Creek 


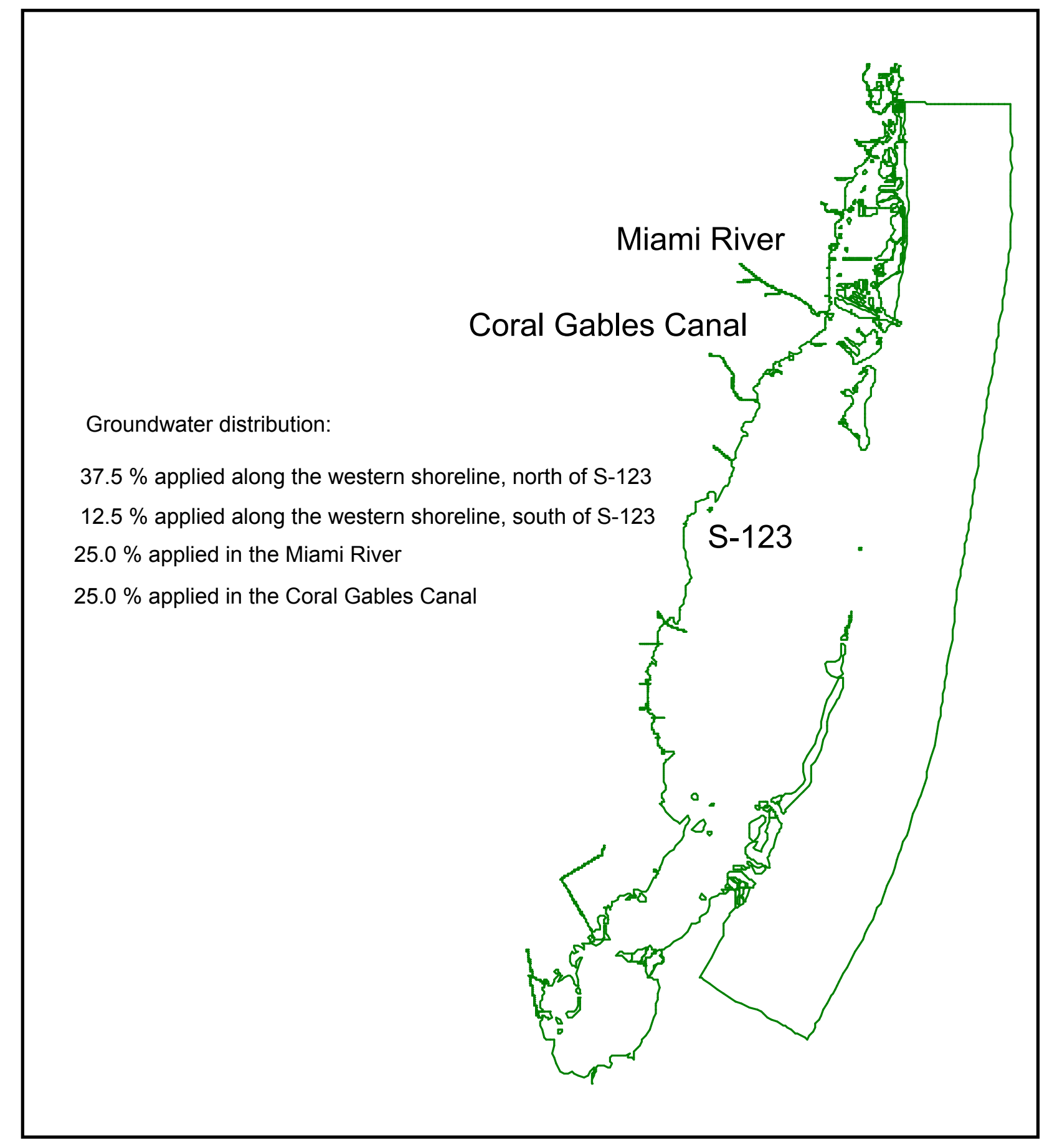

Figure 15. Application locations for groundwater inflow 


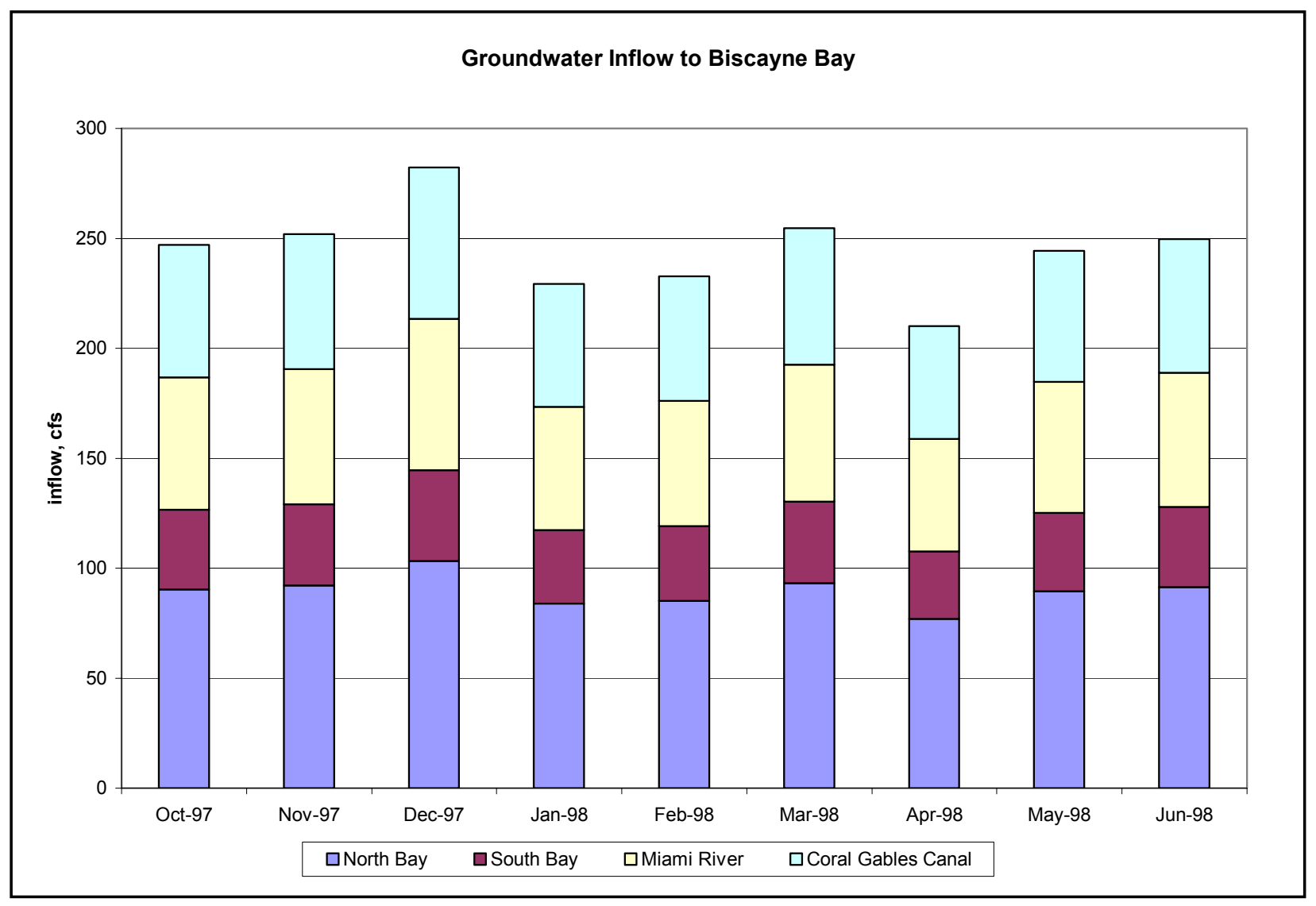

Figure 16. Groundwater inflow to Biscayne Bay 


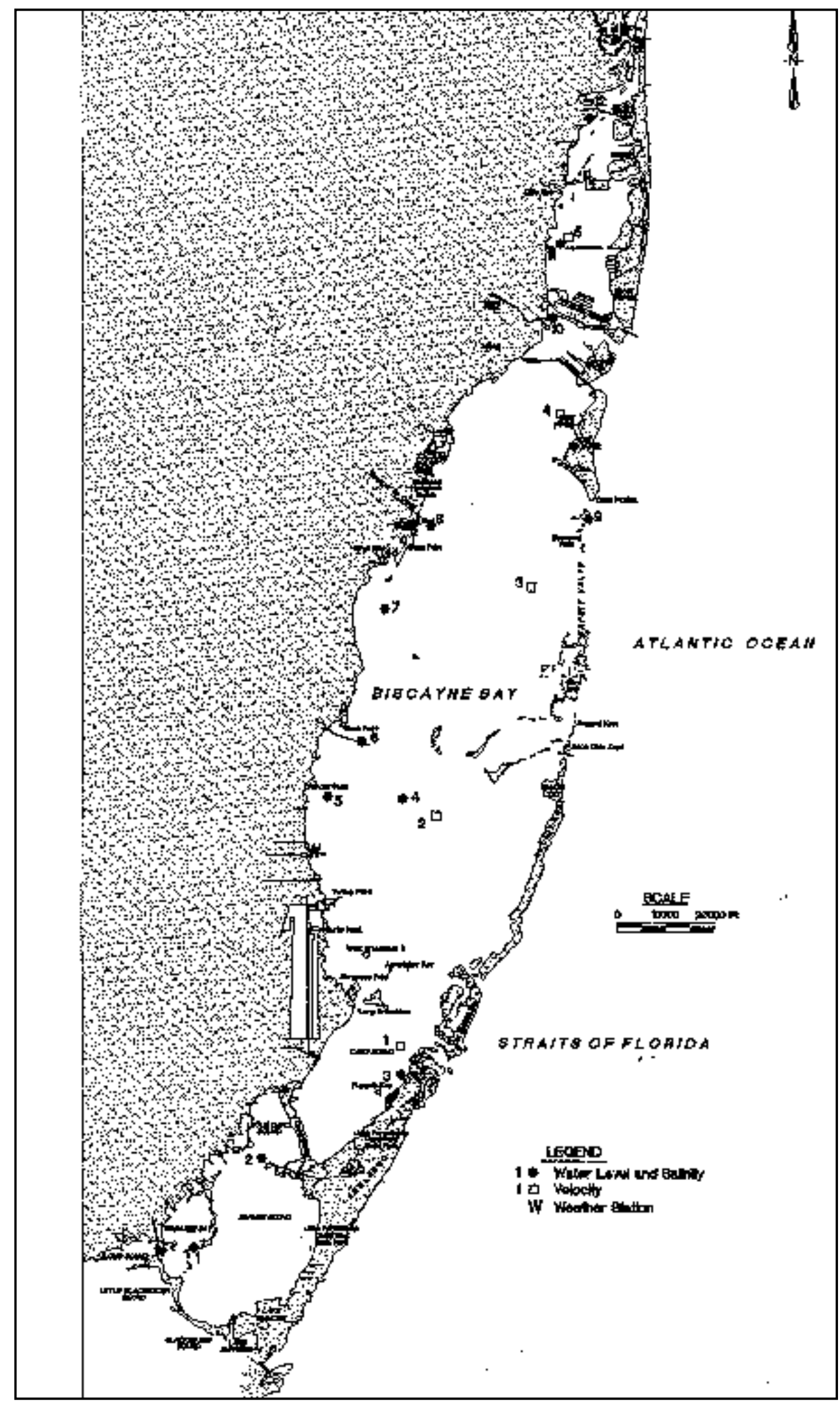

Figure 17. Instrument location map 


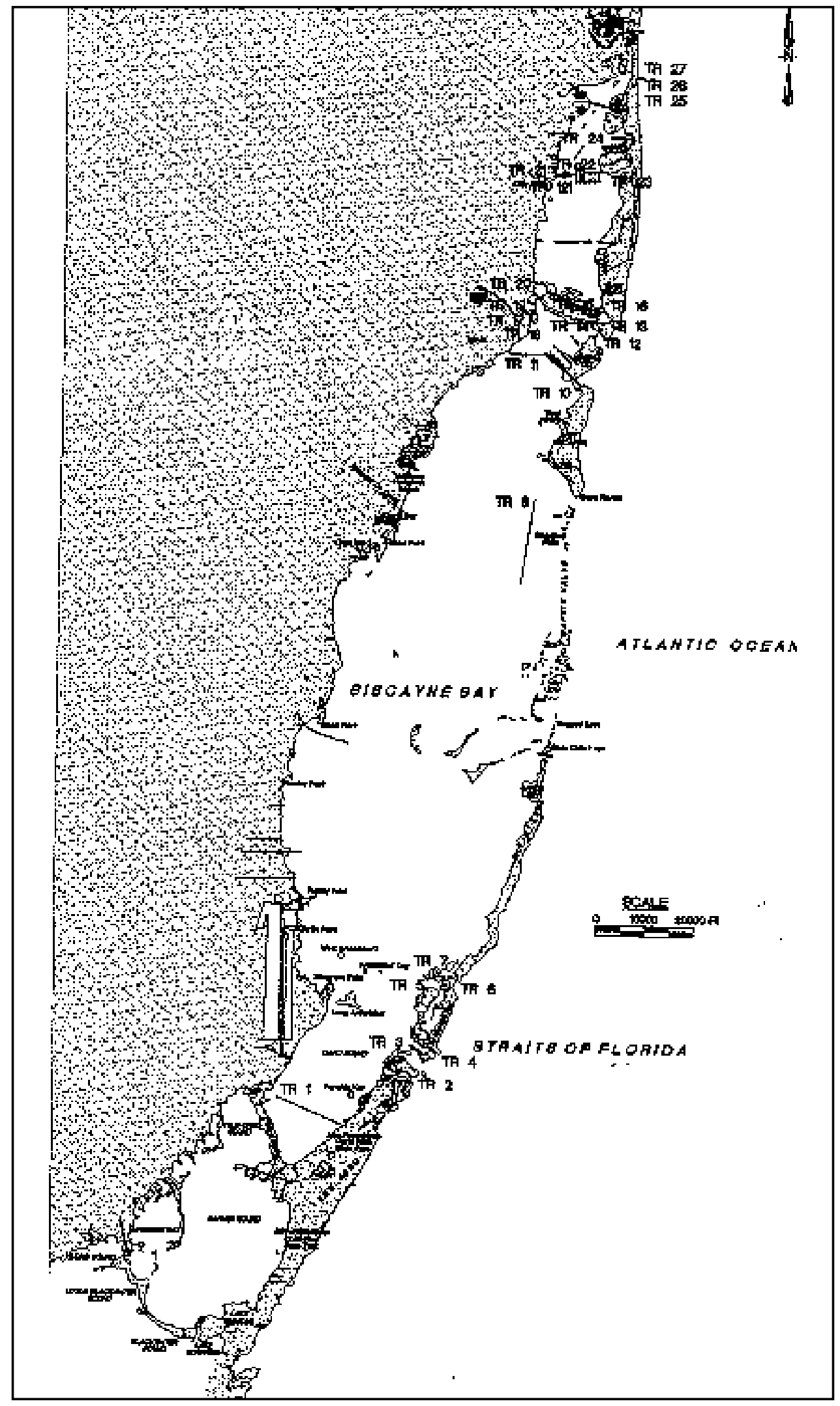

Figure 18. Instrument location map $(T R=$ Transect $)$ 


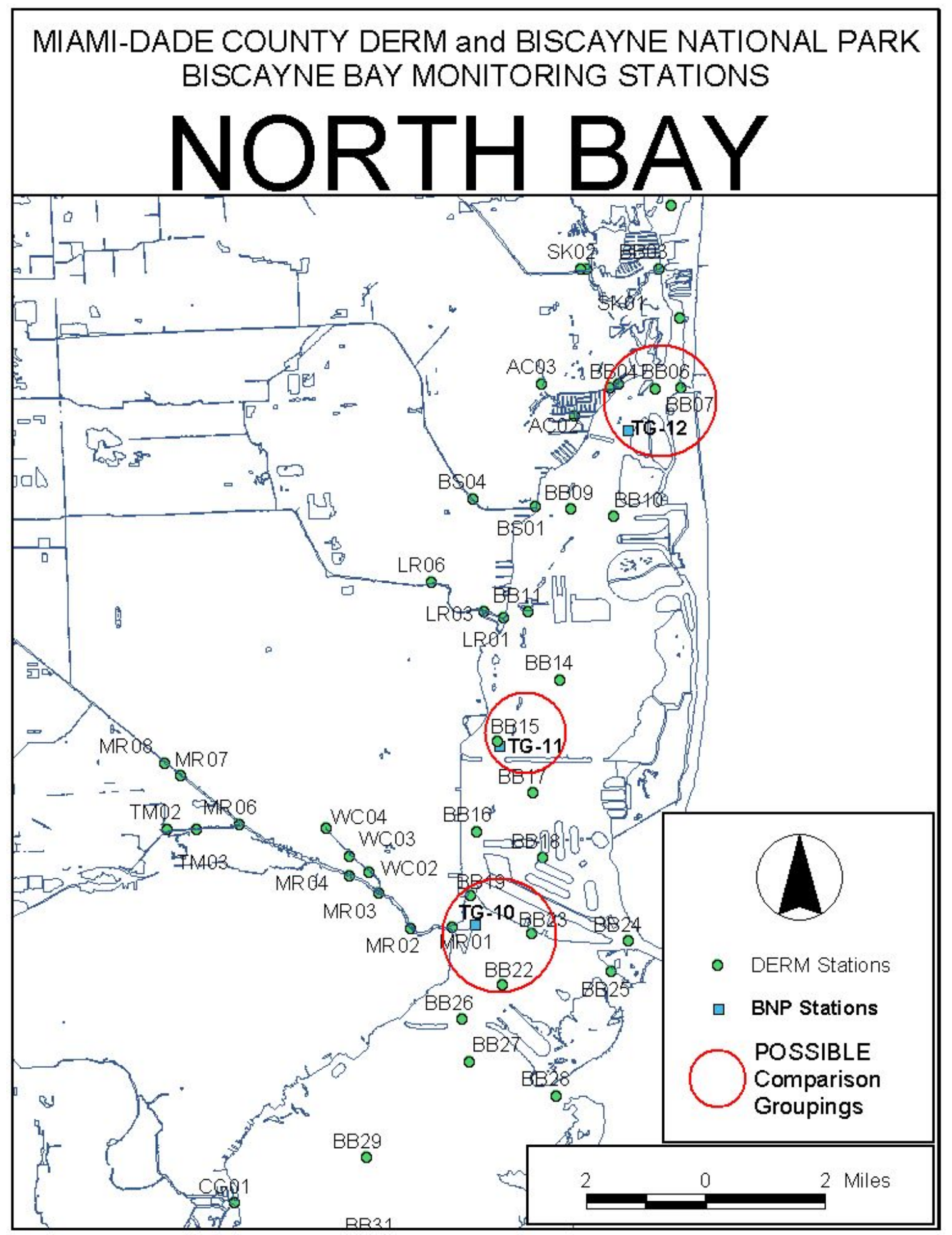

Figure 19. DERM/BNP stations in North Bay (Courtesy Tim McIntosh, DERM.) 


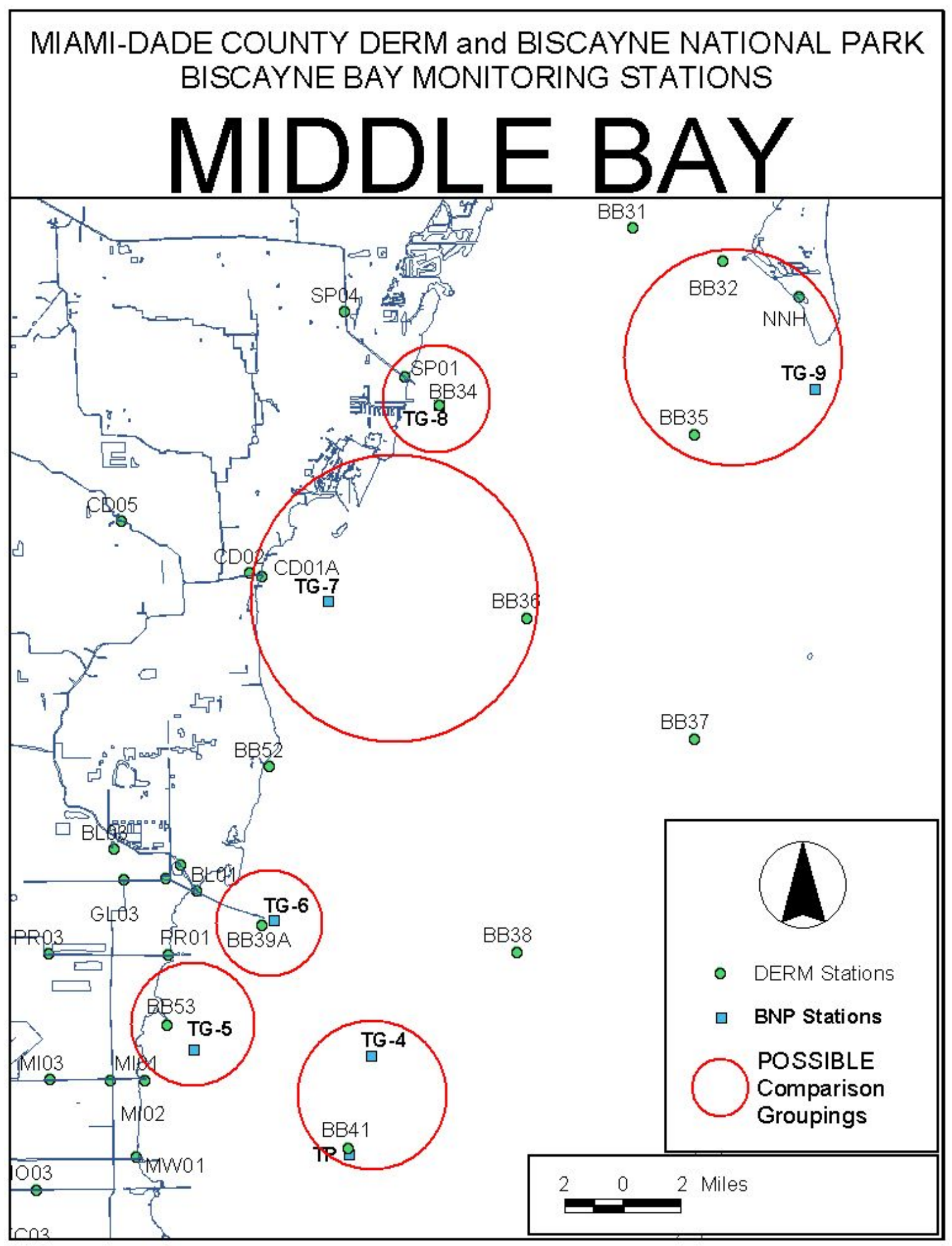

Figure 20. DERM/BNP stations in Middle Bay (Courtesy Tim Mclntosh, DERM) 


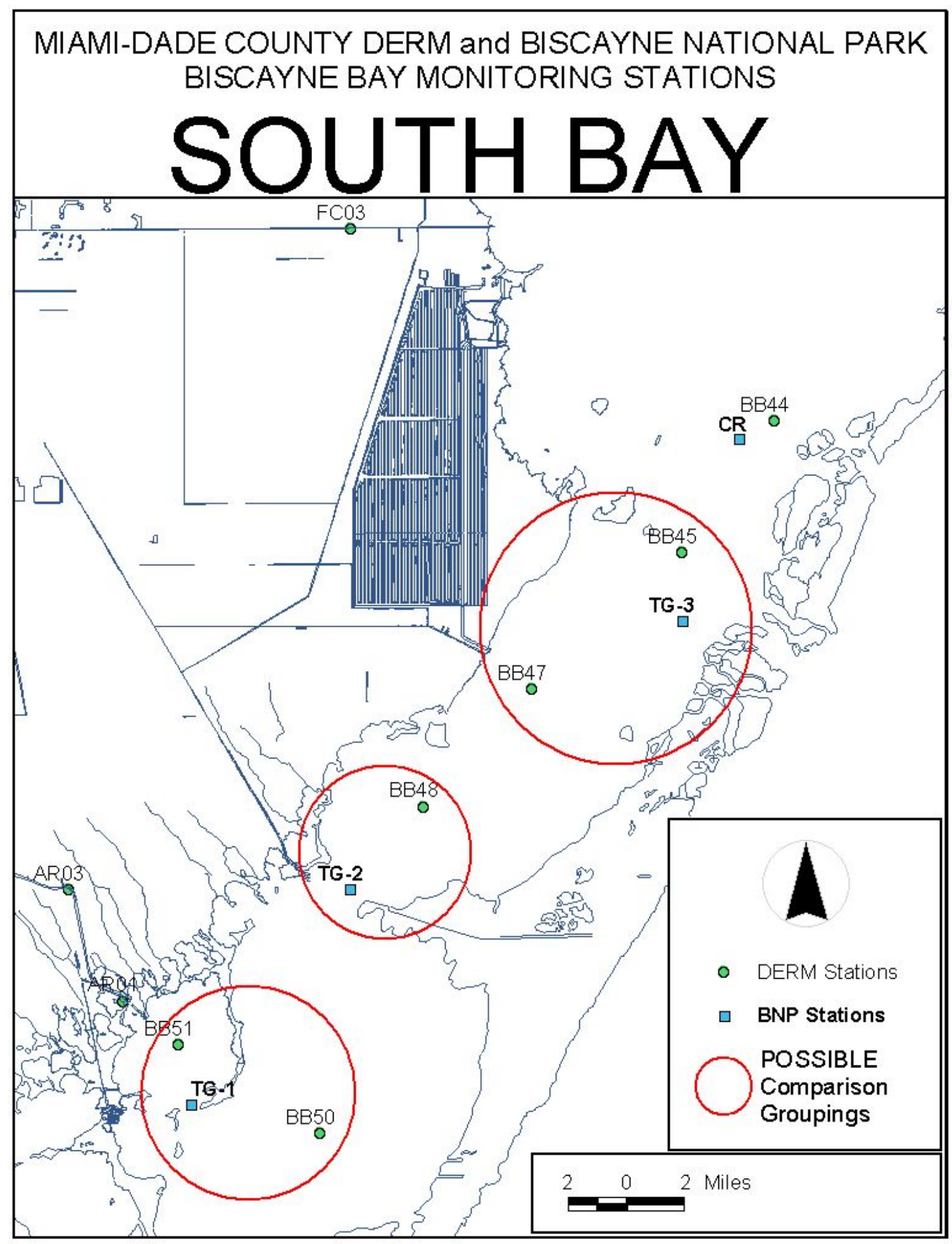

Figure 21. DERM/BNP stations in South Bay (Courtesy Tim Mclntosh, DERM) 


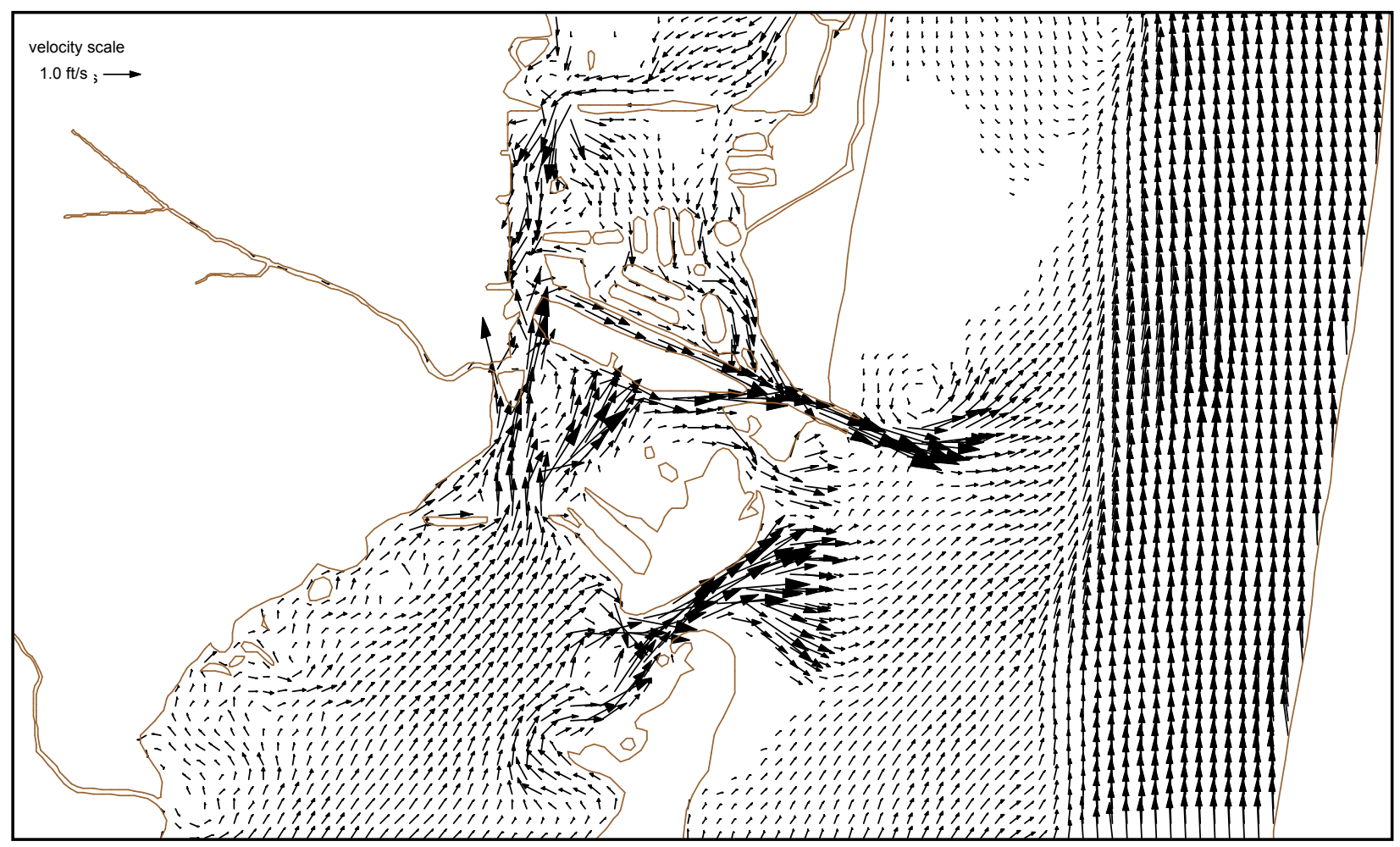

Figure 22. Ebb velocities at Government Cut 


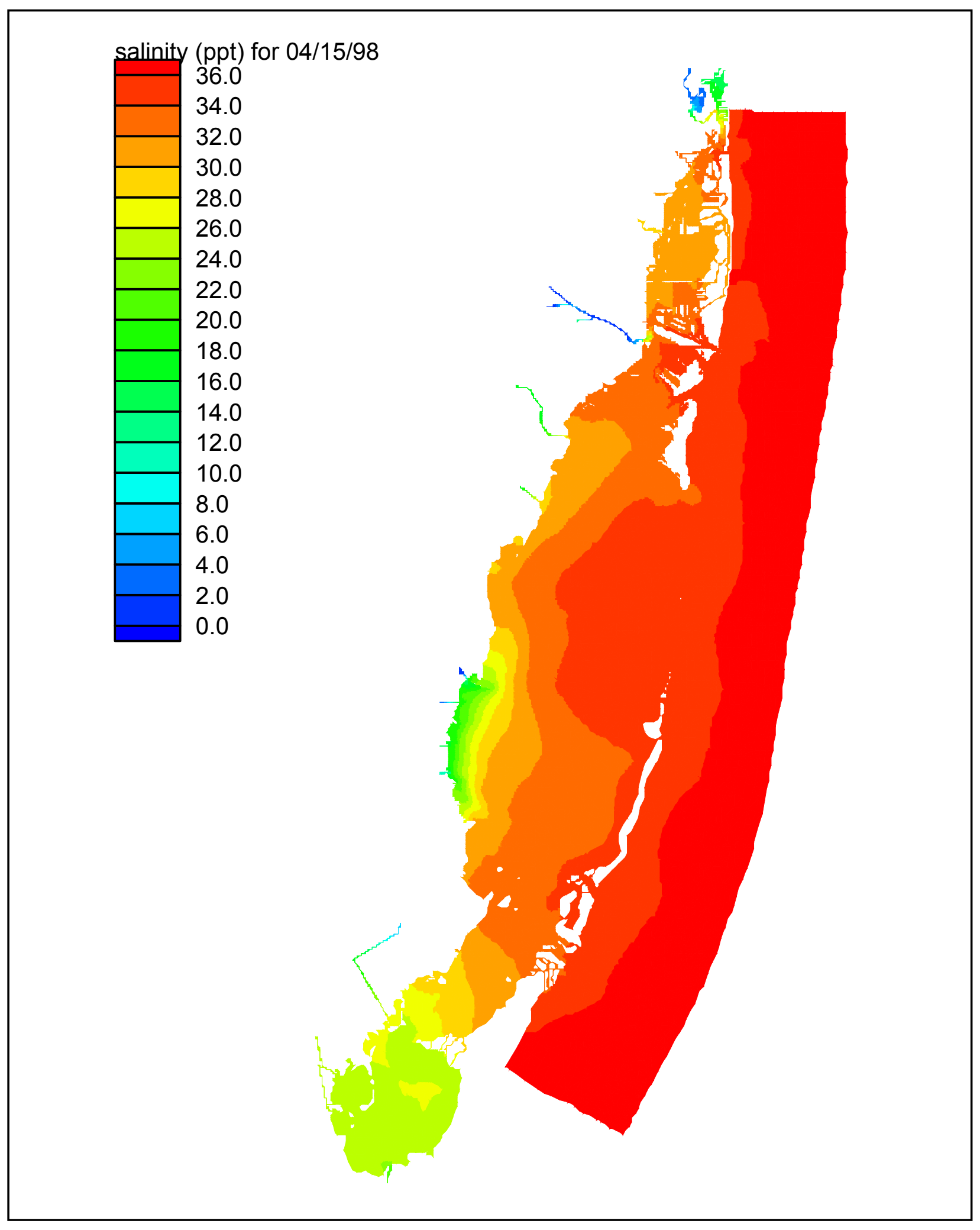

Figure 23. Salinity contours for April 15,1998 , at maximum ebb 


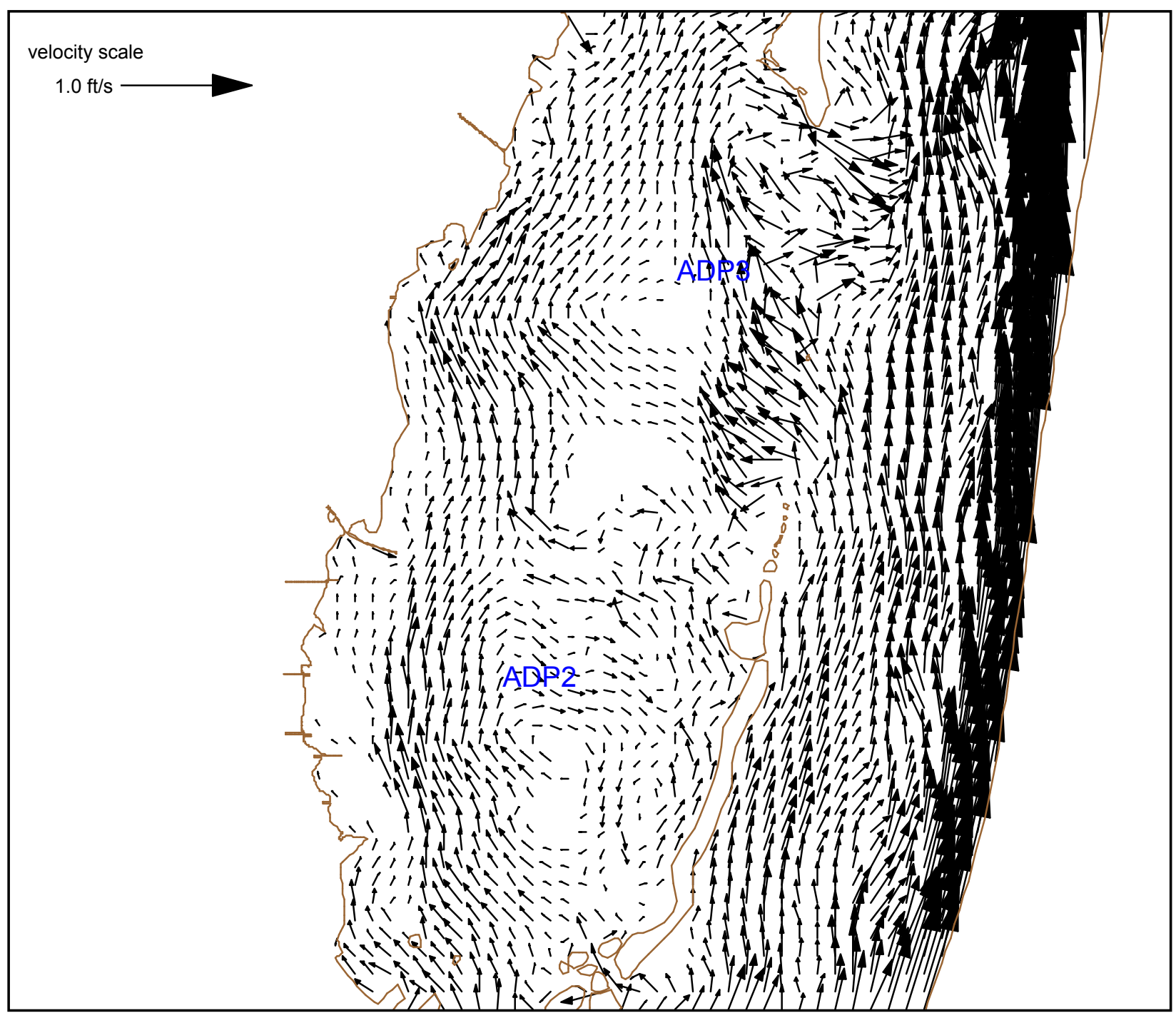

Figure 24. Residual velocities for April 15 and16, 1998, in Central Biscayne Bay 


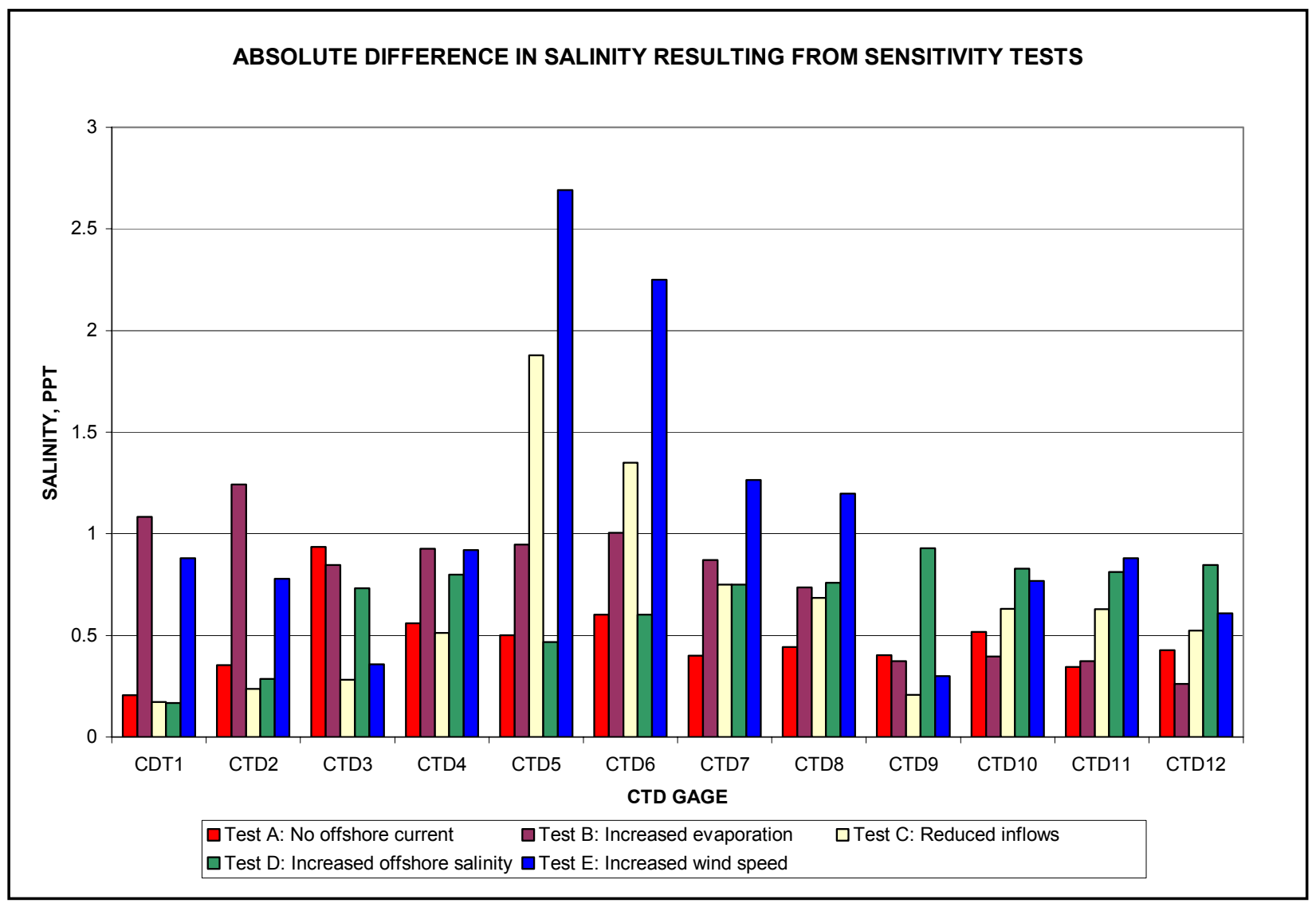

Figure 25. Absolute difference in salinity resulting from sensitivity tests 


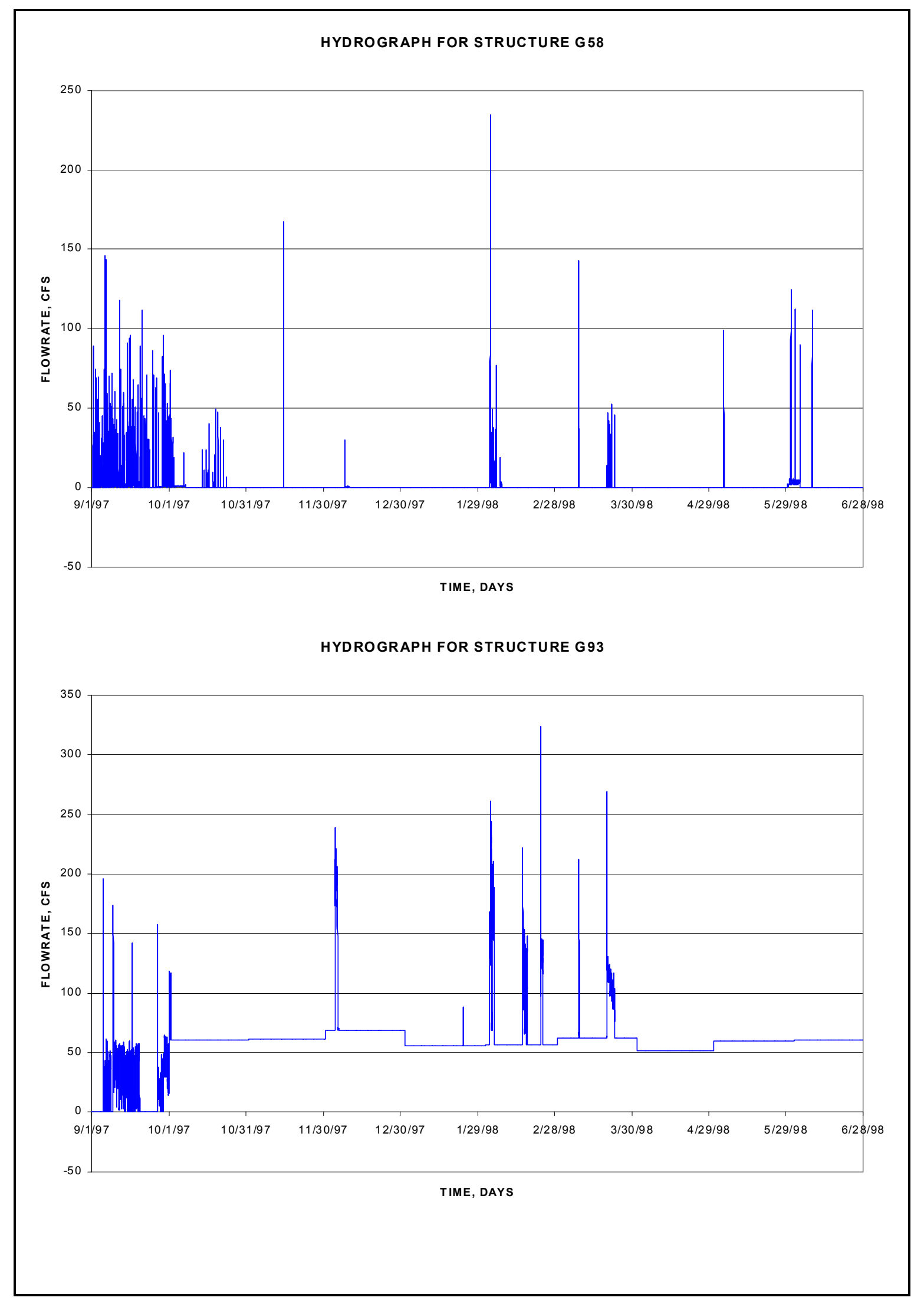

Plate 1 


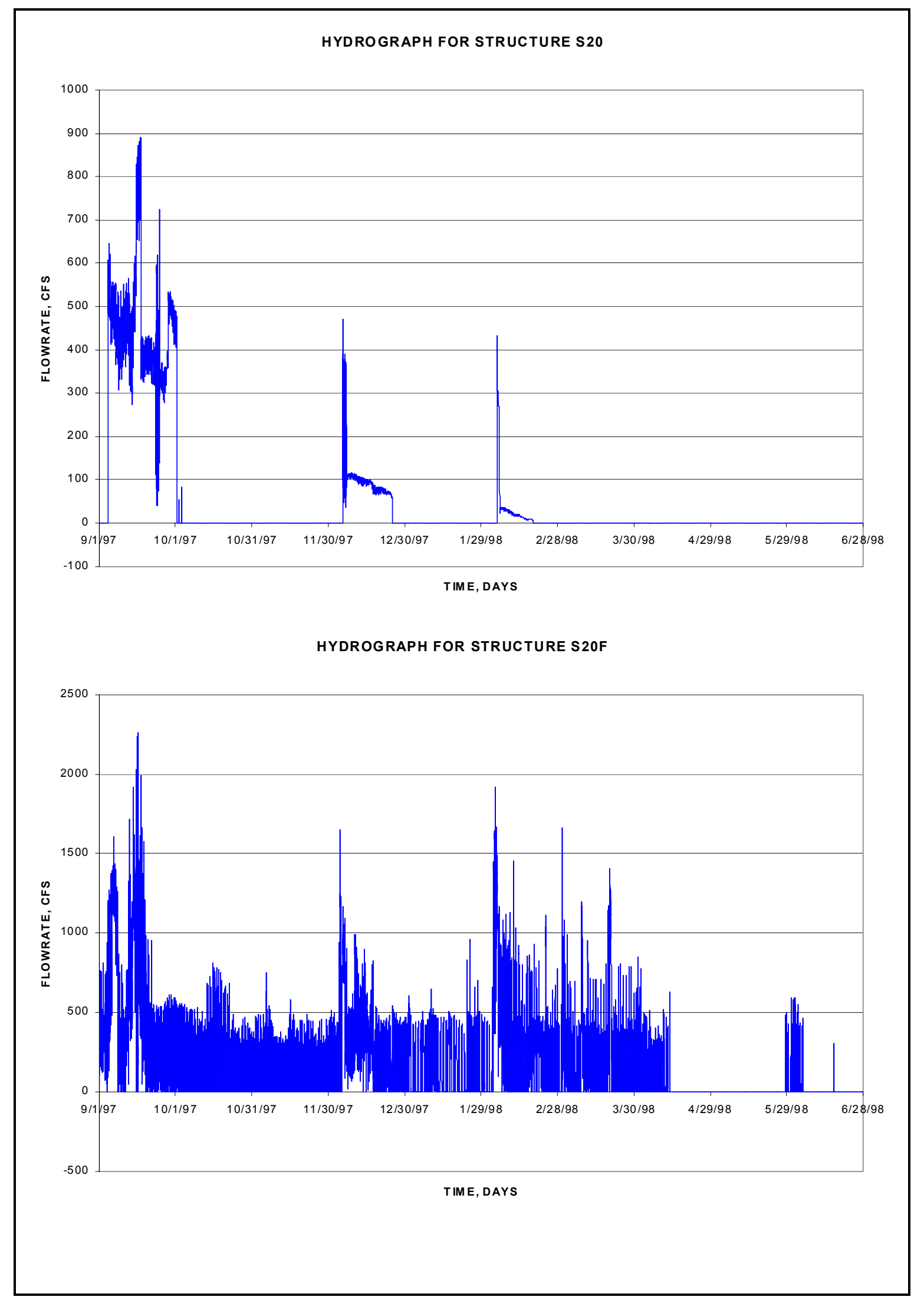

Plate 2 


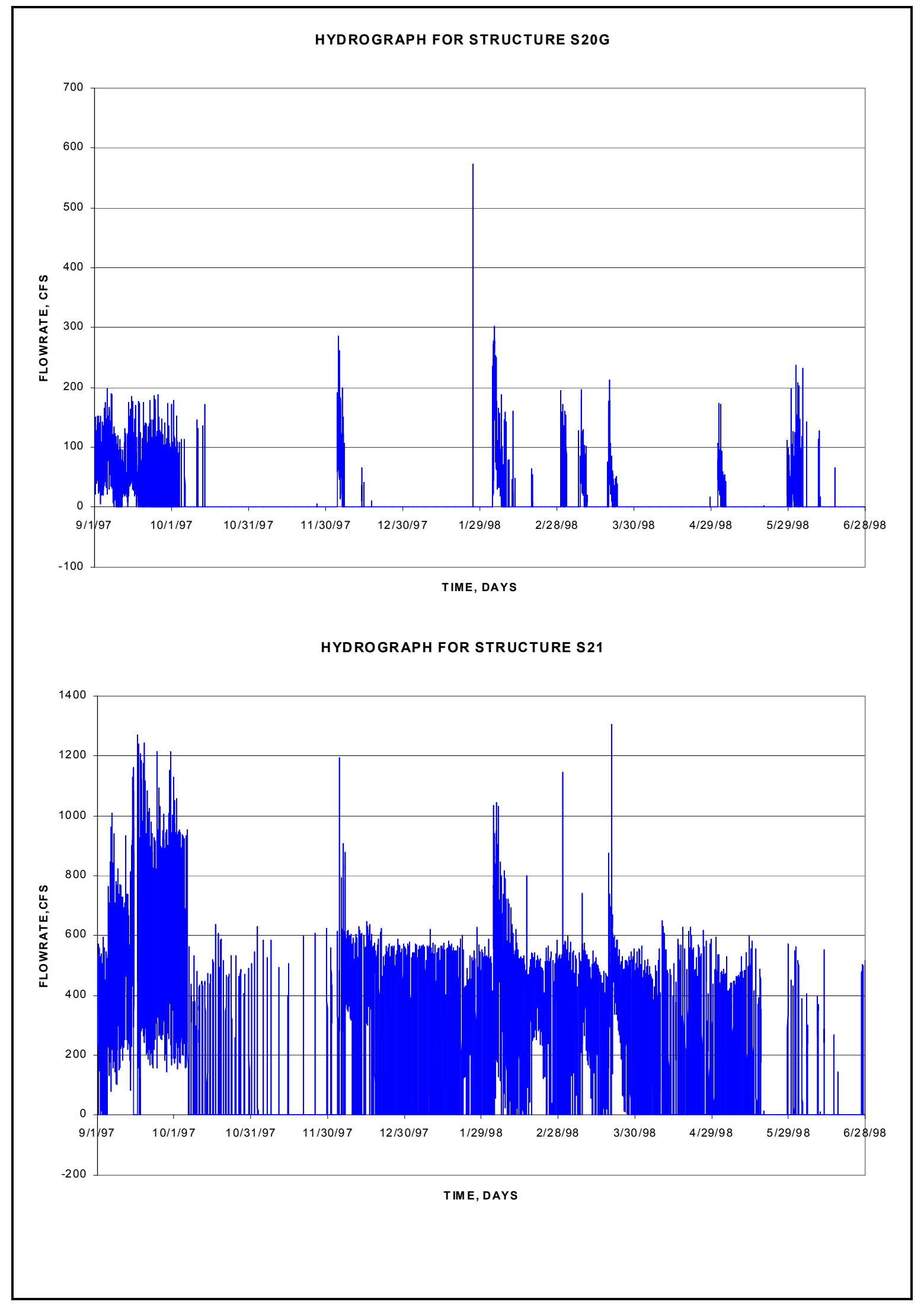

Plate 3 


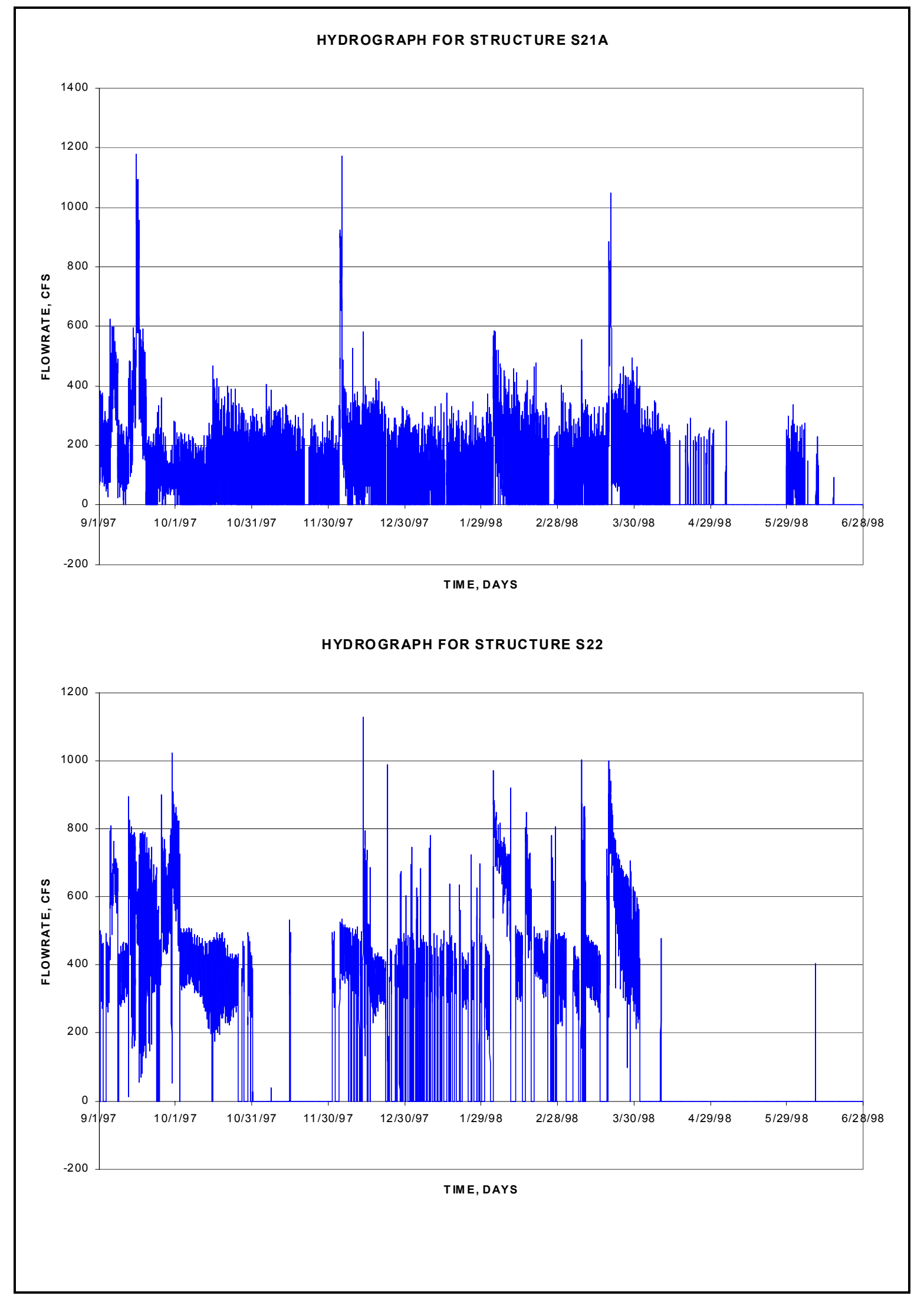

Plate 4 


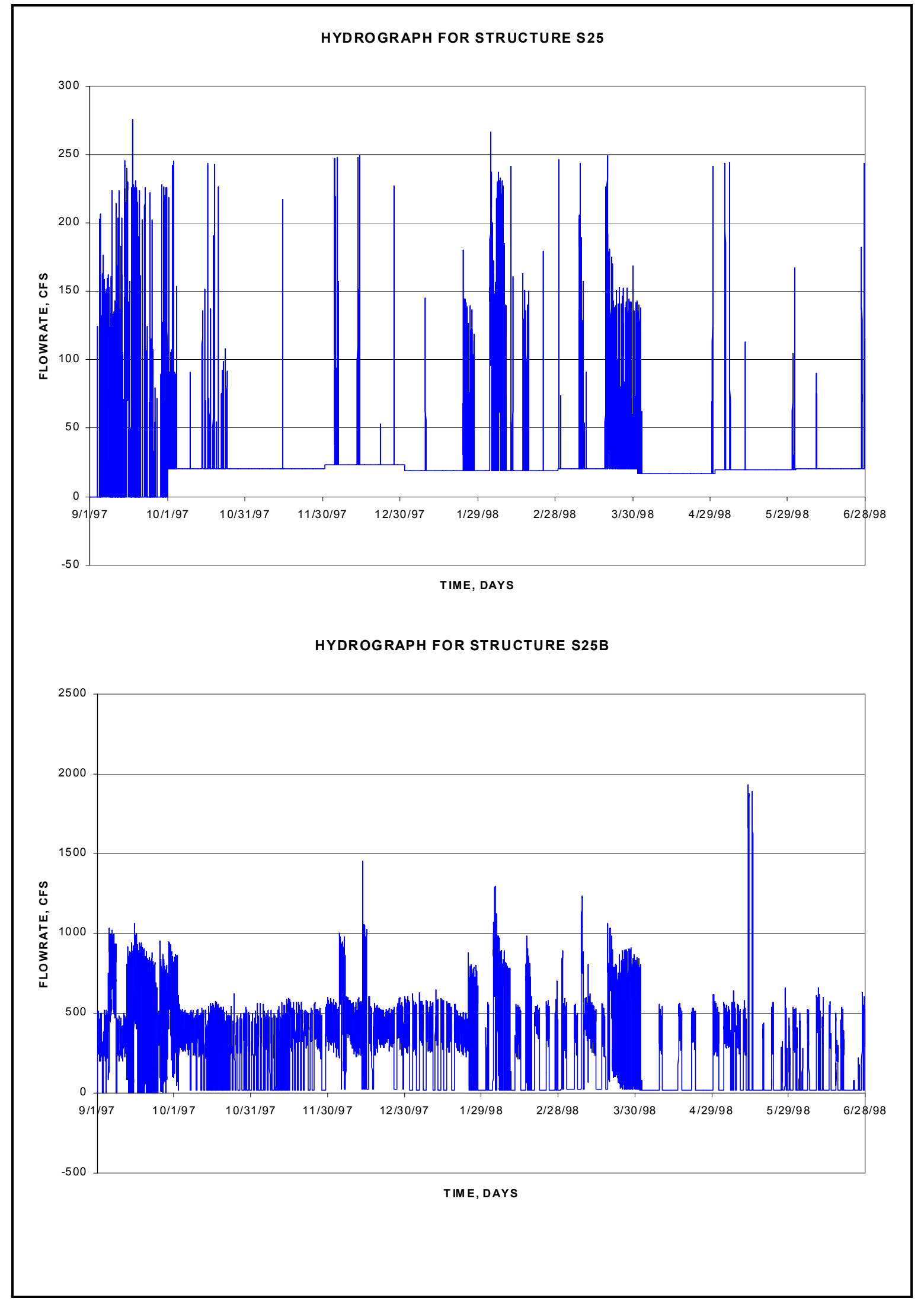

Plate 5 


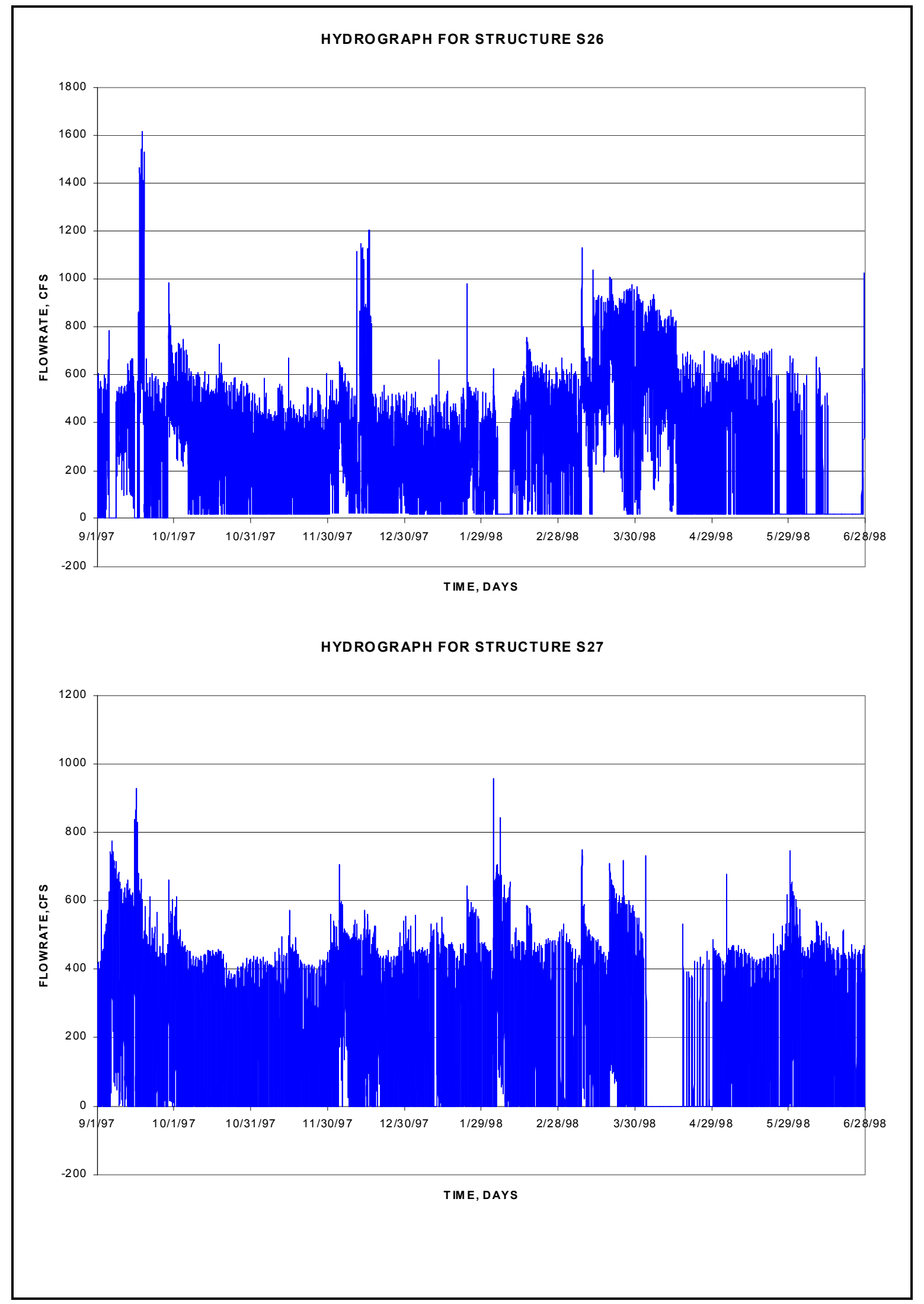

Plate 6 


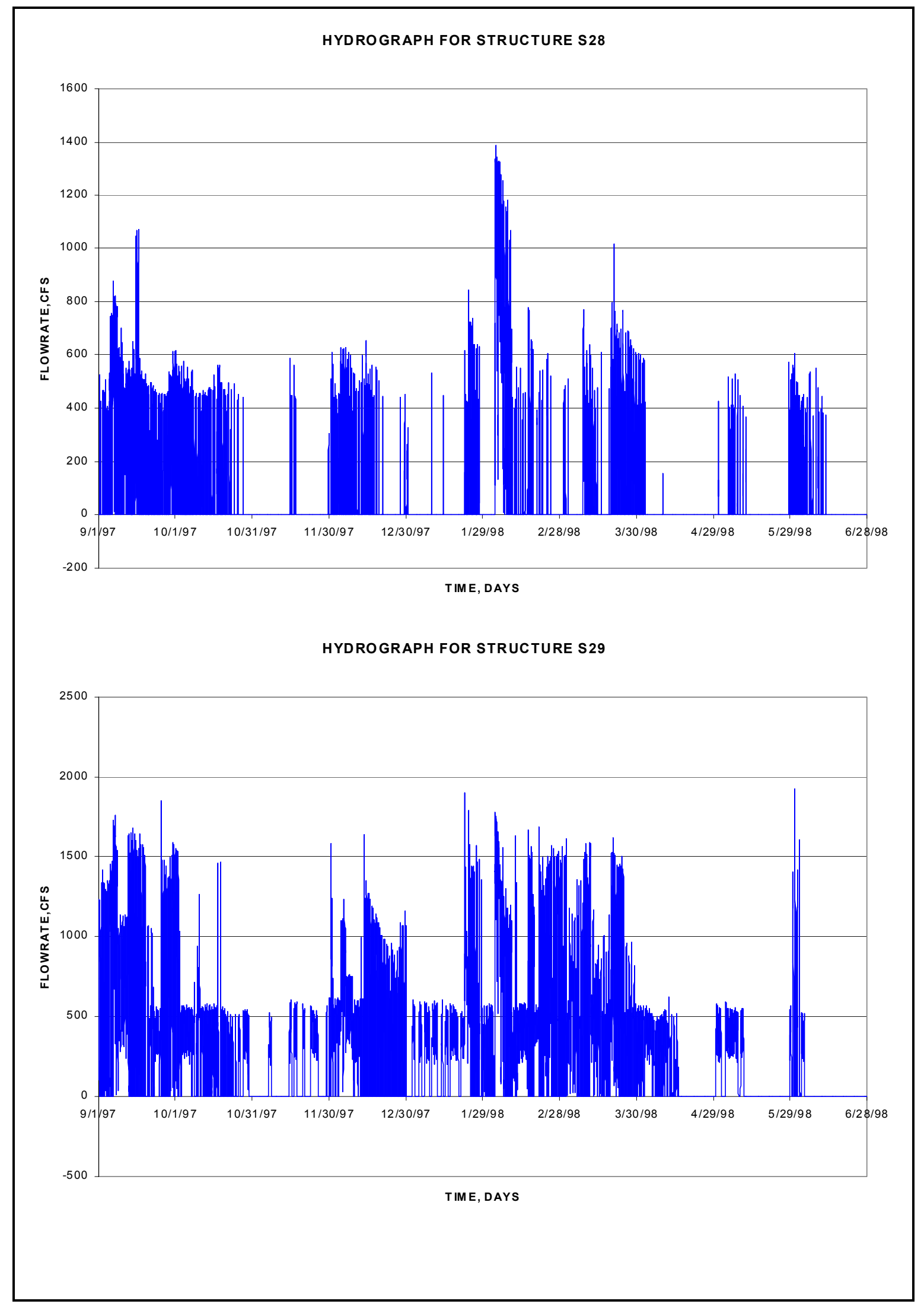

Plate 7 


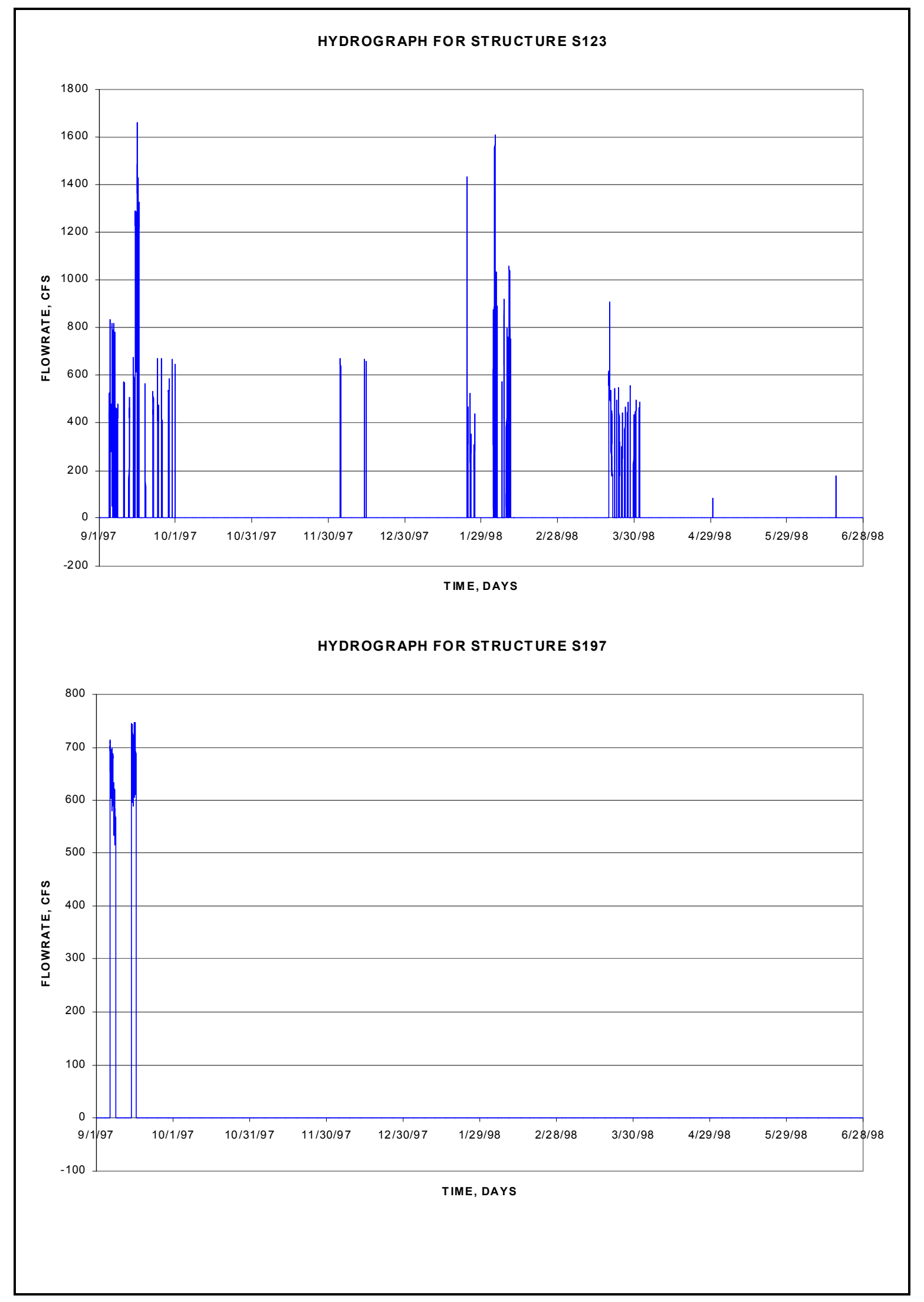

Plate 8 


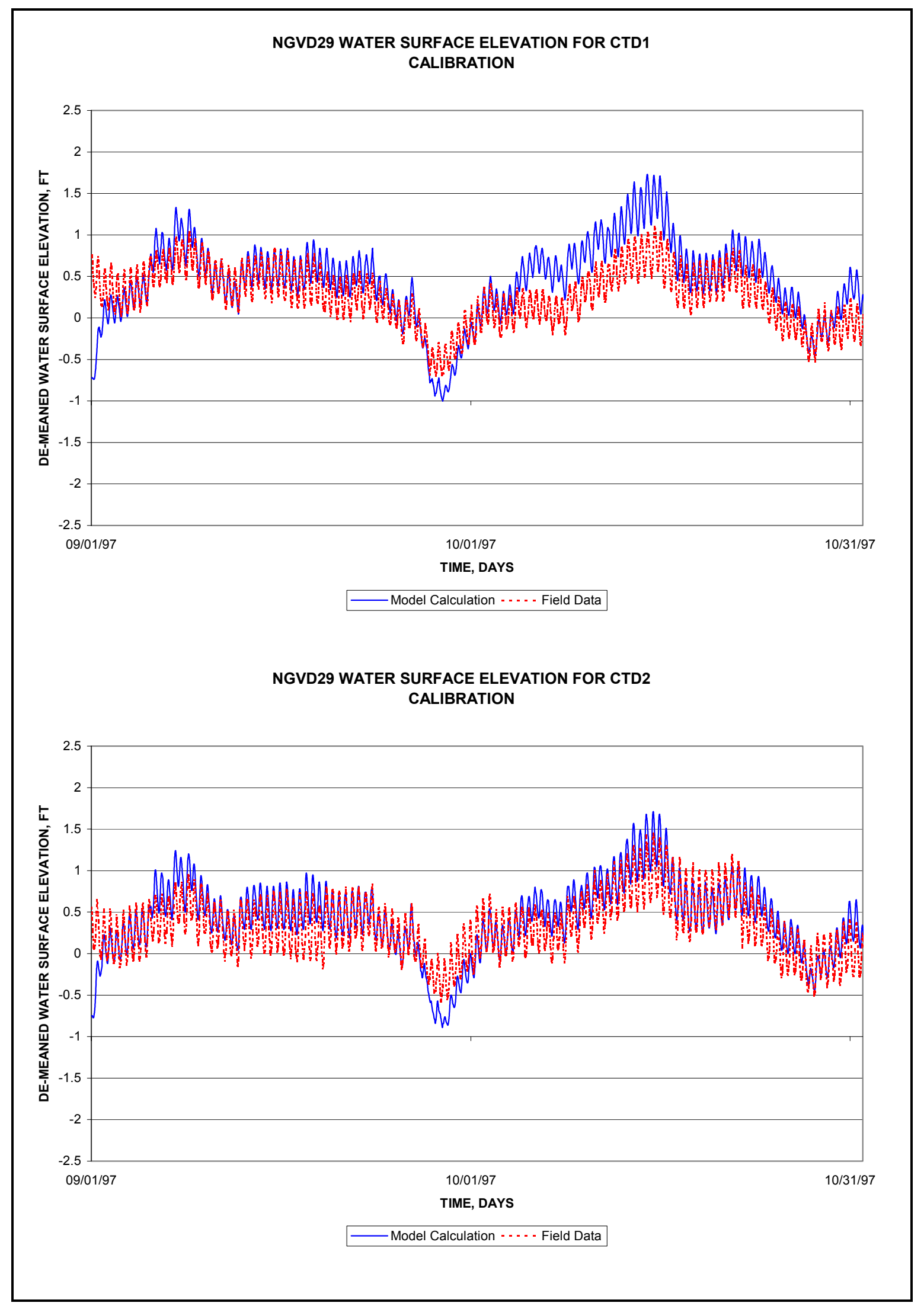

Plate 9 


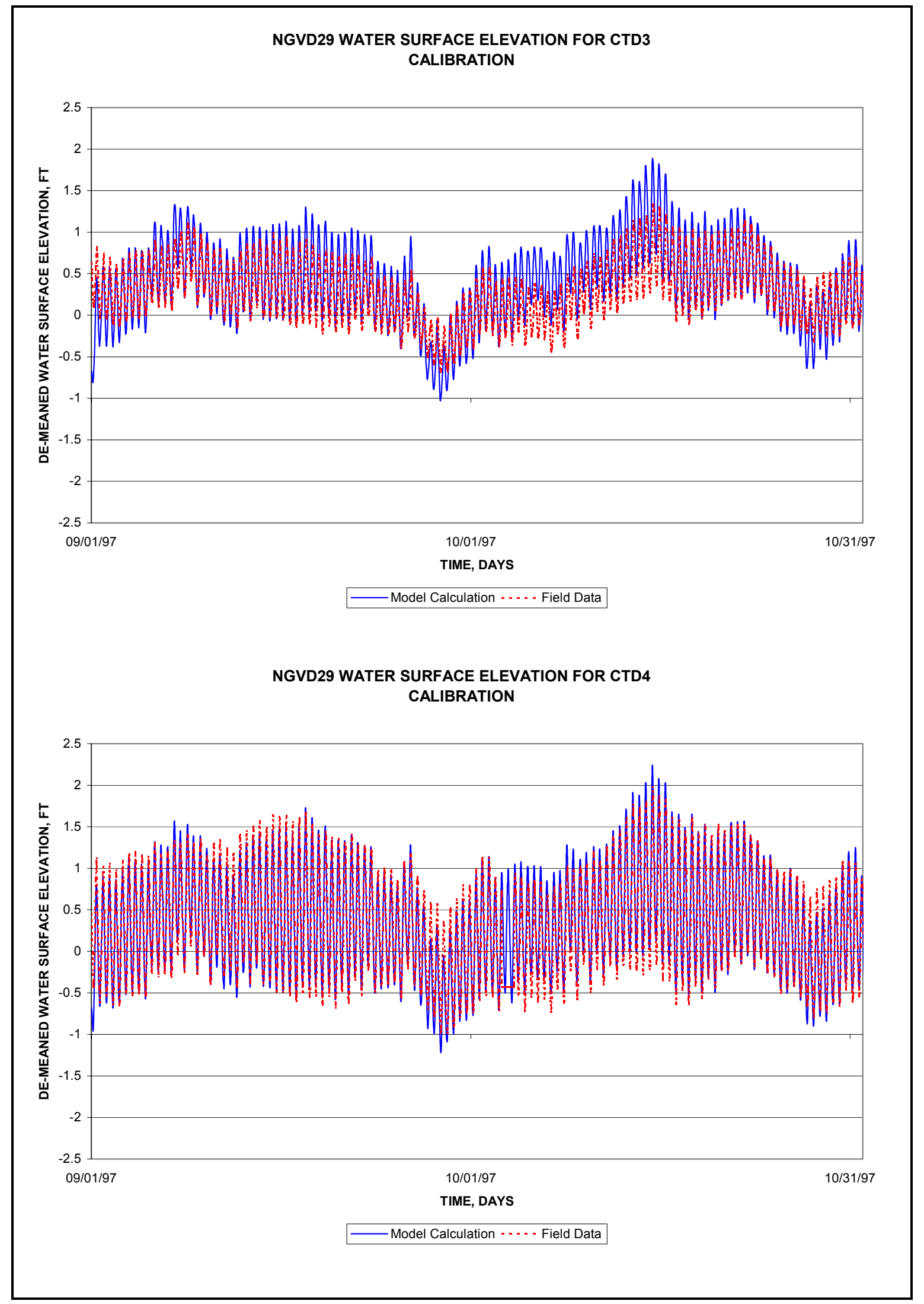

Plate 10 


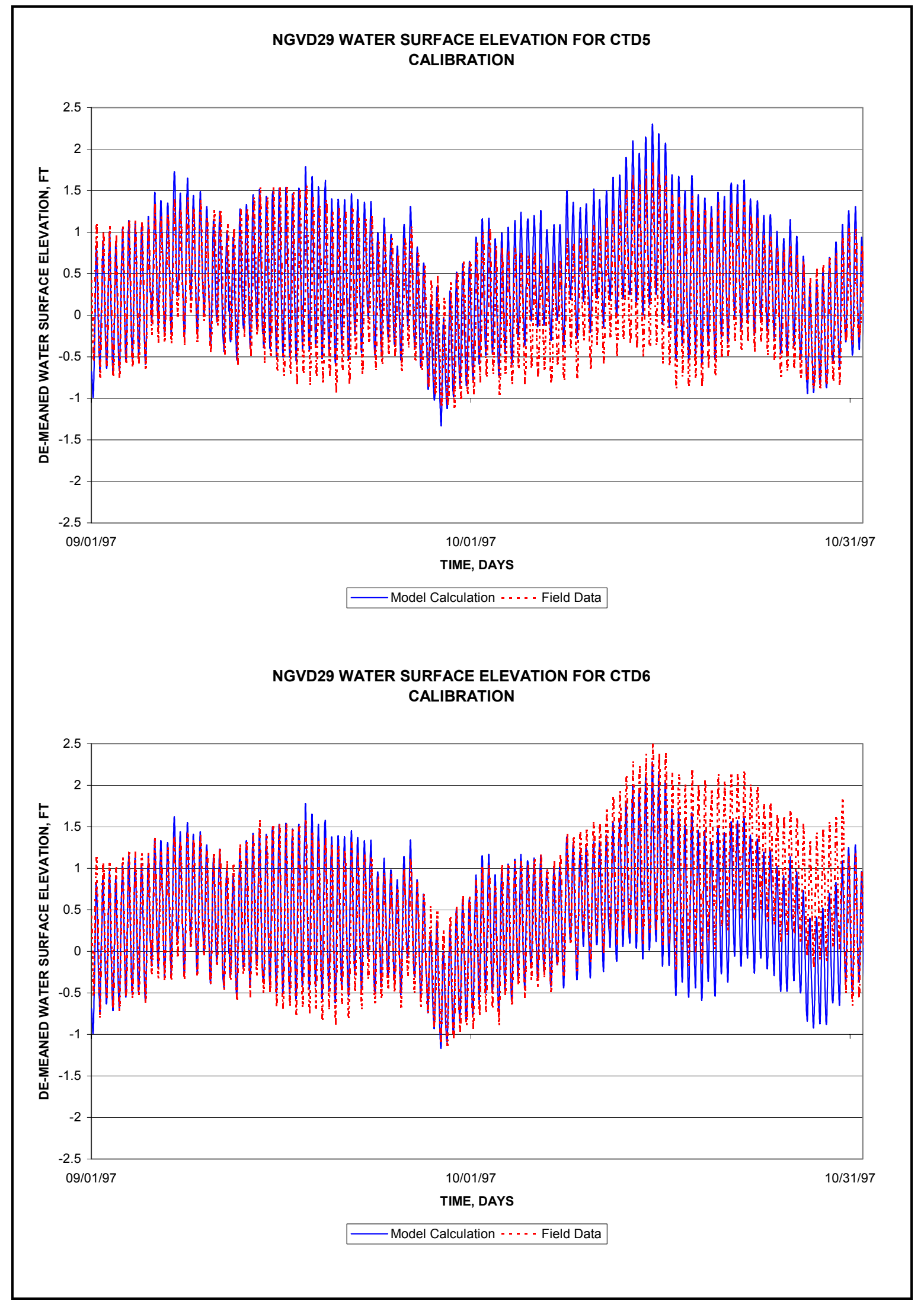

Plate 11 


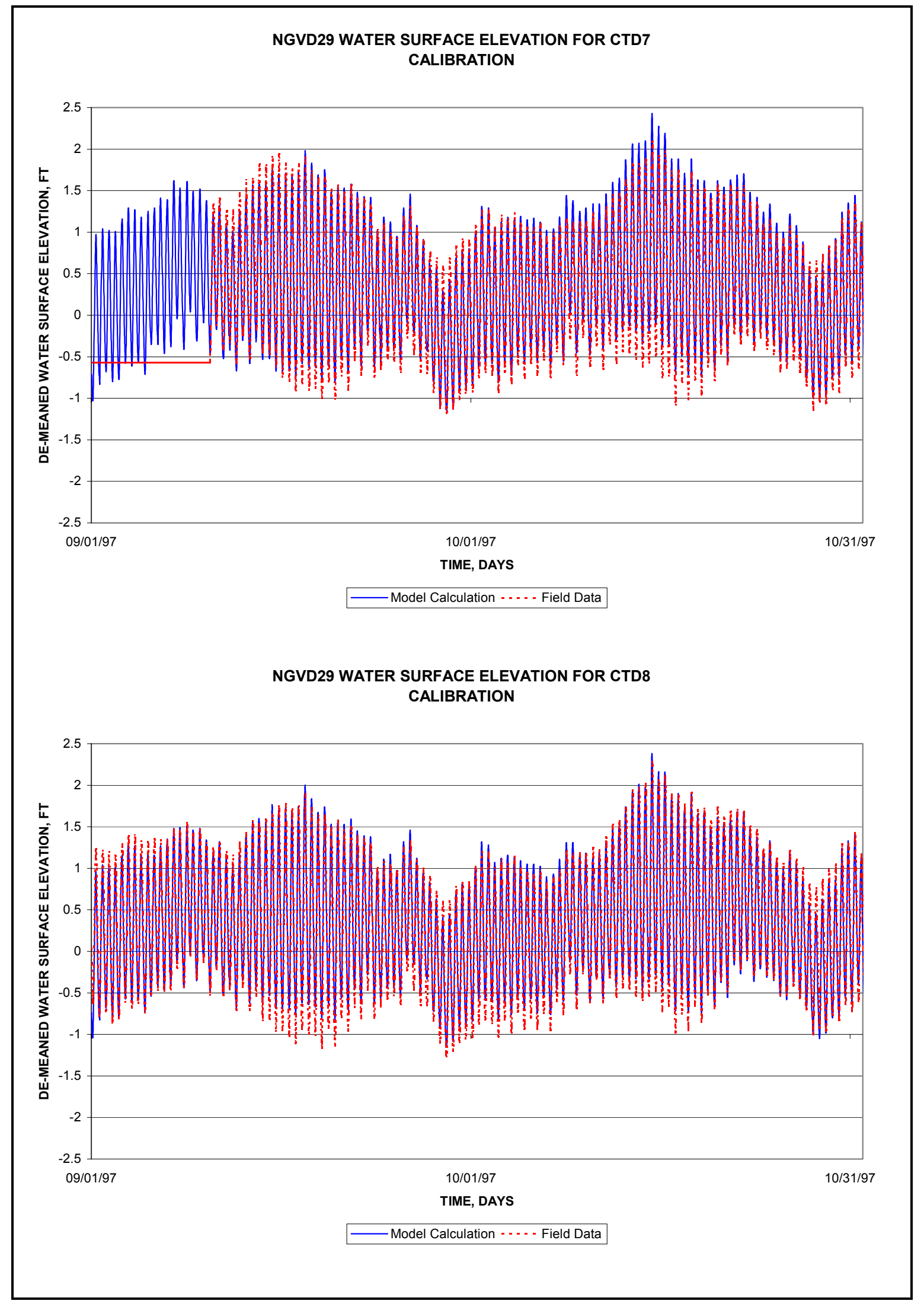

Plate 12 


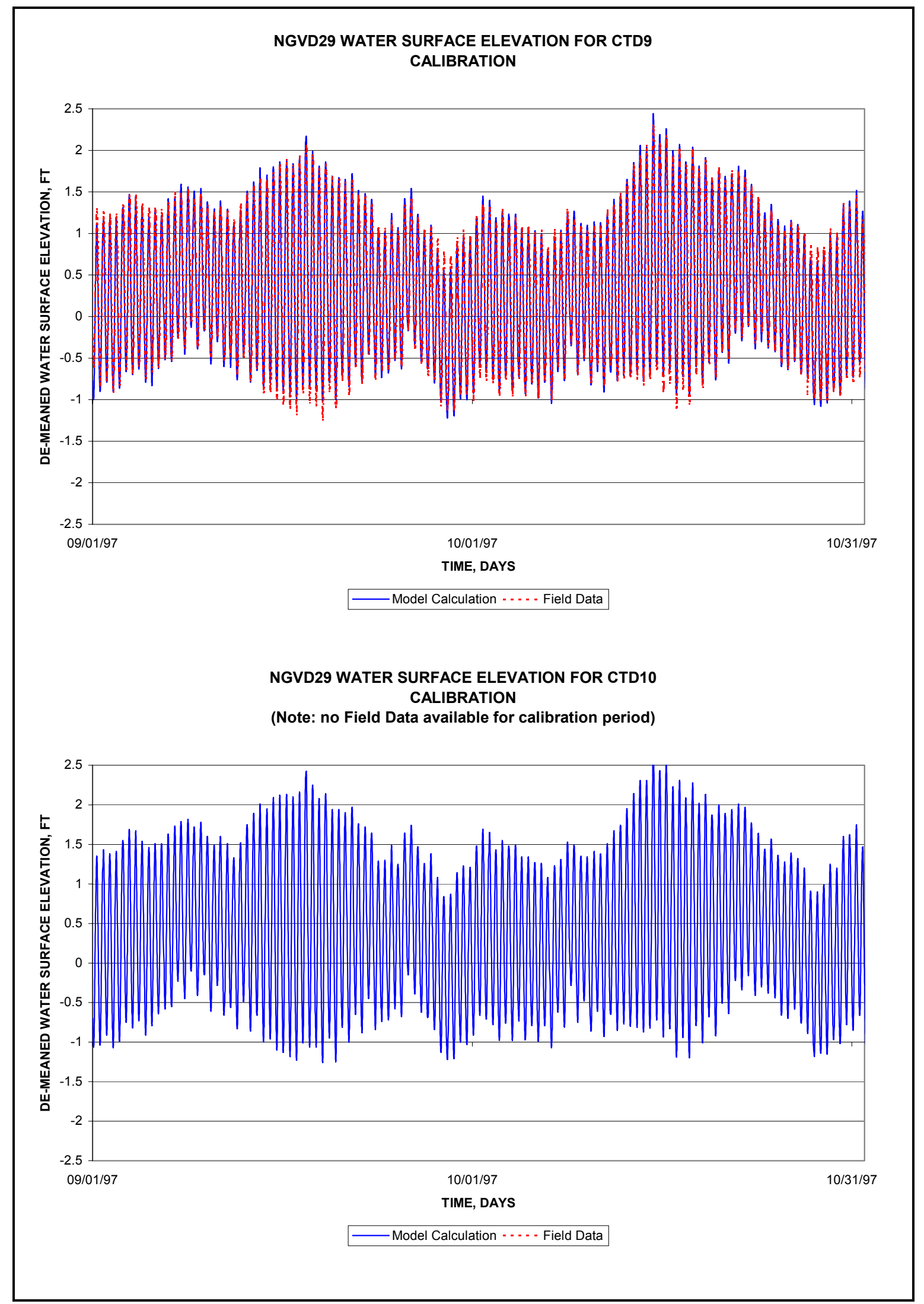

Plate 13 


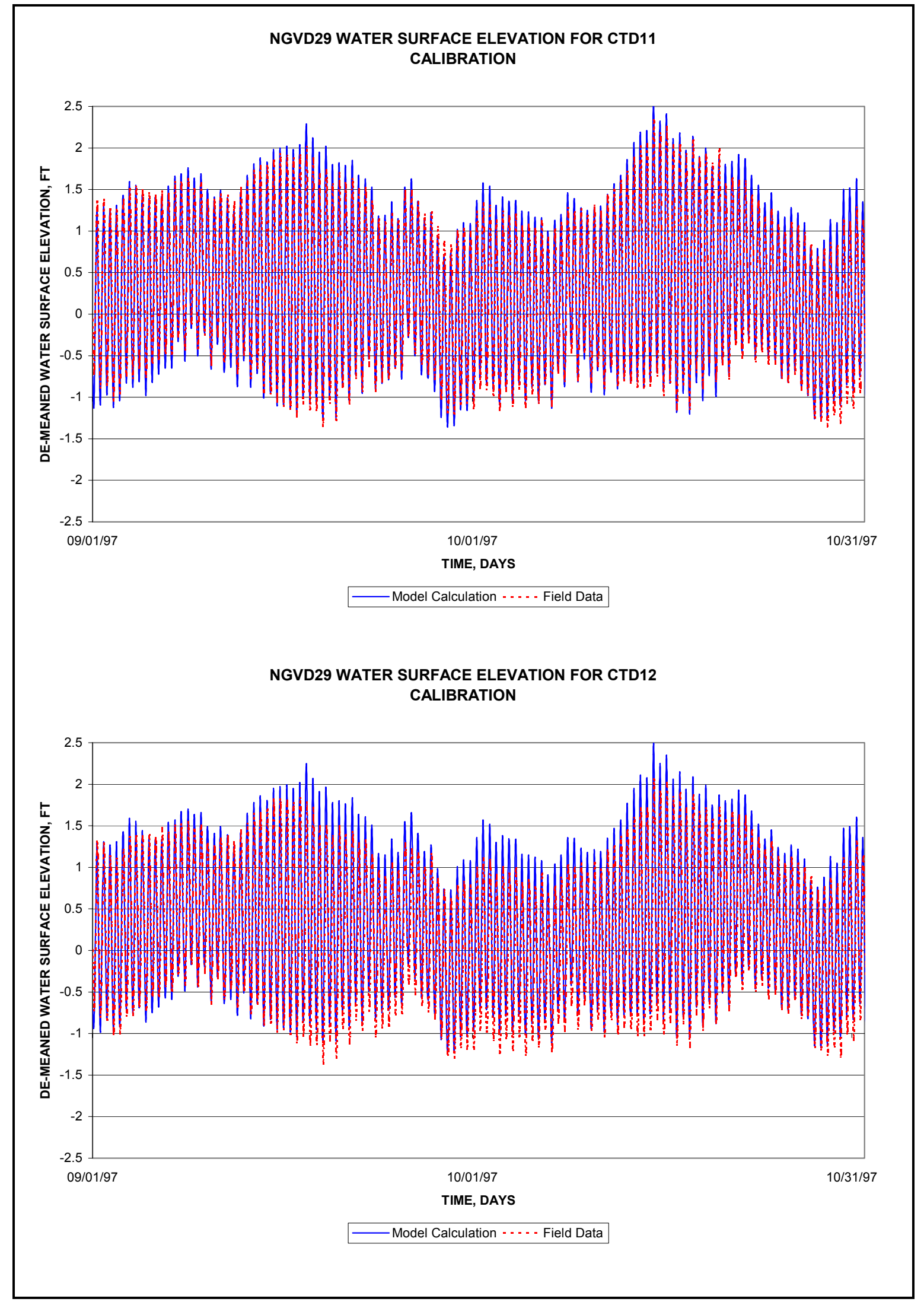

Plate 14 


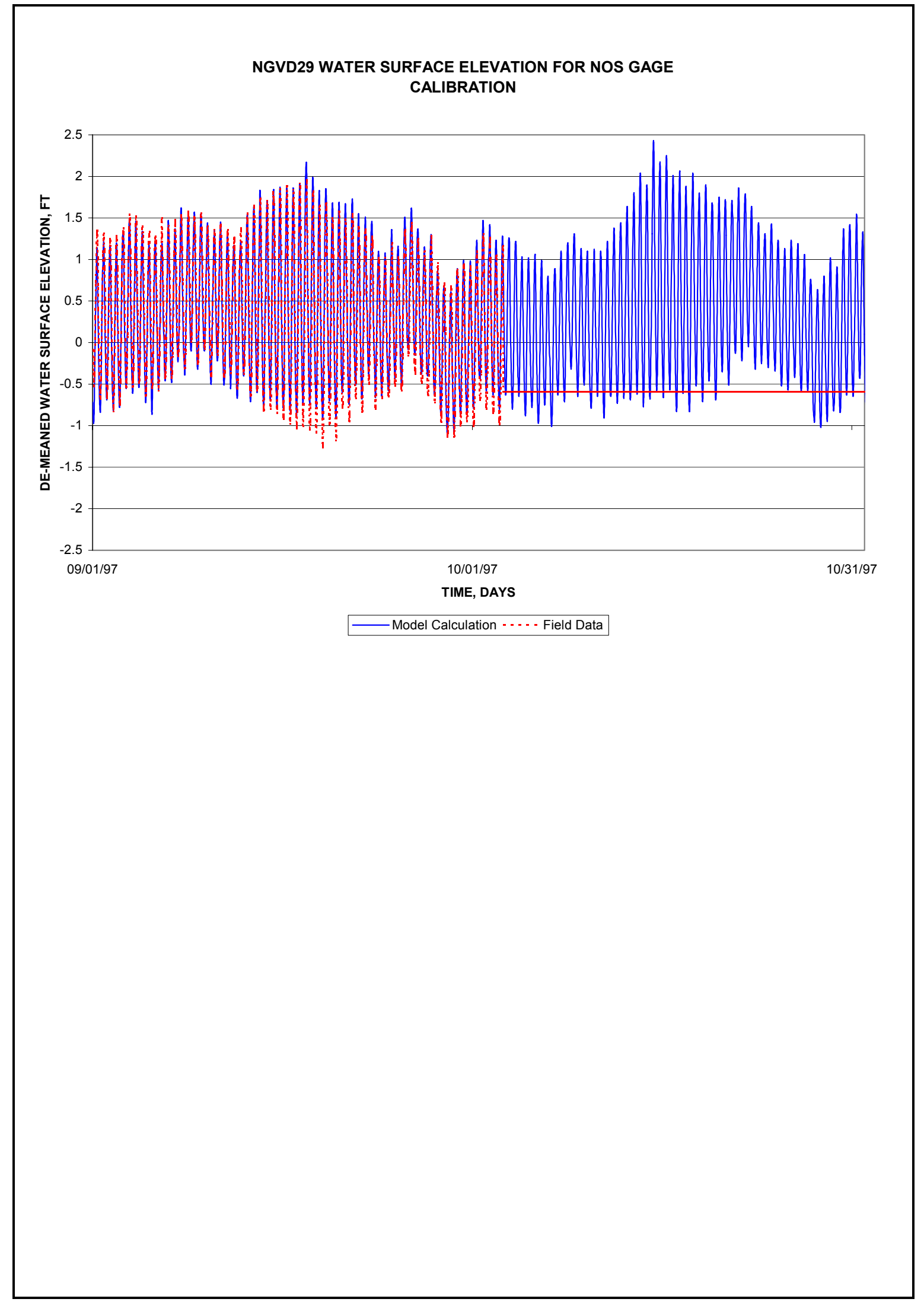

Plate 15 


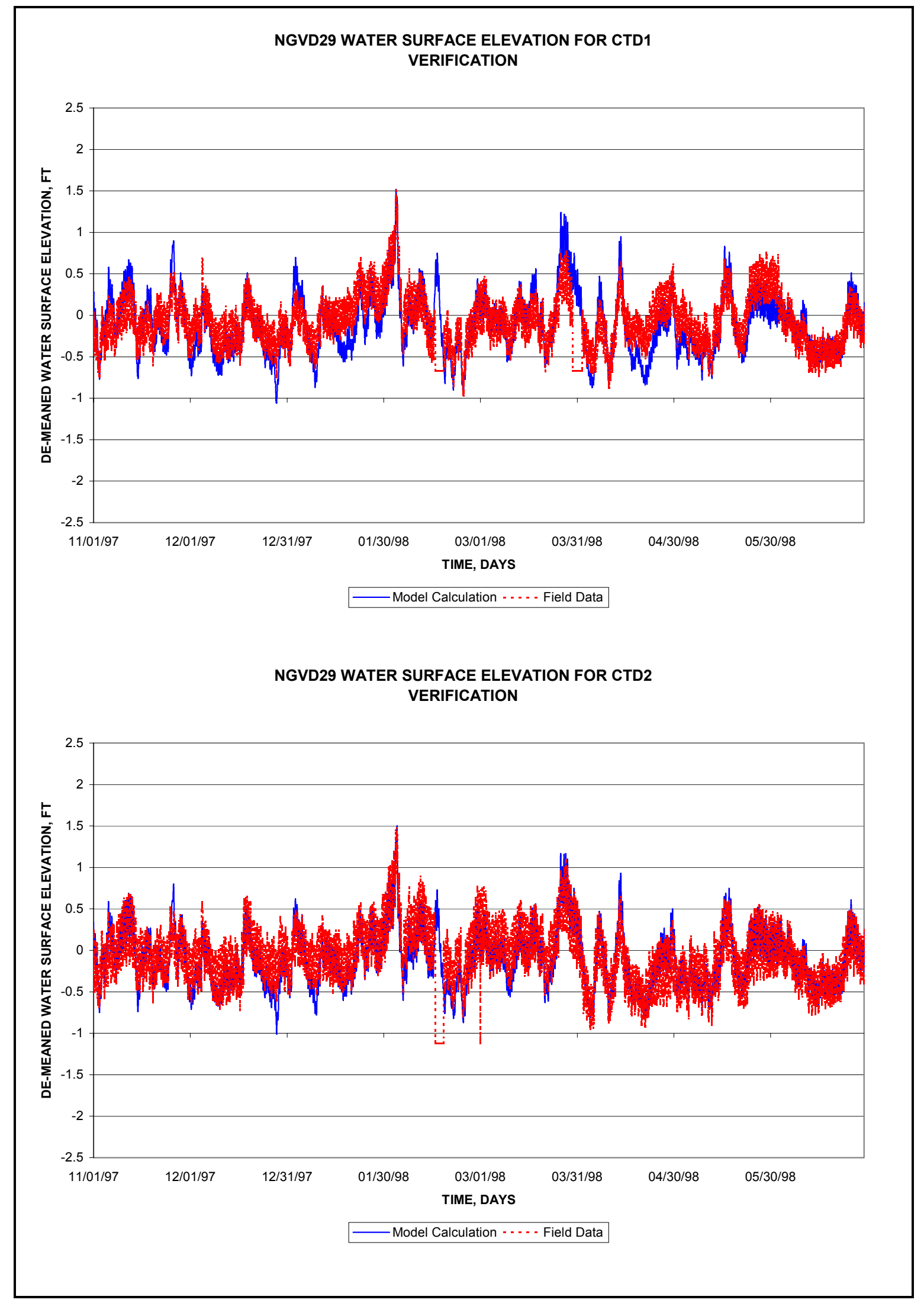

Plate 16 


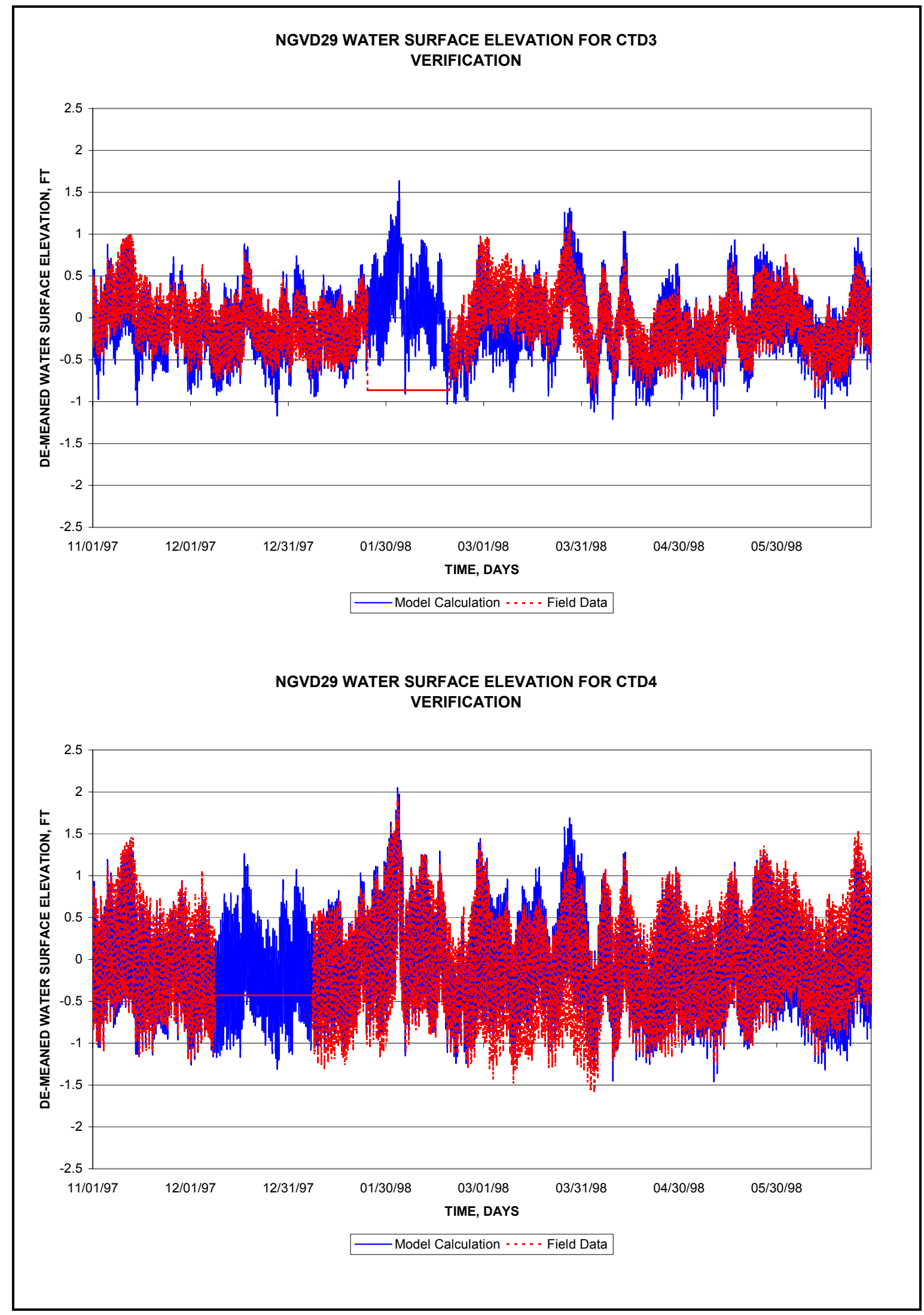

Plate 17 


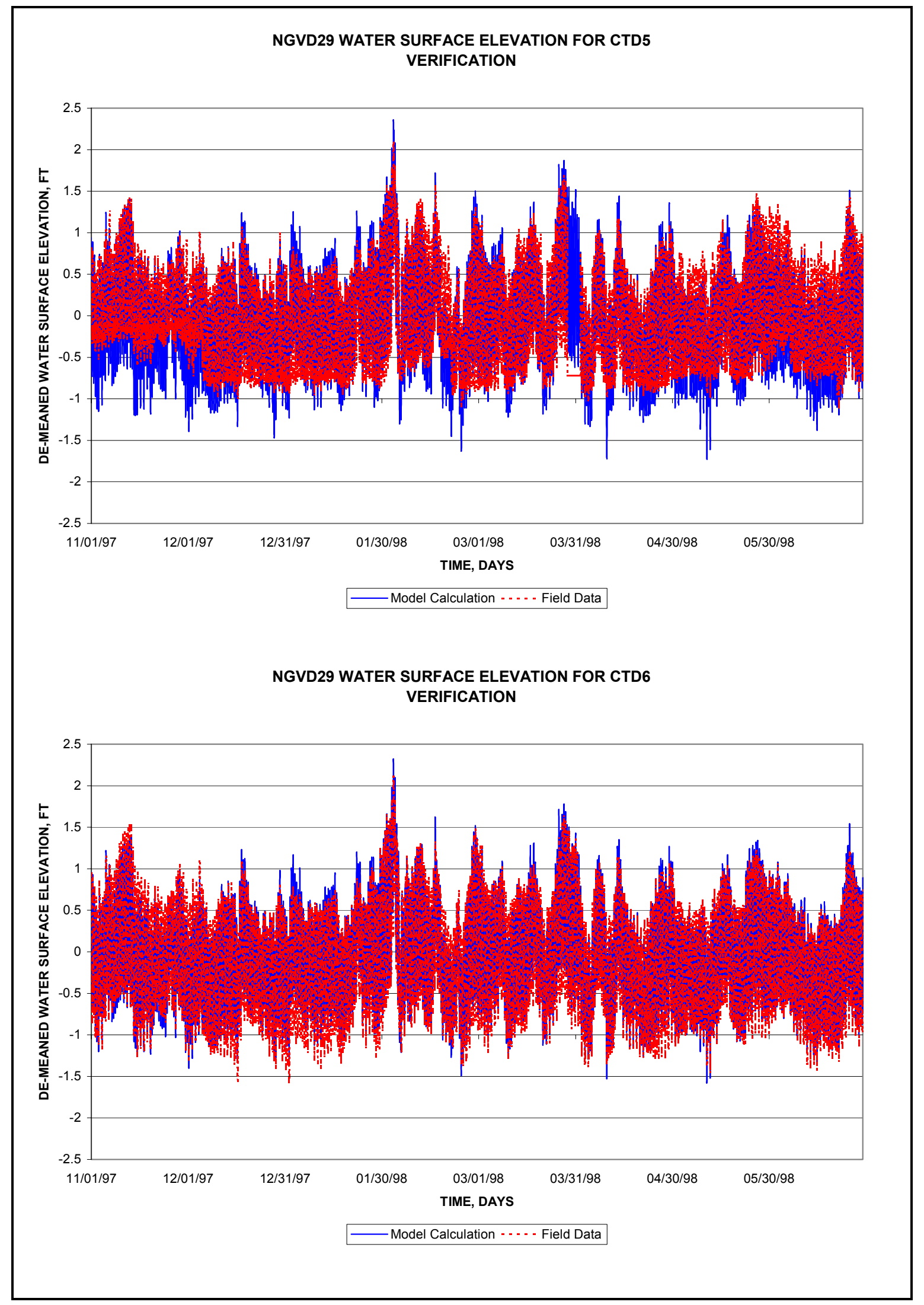

Plate 18 


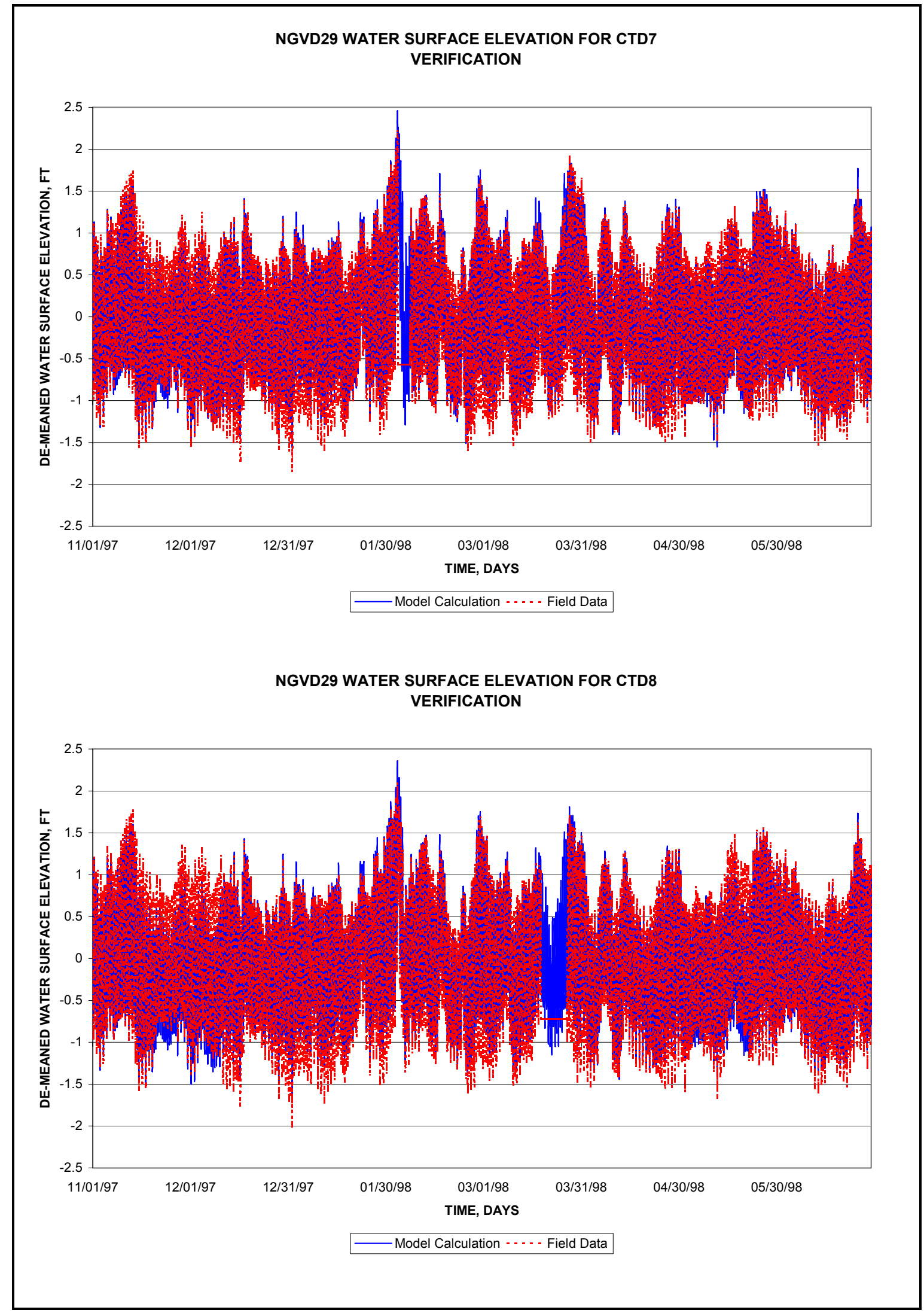

Plate 19 


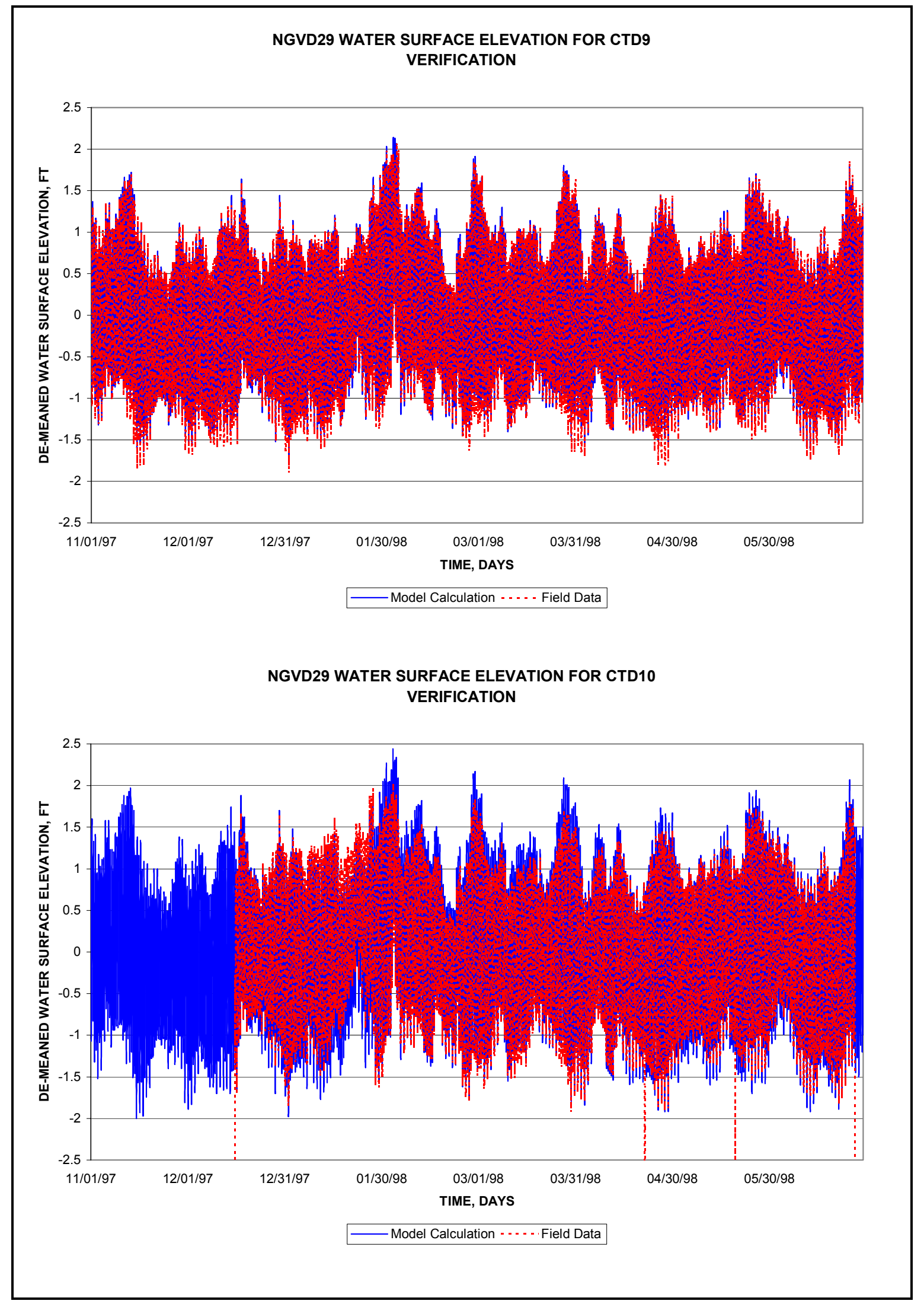

Plate 20 


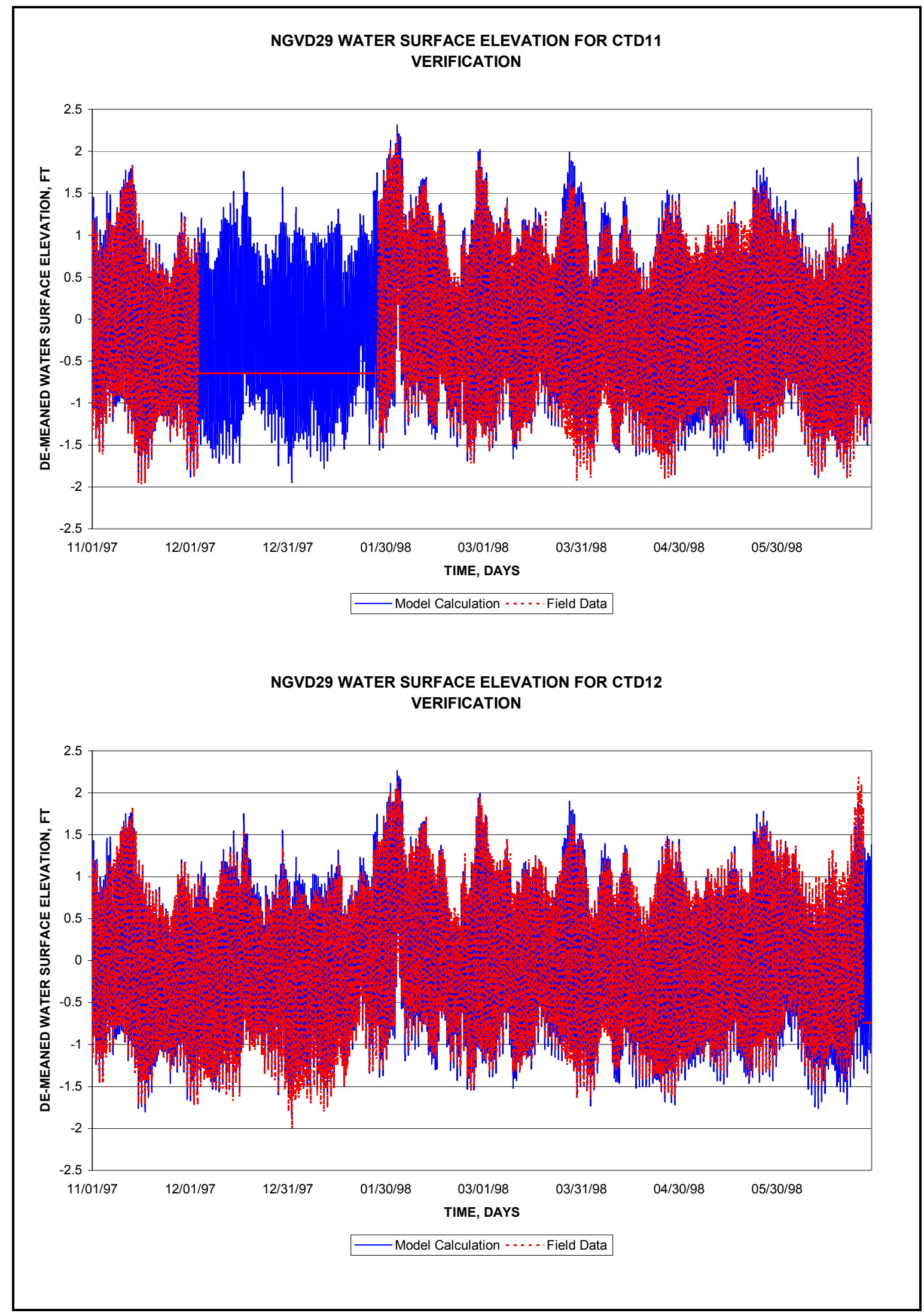

Plate 21 


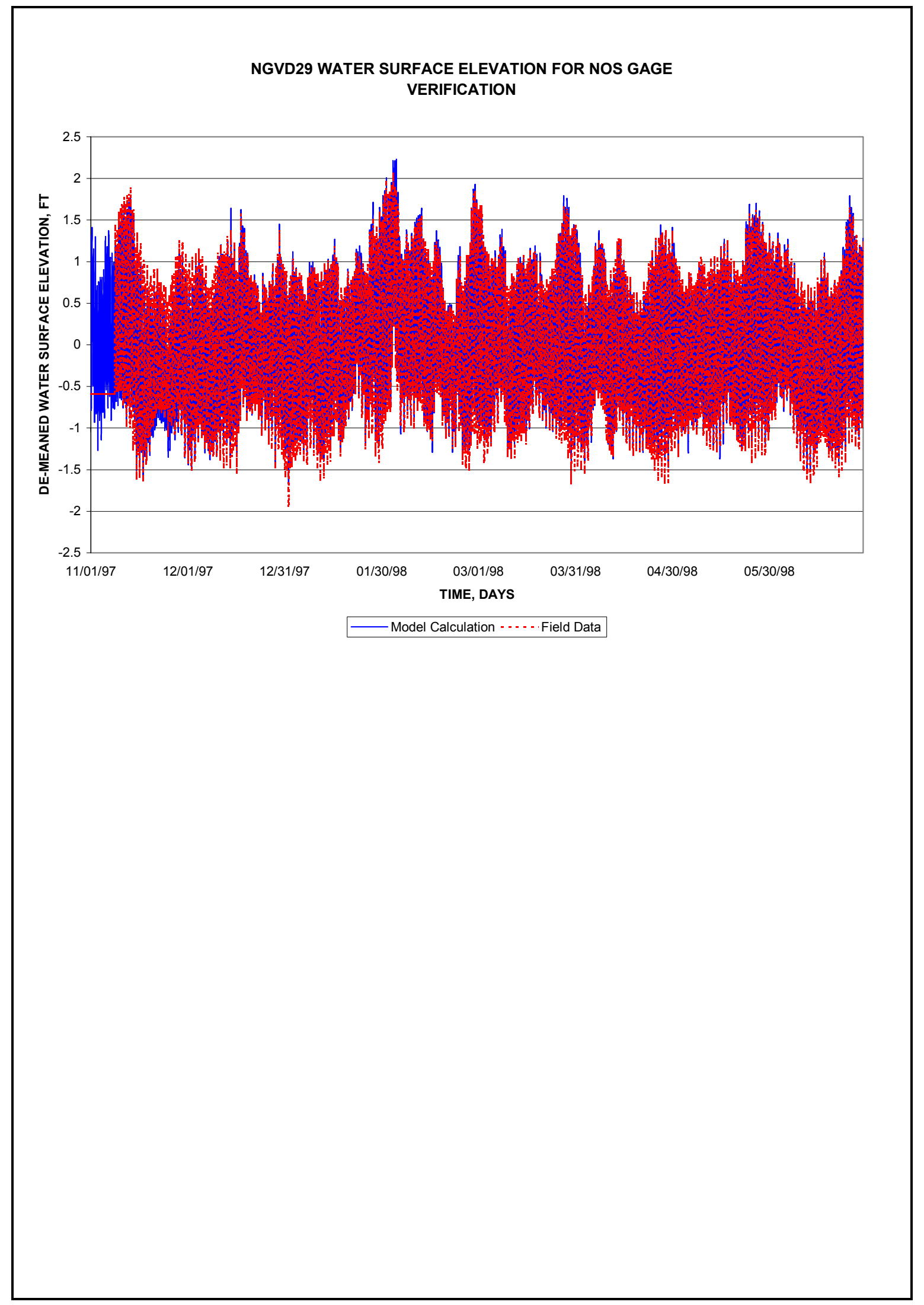

Plate 22 


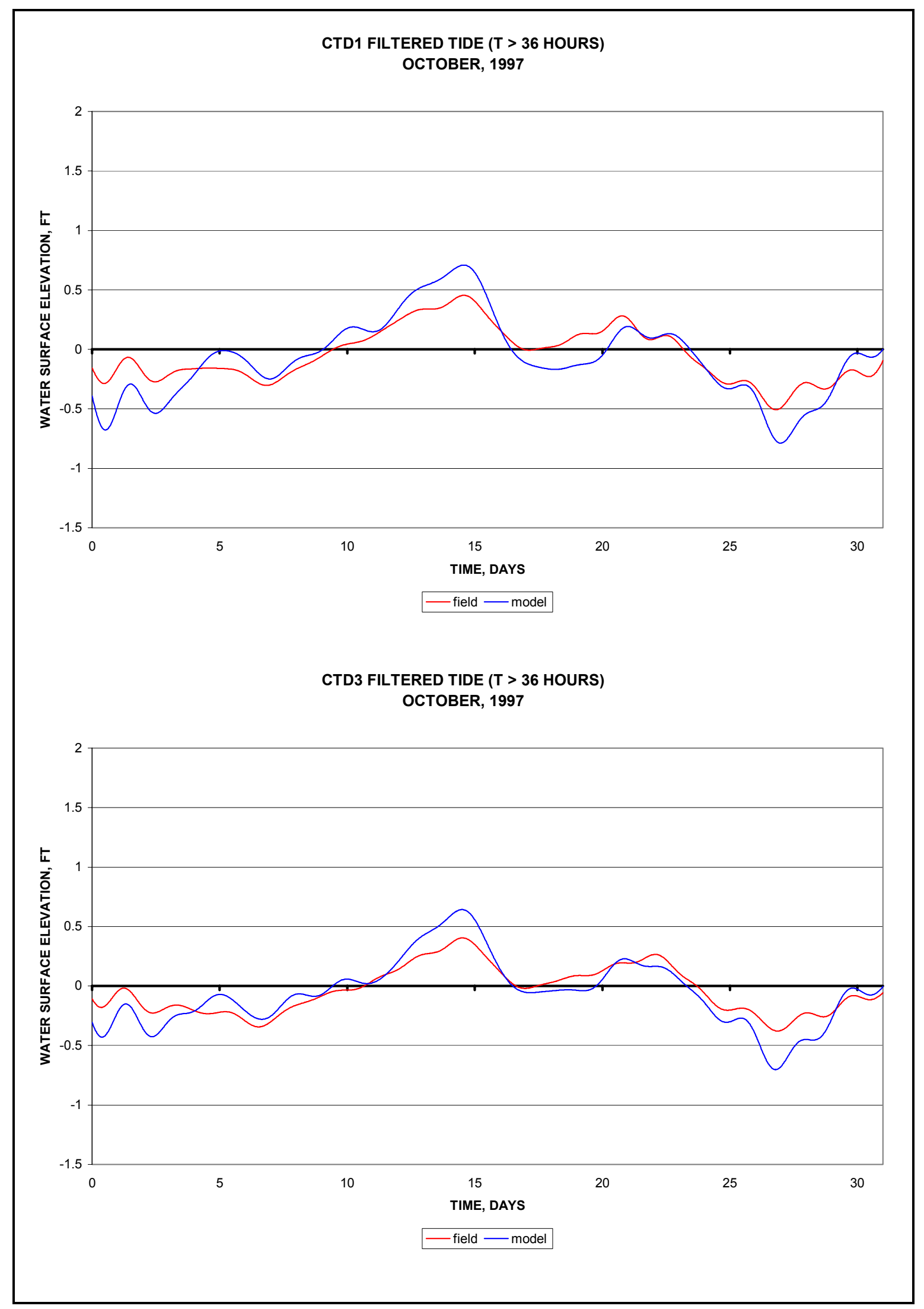

Plate 23 


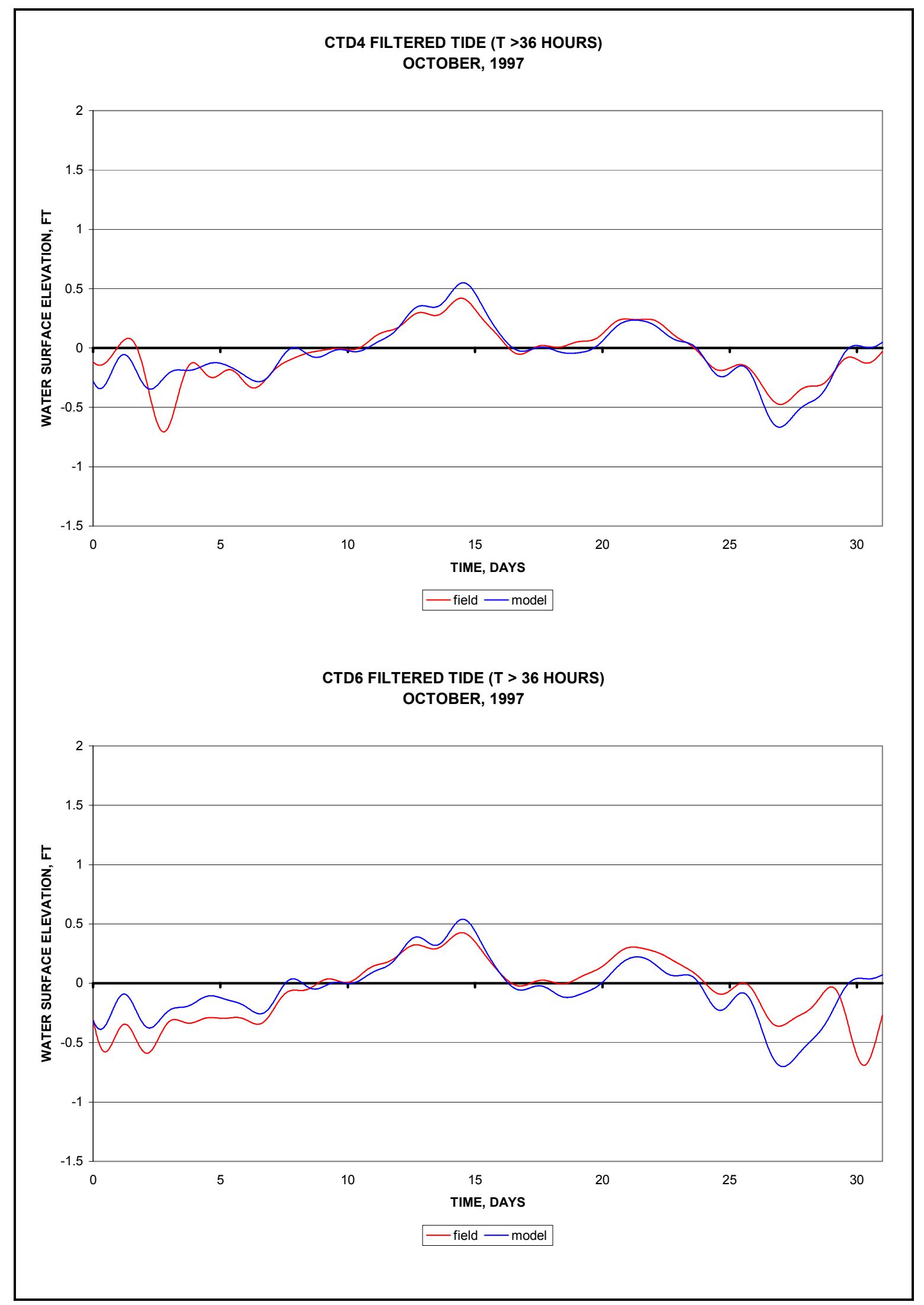

Plate 24 


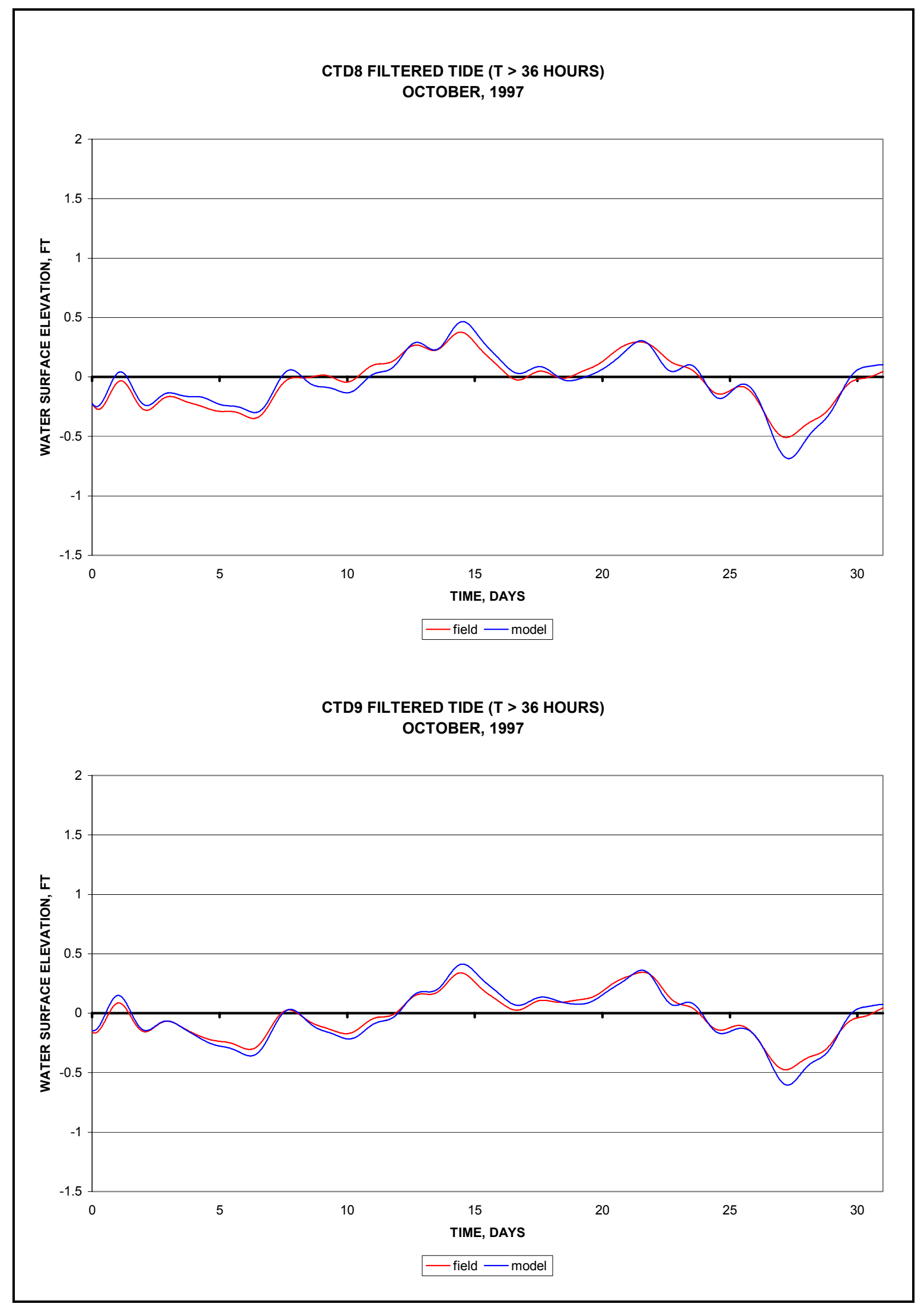

Plate 25 


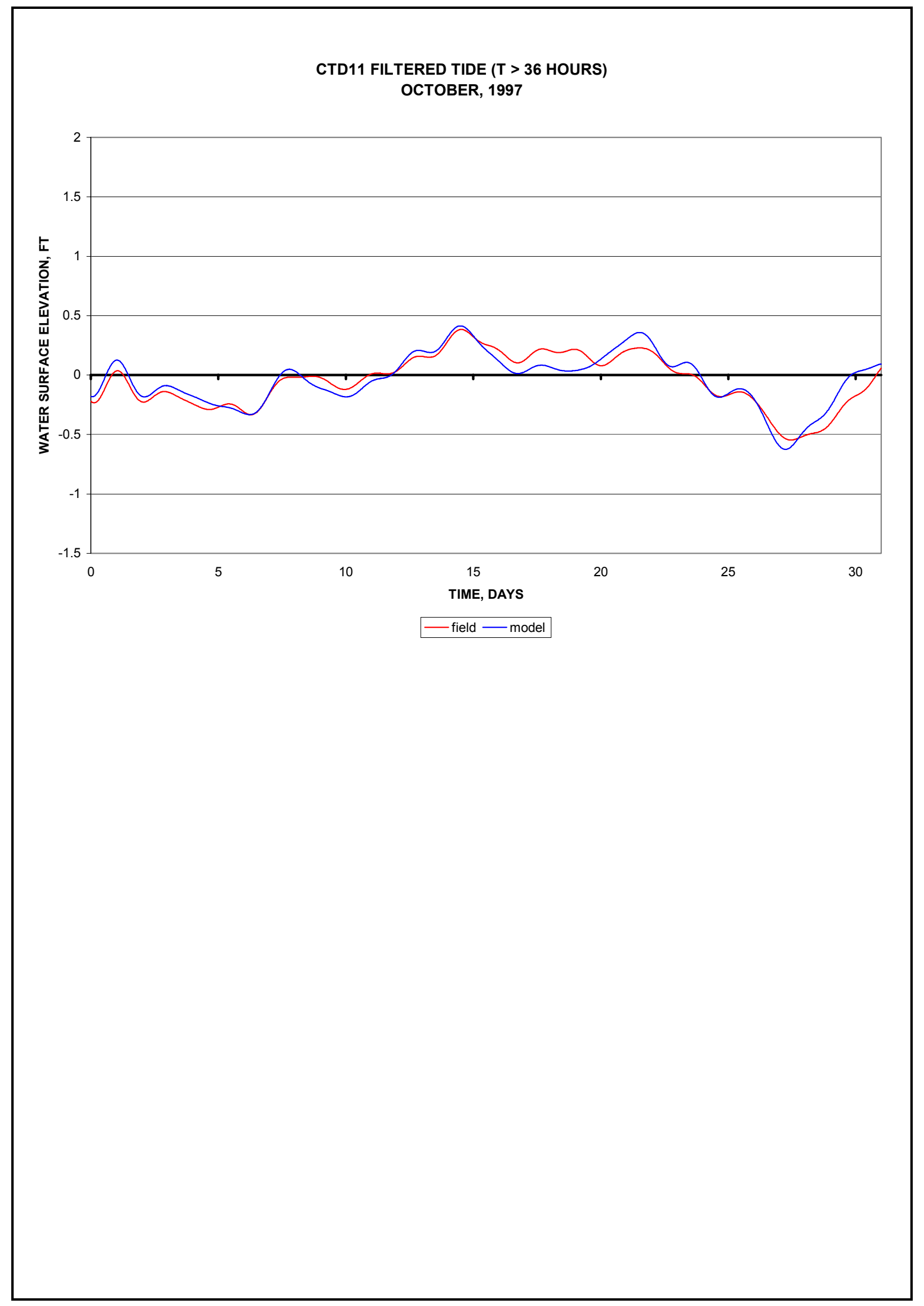

Plate 26 


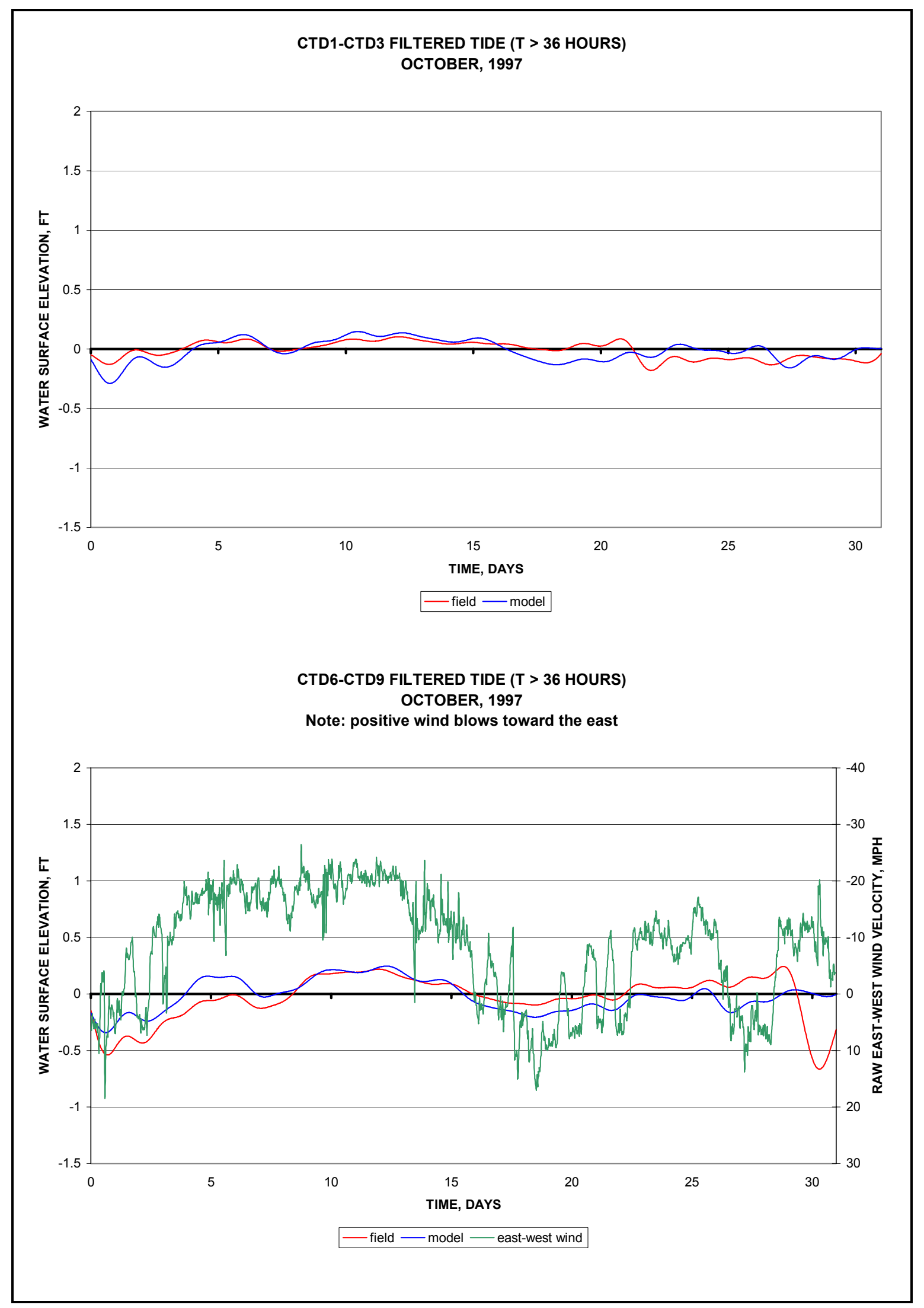

Plate 27 


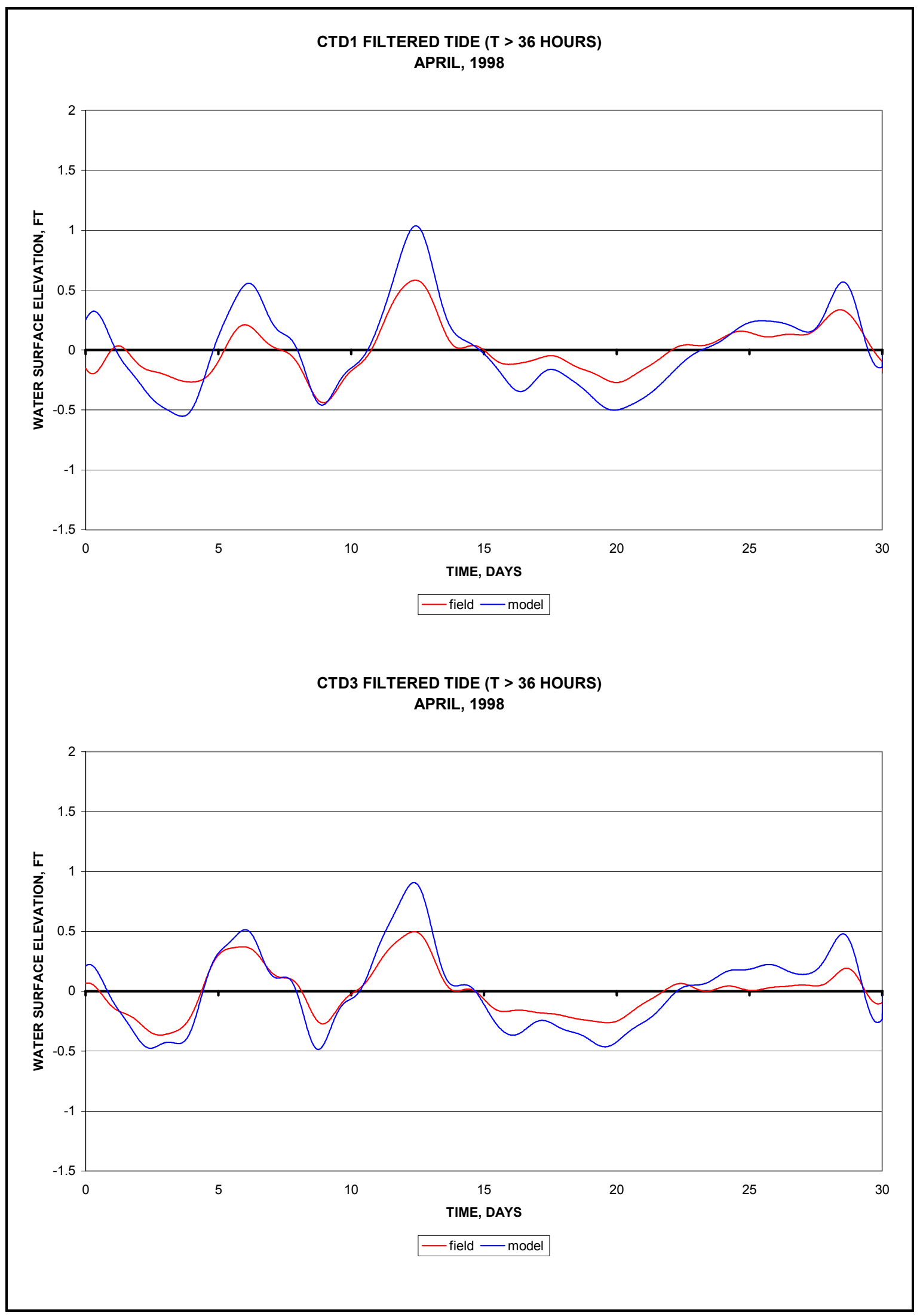

Plate 28 


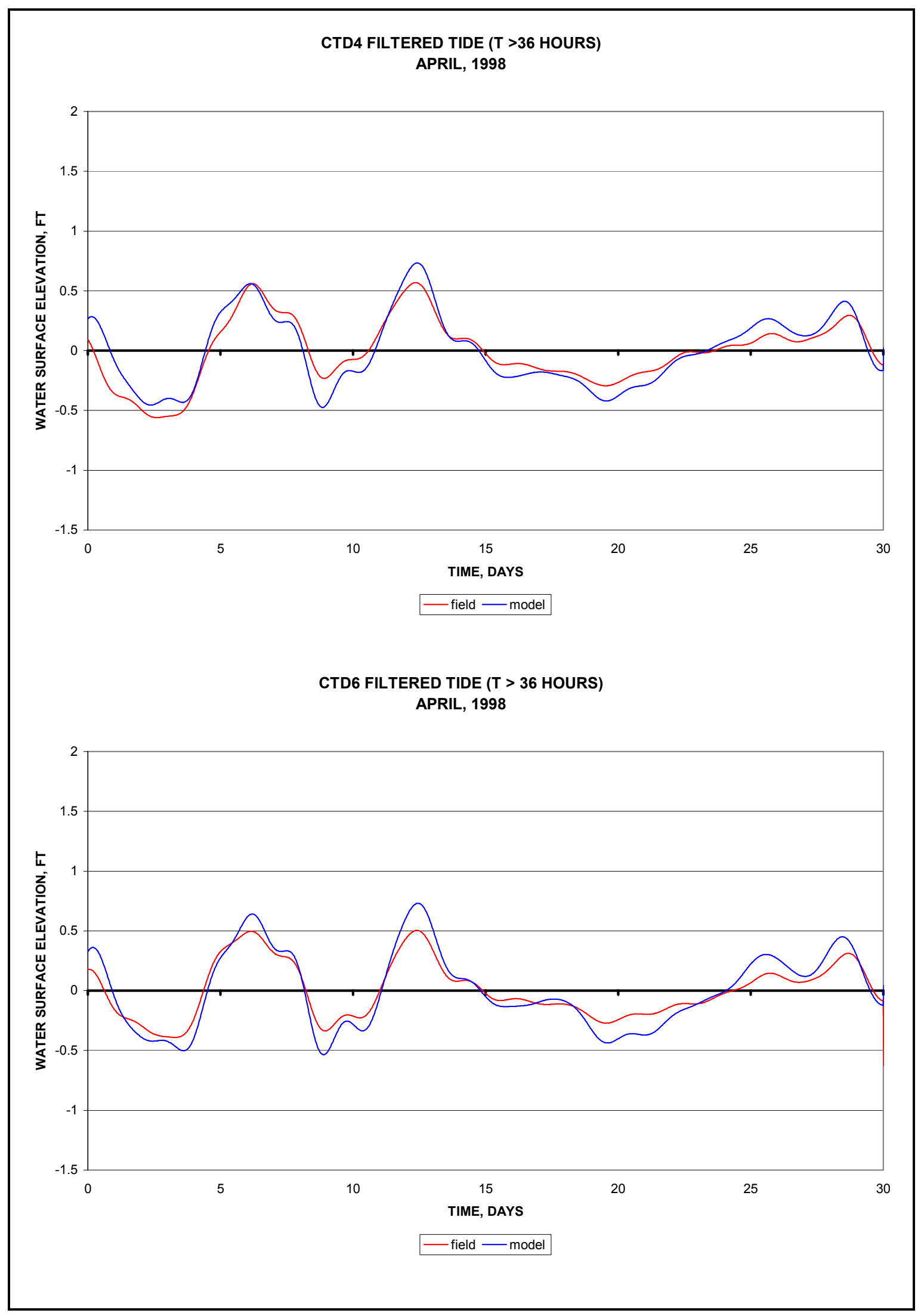

Plate 29 


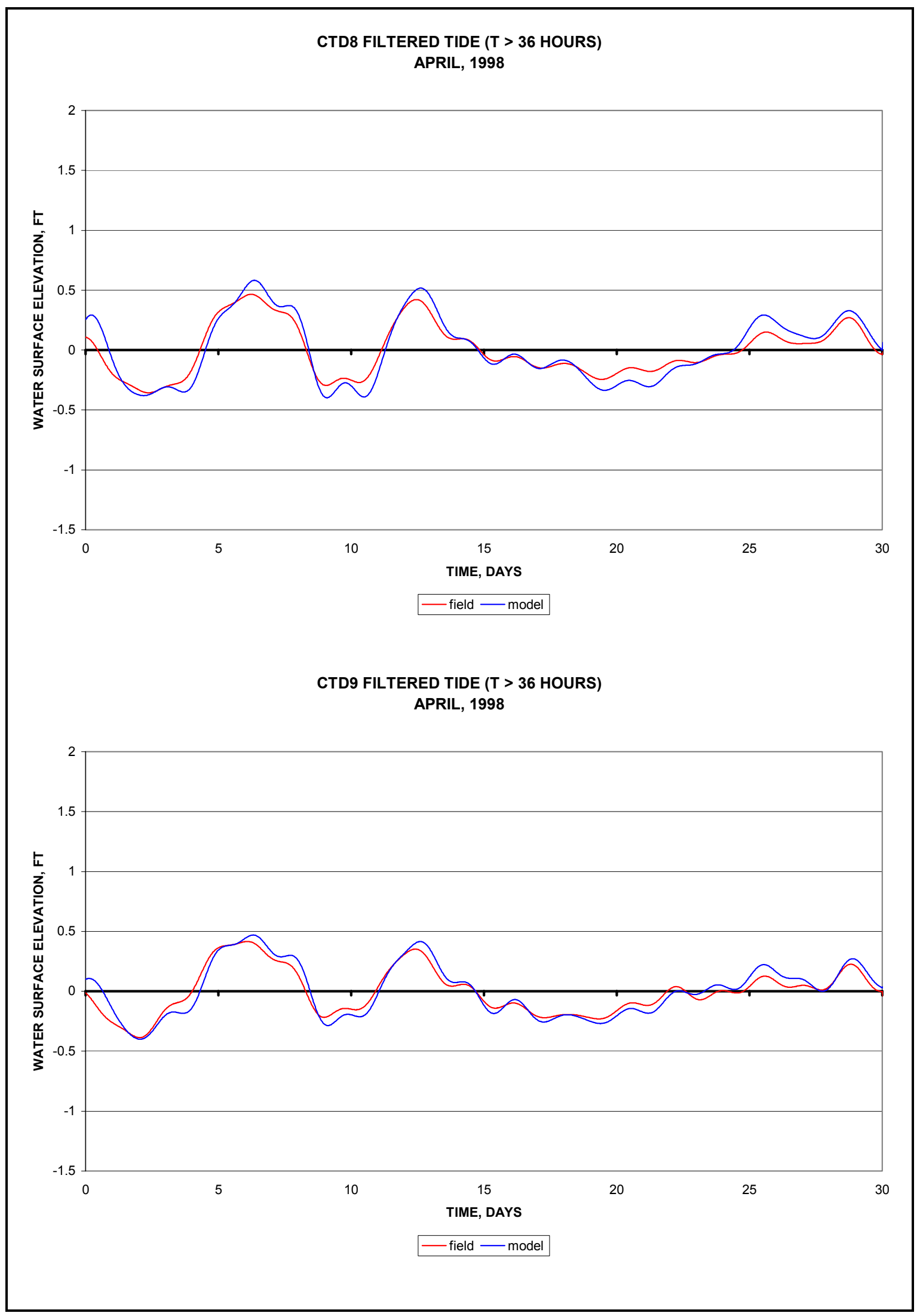

Plate 30 


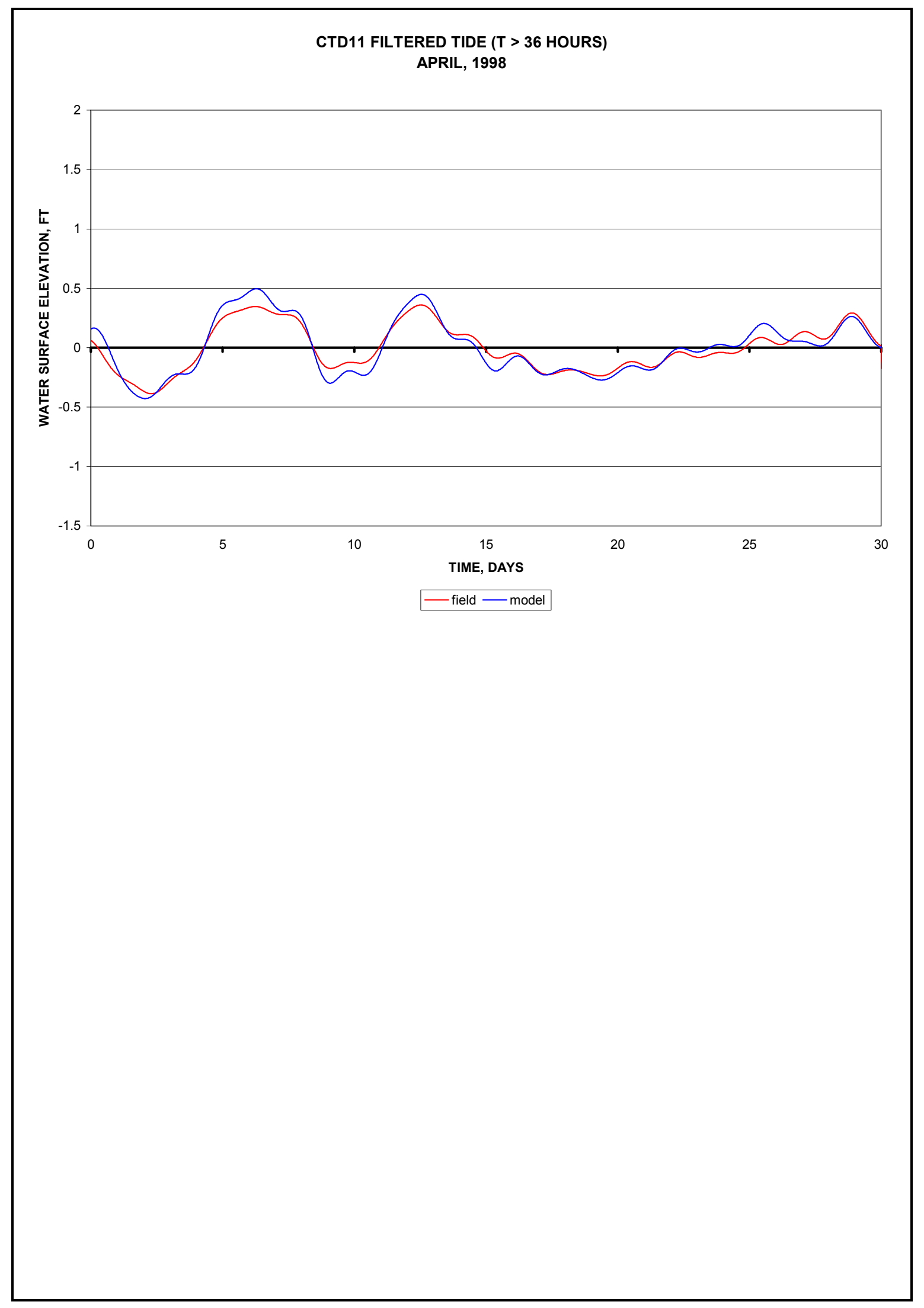

Plate 31 


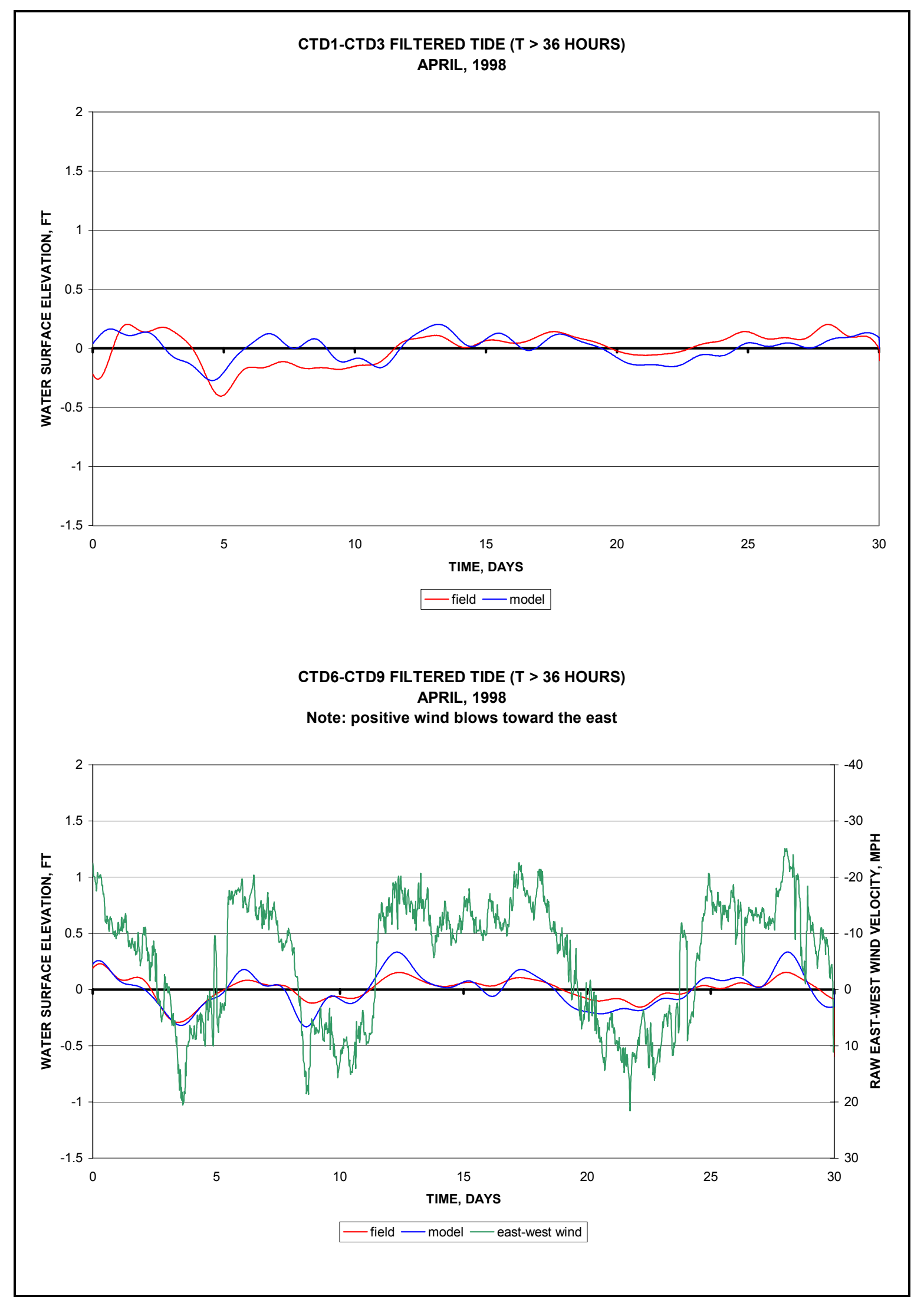

Plate 32 


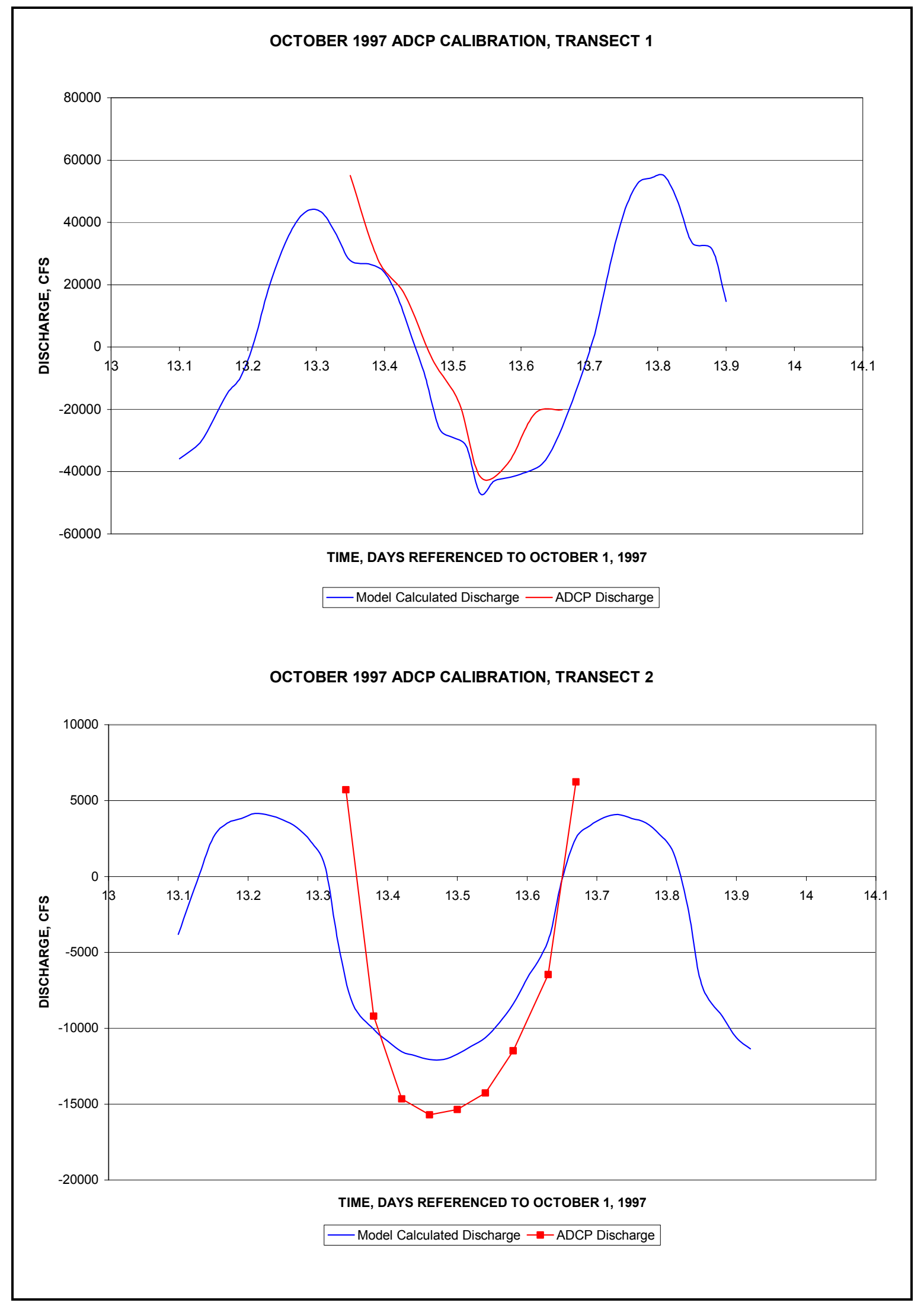

Plate 33 


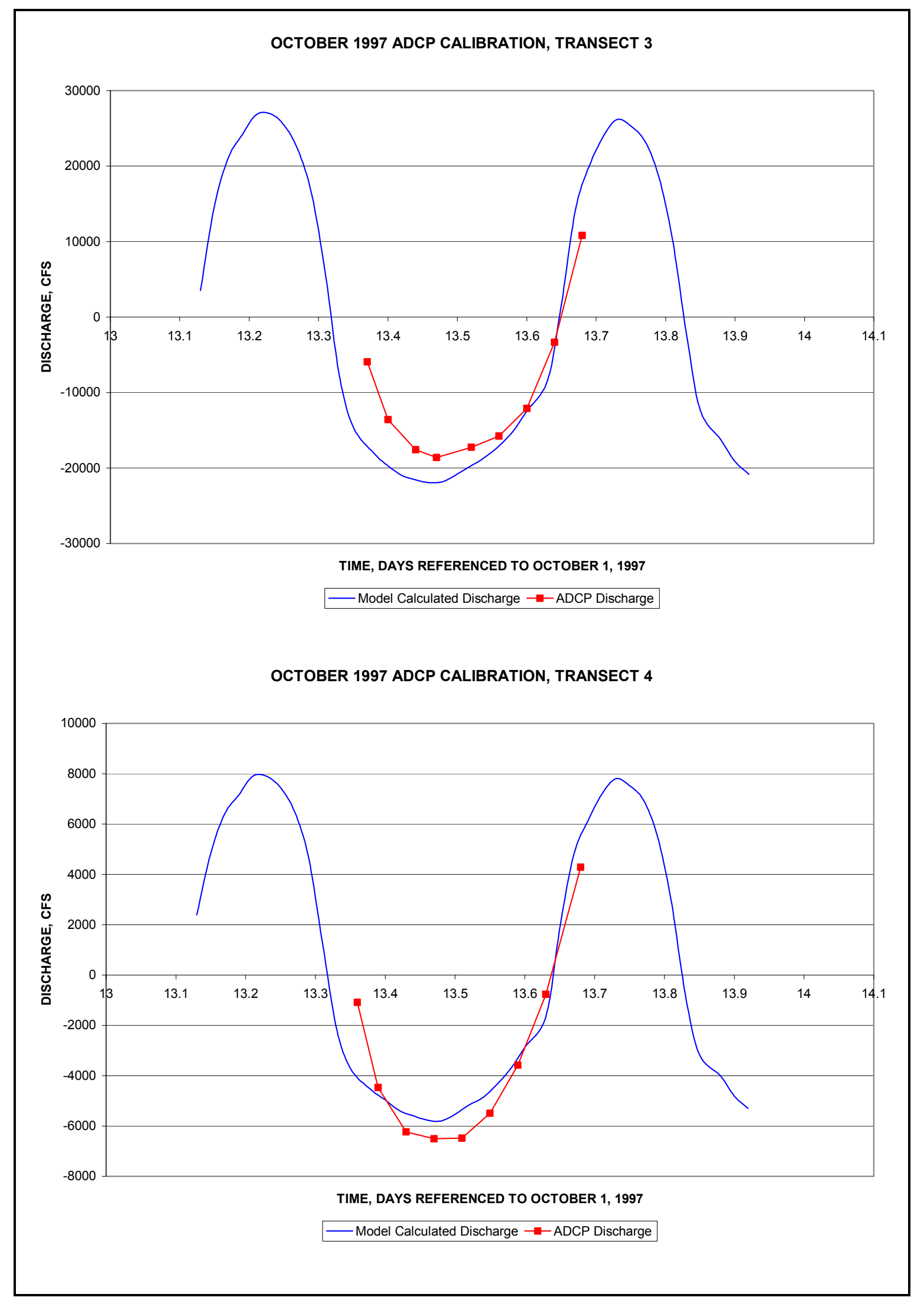

Plate 34 


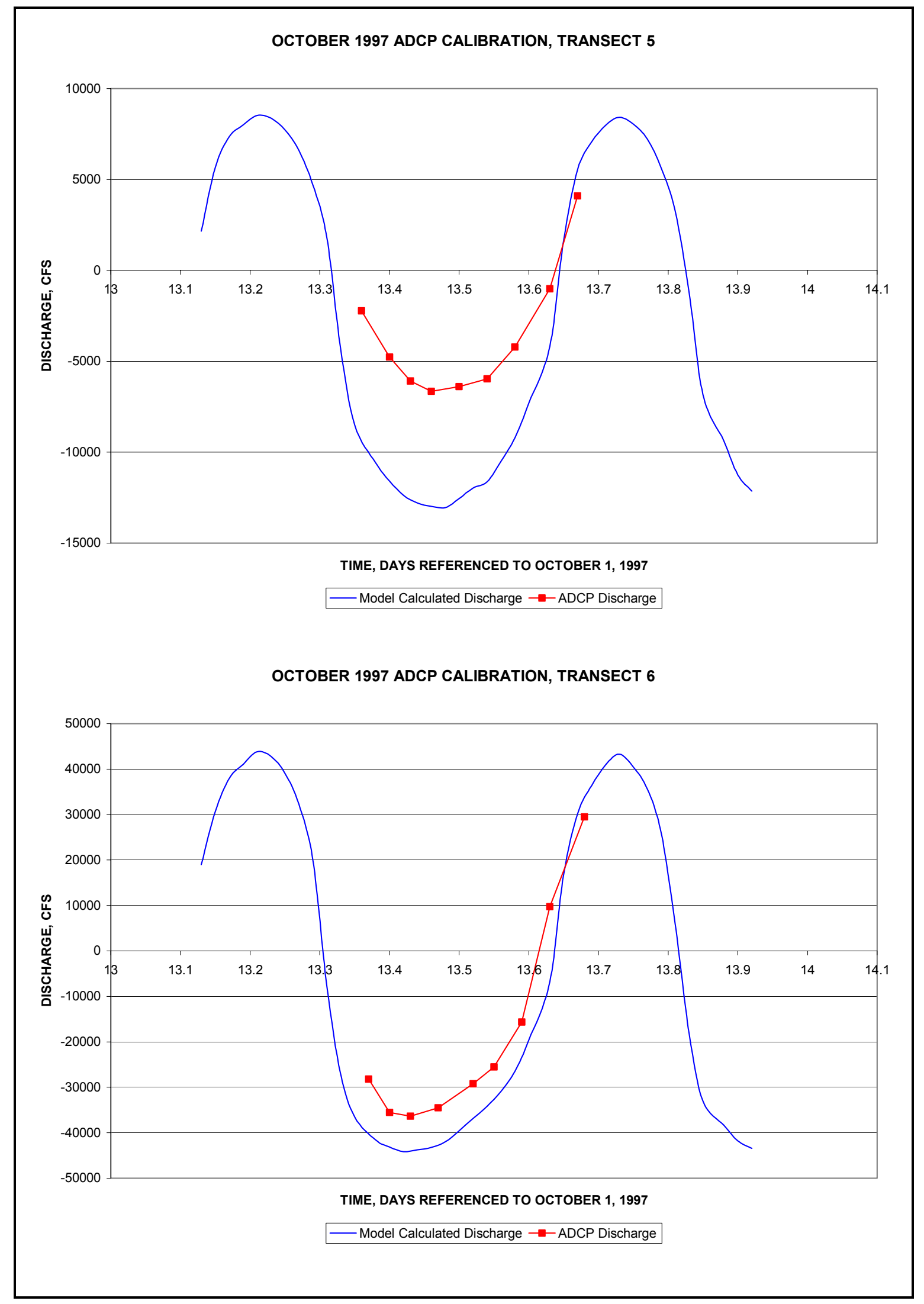

Plate 35 


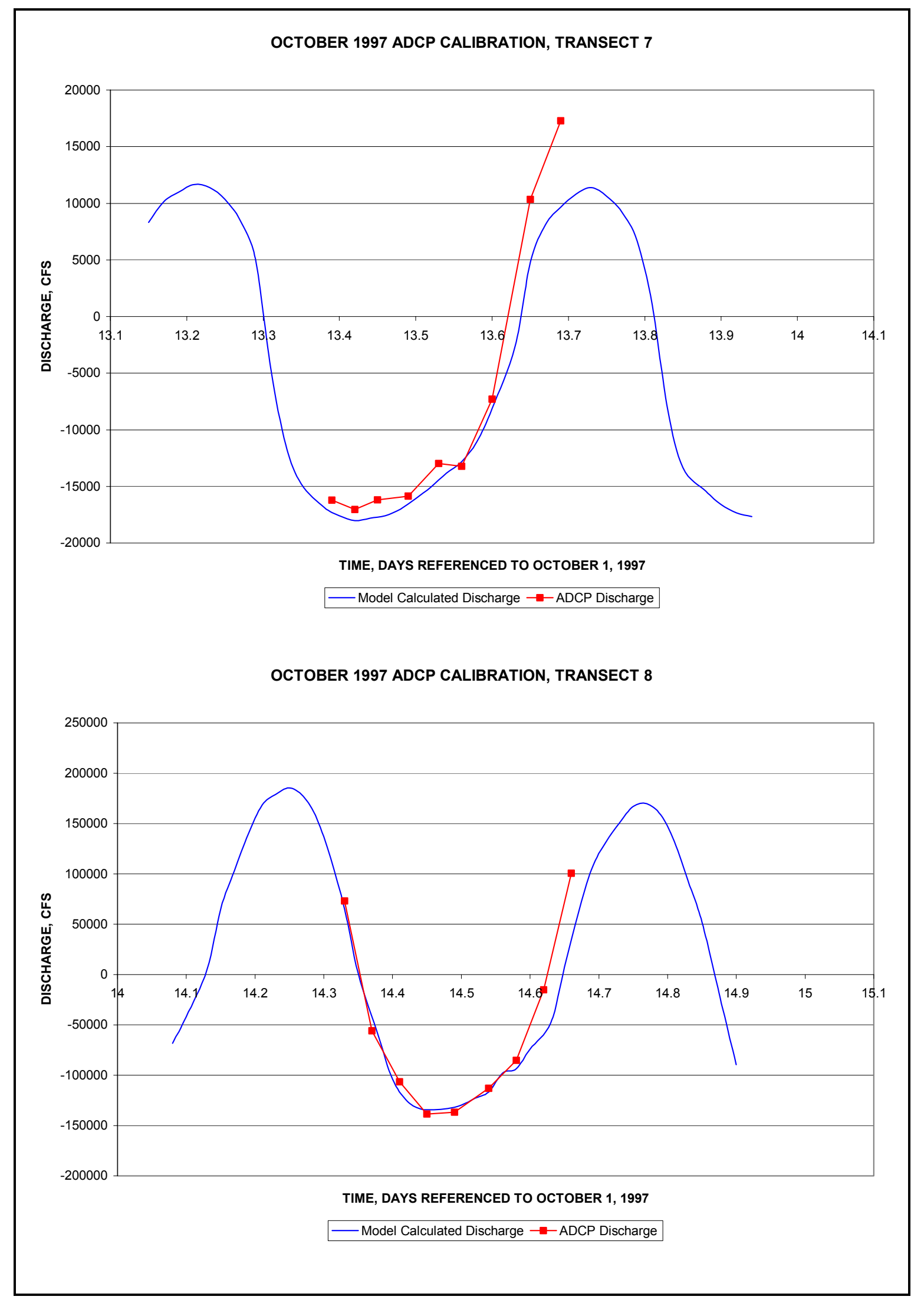

Plate 36 


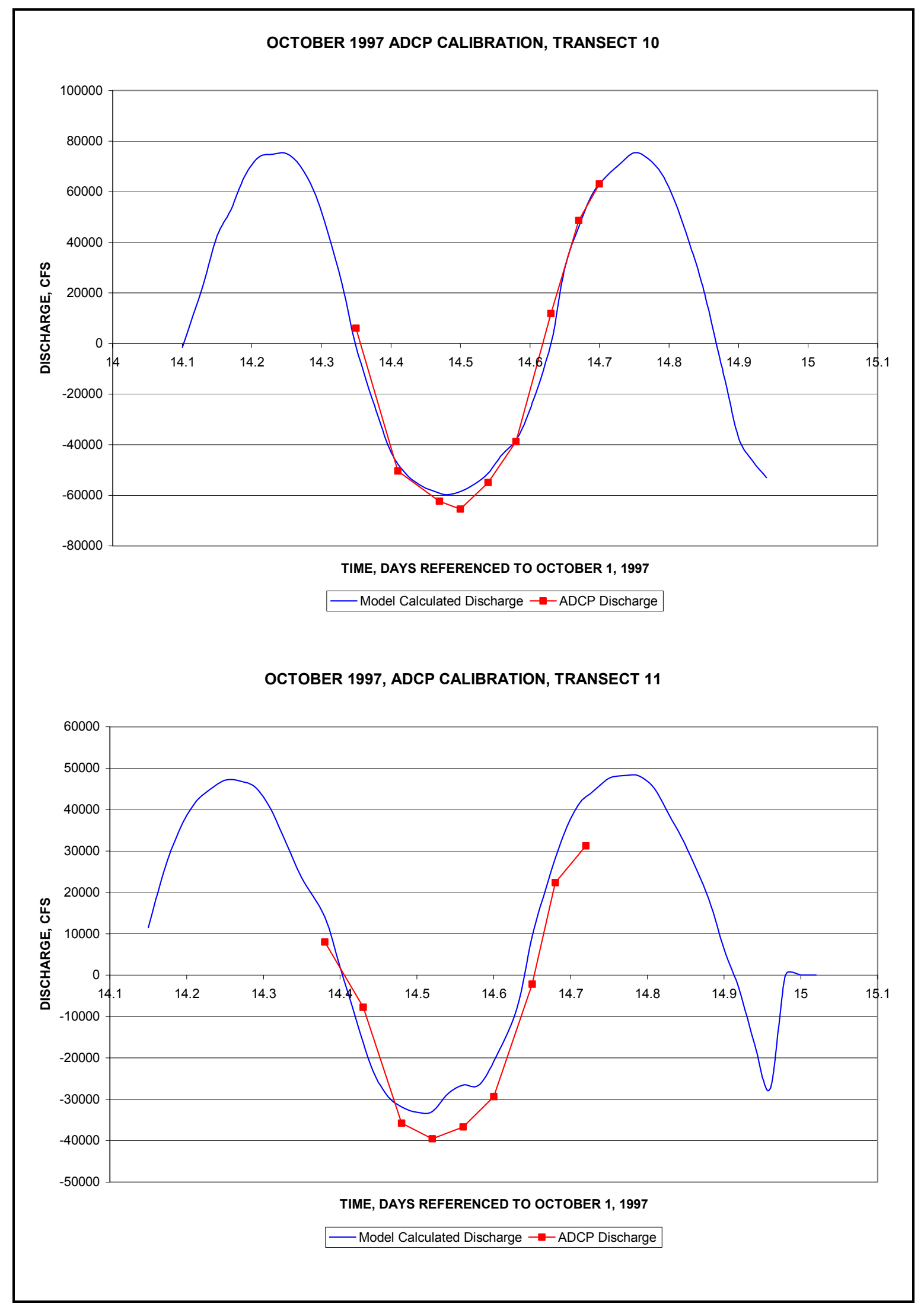

Plate 37 


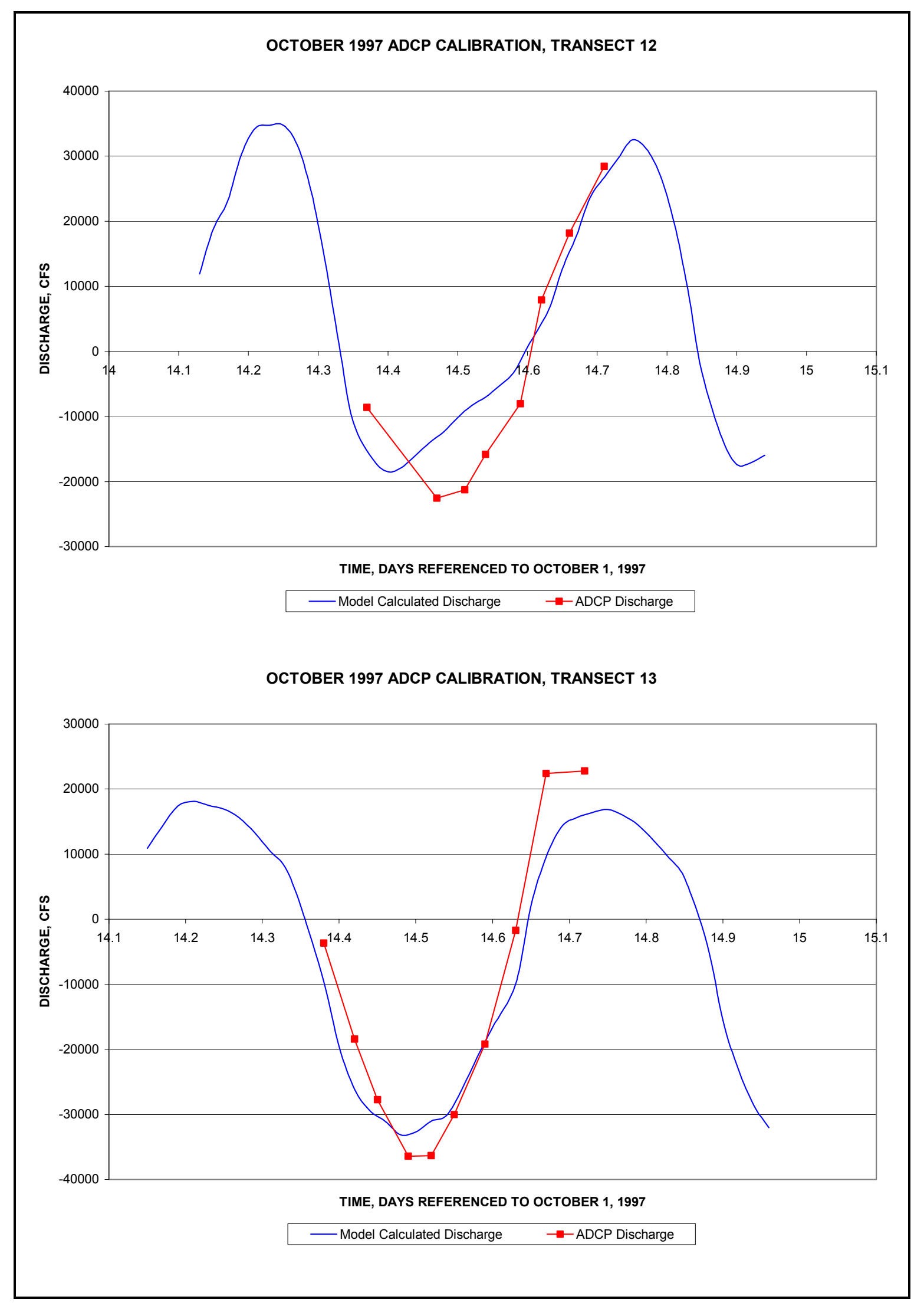

Plate 38 


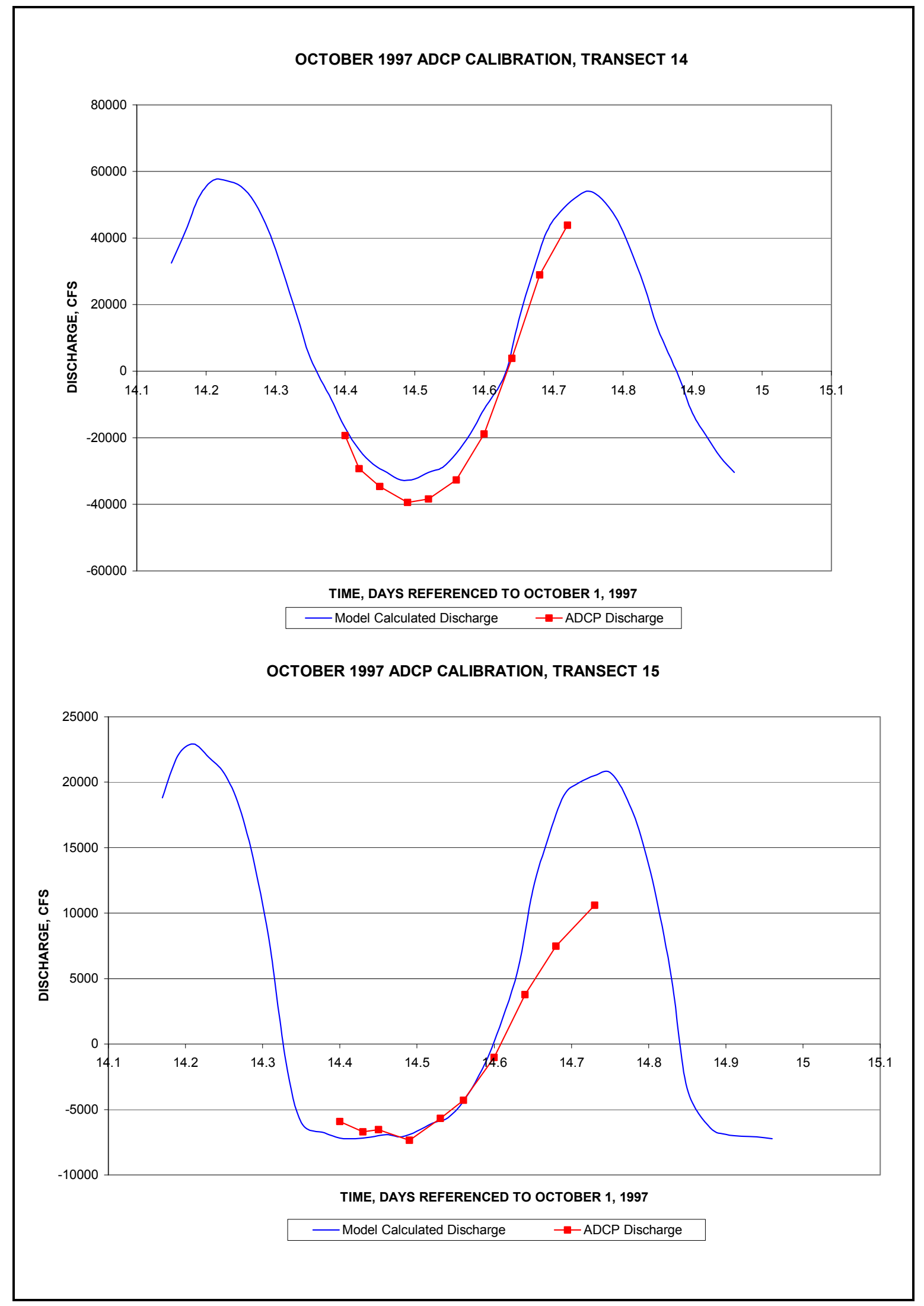

Plate 39 


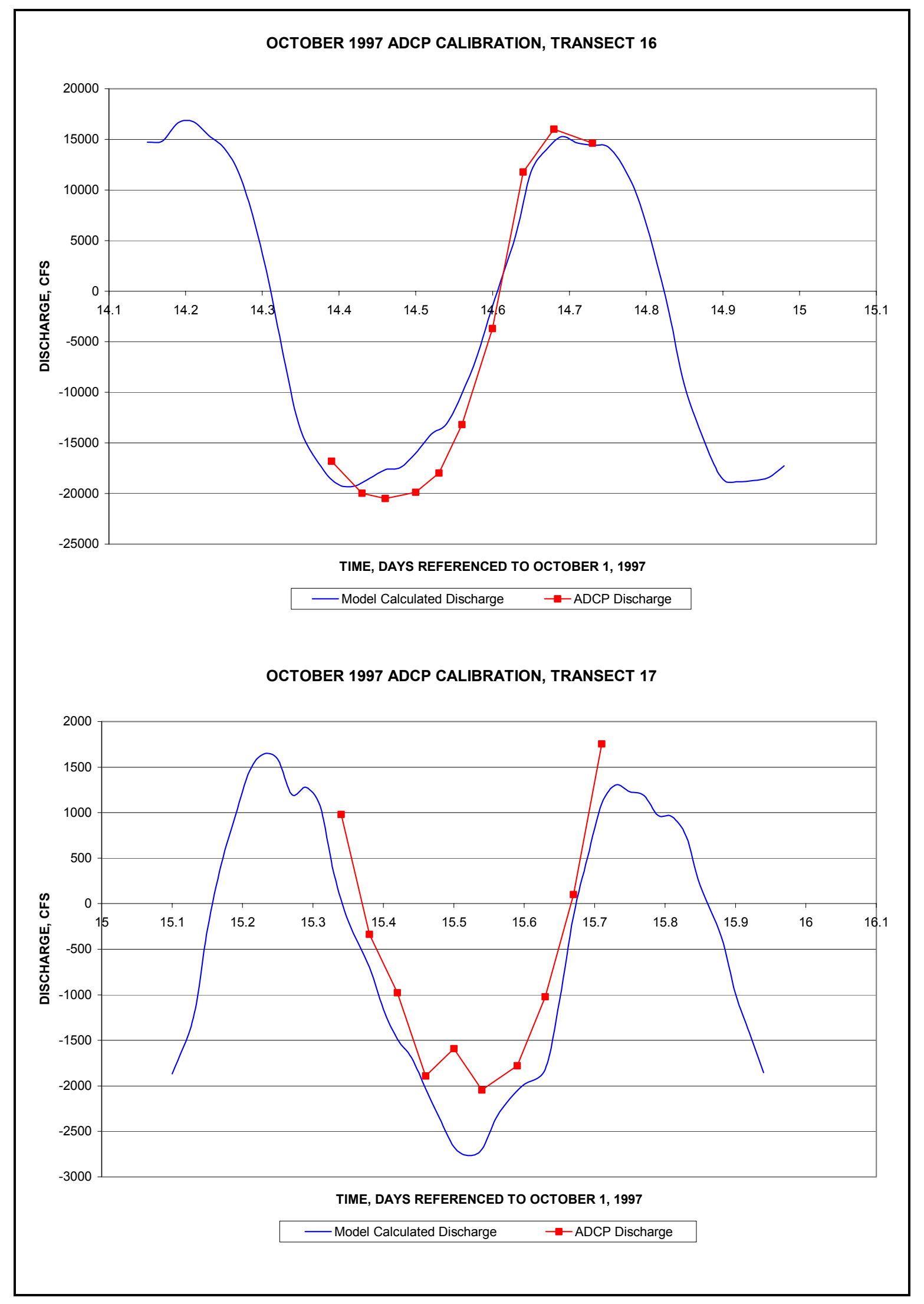

Plate 40 


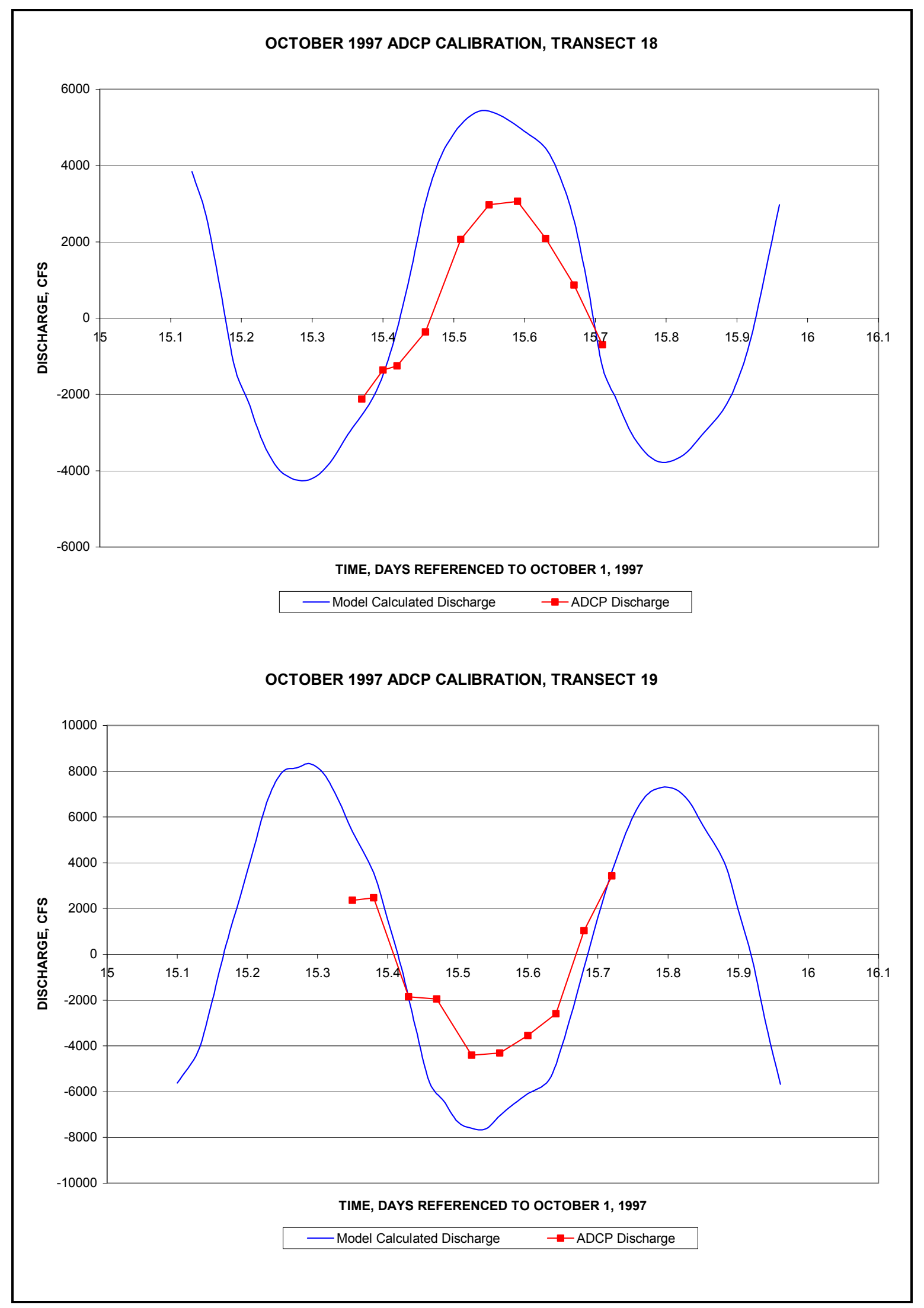

Plate 41 


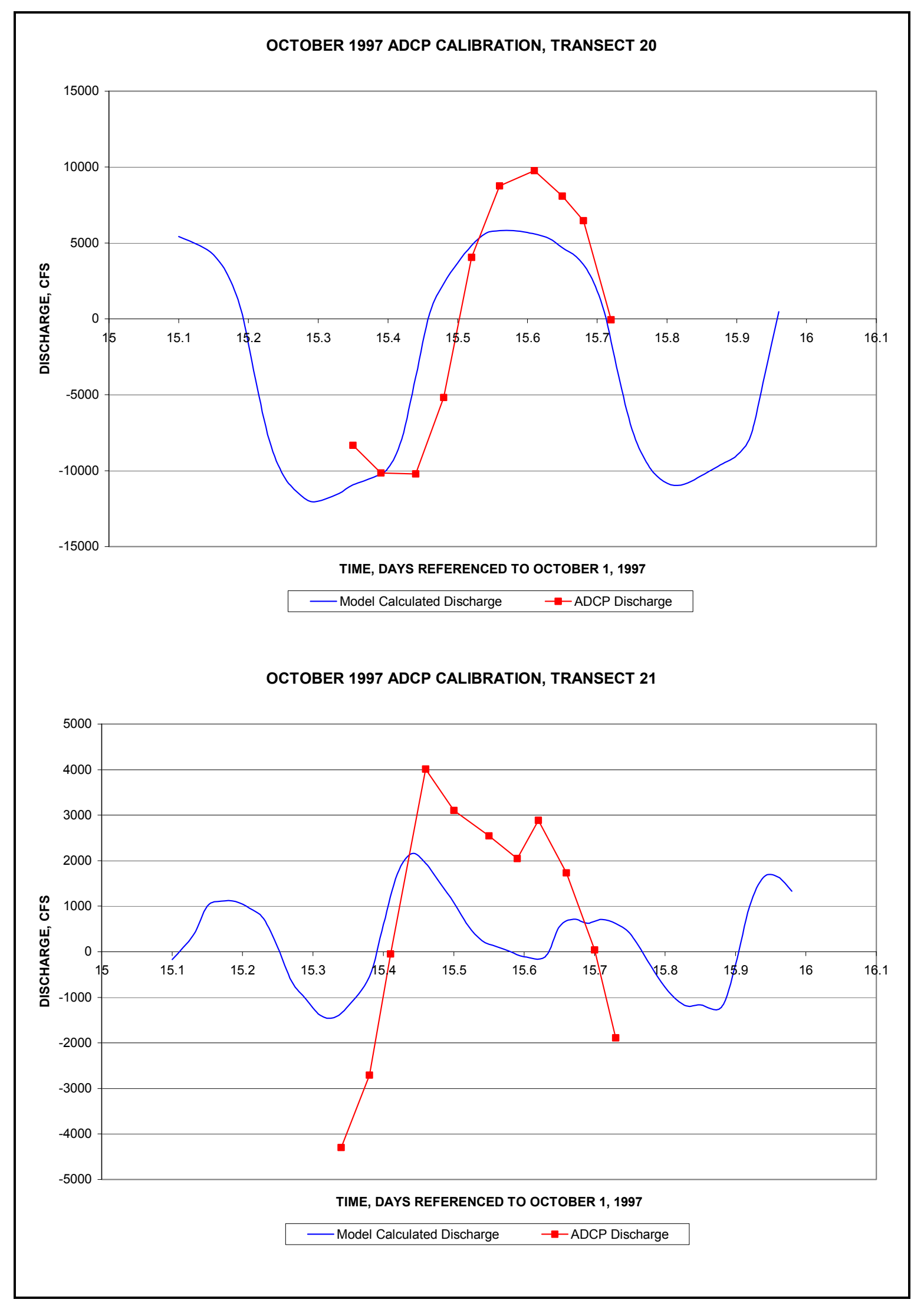

Plate 42 


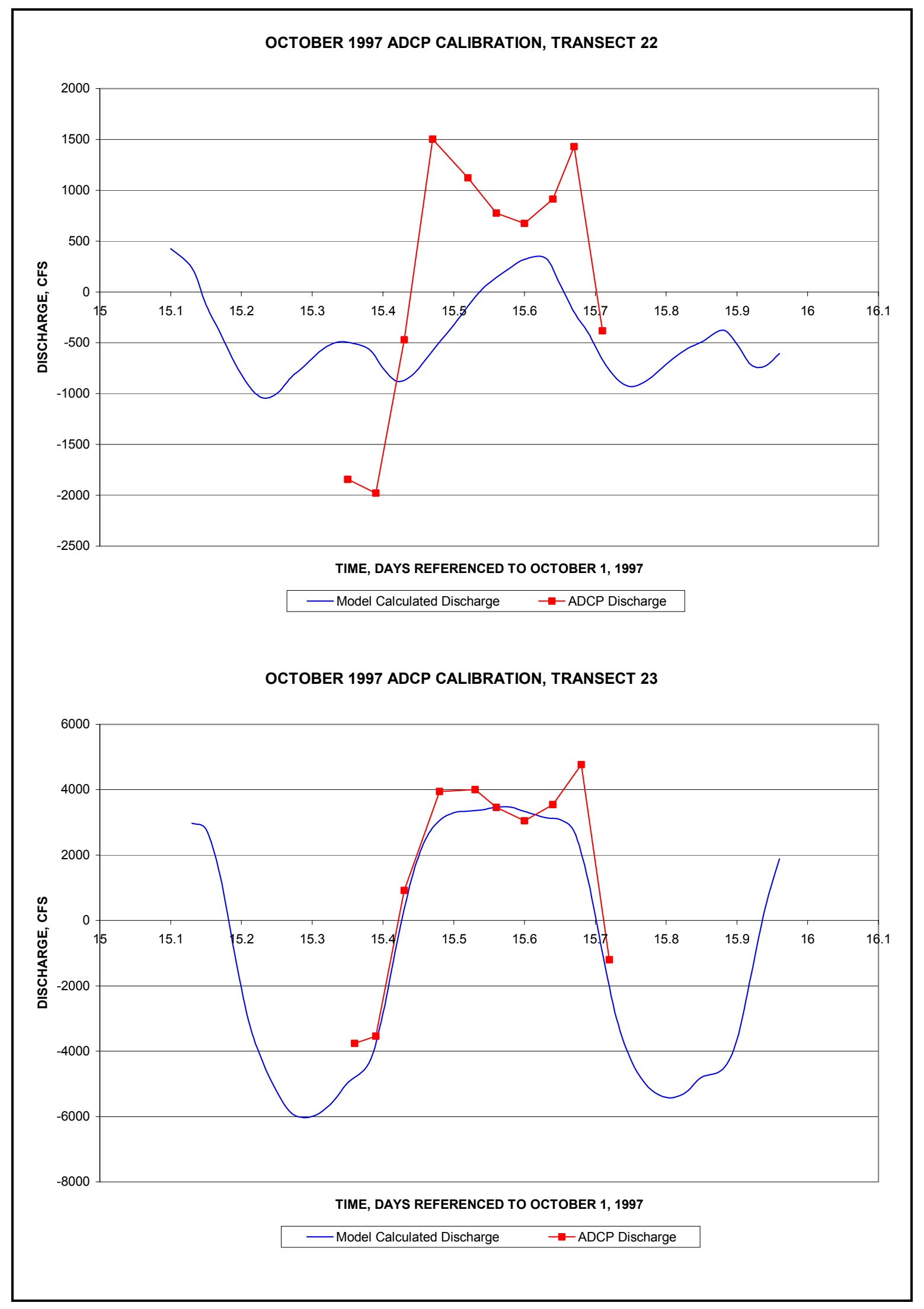

Plate 43 


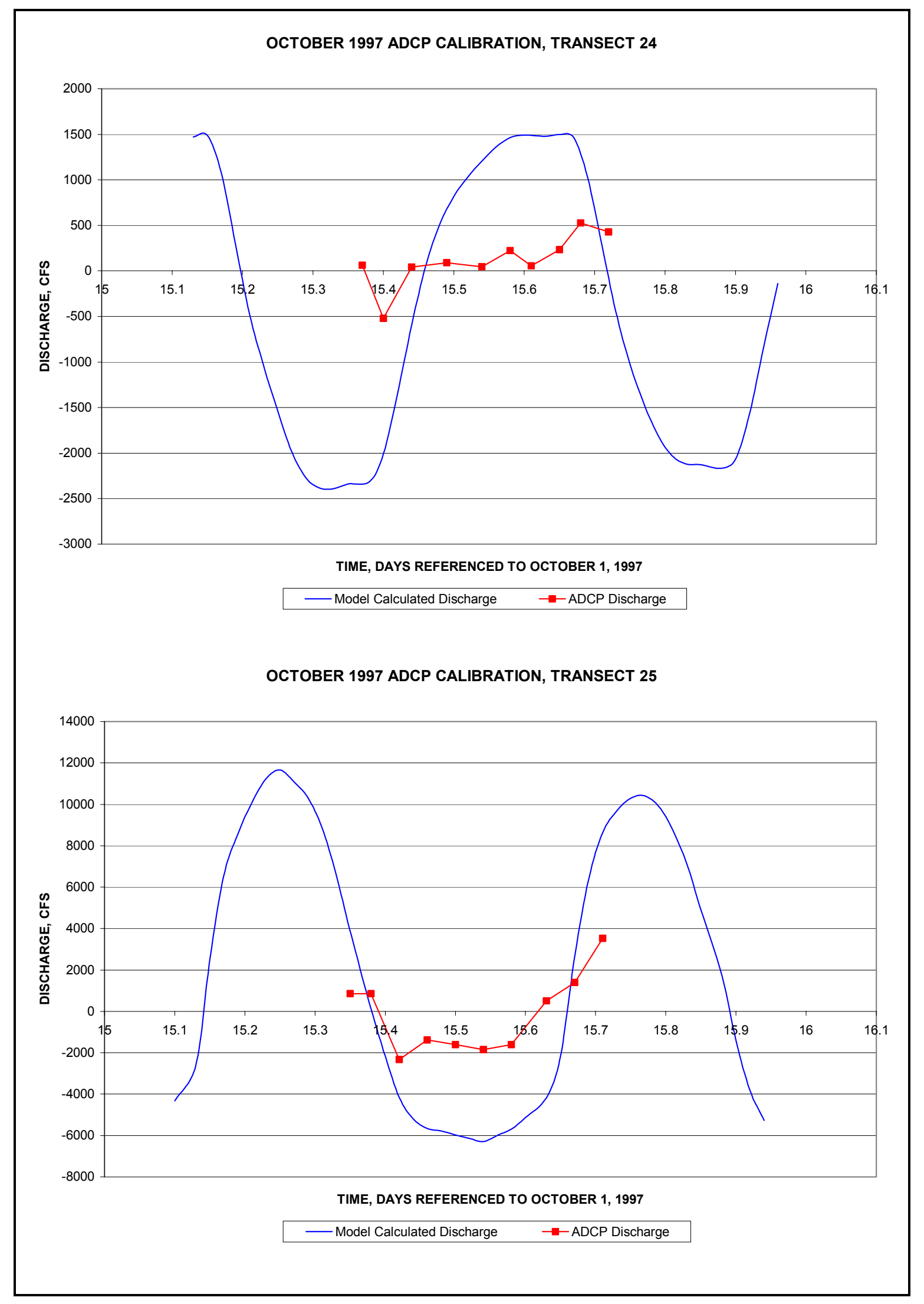

Plate 44 


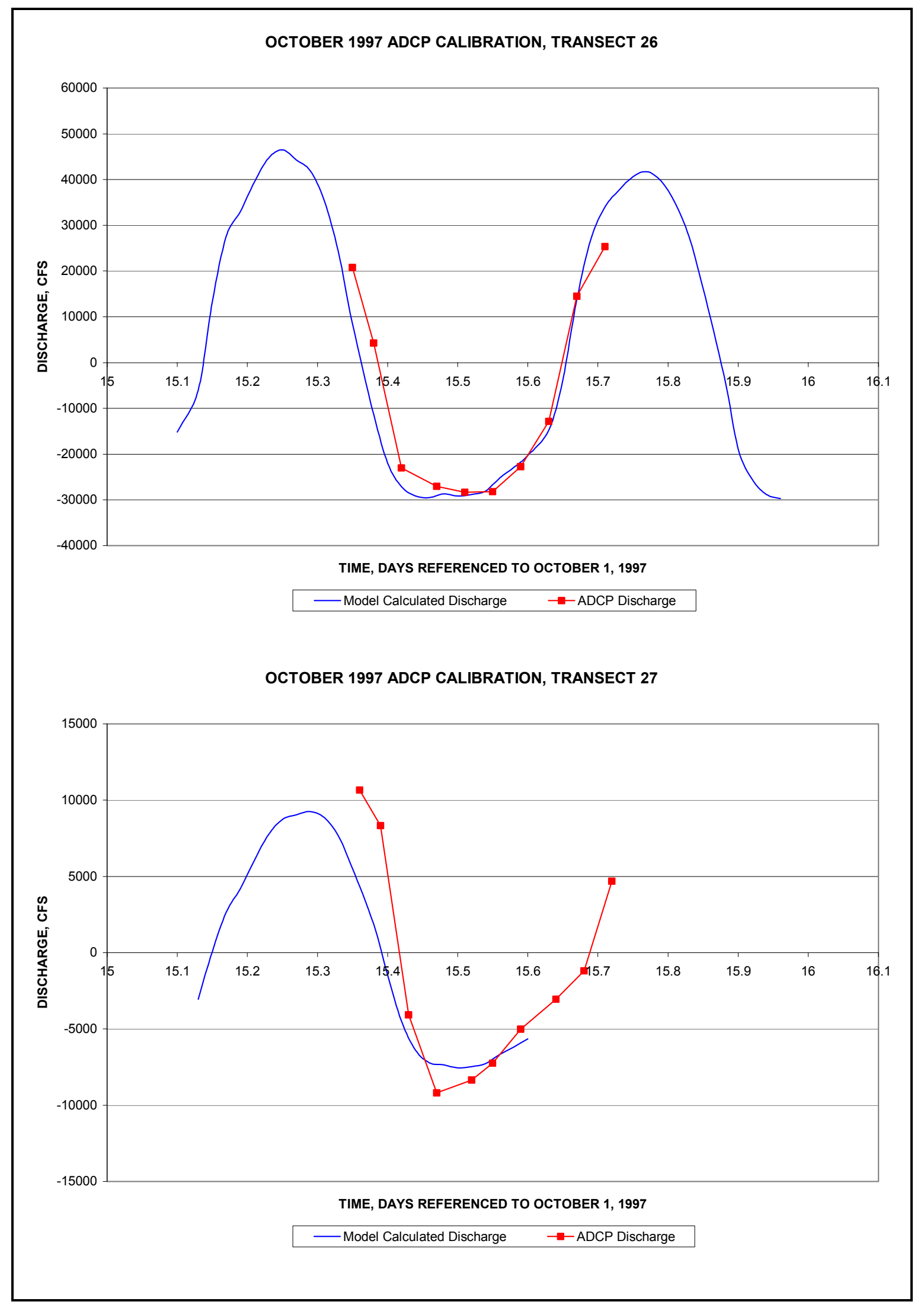

Plate 45 
FEBRUARY 1998 ADCP VERIFICATION, TRANSECT 1

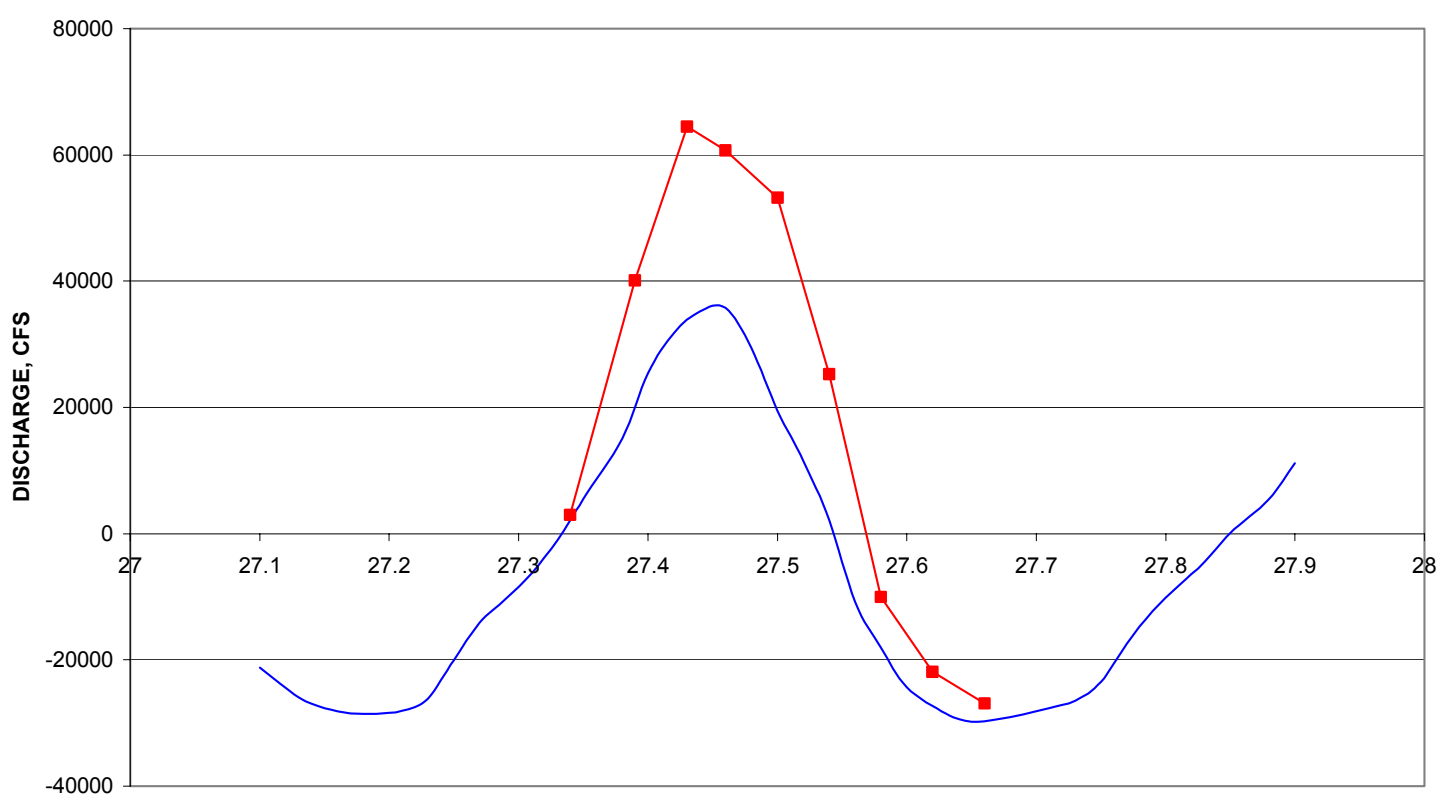

TIME, DAYS REFERENCED TO FEBRUARY 1, 1998

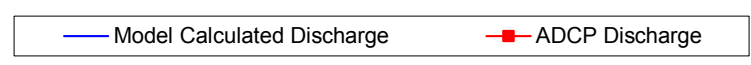

FEBRUARY 1998 ADCP VERIFICATION, TRANSECT 2

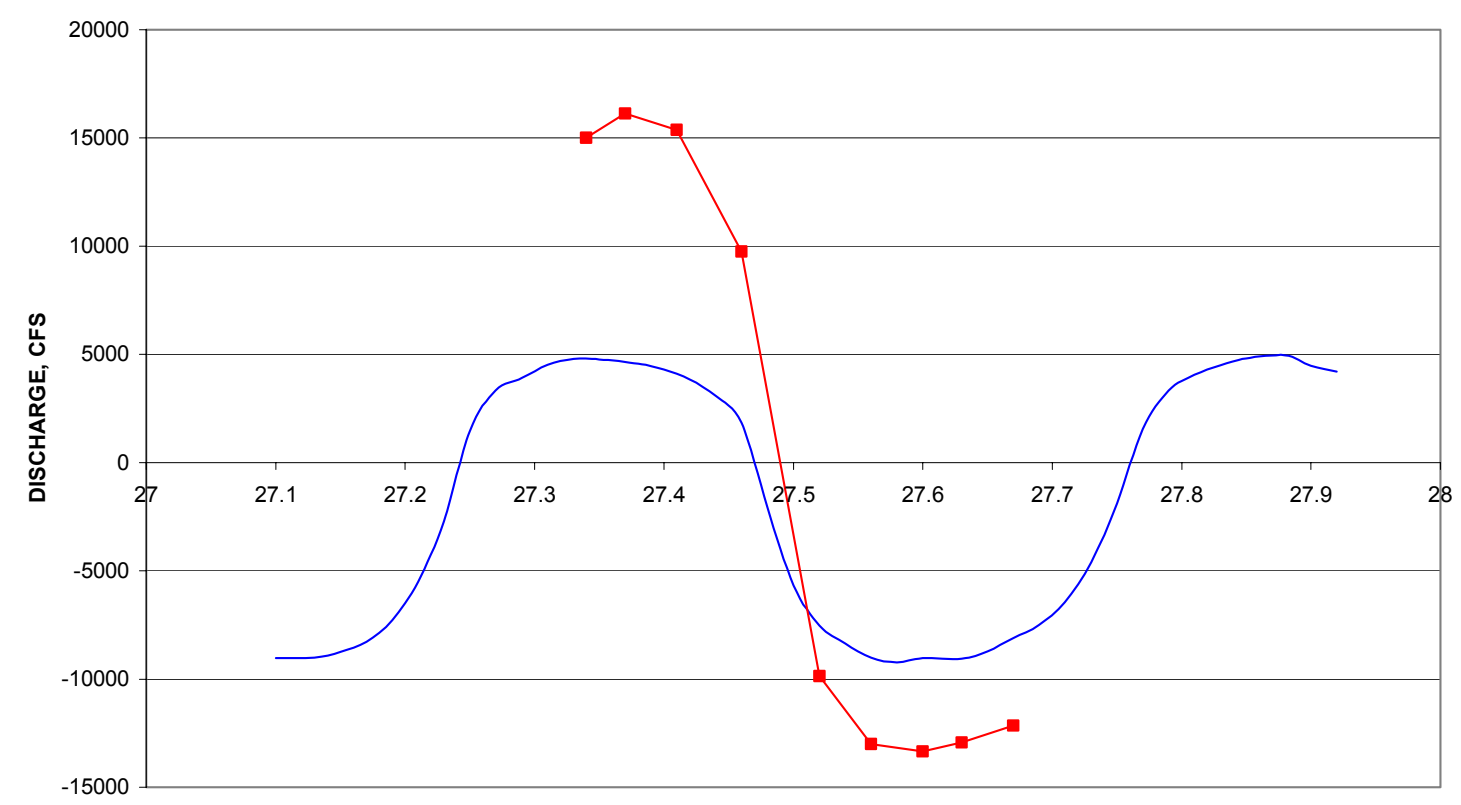

TIME, DAYS REFERENCED TO FEBRUARY 1, 1998

-Model Calculated Discharge $\rightarrow$ ADCP Discharge

\section{Plate 46}




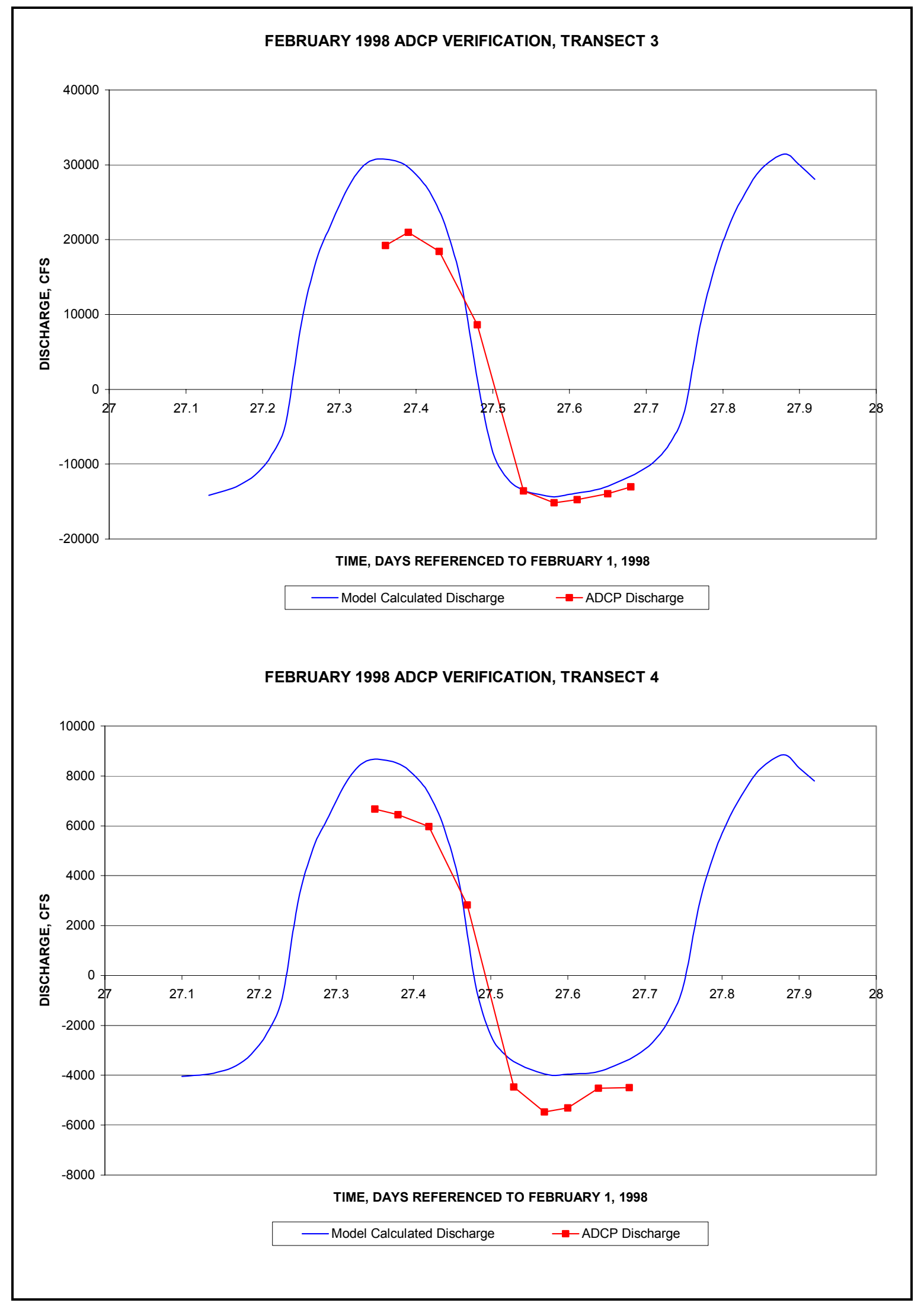

Plate 47 


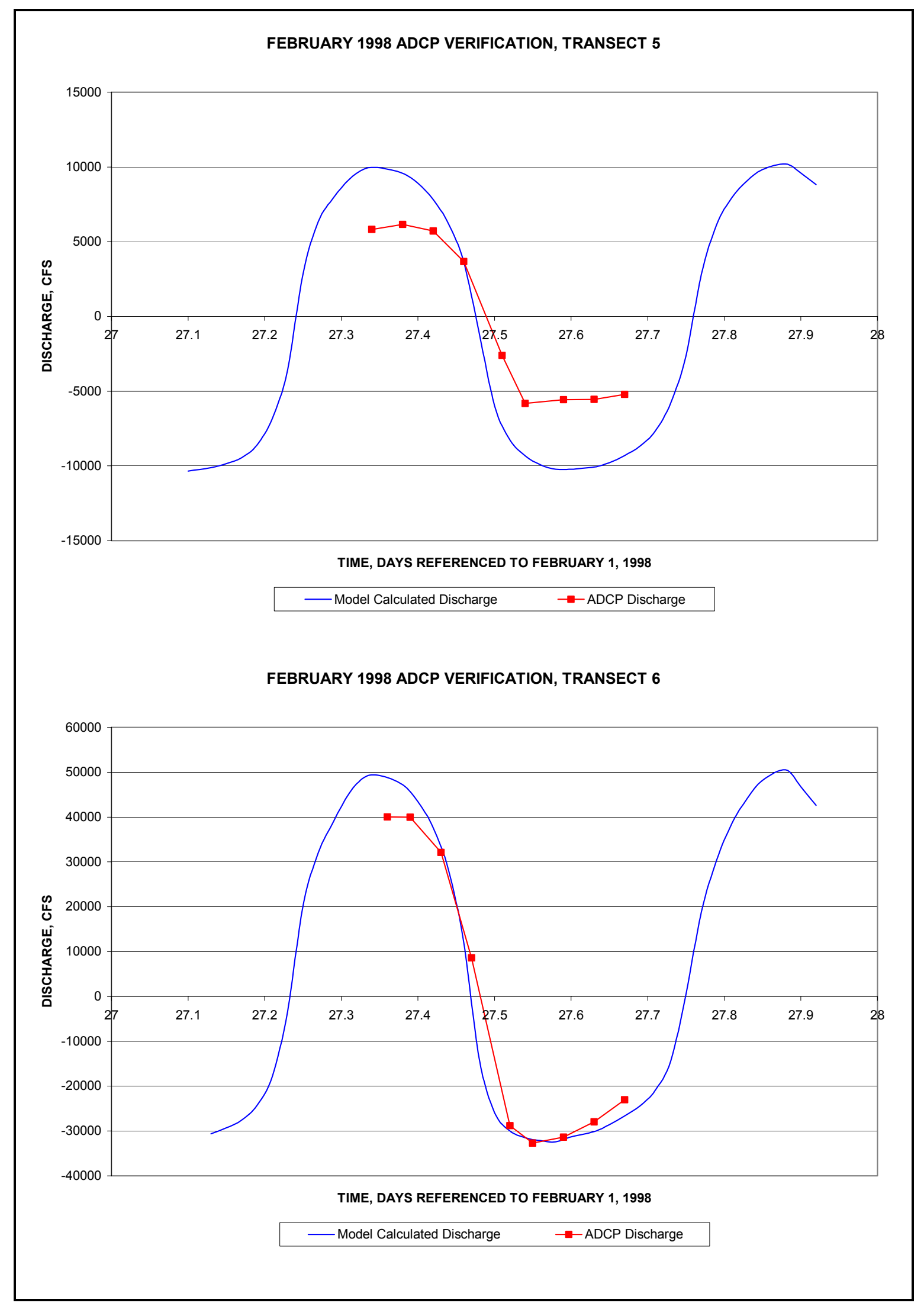

Plate 48 


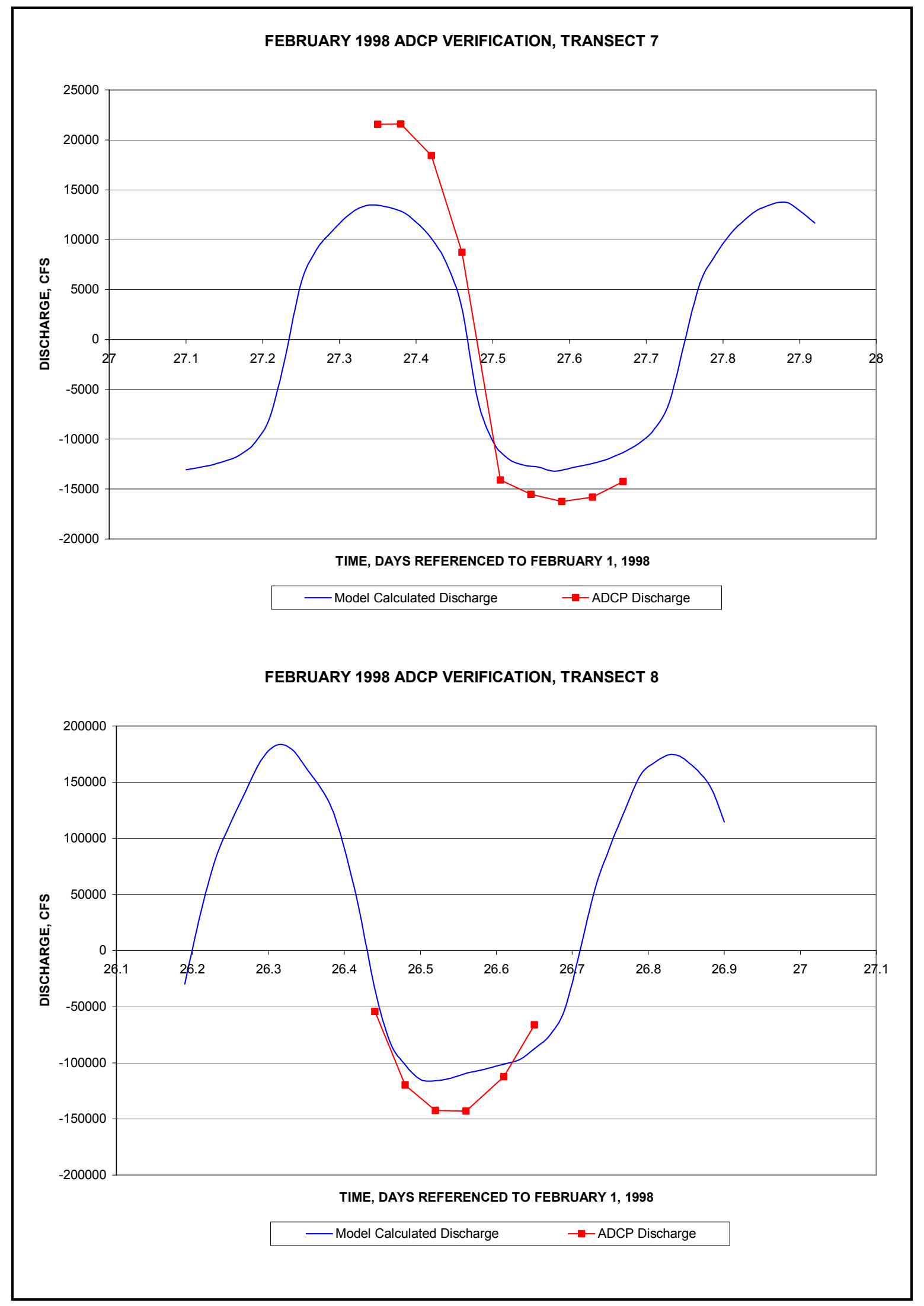

Plate 49 


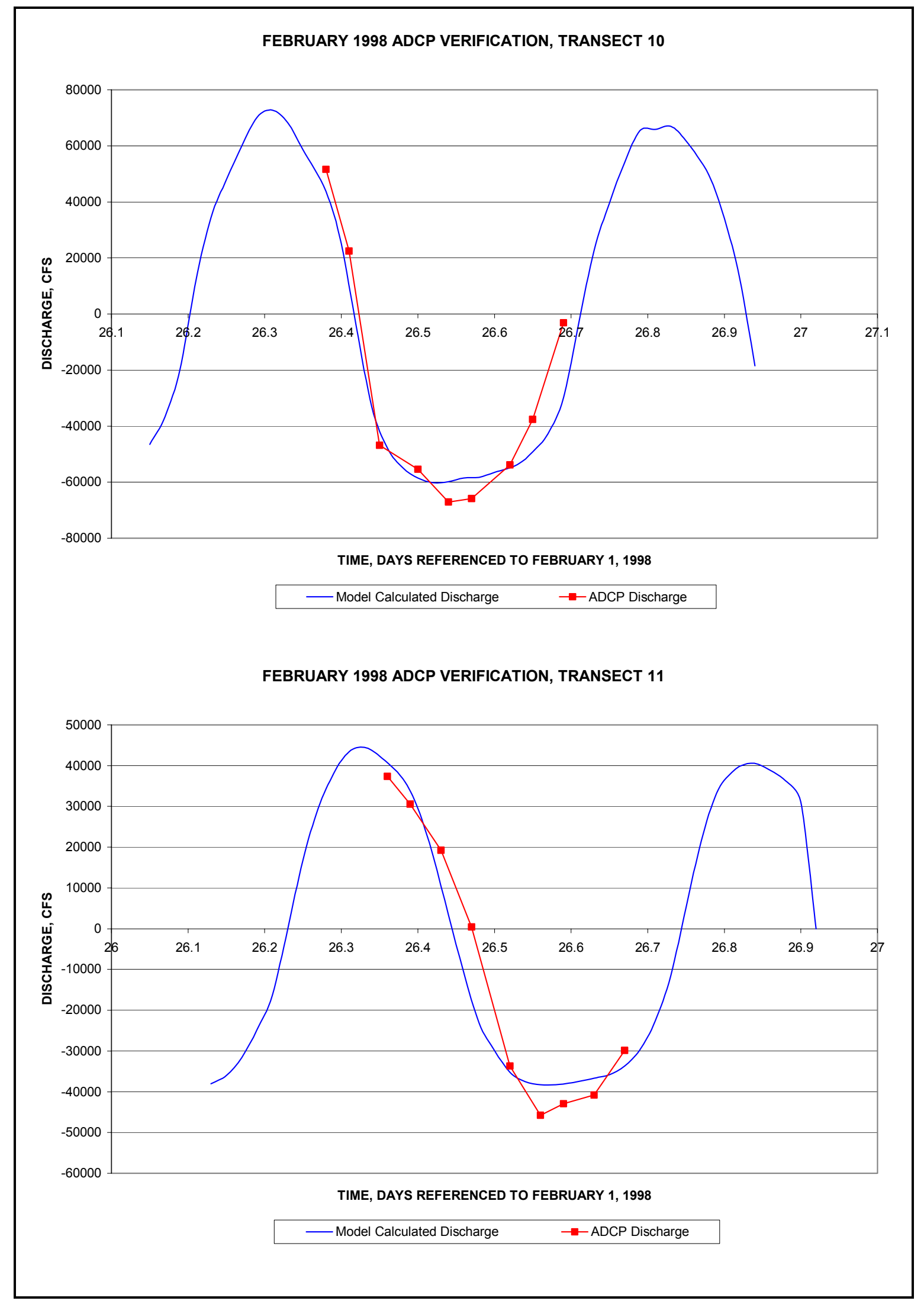

Plate 50 


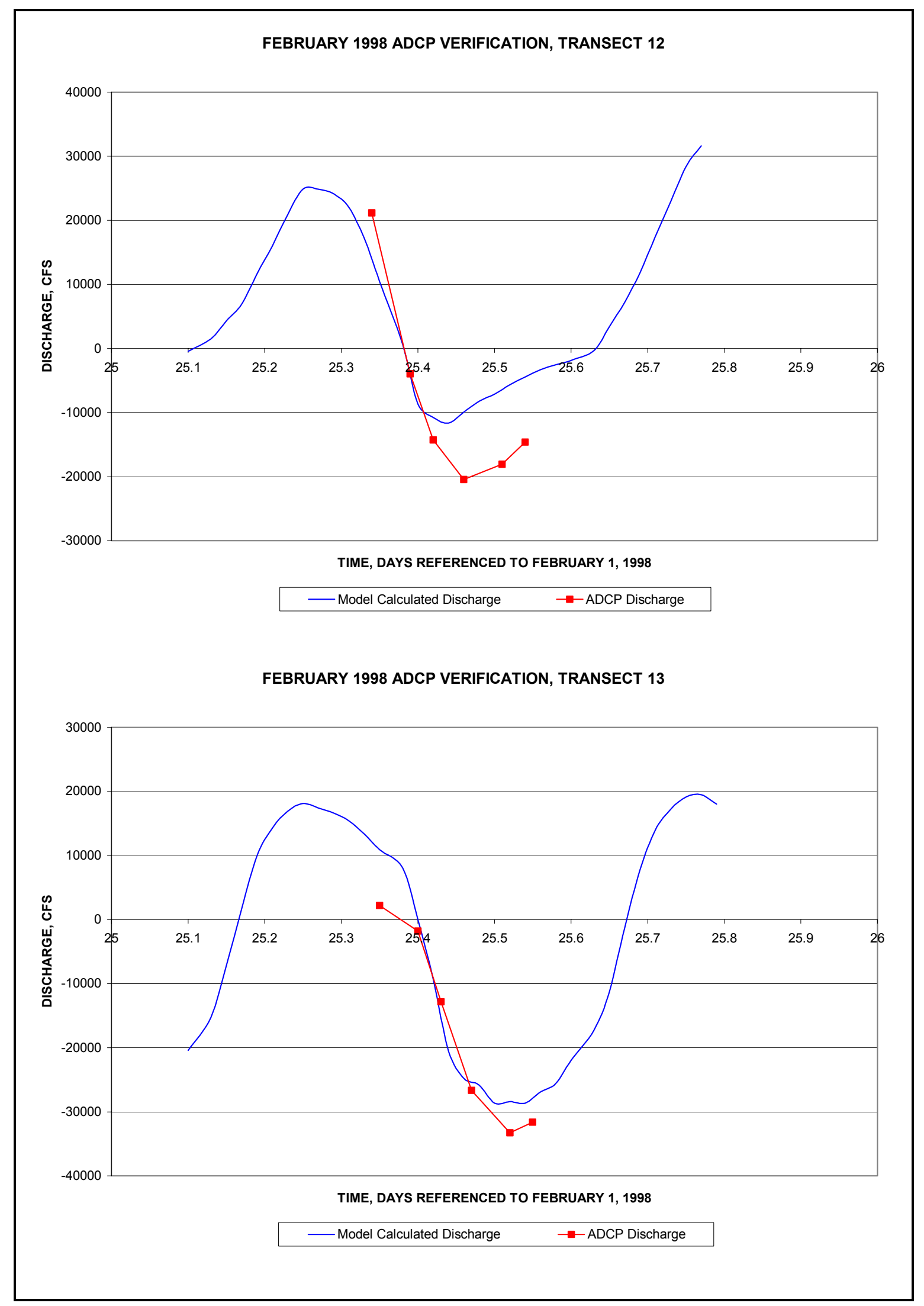

Plate 51 


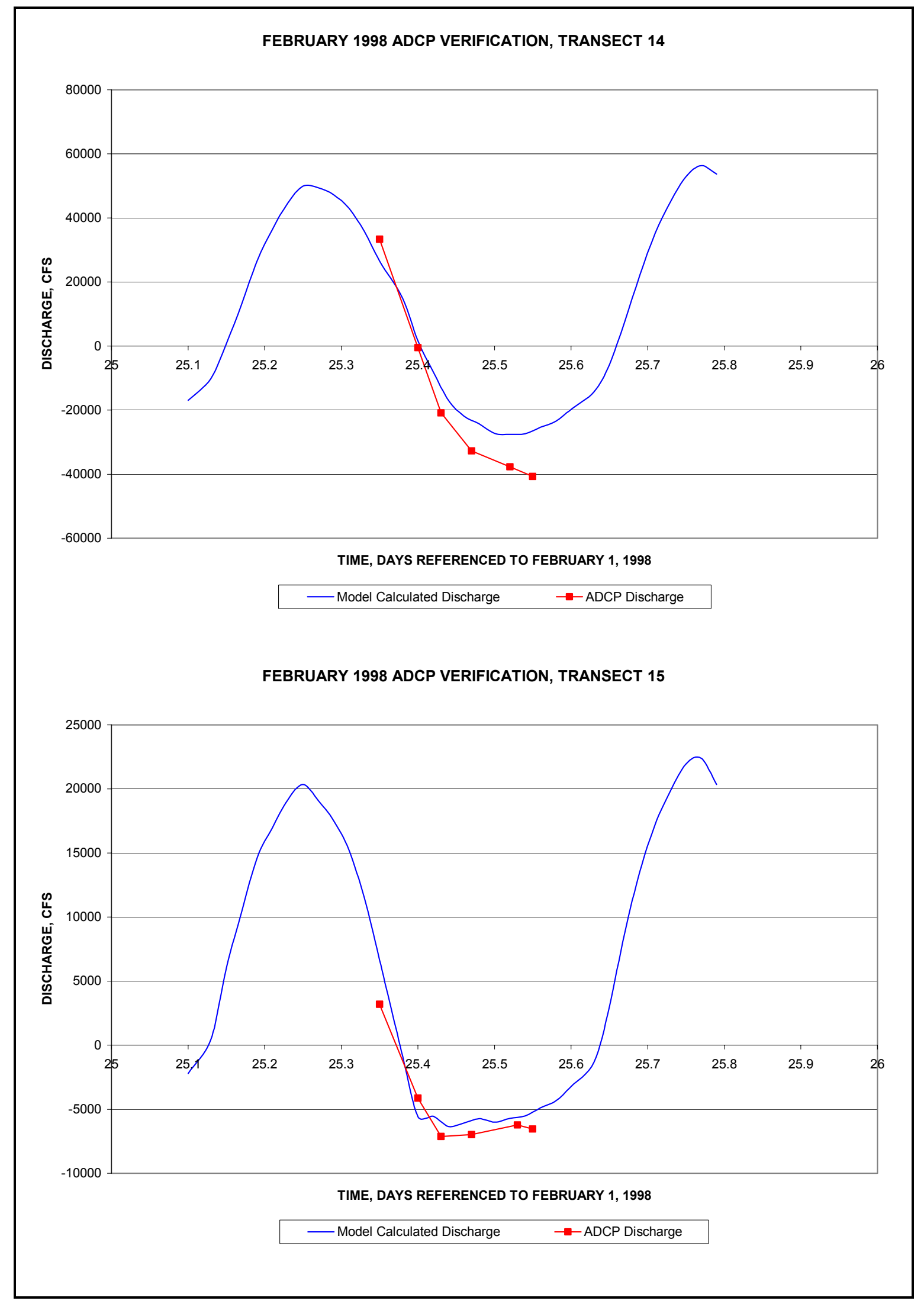

Plate 52 


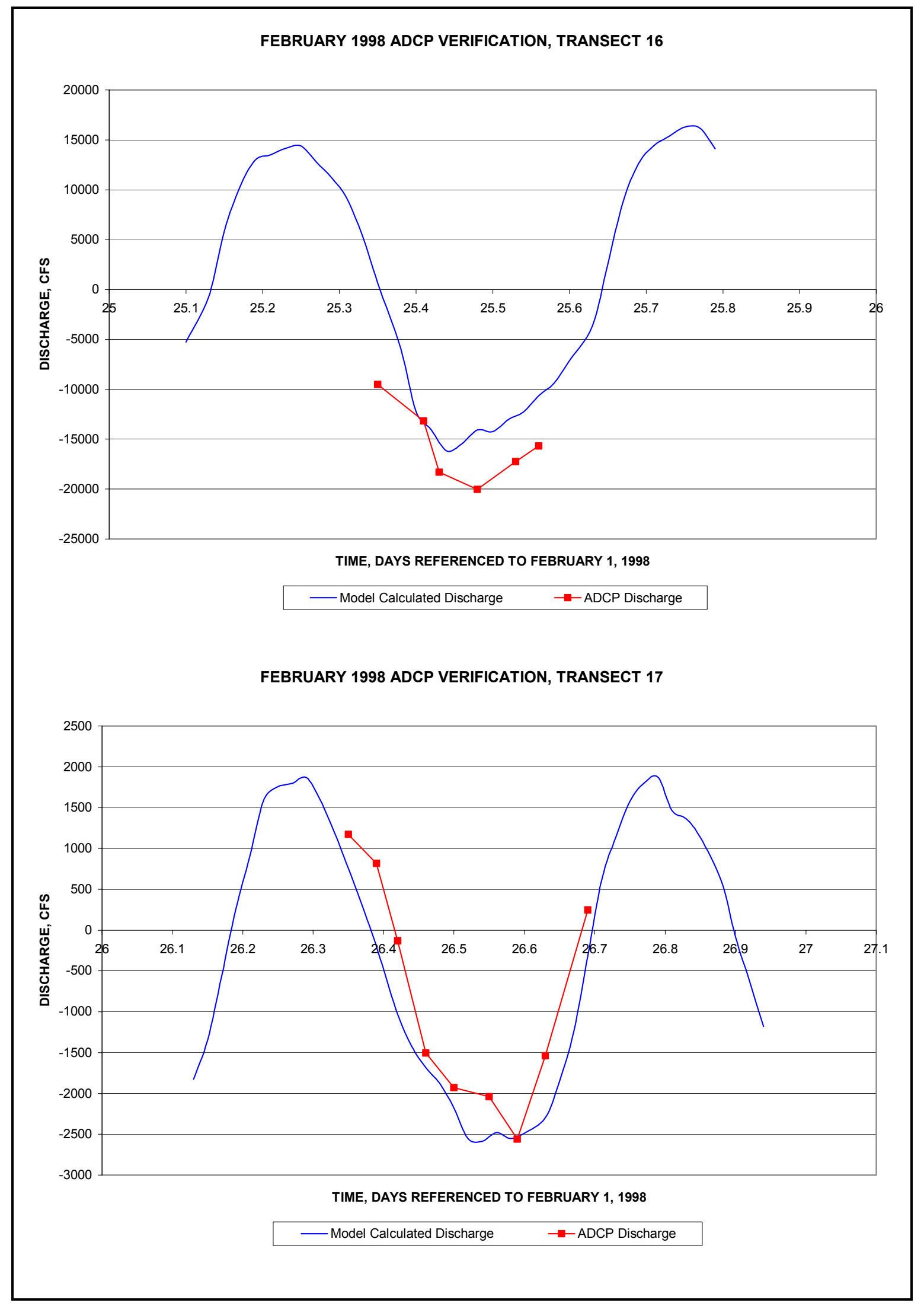

Plate 53 


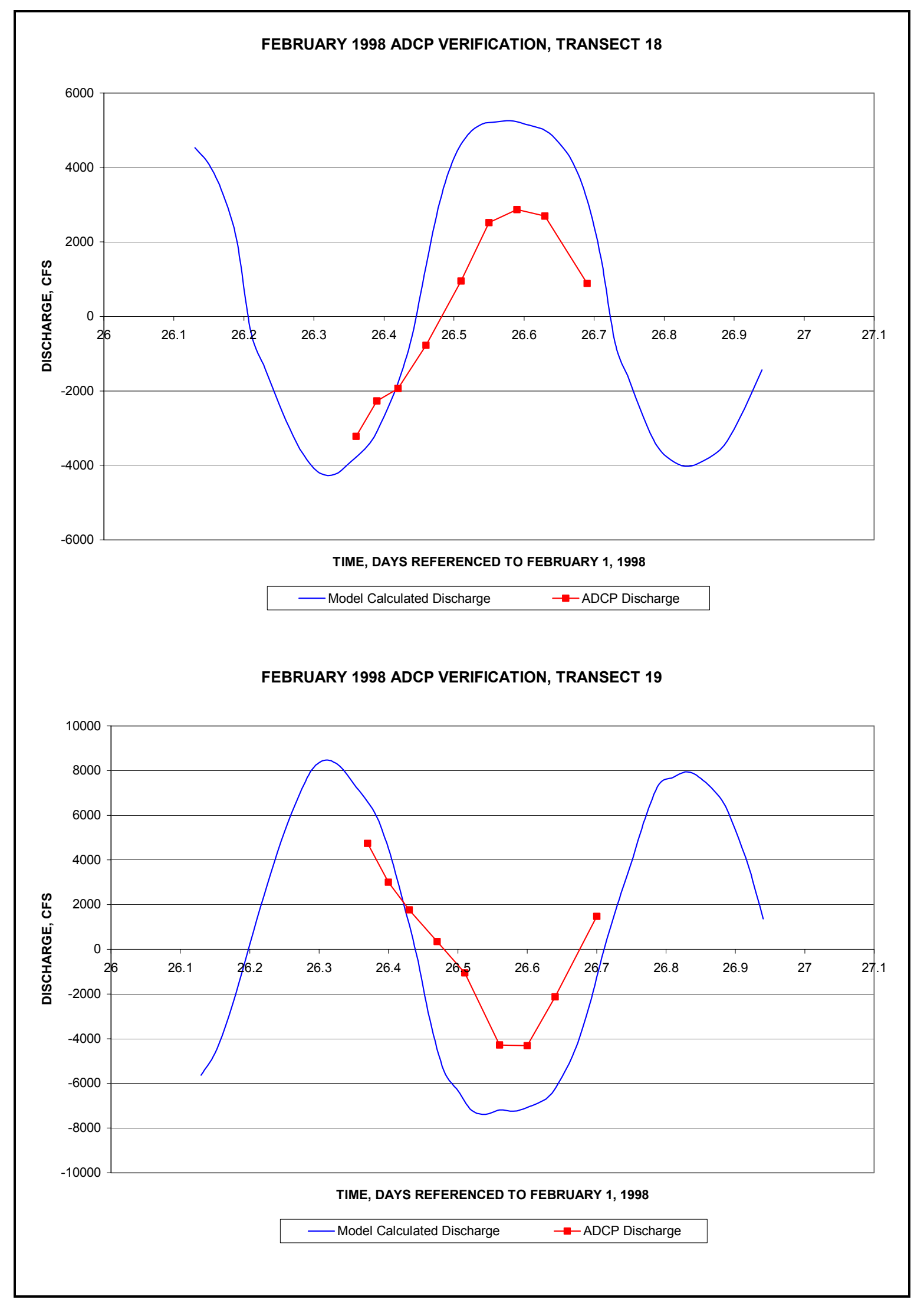

Plate 54 


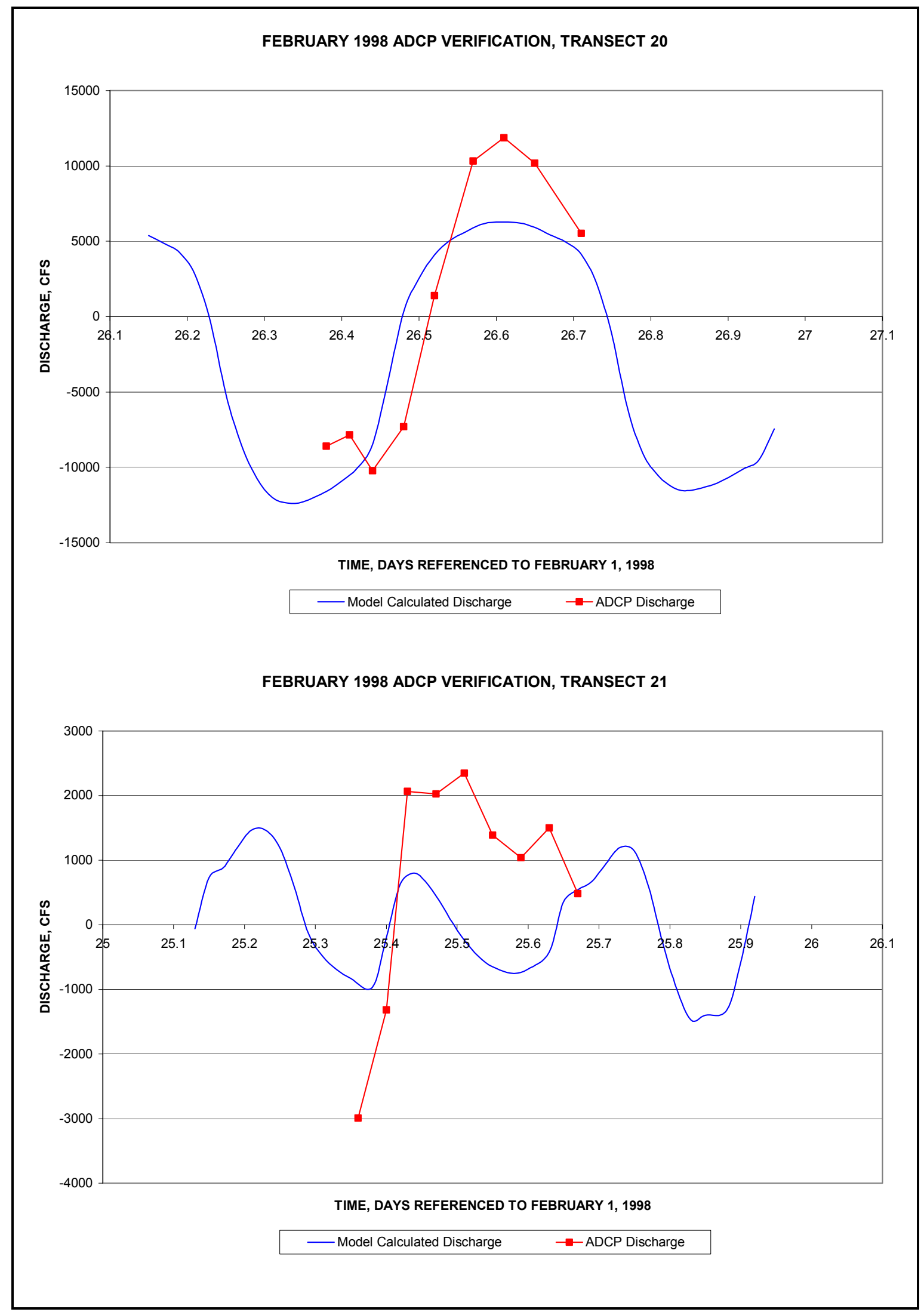

Plate 55 


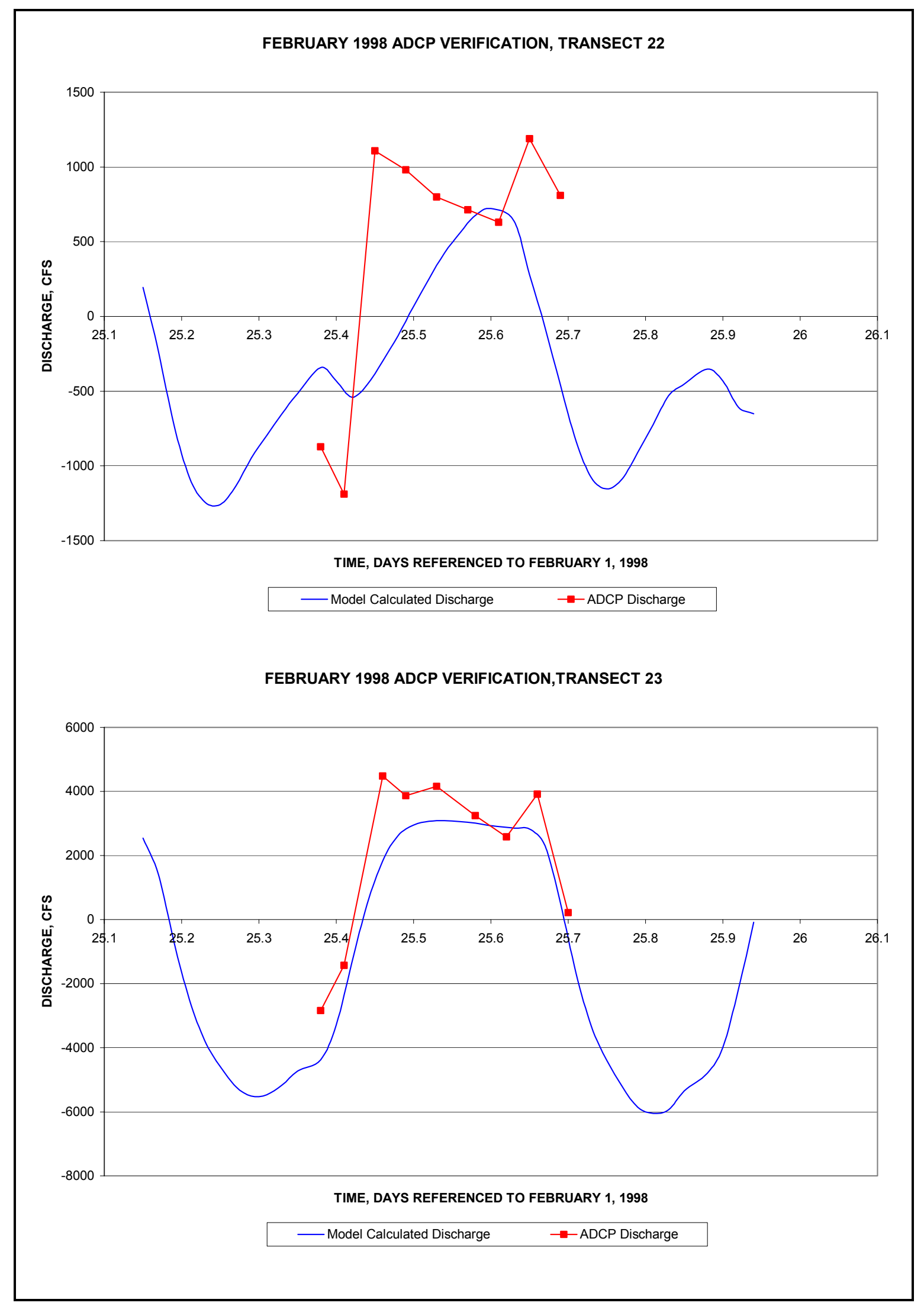

Plate 56 


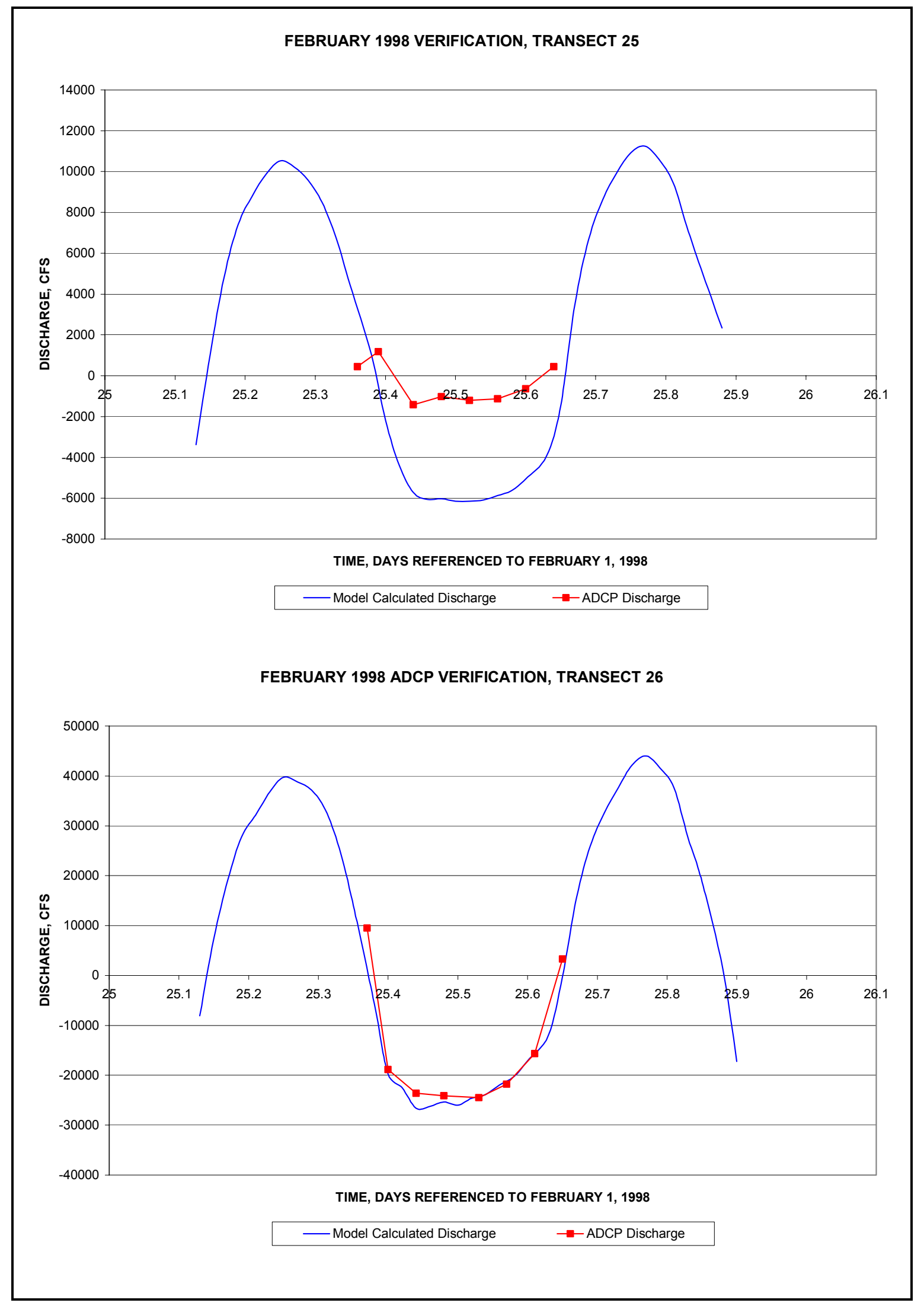

Plate 57 


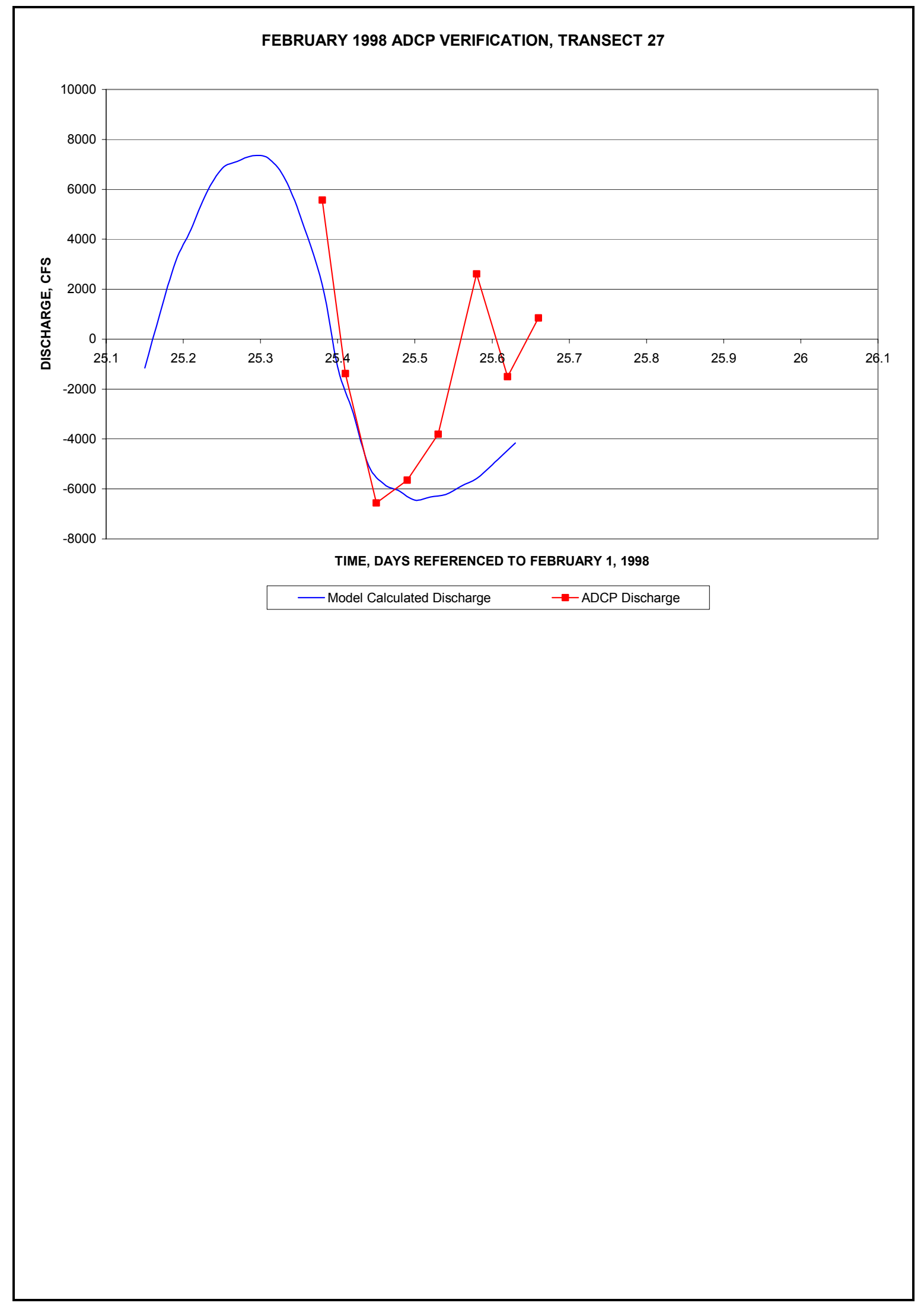

Plate 58 


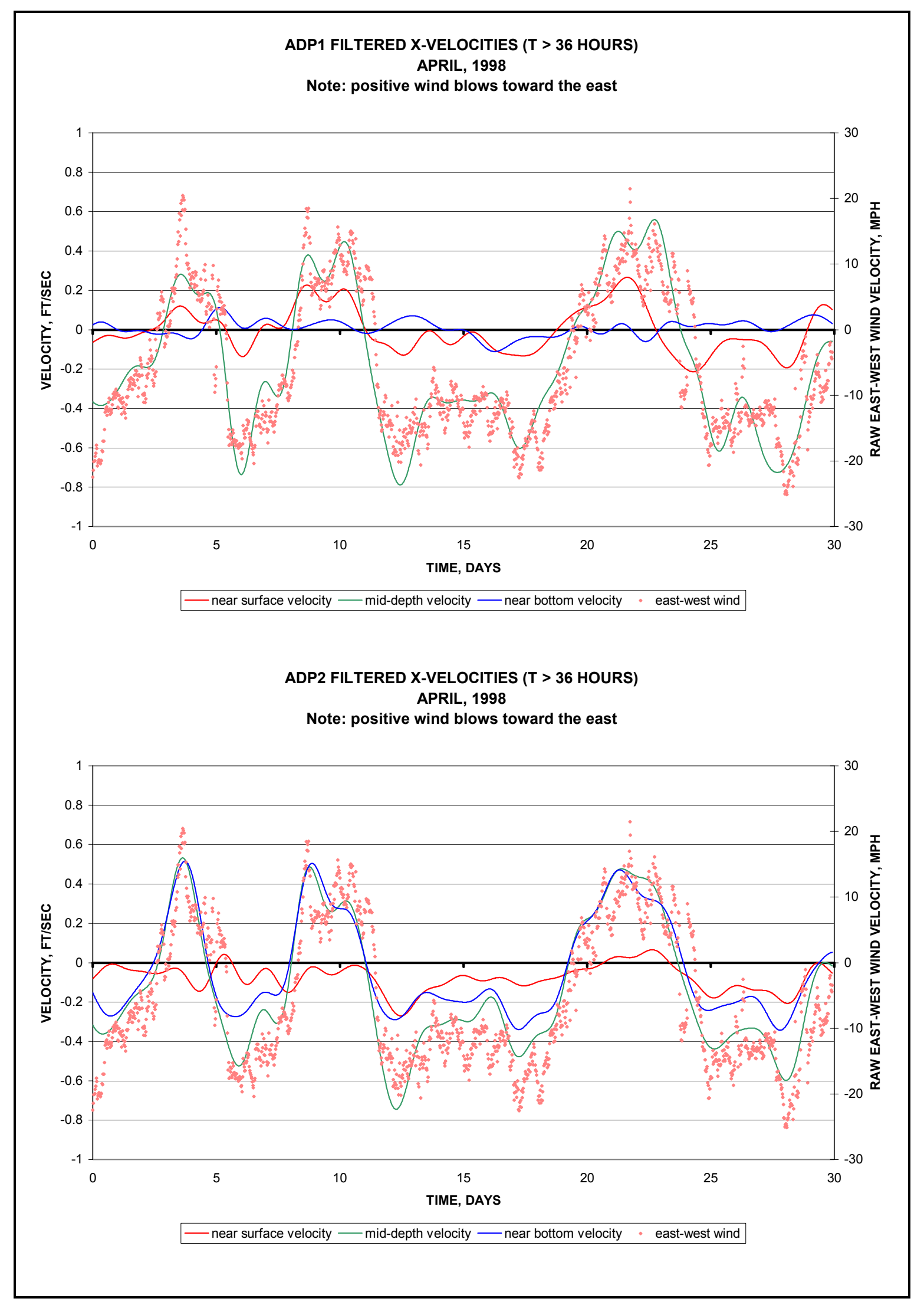

Plate 59 


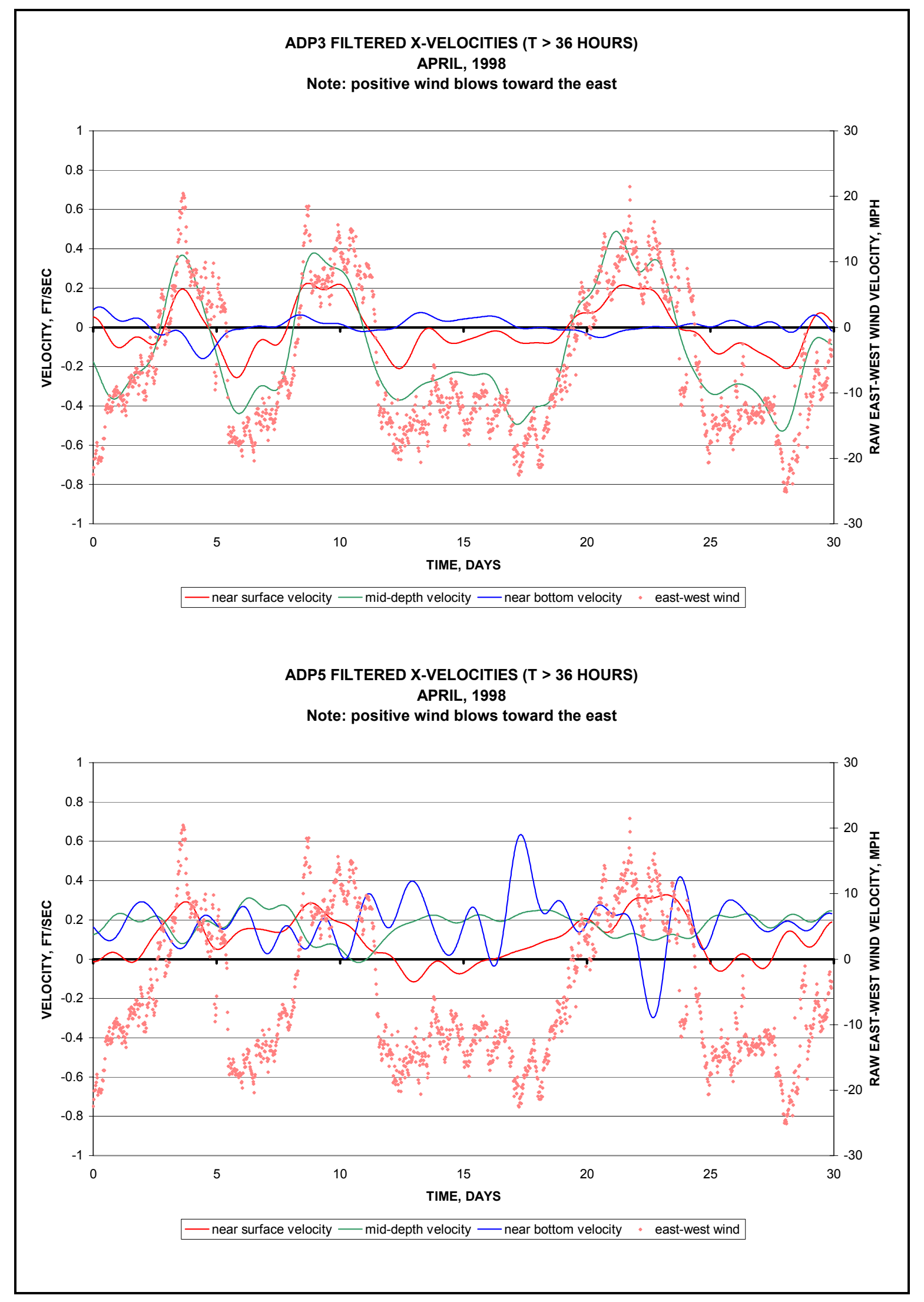

Plate 60 


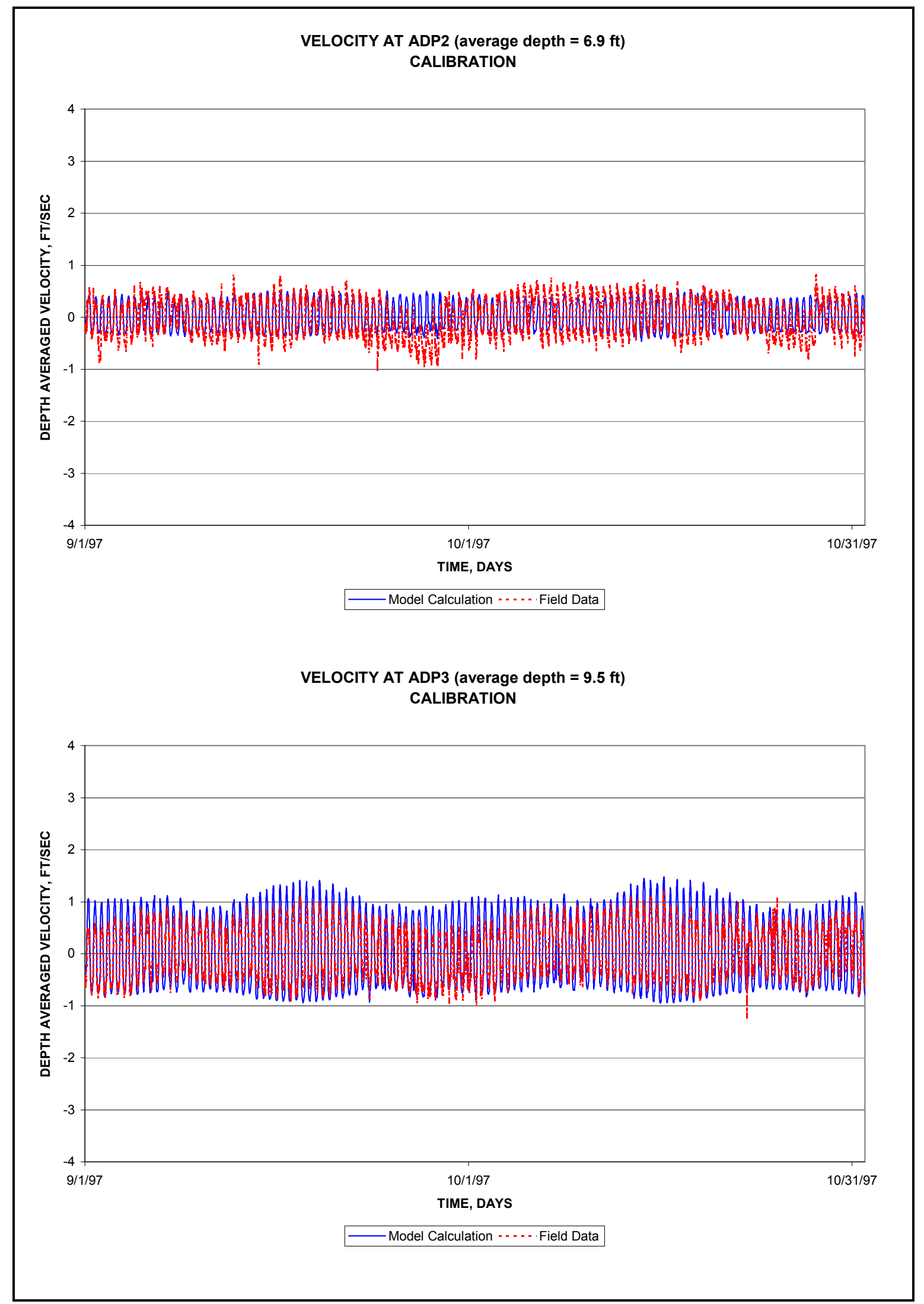

Plate 61 


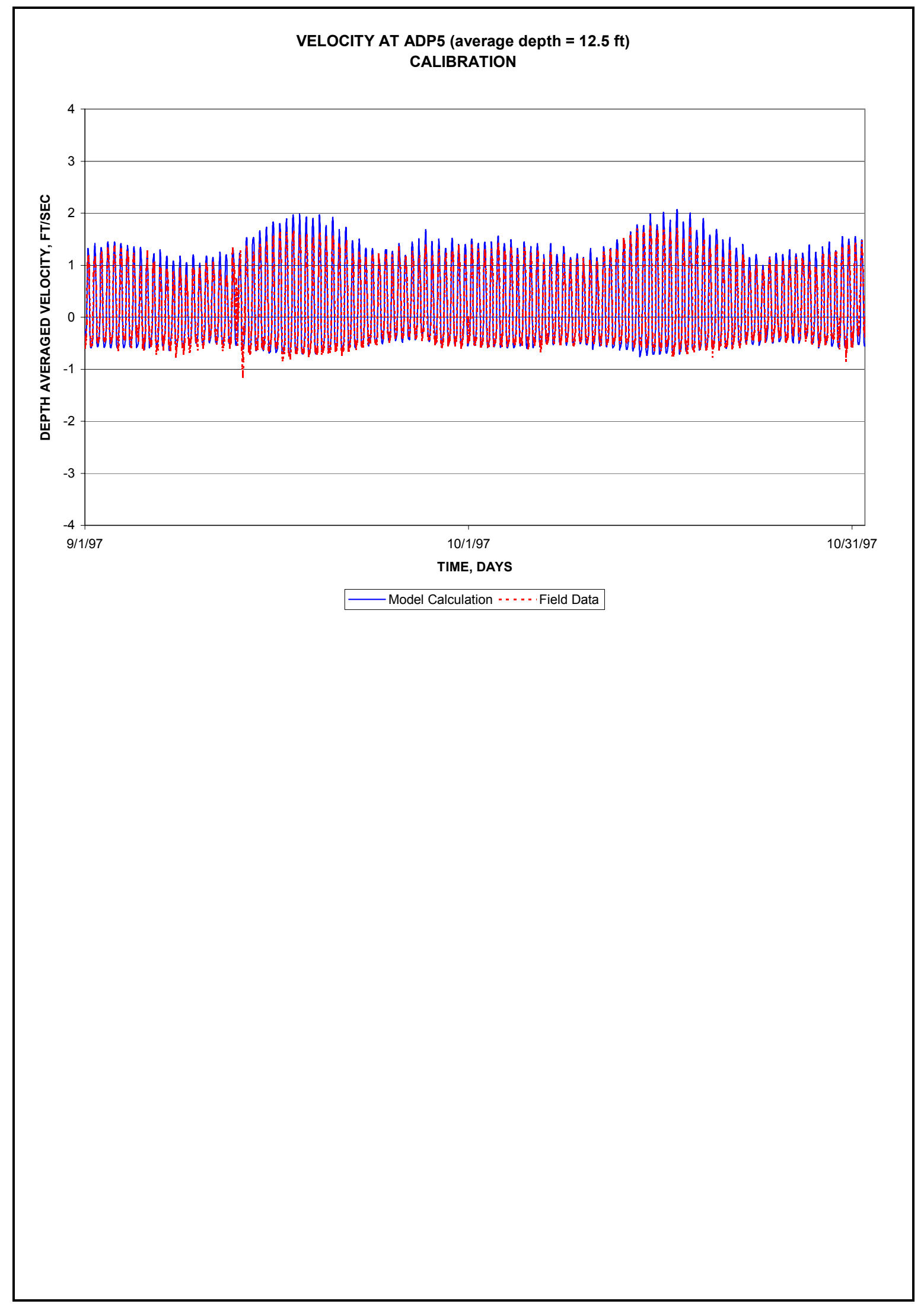

Plate 62 


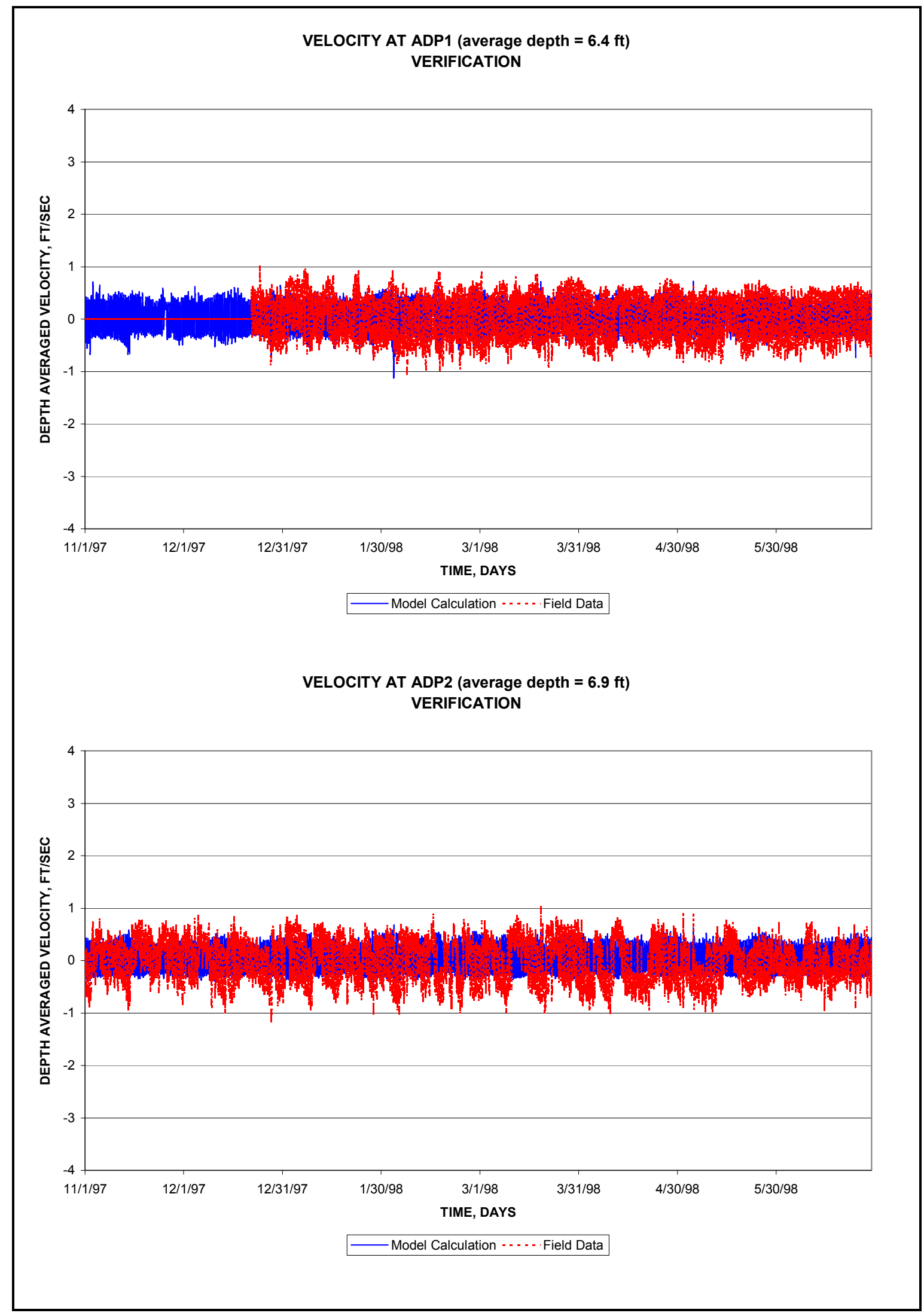

Plate 63 


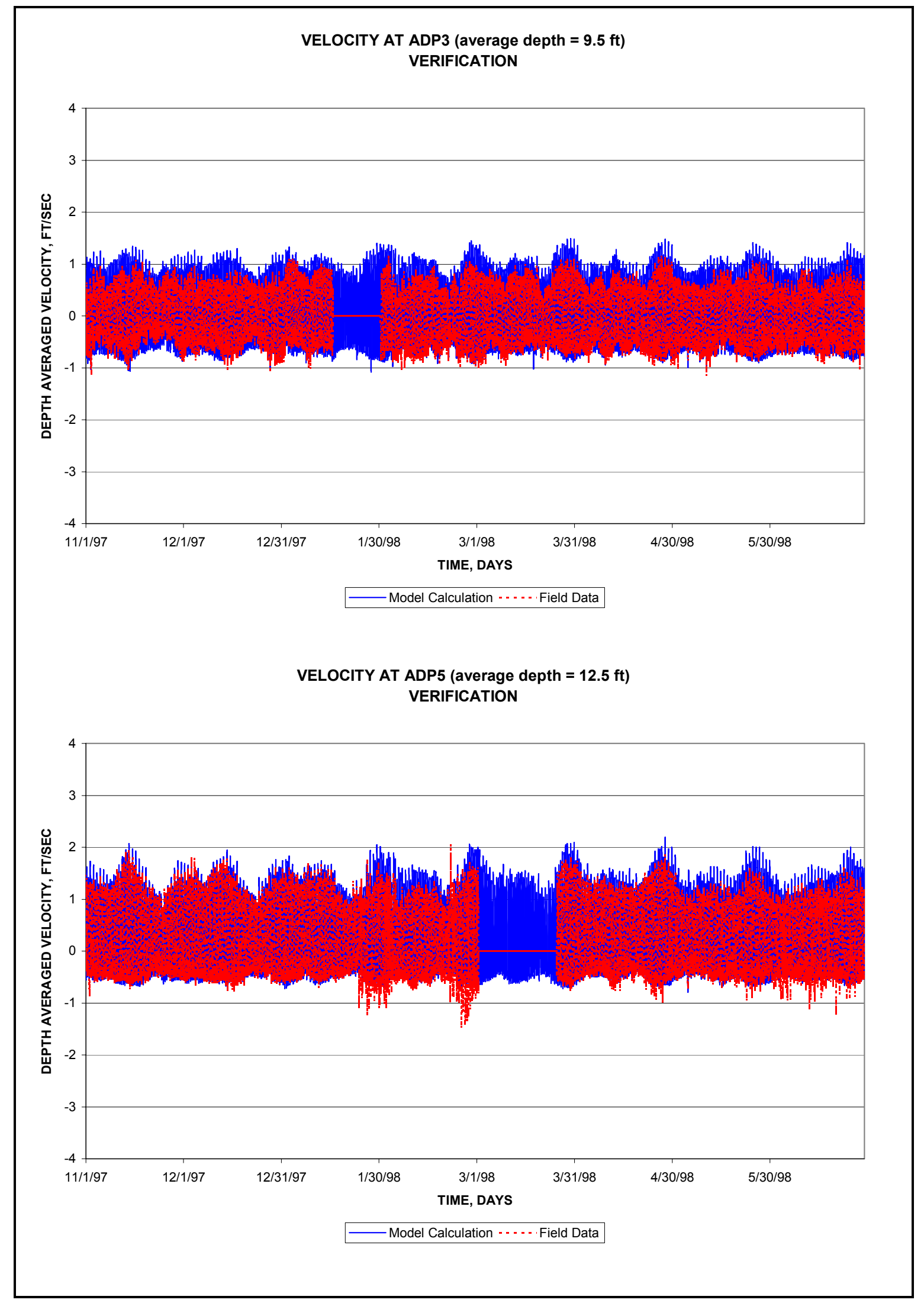

Plate 64 


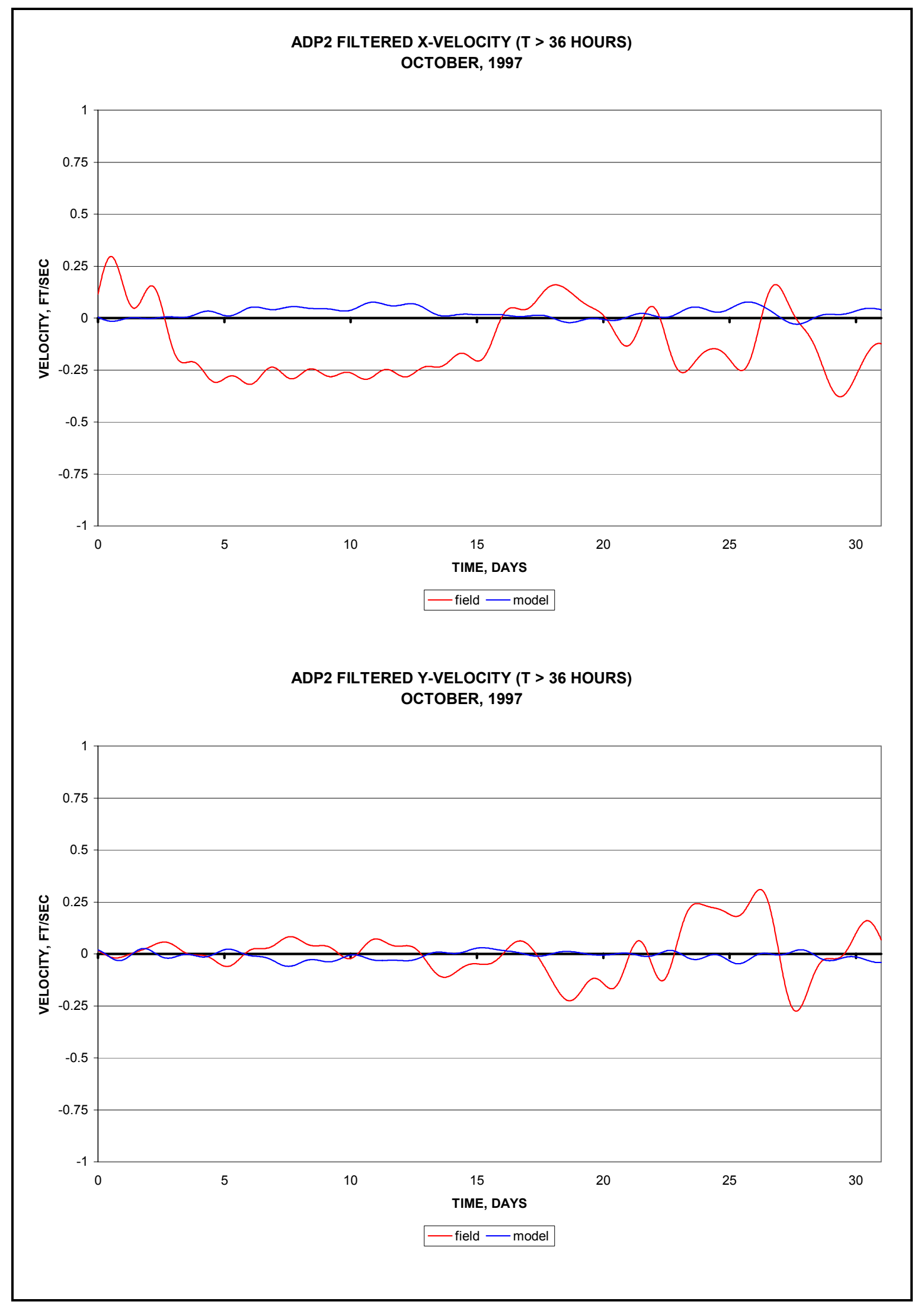

Plate 65 


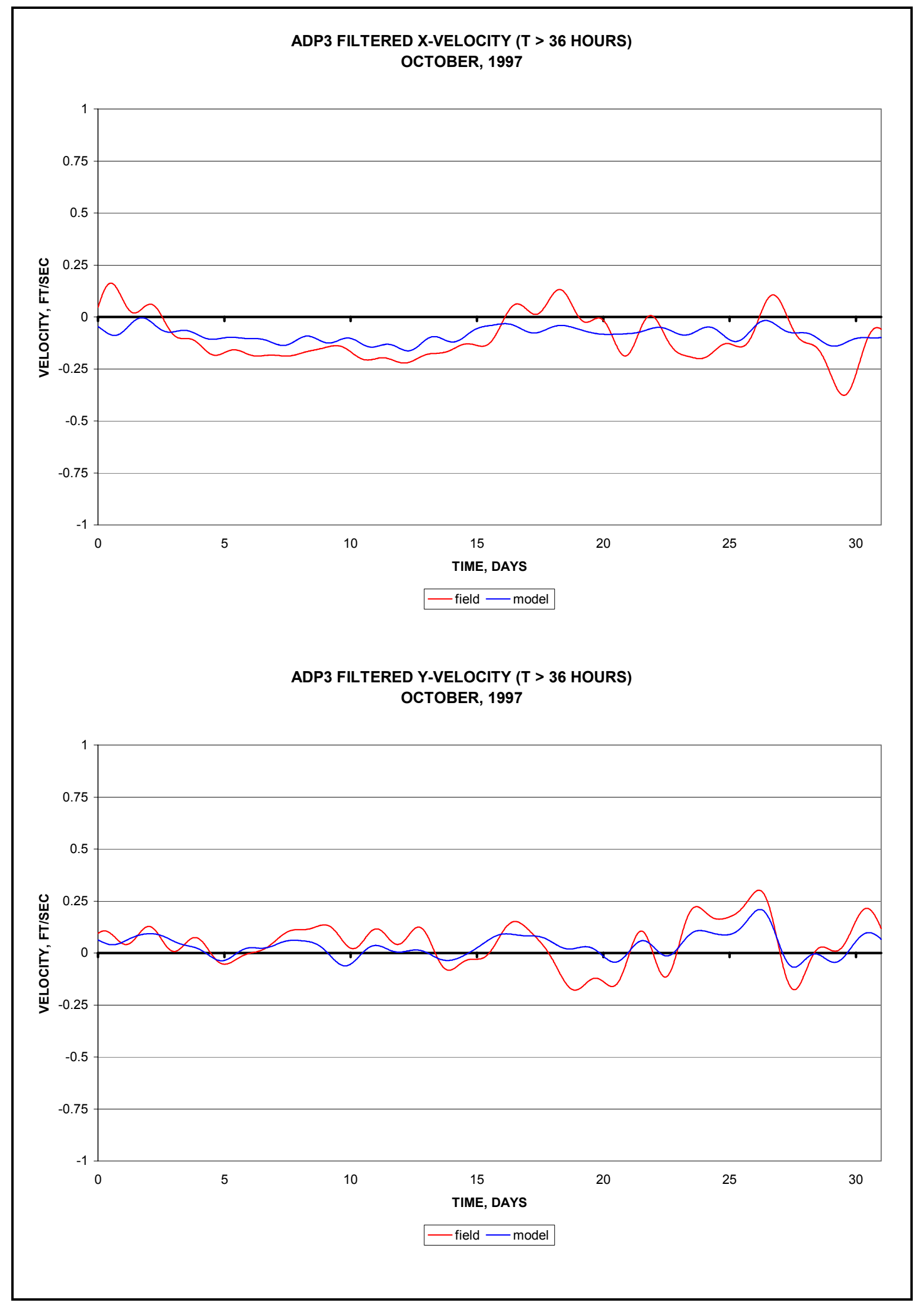

Plate 66 


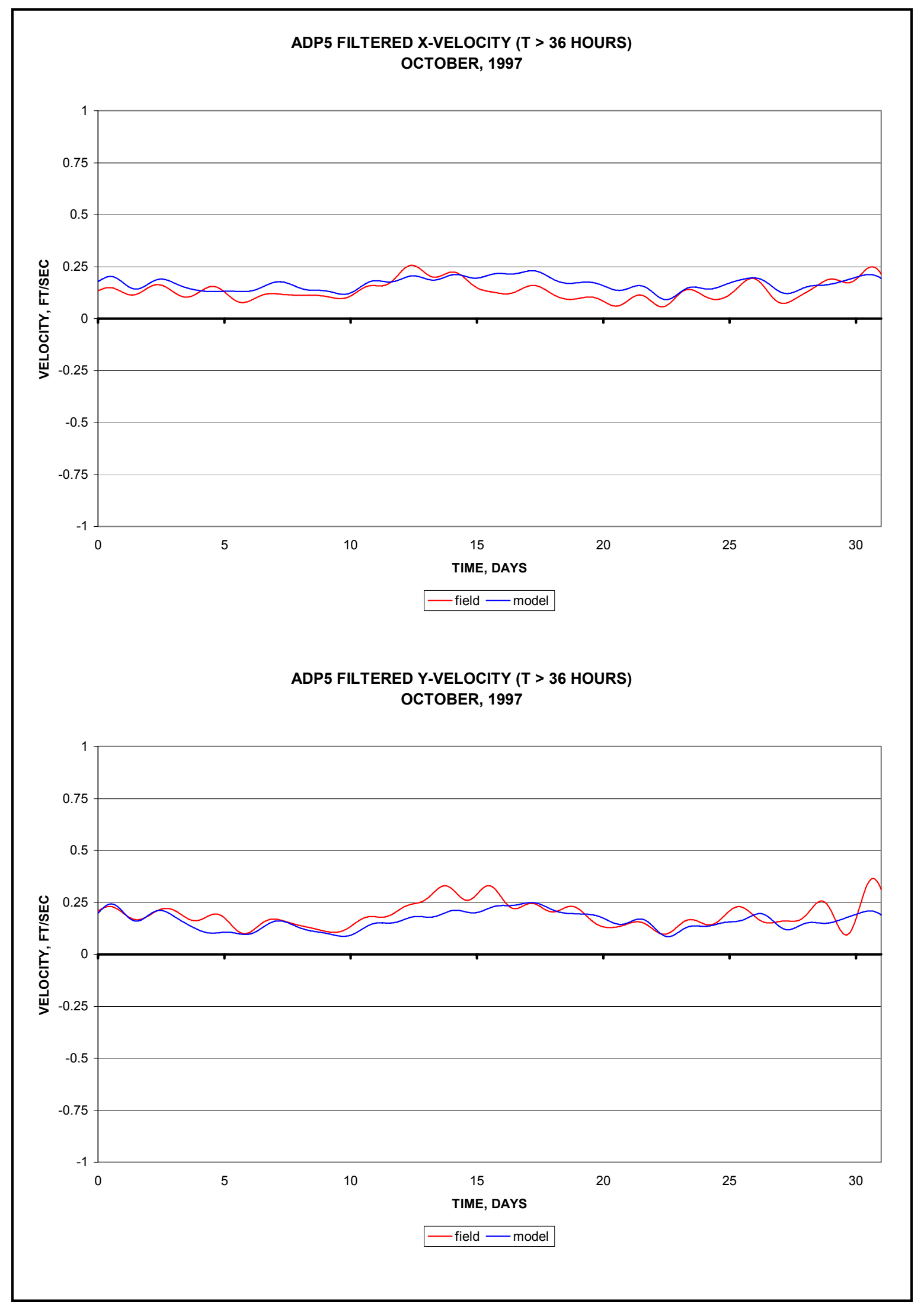

Plate 67 


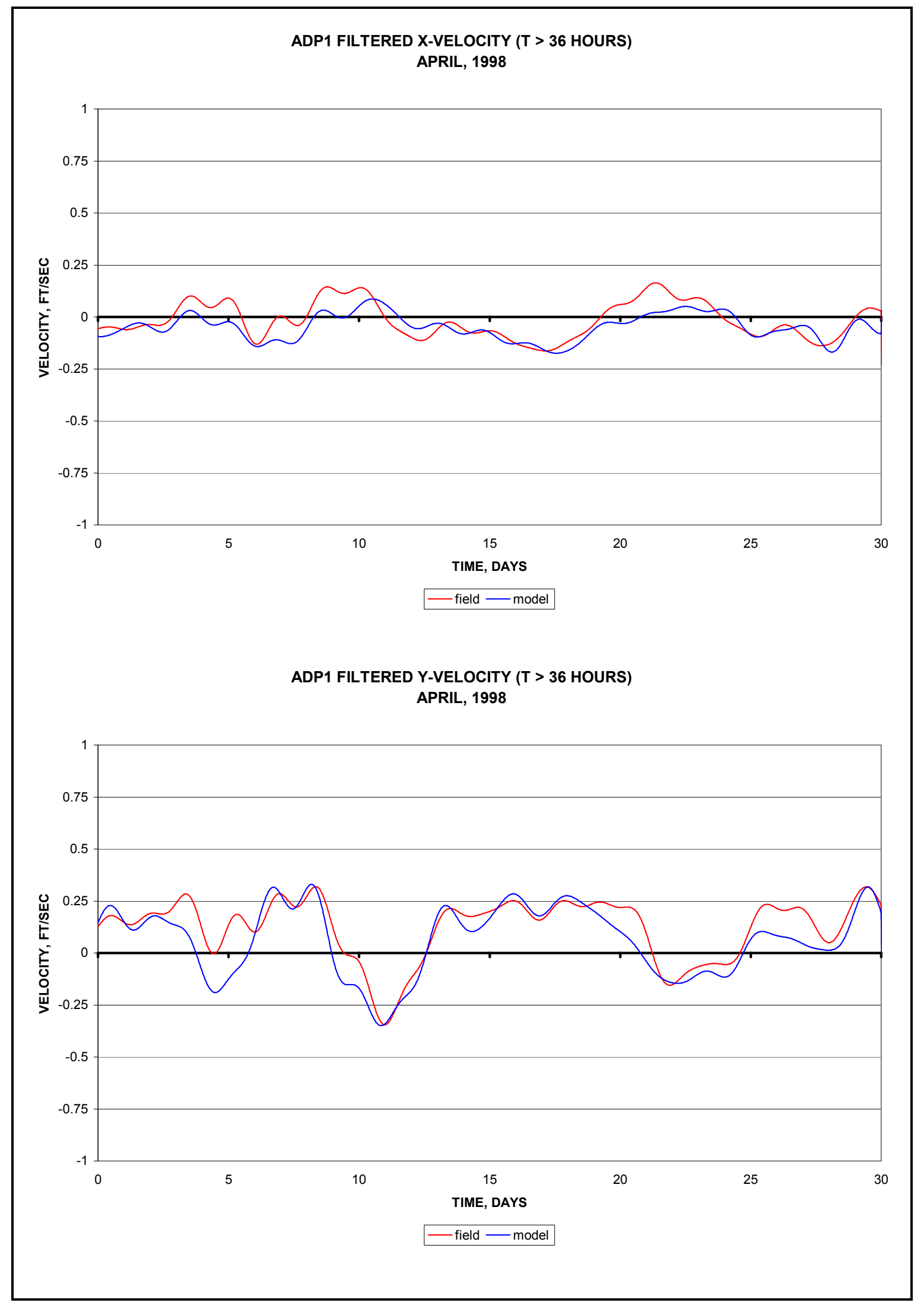

Plate 68 


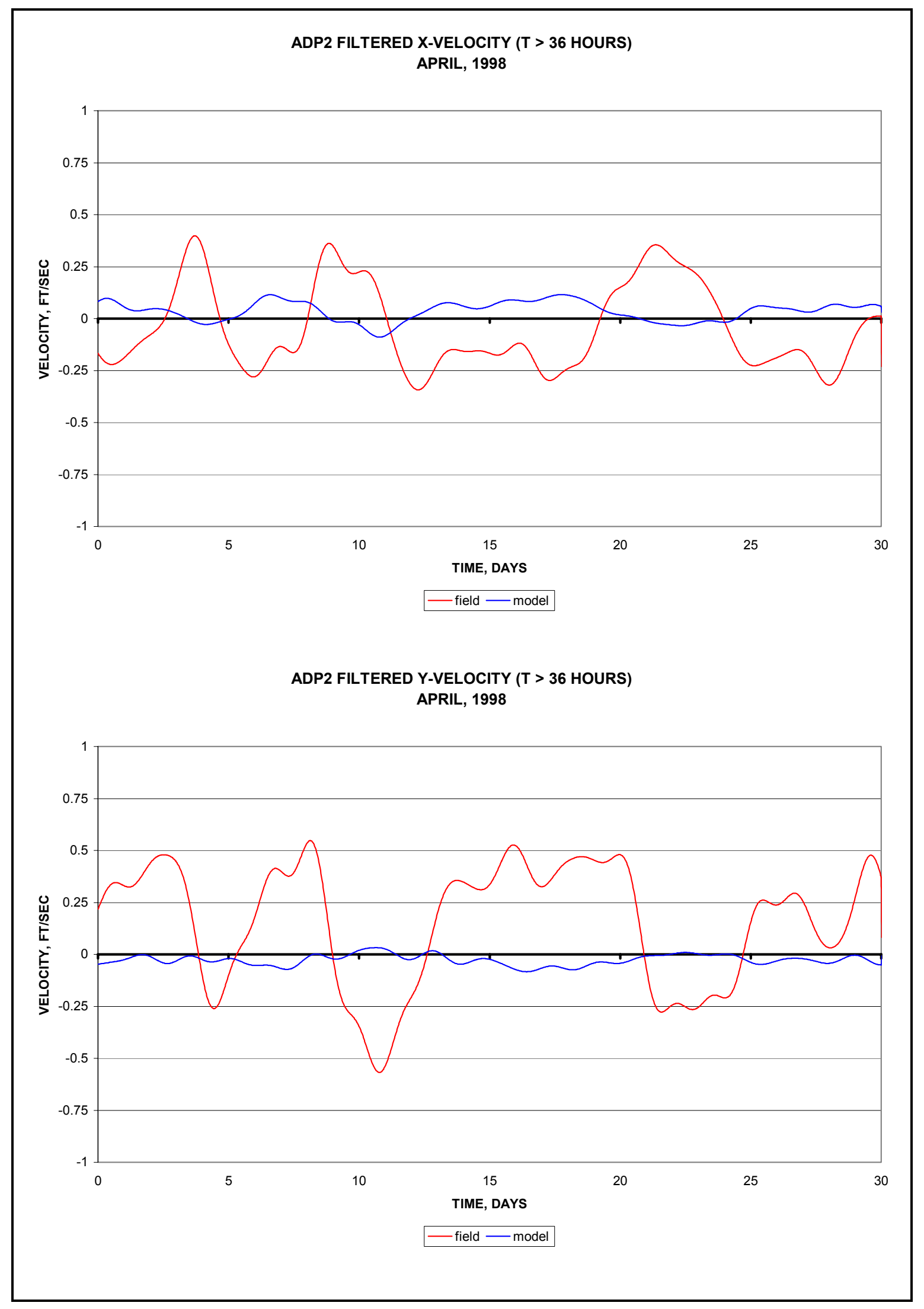

Plate 69 


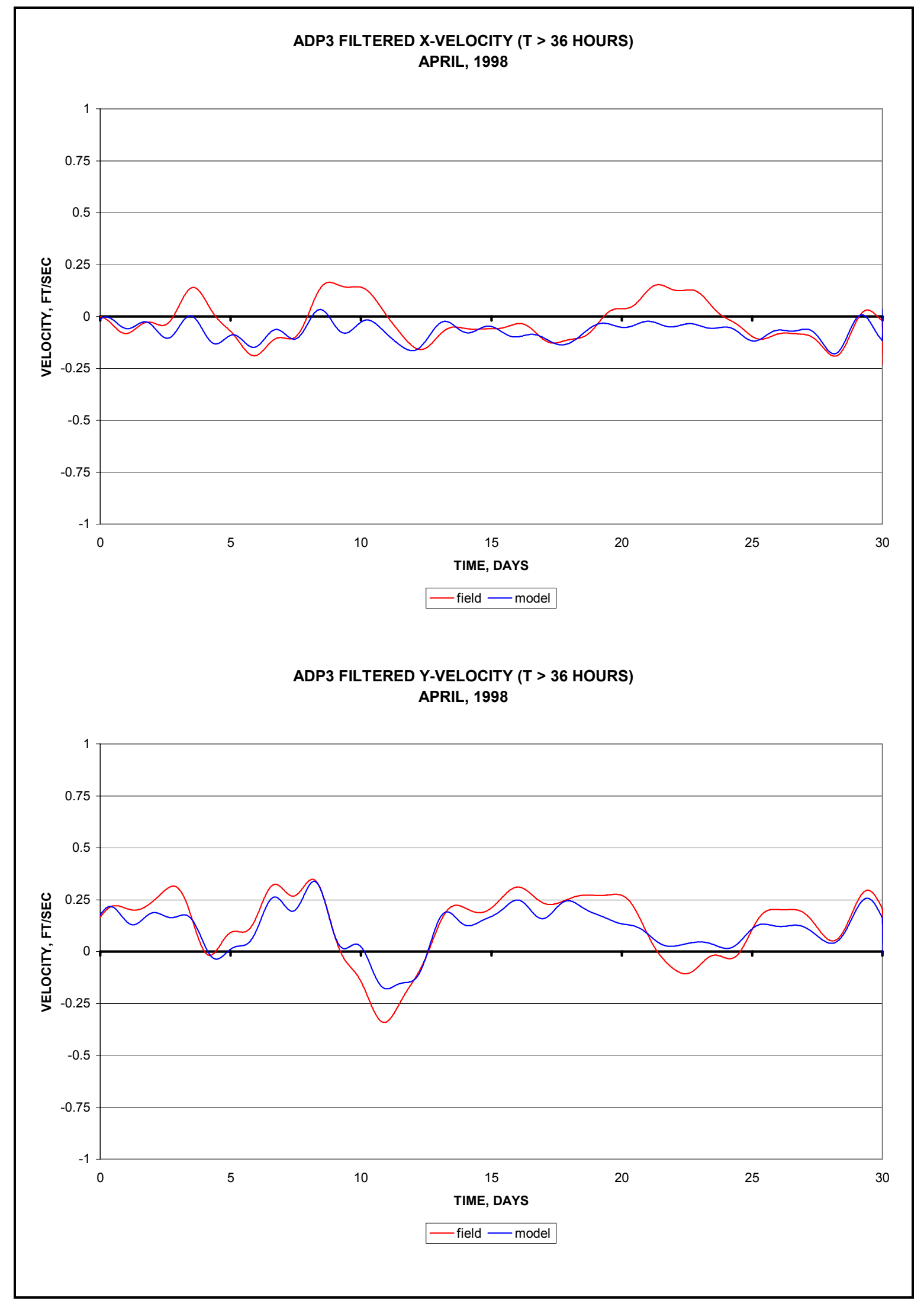

Plate 70 


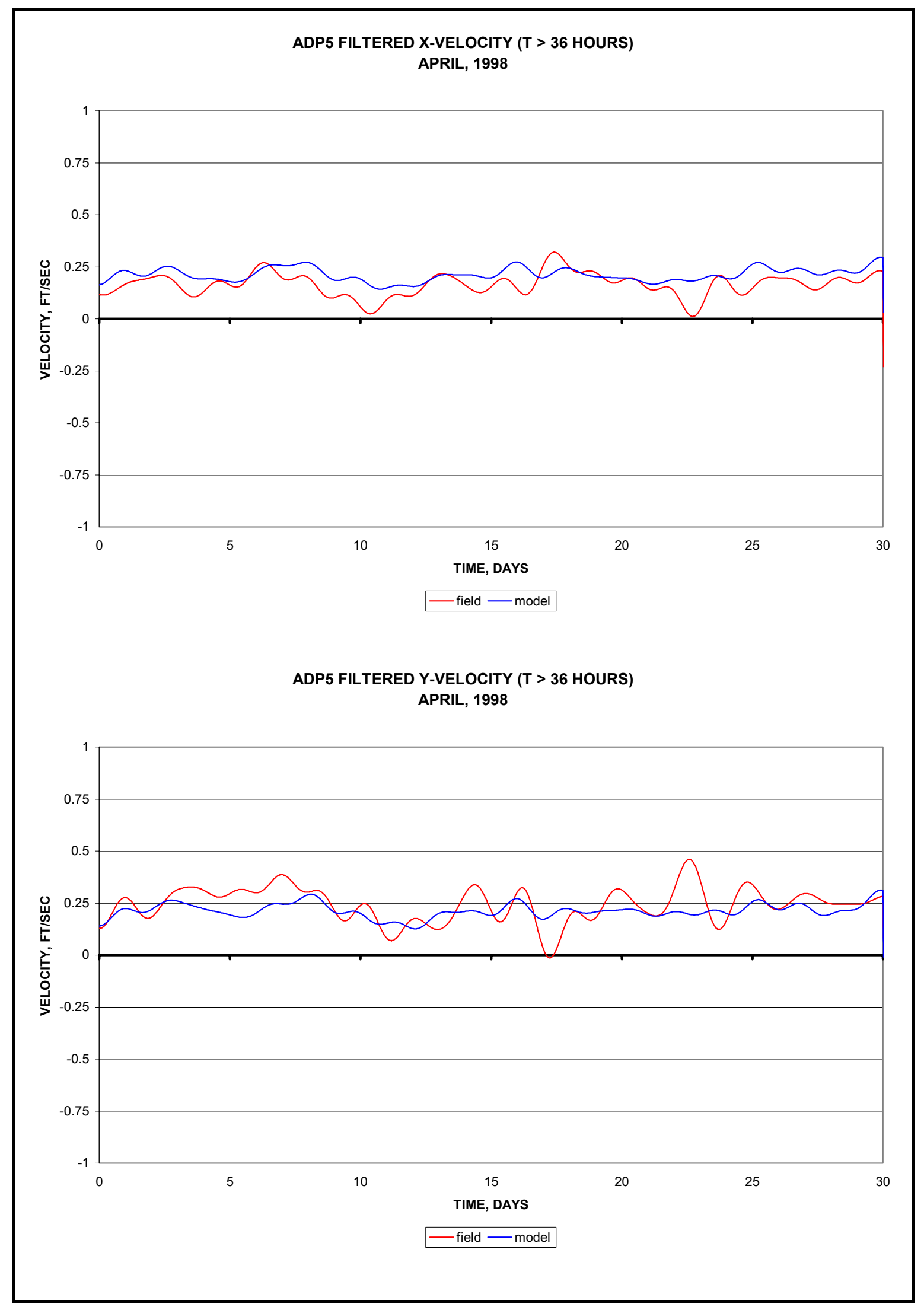

Plate 71 


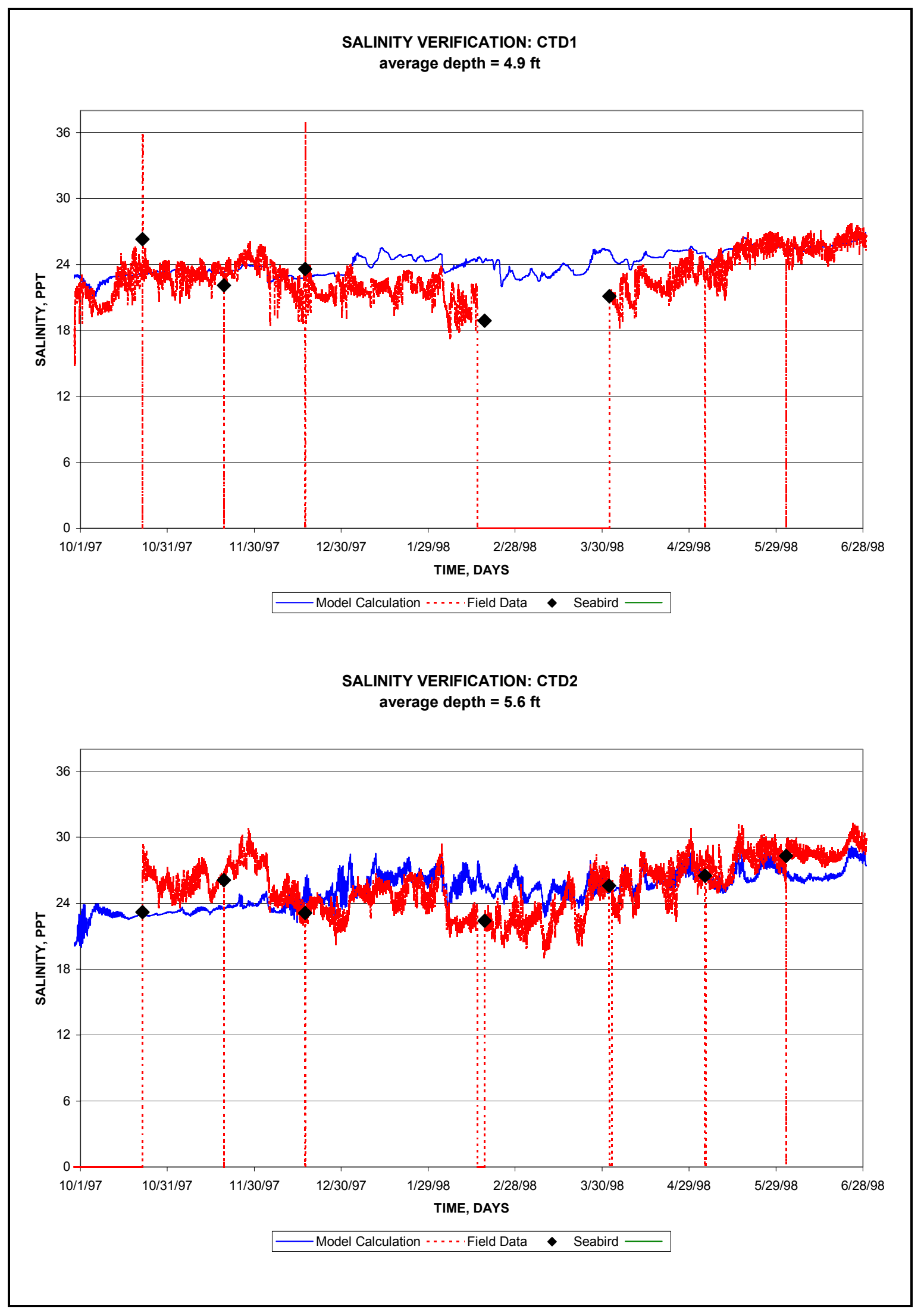

Plate 72 


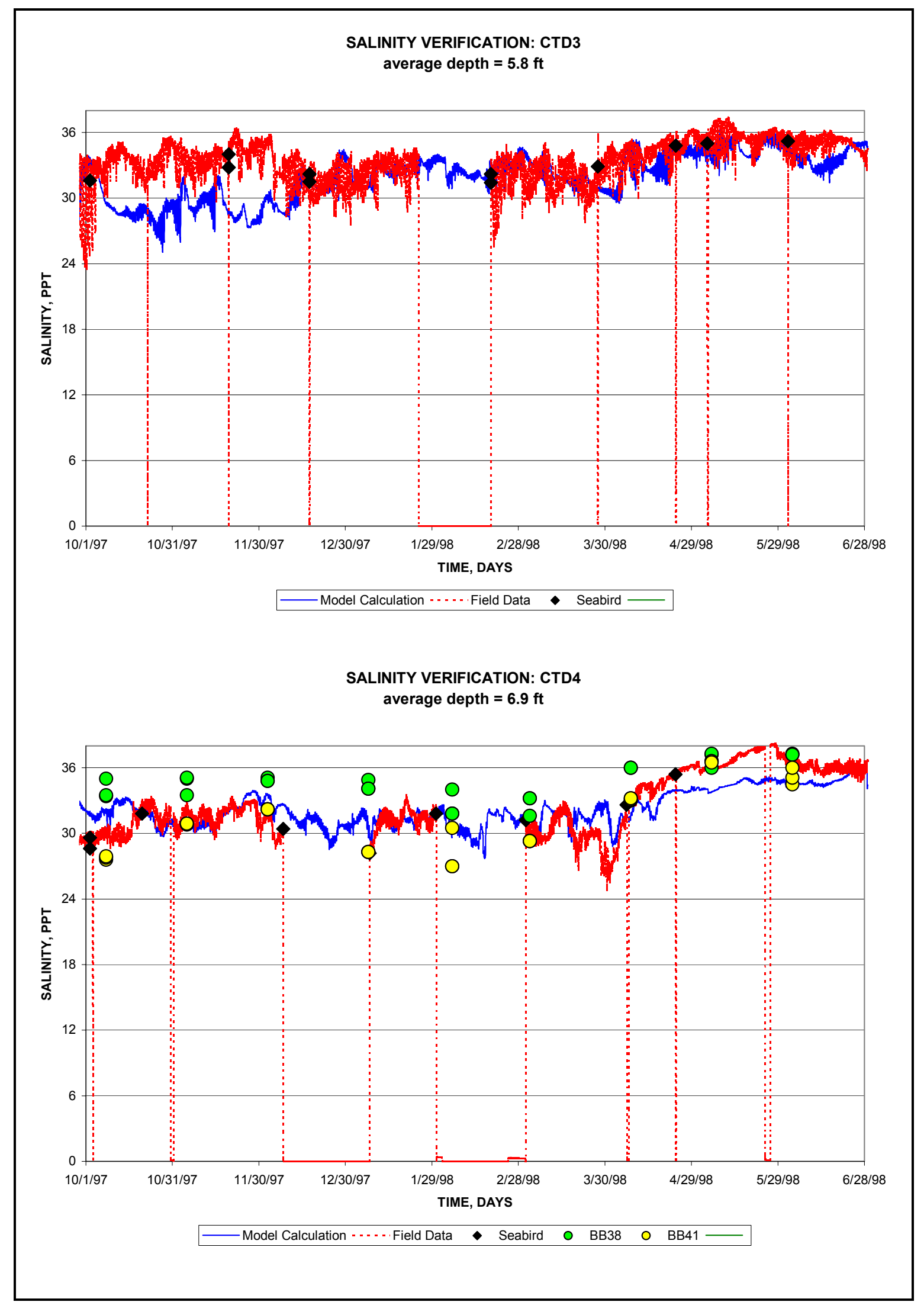

Plate 73 


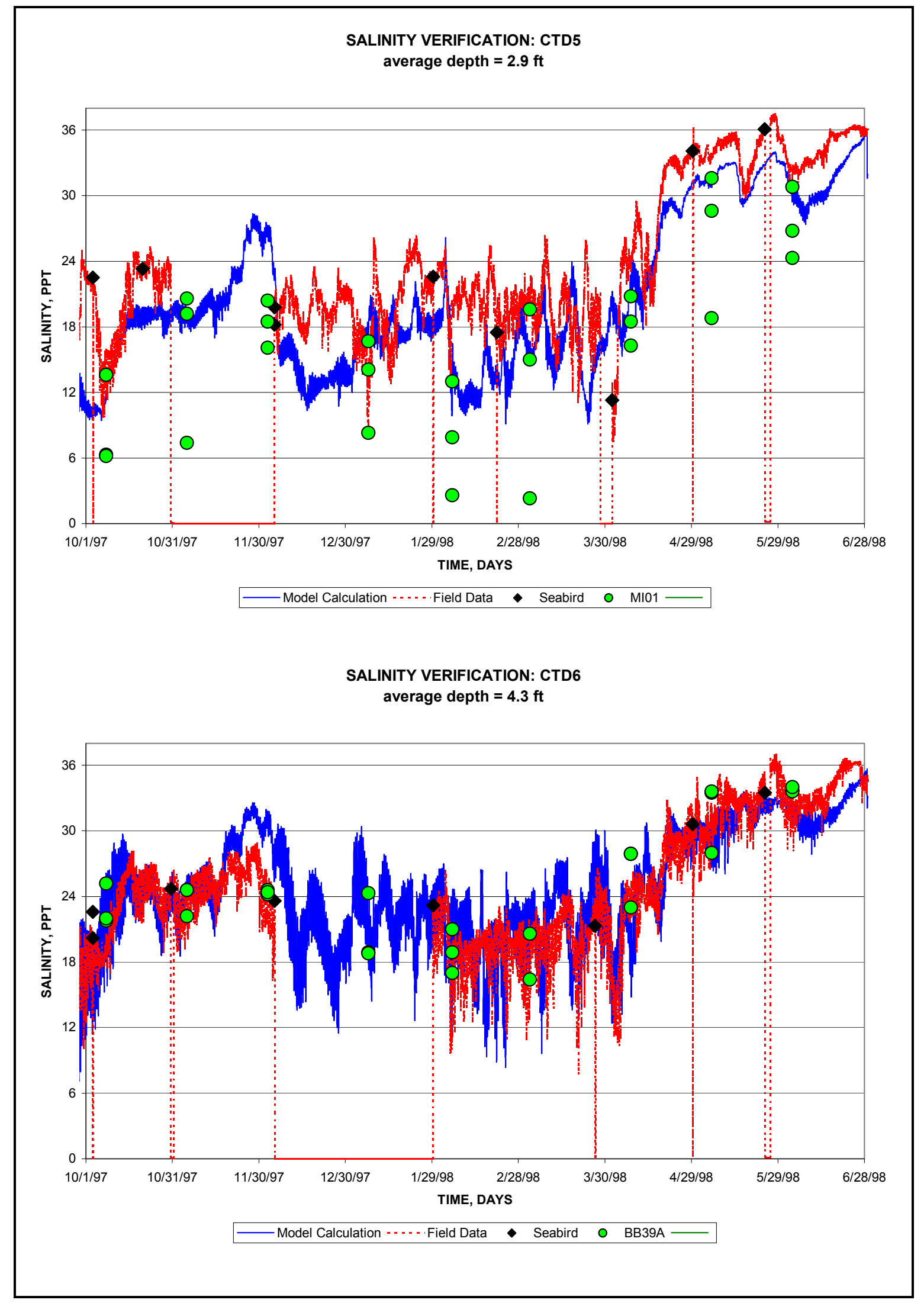

Plate 74 


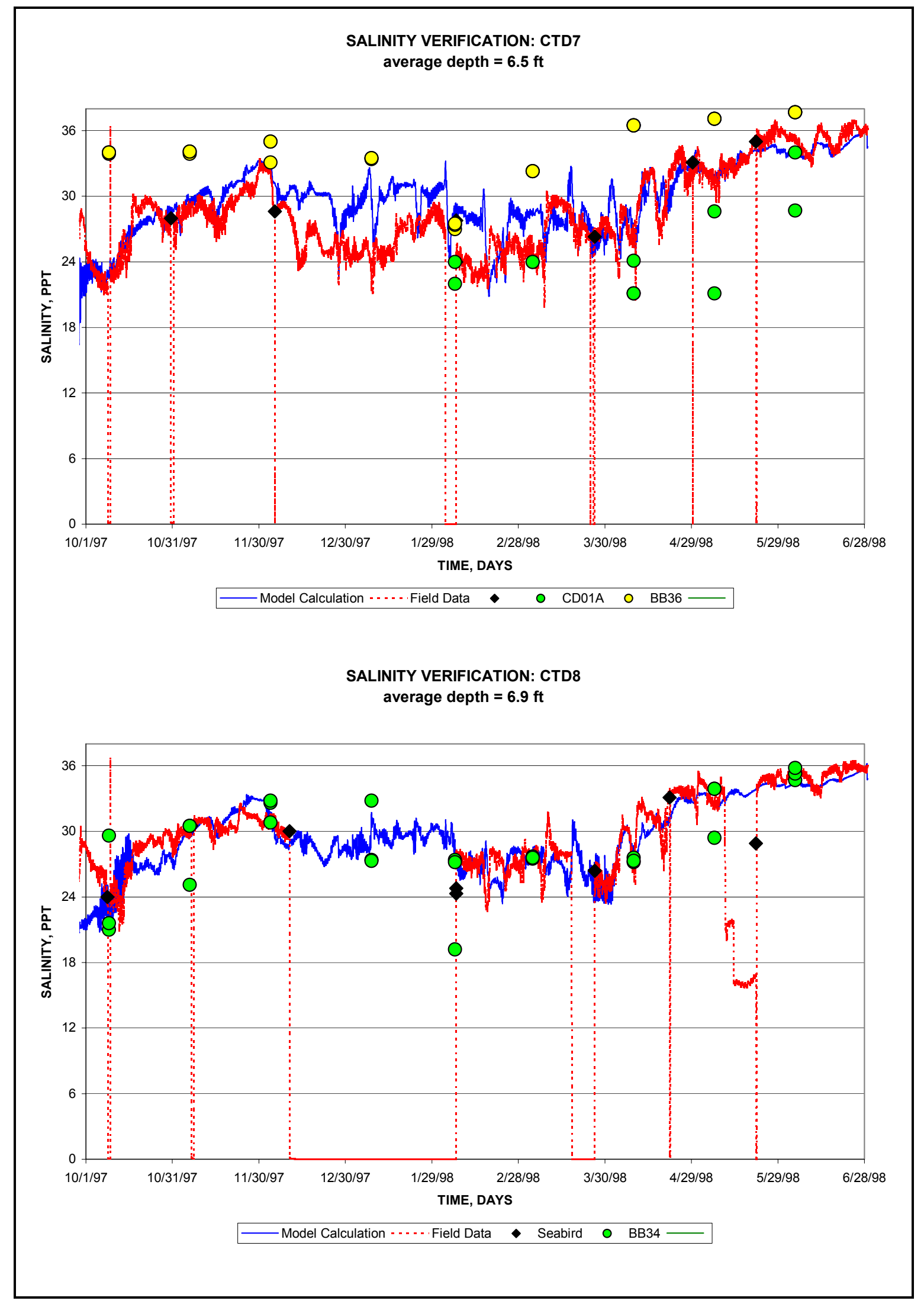

Plate 75 


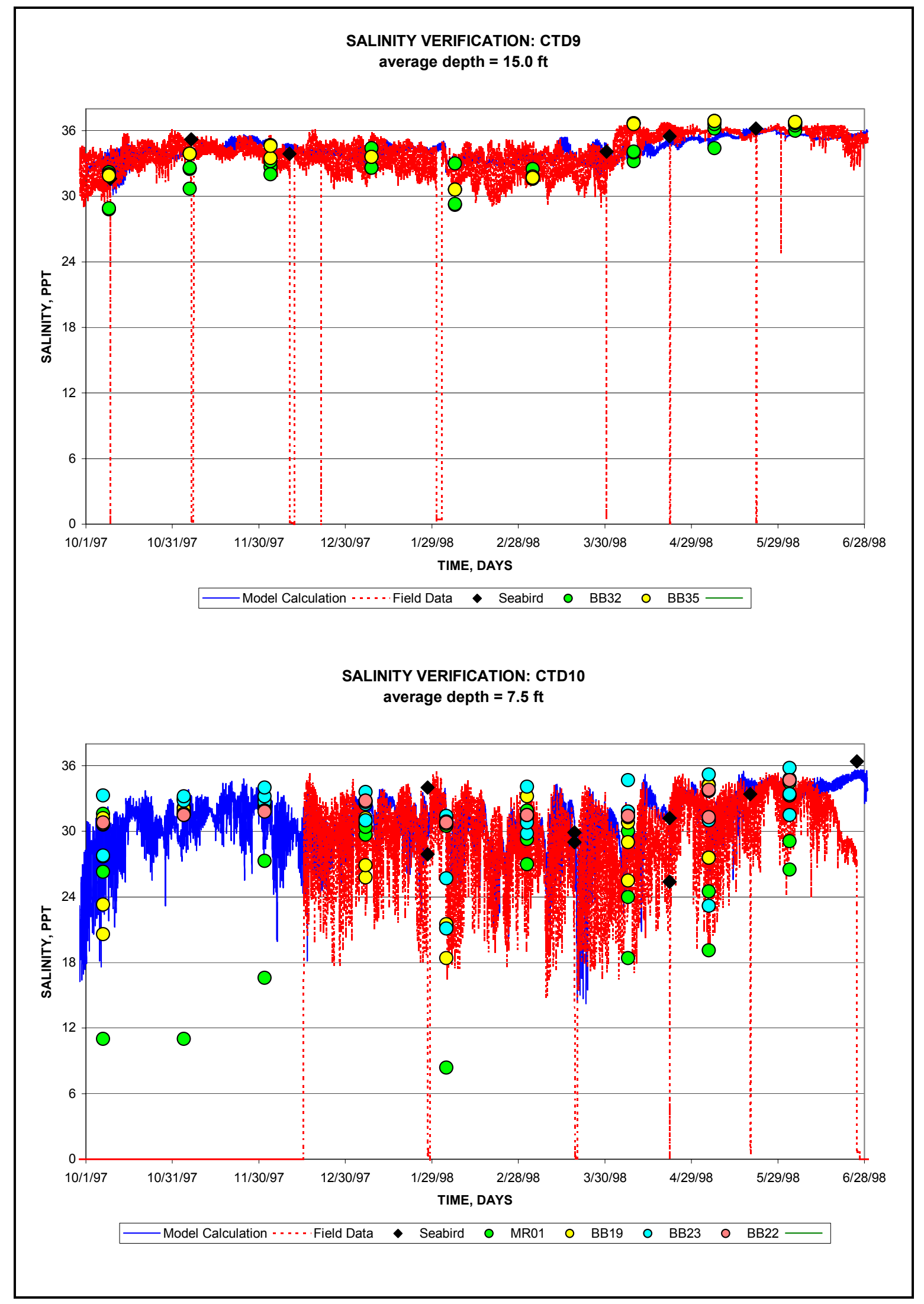

Plate 76 


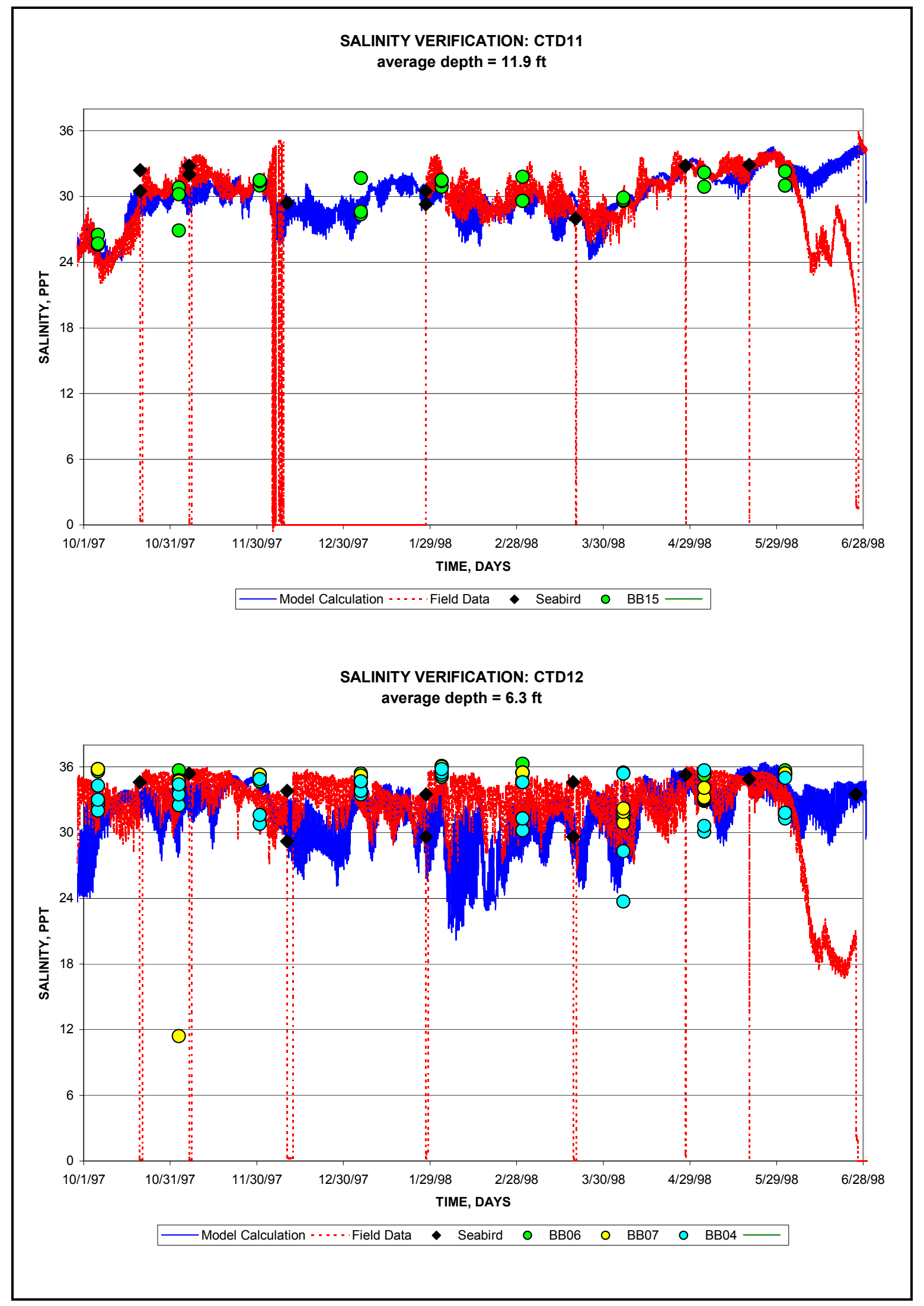

Plate 77 


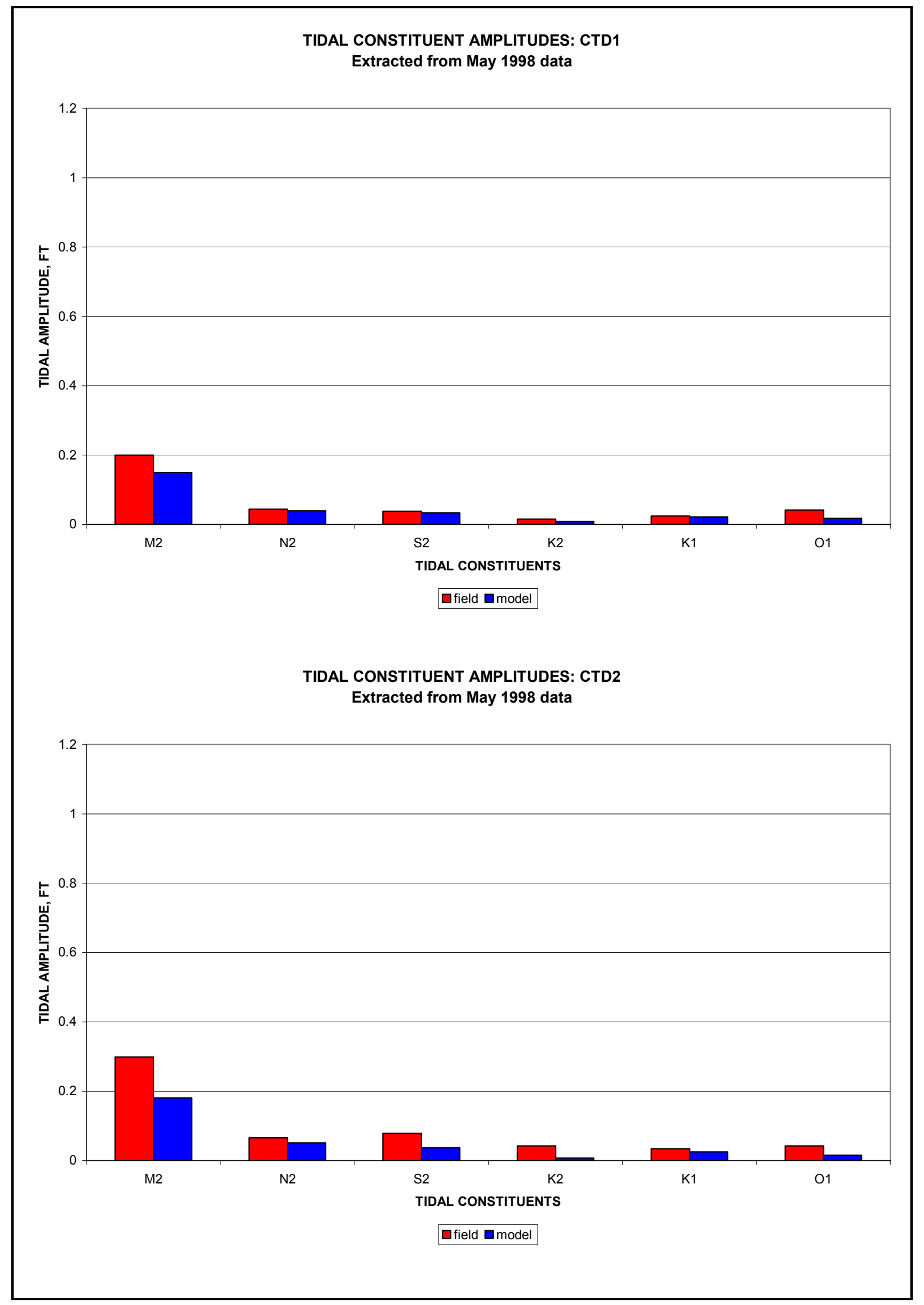

Plate 78 


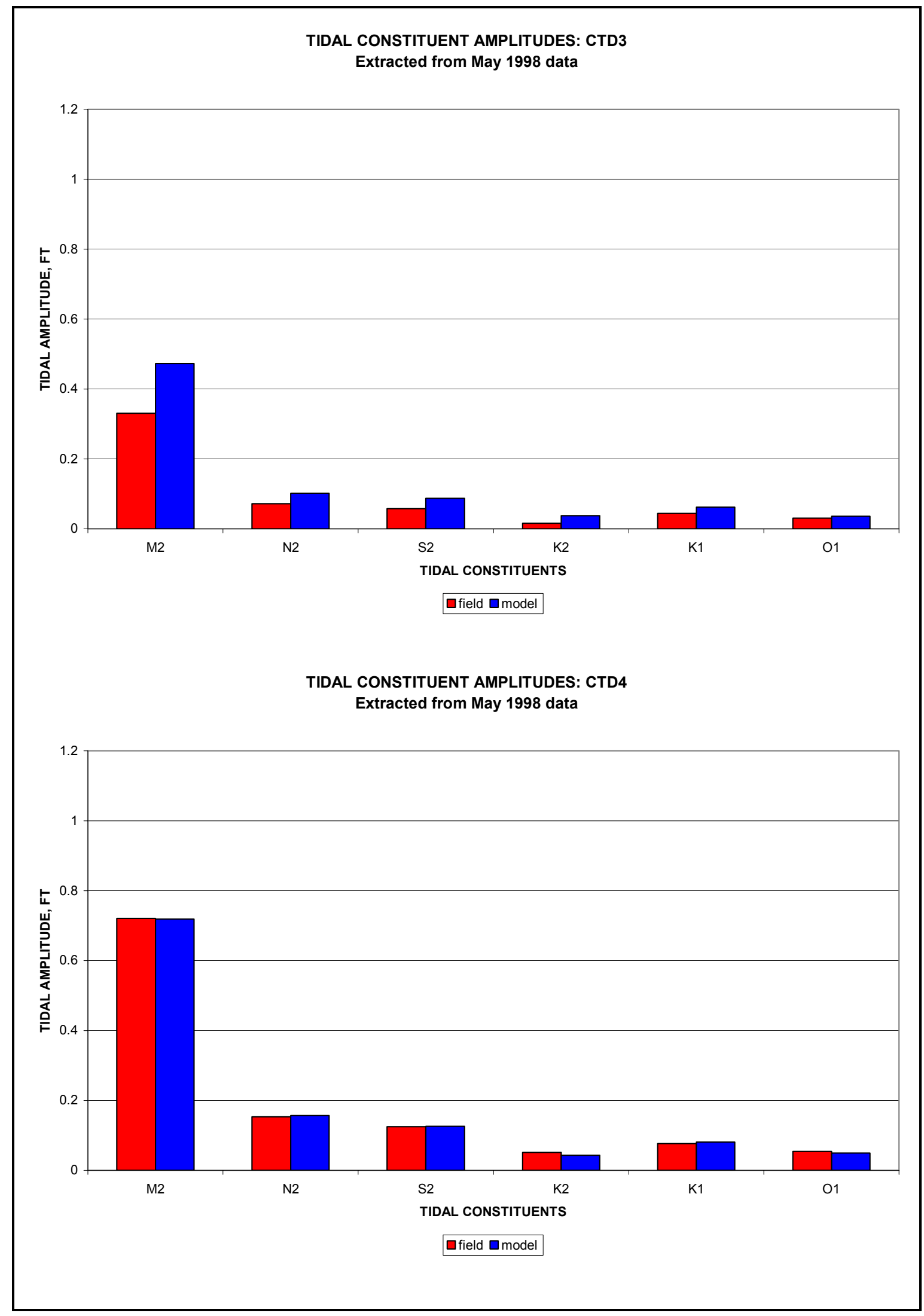

Plate 79 


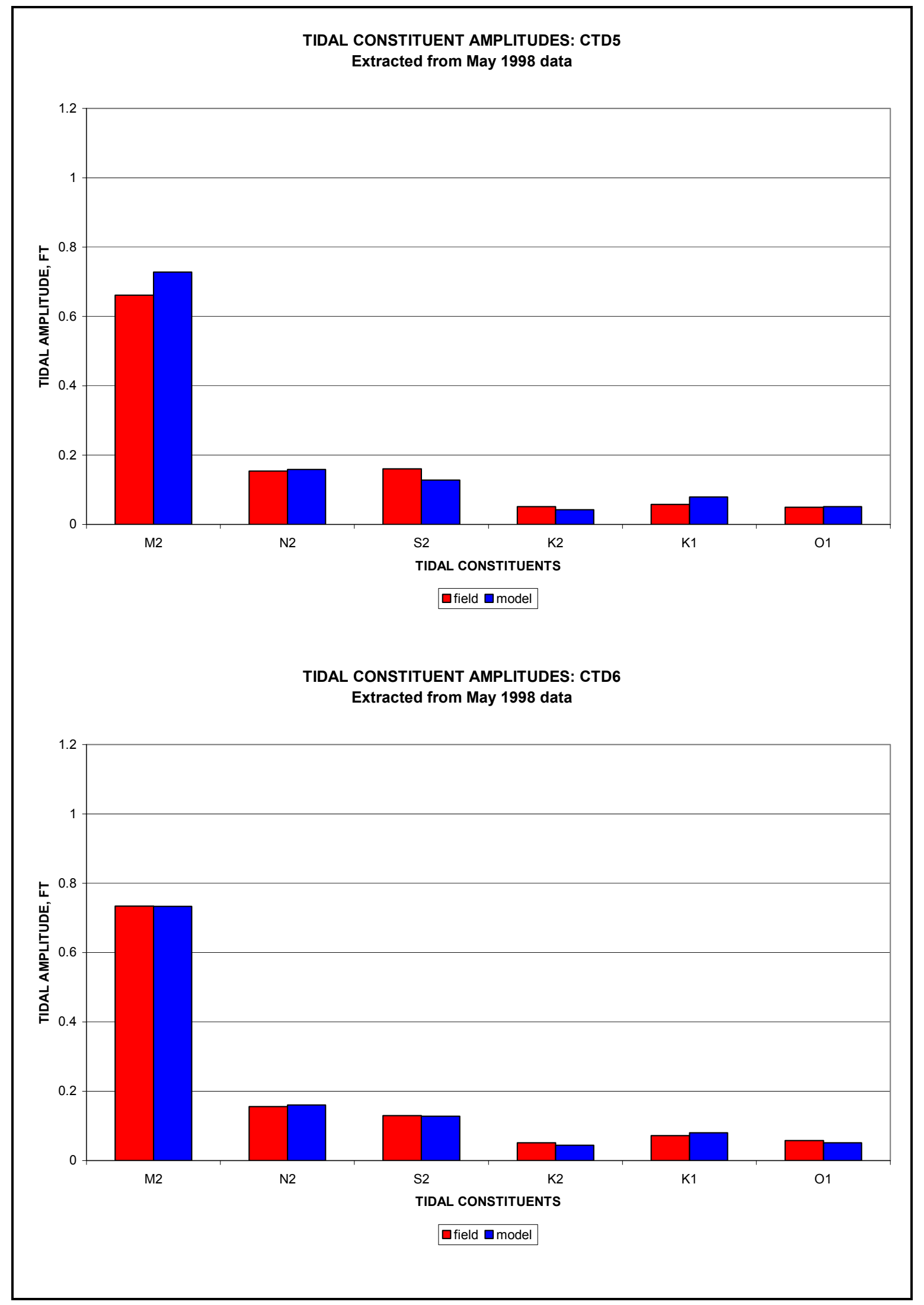

Plate 80 


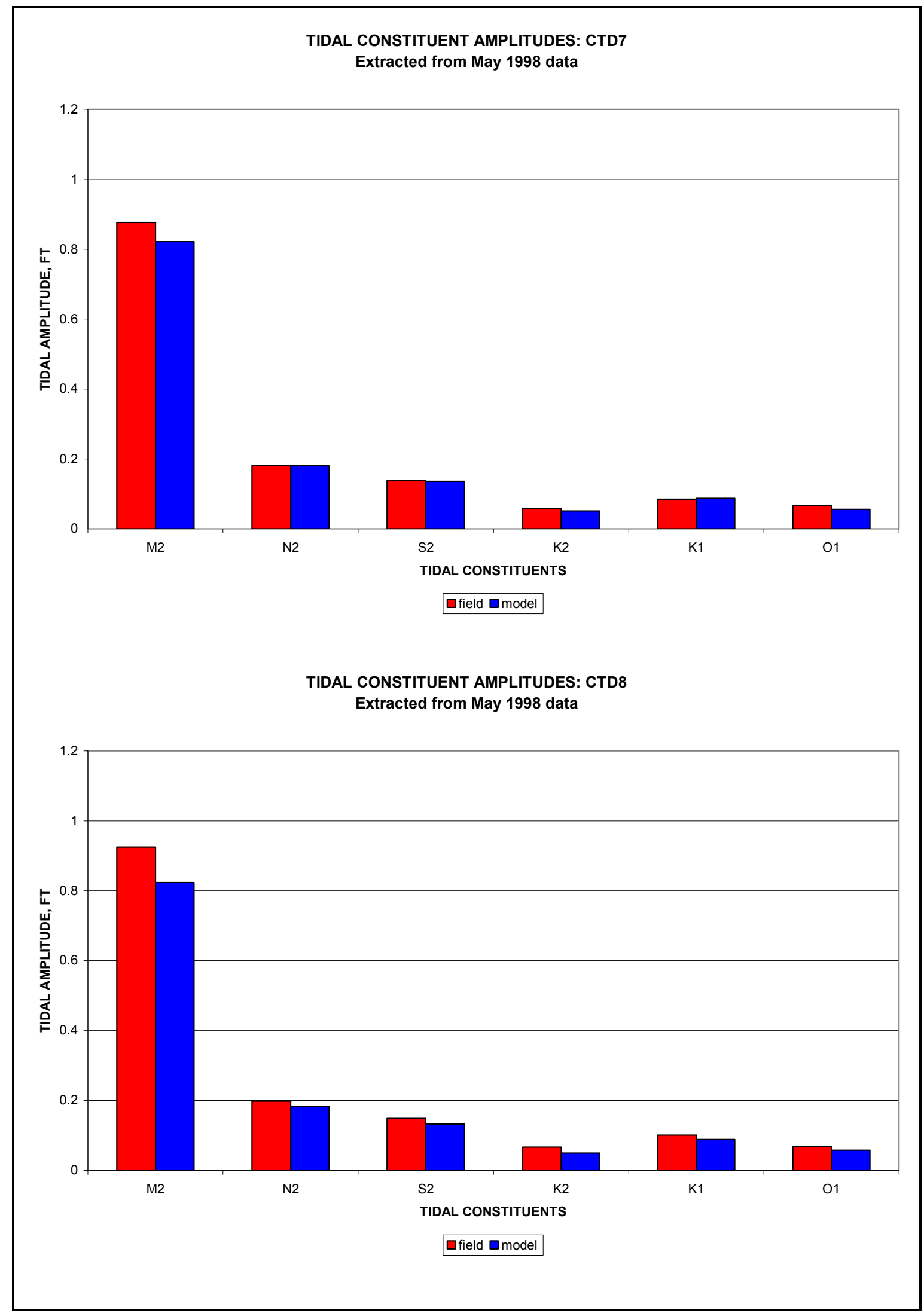

Plate 81 


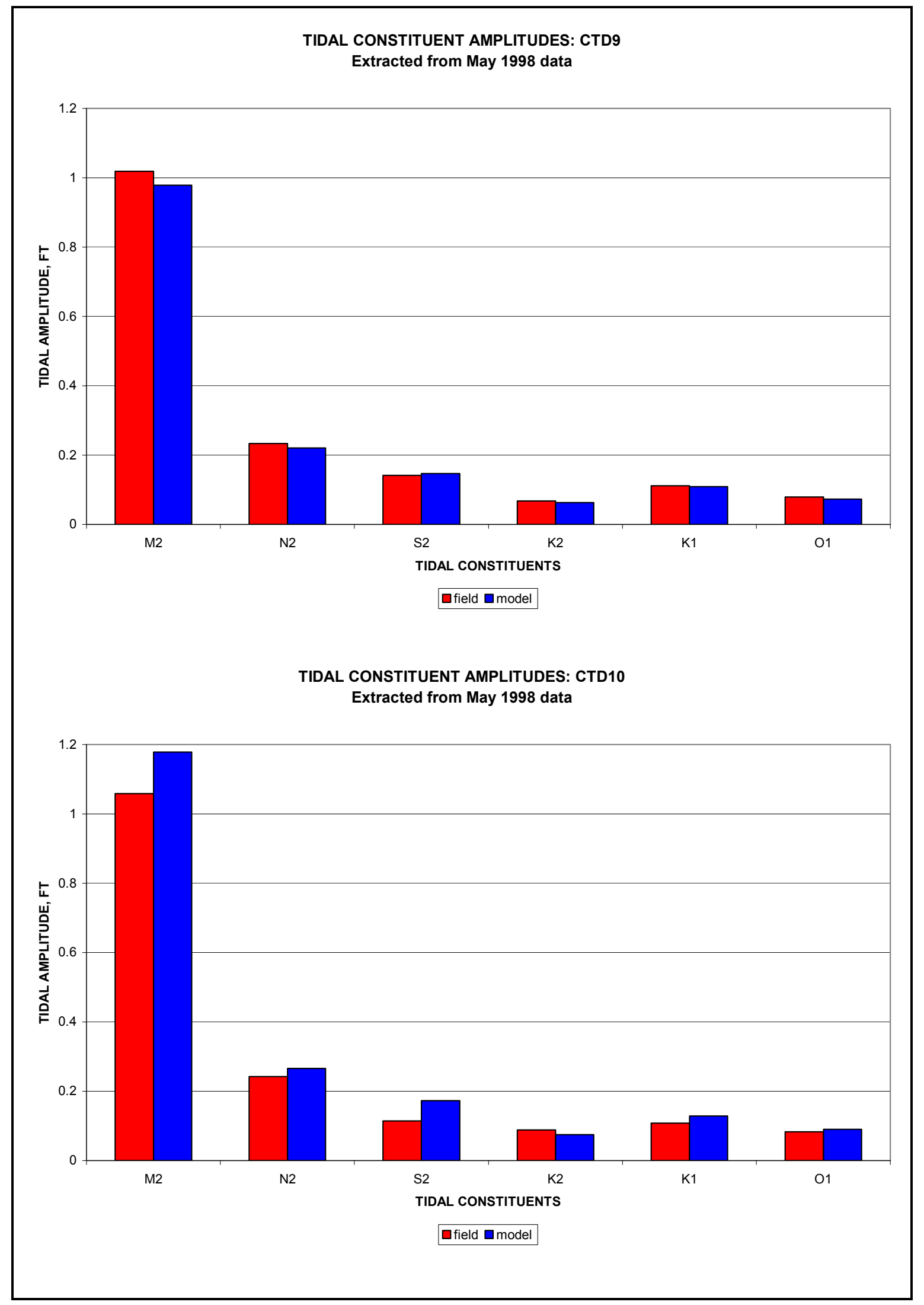

Plate 82 


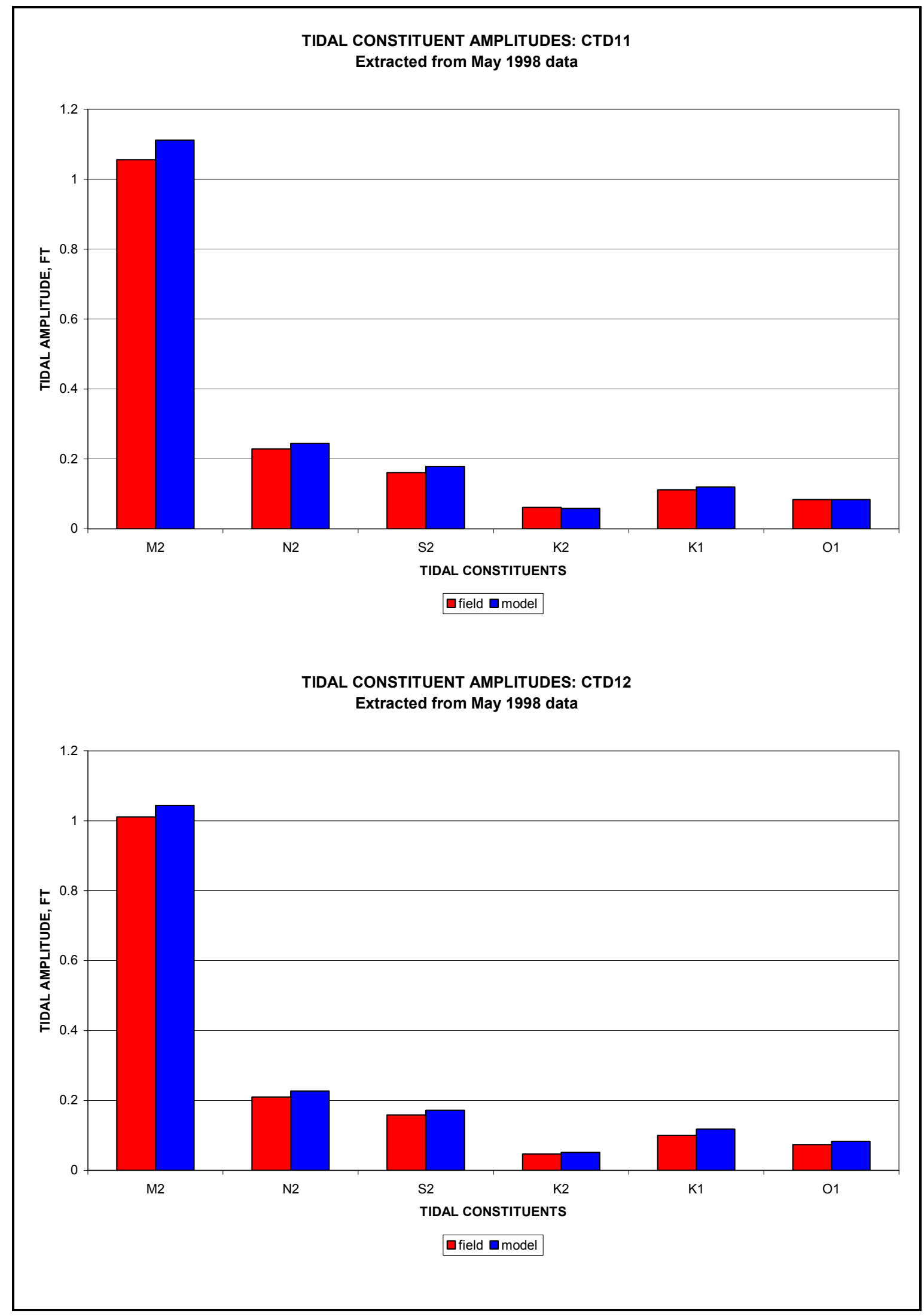

Plate 83 


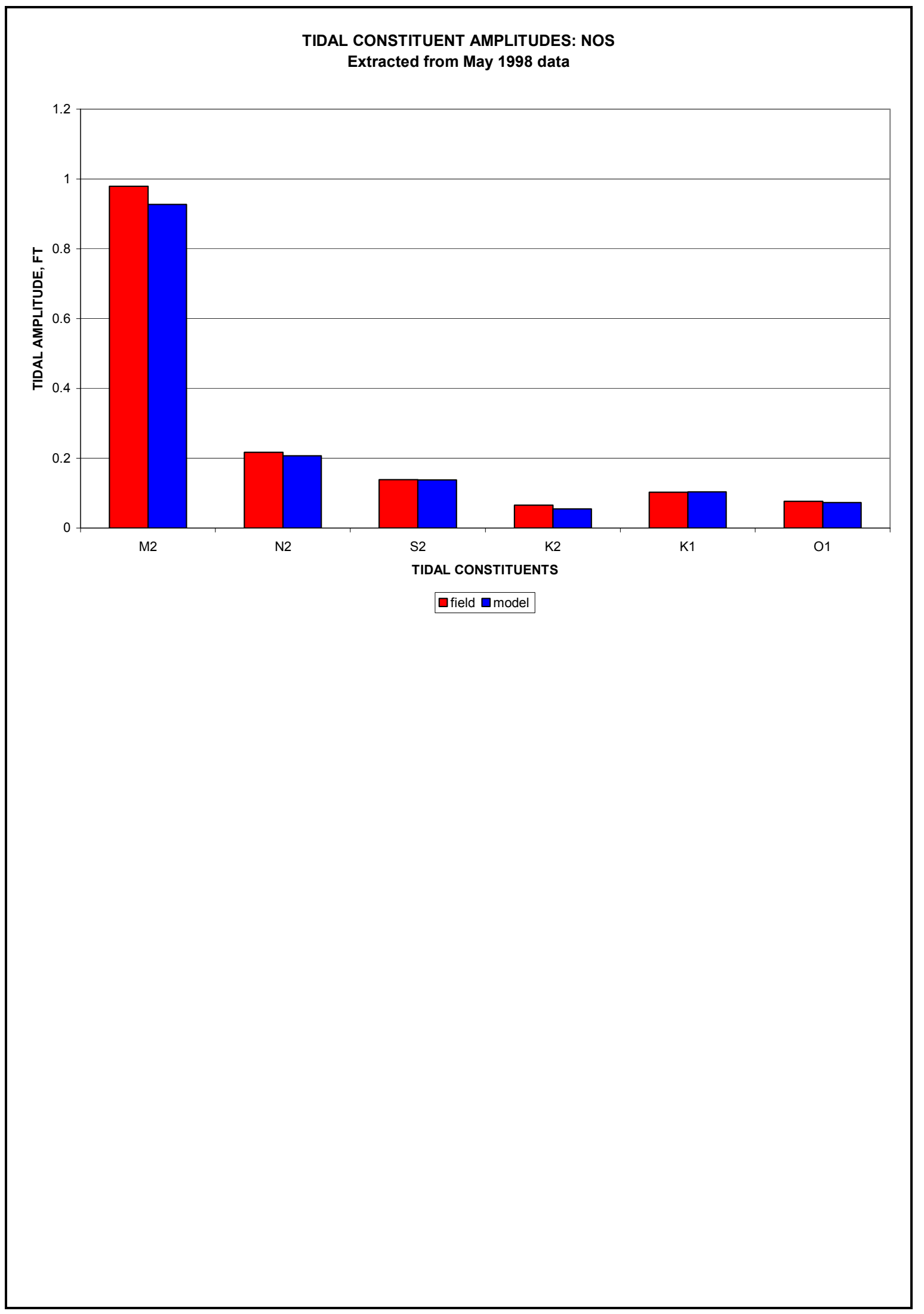

Plate 84 


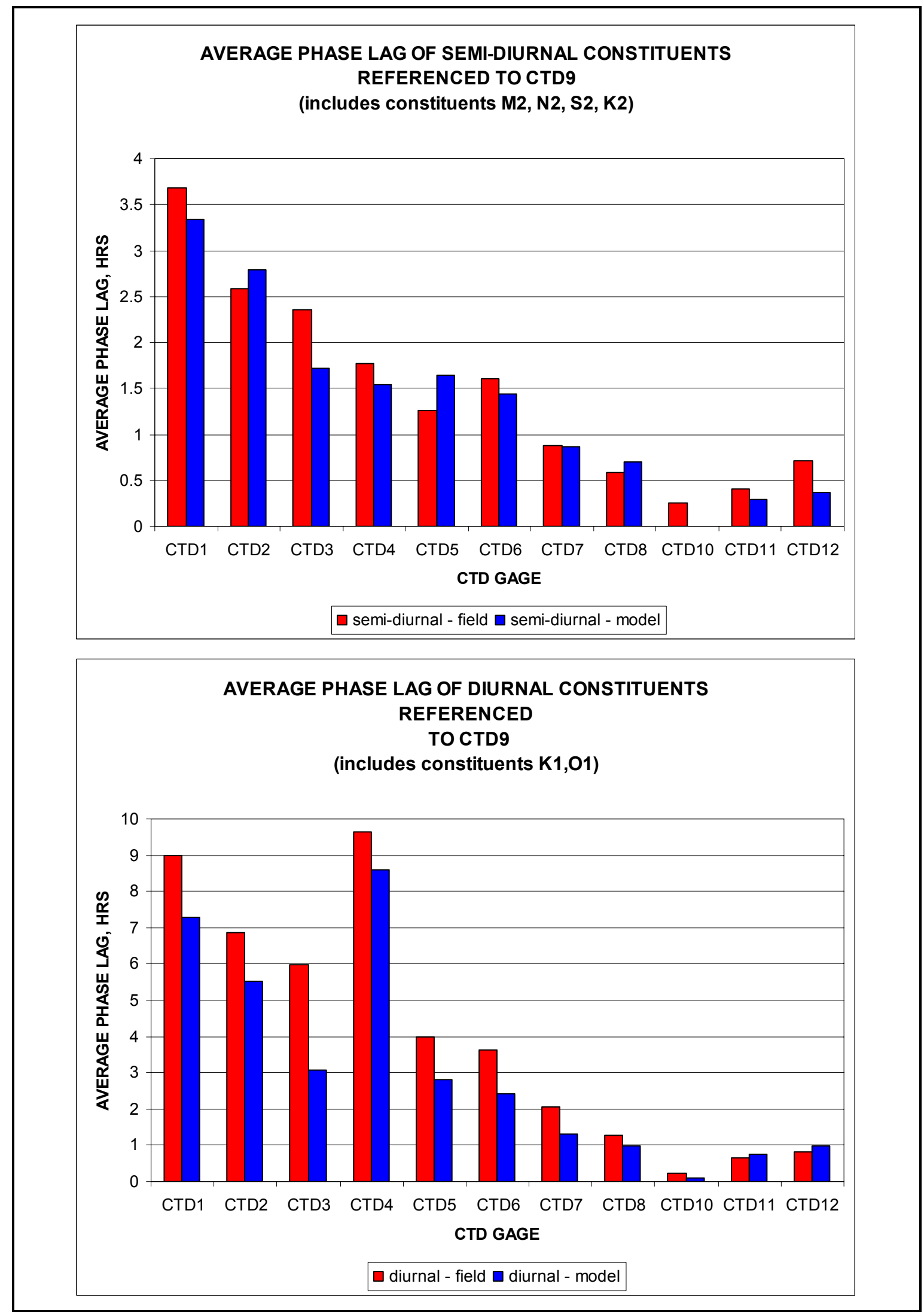

Plate 85 


\section{Appendix A TABS-MDS Theoretical Development}

This appendix contains a partial development of the equations used in TABSMDS (Multi-Dimensional Sediment), as well as a description of some of the empirical and theoretical expressions used to simulate various flow phenomena. The development of the equations includes the development of equations for three-dimensional (3-D), two-dimensional (2-D) laterally averaged, 2-D vertically averaged, and one-dimensional (1-D) elements. Although only 2-D vertically averaged elements are used in the present study, the form of the equations results from their reduction from the 3-D form, and hence an adequate explanation of the 2-D equations requires the inclusion of some discussion of the 3-D equations.

\section{TABS-MDS Introduction}

TABS-MDS is a finite element, hydrodynamic model. It is based on RMA10, a model written by Ian King, Resource Management Associates. ${ }^{1}$ It is capable of modeling turbulent, subcritical flows using 1-D, 2-D, and/or 3-D elements. It is also capable of modeling constituent transport. This includes modeling salinity, temperature, and/or fine-grained sediment. The model is capable of coupling the spatial density variation induced by concentration gradients in the constituent field to the hydrodynamic calculations. This enables the model to simulate phenomena such as saline wedges in estuaries. The model has features that permit the simulation of intermittently wetted regions of the domain, such as coastal wetlands.

\footnotetext{
1 All references cited in this appendix are listed in the References section at the end of the main
} text. 


\section{TABS-MDS Theoretical Development}

\section{3-D equations}

There are six unknowns $(u, v, w, h, s, \rho)$. Therefore, six equations are required.

The Navier-Stokes equations (i.e., conservation of fluid momentum)

$$
\begin{aligned}
& \rho \frac{\partial u}{\partial t}+\rho u \frac{\partial u}{\partial x}+\rho v \frac{\partial u}{\partial y}+\rho w \frac{\partial u}{\partial z}-\frac{\partial}{\partial x}\left(\varepsilon_{x x} \frac{\partial u}{\partial x}\right)-\frac{\partial}{\partial y}\left(\varepsilon_{x y} \frac{\partial u}{\partial y}\right) \\
& -\frac{\partial}{\partial z}\left(\varepsilon_{x z} \frac{\partial u}{\partial z}\right)+\frac{\partial p}{\partial x}-\tau_{x}=0 \\
& \rho \frac{\partial v}{\partial t}+\rho u \frac{\partial v}{\partial x}+\rho v \frac{\partial v}{\partial y}+\rho w \frac{\partial v}{\partial z}-\frac{\partial}{\partial x}\left(\varepsilon_{y x} \frac{\partial v}{\partial x}\right)-\frac{\partial}{\partial y}\left(\varepsilon_{y y} \frac{\partial v}{\partial y}\right) \\
& -\frac{\partial}{\partial z}\left(\varepsilon_{y z} \frac{\partial v}{\partial z}\right)+\frac{\partial p}{\partial y}-\tau_{y}=0 \\
& \rho \frac{\partial w}{\partial t}+\rho u \frac{\partial w}{\partial x}+\rho v \frac{\partial w}{\partial y}+\rho w \frac{\partial w}{\partial z}-\frac{\partial}{\partial x}\left(\varepsilon_{z x} \frac{\partial w}{\partial x}\right)-\frac{\partial}{\partial y}\left(\varepsilon_{z y} \frac{\partial w}{\partial y}\right) \\
& -\frac{\partial}{\partial z}\left(\varepsilon_{z z} \frac{\partial w}{\partial z}\right)+\frac{\partial p}{\partial z}+\rho g-\tau z=0
\end{aligned}
$$

\section{The Volume Continuity Equation}

$$
\frac{\partial u}{\partial x}+\frac{\partial v}{\partial y}+\frac{\partial w}{\partial z}=0
$$




\section{The Advection-Diffusion Equation}

$$
\begin{aligned}
& \frac{\partial s}{\partial t}+u \frac{\partial s}{\partial x}+v \frac{\partial s}{\partial y}+w \frac{\partial s}{\partial z}-\frac{\partial}{\partial x}\left(D_{x} \frac{\partial s}{\partial x}\right)-\frac{\partial}{\partial y}\left(D_{y} \frac{\partial s}{\partial y}\right) \\
& -\frac{\partial}{\partial z}\left(D_{z} \frac{\partial s}{\partial z}\right)-\theta_{s}=0
\end{aligned}
$$

\section{The Equation of State}

$$
\rho=F(s, t)
$$

where

$\tau=$ applied forces (e.g., wind stress, bed shear stress, Coriolis force)

$\theta_{s}=$ salinity source/sink term

Now reduce the number of unknowns requiring a simultaneous solution from 6 to 3 .

Assuming that the influence of vertical momentum on the system is small and may be neglected, Equation 3 reduces to the following equation:

$$
\frac{\partial p}{\partial z}+\rho g=0
$$

Equation 7 is a statement that the vertical pressure distribution is hydrostatic.

Equation 4 may then be integrated in the vertical direction to yield the following equation:

$$
\int_{a}^{a+h}\left(\frac{\partial u}{\partial x}+\frac{\partial v}{\partial y}\right) d \eta=-\int_{a}^{a+h} \frac{\partial w}{\partial z} d \eta=-w_{s}+w_{b}
$$

where

$$
\begin{aligned}
& w_{s}=\text { vertical velocity at the water surface } \\
& w_{b}=\text { vertical velocity at the bed }
\end{aligned}
$$

The surface velocity can be expressed as follows: 


$$
w_{s}=u_{s} \frac{\partial\left(z_{b}+h\right)}{\partial x}+v_{s} \frac{\partial\left(z_{b}+h\right)}{\partial y}+\frac{\partial\left(z_{b}+h\right)}{\partial t}
$$

Similarly, the bed velocity can be expressed as:

$$
w_{b}=u_{b} \frac{\partial z_{b}}{\partial x}+v_{b} \frac{\partial z_{b}}{\partial y}+\frac{\partial z_{b}}{\partial t}
$$

where

$$
\begin{aligned}
u_{s}, v_{s} & =\text { surface horizontal velocity components } \\
u_{b}, v_{b} & =\text { near bed horizontal velocity components } \\
z_{b} & =\text { bed elevation }
\end{aligned}
$$

Note that by replacing Equations 3 and 4 with 6 and 8, we recast the equations such that $\mathrm{w}$ is present only in the horizontal momentum equations and the advection diffusion equation. It can now be solved in a separate decoupled calculation using the original form of the continuity equation (Equation 4). This is done by taking the derivative of equation 4 with respect to $z$ and solving for $w$, applying $w_{s}$ and $w_{b}$ as boundary conditions.

You can further eliminate $\rho$ from the list of unknowns requiring a simultaneous solution by solving the equation of state (Equation 6) in a decoupled step.

Thus, you are left with four equations $(1,2,8$, and 5) and four unknowns ( $u$, $v, h$ and $s$ ) to be solved simultaneously. In practice, however, the solution is broken up into two steps. First the velocities and depth are solved simultaneously, and then the constituent concentration is solved. This method improves solution efficiency dramatically over the simultaneous solution of all four equations and unknowns.

Hence, the solution of a system of four equations and four unknowns becomes the solution of a system of three equations $(1,2$, and 8$)$ and three unknowns $(u, v$, and $h)$, followed by the solution of one equation (5) and one unknown $(s)$.

\section{Geometric transform}

In order to use a fixed geometry to model a system with a time varying vertical dimension (depth) it is convenient to use a geometric transformation to map the system to a fixed geometry. 
Time varying system

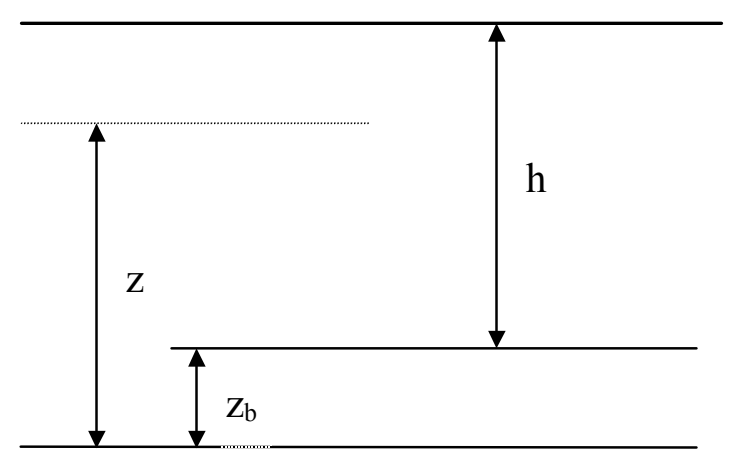

Fixed grid system

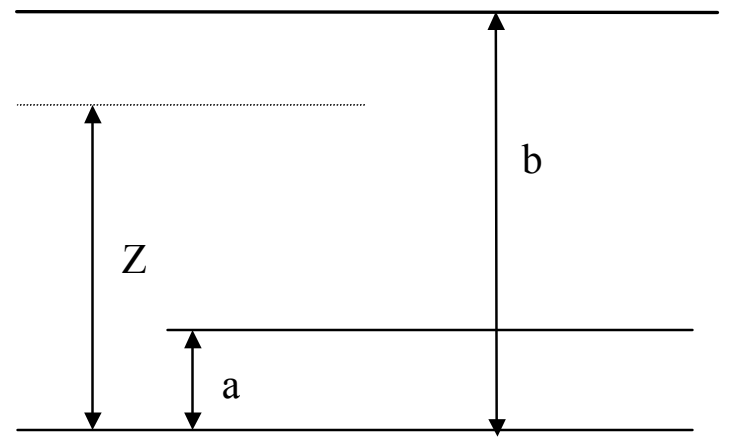

The transformation is based on the following relation:

$$
\begin{aligned}
& \frac{h}{\left(z-z_{b}\right)}=\frac{(b-a)}{(Z-a)} \\
& z=\frac{(Z-a)}{(b-a)} h+z_{b}
\end{aligned}
$$

Hence:

$$
U(x, y, z)=u\left(X, Y,\left(\left(\frac{Z-a}{b-a}\right) h+z_{b}\right)\right)
$$

After completing the transformation of the terms and simplifying, we arrive at the following transformed equations: 


\section{The Momentum equations}

$$
\begin{aligned}
& \left.\int\left[h \frac{\partial u}{\partial t}+h u \frac{\partial u}{\partial x}+h v \frac{\partial u}{\partial y}+\frac{\partial u}{\partial z}(b-a)\left(w-u T_{x}-v T_{y}-\frac{(z-a)}{(b-a)} \frac{\partial h}{\partial t}-\frac{\partial z b}{\partial t}\right)\right]\right] \\
& \left\{\begin{array}{l}
-h \frac{\partial}{\partial x}\left(\varepsilon_{x x} \frac{\partial u}{\partial x}\right)-h \frac{\partial}{\partial y}\left(\varepsilon_{x y} \frac{\partial u}{\partial y}\right)-(b-a) \frac{\partial}{\partial z}\left(\varepsilon_{x z}\left(\frac{(b-a)}{h}\right) \frac{\partial u}{\partial z}\right) \\
+\rho g h \frac{\partial z}{\partial x}+\rho g h \frac{\partial h}{\partial x}+h \frac{\partial p}{\partial x}+\rho g h \frac{\partial h_{D}}{\partial x}-h \tau_{x}
\end{array}\right\} \frac{1}{(b-a)}=0 \\
& \left\{\begin{array}{l}
\rho\left[h \frac{\partial v}{\partial t}+h u \frac{\partial v}{\partial x}+h v \frac{\partial v}{\partial y}+\frac{\partial v}{\partial z}(b-a)\left(w-u T_{x}-v T_{y}-\frac{(z-a)}{(b-a)} \frac{\partial h}{\partial t}-\frac{\partial z_{b}}{\partial t}\right)\right] \\
-h \frac{\partial}{\partial x}\left(\varepsilon_{y x} \frac{\partial v}{\partial x}\right)-h \frac{\partial}{\partial y}\left(\varepsilon_{y y} \frac{\partial v}{\partial y}\right)-(b-a) \frac{\partial}{\partial z}\left(\varepsilon_{y z}\left(\frac{(b-a)}{h}\right) \frac{\partial v}{\partial z}\right) \\
+\rho g h \frac{\partial z}{\partial y}+\rho g h \frac{\partial h}{\partial y}+h \frac{\partial p}{\partial y}+\rho g h \frac{\partial h D}{\partial y}-h \tau_{y}
\end{array}\right\} \frac{1}{(b-a)}=0
\end{aligned}
$$

\section{Volume continuity}

$$
\begin{aligned}
& \int_{a}^{b}\left[\frac{h}{(b-a)}\left(\frac{\partial u}{\partial x}+\frac{\partial v}{\partial y}\right)-\frac{\partial u}{\partial z} T_{x}-\frac{\partial v}{\partial z} T_{y}\right] d z \\
& +u_{s} \frac{\partial\left(z_{b}+h\right)}{\partial x}+v_{s} \frac{\partial\left(z_{b}+h\right)}{\partial y}+\frac{\partial\left(z_{b}+h\right)}{\partial t}-u_{b} \frac{\partial z_{b}}{\partial x}-v_{b} \frac{\partial z_{b}}{\partial y}-\frac{\partial z_{b}}{\partial t}=0
\end{aligned}
$$

\section{Advection-diffusion equation}

$$
\left\{\begin{array}{l}
h \frac{\partial s}{\partial t}+h u \frac{\partial s}{\partial x}+h v \frac{\partial s}{\partial y}+\frac{\partial s}{\partial z}(b-a)\left(w-u T_{x}-v T_{y}-\frac{(z-a)}{(b-a)} \frac{\partial h}{\partial t}-\frac{\partial z_{b}}{\partial t}\right) \\
-h \frac{\partial}{\partial x}\left(D_{x} \frac{\partial s}{\partial x}\right)-h \frac{\partial}{\partial y}\left(D_{y} \frac{\partial s}{\partial y}\right)-(b-a) \frac{\partial}{\partial z}\left(D_{z}\left(\frac{(b-a)}{h}\right) \frac{\partial s}{\partial z}\right)-h \theta_{s}
\end{array}\right\} \frac{1}{(b-a)}=0
$$


where

$$
\begin{aligned}
& T_{x}=\frac{\partial z_{b}}{\partial x}+\frac{(z-a)}{(b-a)} \frac{\partial h}{\partial x}-\frac{h}{(b-a)} \frac{\partial a}{\partial x}+\frac{(z-a)}{(b-a)^{2}} h \frac{\partial a}{\partial x} \\
& T_{y}=\frac{\partial z_{b}}{\partial y}+\frac{(z-a)}{(b-a)} \frac{\partial h}{\partial y}-\frac{h}{(b-a)} \frac{\partial a}{\partial y}+\frac{(z-a)}{(b-a)^{2}} h \frac{\partial a}{\partial y} \\
& h_{D}=-\frac{(b-z)}{(b-a)} h
\end{aligned}
$$

\section{2-D vertically averaged equations}

If $u, v$, and $s$ are assumed constant with respect to elevation (z), the 3-D equations can be integrated over depth to yield 2-D vertically averaged equations. For example, the X-momentum equation reduces to the following:

$$
\left\{\begin{array}{l}
\rho(b-a)\left[h \frac{\partial u}{\partial t}+h u \frac{\partial u}{\partial x}+h v \frac{\partial u}{\partial y}\right] \\
-h(b-a) \frac{\partial}{\partial x}\left(\varepsilon_{x x} \frac{\partial u}{\partial x}\right)-h(b-a) \frac{\partial}{\partial y}\left(\varepsilon_{x y} \frac{\partial u}{\partial y}\right) \\
+\rho g h(b-a)\left(\frac{\partial z_{b}}{\partial x}+\frac{\partial h}{\partial x}\right)+(b-a) \frac{g h^{2}}{2} \frac{\partial \rho}{\partial x}-h(b-a) \tau_{x}
\end{array}\right\} \frac{1}{(b-a)}=0
$$

Similarly, the continuity equation reduces to:

$$
h\left(\frac{\partial u}{\partial x}+\frac{\partial v}{\partial y}\right)+u \frac{\partial h}{\partial x}+v \frac{\partial h}{\partial y}+\frac{\partial h}{\partial t}=0
$$

And the advection-diffusion equation reduces to:

$$
\left\{\begin{array}{l}
h(b-a) \frac{\partial s}{\partial t}+h(b-a) u \frac{\partial s}{\partial x}+h(b-a) v \frac{\partial s}{\partial y} \\
-h(b-a) \frac{\partial}{\partial x}\left(D_{x} \frac{\partial s}{\partial x}\right)-h(b-a) \frac{\partial}{\partial y}\left(D_{y} \frac{\partial s}{\partial y}\right)-h(b-a) \theta_{s}
\end{array}\right\} \frac{1}{(b-a)}=0
$$




\section{2-D laterally averaged equations}

Lateral averaging eliminates the momentum equation in the direction normal to the dominant flow direction. The equations are integrated across the width of the channel. This operation requires that the channel width $c$ is specified. For the purposes of TABS-MDS, the channel width in laterally averaged elements is constrained such that it is constant with respect to depth, but can vary with respect to $\mathrm{x}$ and $\mathrm{y}$ (i.e., along the channel length). For example, the Xmomentum equation reduces to the following.

$$
\left\{\begin{array}{l}
\rho\left[h \frac{\partial u}{\partial t}+h u \frac{\partial u}{\partial x}+\frac{\partial u}{\partial z}(b-a)\left(w-u T_{x}-\frac{(z-a)}{(b-a)} \frac{\partial h}{\partial t}-\frac{\partial z_{b}}{\partial t}\right)\right] \\
-h \frac{\partial}{\partial x}\left(\varepsilon_{x x} \frac{\partial u}{\partial x}\right)-(b-a) \frac{\partial}{\partial z}\left(\varepsilon_{x z}\left(\frac{(b-a)}{h}\right) \frac{\partial u}{\partial z}\right) \\
+\rho g h \frac{\partial z_{b}}{\partial x}+\rho g h \frac{\partial h}{\partial x}+h \frac{\partial p}{\partial x}+\rho g h \frac{\partial h_{D}}{\partial x}-h \tau_{x}
\end{array}\right\} \frac{c}{(b-a)}=0
$$

Similarly, the continuity equation reduces to:

$$
\begin{aligned}
& \int_{a}^{b}\left[\frac{h}{(b-a)}\left(c \frac{\partial u}{\partial x}+u \frac{\partial c}{\partial x}\right)-c \frac{\partial u}{\partial z} T_{x}\right] d z \\
& +c u_{s} \frac{\partial\left(z_{b}+h\right)}{\partial x}+\frac{\partial\left(z_{b}+h\right)}{\partial t}-c u_{b} \frac{\partial a}{\partial x}-\frac{\partial z_{b}}{\partial t}=0
\end{aligned}
$$

And the advection-diffusion equation reduces to:

$$
\left\{\begin{array}{l}
h \frac{\partial s}{\partial t}+h u \frac{\partial s}{\partial x}+\frac{\partial s}{\partial z}(b-a)\left(w-u T_{x}-\frac{(z-a)}{(b-a)} \frac{\partial h}{\partial t}-\frac{\partial z_{b}}{\partial t}\right) \\
-h \frac{\partial}{\partial x}\left(D_{x} \frac{\partial s}{\partial x}\right)-(b-a) \frac{\partial}{\partial z}\left(D_{z}\left(\frac{(b-a)}{h}\right) \frac{\partial s}{\partial z}\right)-h \theta_{s}
\end{array}\right\} \frac{c}{(b-a)}=0
$$




\section{1-D equations}

Under this approximation both vertical and lateral integration are applied. Hence, the form of the cross section must be defined. In TABS-MDS, the cross section is assumed trapezoidal, with allowance made for off-channel storage. For example, the $\mathrm{X}$-momentum equation reduces to the following:

$$
\left\{\begin{array}{l}
\rho\left[A \frac{\partial u}{\partial t}+A u \frac{\partial u}{\partial x}\right] \\
-A \frac{\partial}{\partial x}\left(\varepsilon_{x x} \frac{\partial u}{\partial x}\right) \\
+\rho g A \frac{\partial z_{b}}{\partial x}+\rho g A \frac{\partial h}{\partial x}+\frac{g A h}{2} \frac{\partial \rho}{\partial x}-A \tau_{x}
\end{array}\right\}=0
$$

Similarly, the continuity equation reduces to:

$$
A\left(\frac{\partial u}{\partial x}\right)+u \frac{\partial A}{\partial x}+\frac{\partial\left(A+A_{O C}\right)}{\partial t}=0
$$

And the advection diffusion equation reduces to:

$$
\left\{\left(A+A_{O C}\right) \frac{\partial s}{\partial t}+A \frac{\partial s}{\partial x}-A \frac{\partial}{\partial x}\left(D_{x} \frac{\partial s}{\partial x}\right)-A \theta_{s}\right\}=0
$$

where

$$
\begin{aligned}
A & =\text { main channel cross-sectional area } \\
A_{O C} & =\text { off-channel storage cross-sectional area }
\end{aligned}
$$




\section{Finite element formulation}

To generate the finite element equations, integrate each of the equations over the element volume (for 3-D), area (for 2-D), or length (for 1-D), remembering to include the weight function in the integration (which, for the Galerkin method, is the same as the basis function).

In addition, recast the higher-order terms using integration by parts. This causes the boundary terms to drop out of the equations. For example, take the following pressure term, multiplied through by a weight function $N$ :

$$
N \frac{\rho g h}{(b-a)} \frac{\partial h}{\partial x}
$$

This can be rewritten as:

$$
N \frac{\rho g}{2(b-a)} \frac{\partial h^{2}}{\partial x}
$$

Then, it can be integrated by parts:

$$
\begin{aligned}
& N \frac{\rho g}{2(b-a)} \frac{\partial h^{2}}{\partial x}=\frac{\partial}{\partial x}\left(N \frac{\rho g h^{2}}{2(b-a)}\right)-\frac{\partial N}{\partial x}\left(\frac{\rho g h^{2}}{2(b-a)}\right) \\
& -N \frac{g h^{2}}{2(b-a)} \frac{\partial \rho}{\partial x}-N \frac{\rho g h^{2}}{2(b-a)^{2}} \frac{\partial a}{\partial x}
\end{aligned}
$$

Note that the first term on the right-hand side of the equation can be evaluated as an area integral via the Gauss Divergence Theorem. Hence, it becomes a boundary term.

\section{Time derivative solution method}

The time derivative is approximated with a simple, fully implicit finite difference formulation, i.e.,

$$
\frac{\partial \beta_{t}}{\partial t}=\frac{\left(\beta_{t}-\beta_{t-\Delta t}\right)}{\Delta t}
$$


where

$$
\begin{aligned}
\beta_{t} & =\text { any of the unknown variables at time } \mathrm{t} \\
\Delta t & =\text { the time-step }
\end{aligned}
$$

\section{Newton-Rhapson implementation}

Once the finite element equations are built, they are solved using the Newton-Rhapson iterative method. In order to do this, partial derivatives with respect to each of the unknown variables must be derived for each system equation. These derivatives compose the stiffness matrix and are used to drive the residual (i.e., the integral of each equation across an element) to 0.

$$
\left[\begin{array}{c}
X_{u} Y_{u} Z_{u} \\
X_{v} Y_{v} Z_{v} \\
X_{h} Y_{h} Z_{h}
\end{array}\right]\left[\begin{array}{c}
u \\
v \\
h
\end{array}\right]=\left[\begin{array}{c}
X \\
Y \\
Z
\end{array}\right]
$$

\section{Expressions for Applied Loads and Turbulent Mixing}

\section{Bed shear stress}

The bed shear stress is given by a modified form of Manning's Equation, as given by Christensen (1970). Any of 3 expressions can be used, depending on the instantaneous value of the depth/roughness height ratio $\left(\frac{d}{k}\right)$. The expressions are as follows (given for the $\mathrm{X}$-direction only):

$$
\begin{aligned}
& \text { for } \frac{d}{k}<4.32 \quad \tau_{x}=\frac{\rho g}{L^{2}} \frac{|v| v_{x}}{d^{2 / 3}} \quad \text { where } L=\frac{6.46 \sqrt{g}}{k^{1 / 3}} \\
& \text { for } 4.32<\frac{d}{k}<276 \quad \tau_{x}=\frac{\rho g}{M^{2}} \frac{|v| v_{x}}{d^{1 / 3}} \quad \text { where } M=\frac{8.25 \sqrt{g}}{k^{1 / 6}} \\
& \text { for } \frac{d}{k}>276 \quad \tau_{x}=\frac{\rho g}{N^{2}} \frac{|v| v_{x}}{d^{1 / 6}} \quad \text { where } N=\frac{13.18 \sqrt{g}}{k^{1 / 12}}
\end{aligned}
$$


where

$$
\begin{aligned}
\tau_{x} & =\text { bed shear in the } \mathrm{x} \text {-direction } \\
k & =\text { roughness height } \\
d & =\text { local depth } \\
v & =\text { local velocity } \\
g & =\text { gravitational constant } \\
\rho & =\text { density of water }
\end{aligned}
$$

$k$ is found as a function of Manning's $\mathrm{n}$ from the following expression:

$$
k=\left(\frac{8.25 \sqrt{g} n}{1.486}\right)^{6}
$$

\section{Wind stress}

The wind stress is given by the following expression (given for the $\mathrm{x}-$ direction only):

$$
\tau_{w x}=\rho_{a} C_{w} V_{w}^{2} \cos \theta_{w}
$$

where

$$
\begin{aligned}
\tau_{w x}= & \text { wind stress in x-direction } \\
\rho_{a}= & \text { density of air } \\
V_{w}= & \text { wind velocity } \\
\theta_{w}= & \text { direction from which the wind is blowing, measured counterclockwise } \\
& \text { from positive } \mathrm{x} \text {-axis. } \\
C_{w}= & \text { wind stress coefficient }
\end{aligned}
$$

The wind stress coefficient is given by $\mathrm{Wu}(1980)$.

$$
C_{w}=\frac{0.8+0.065 \times V_{w}}{1000}
$$




\section{Horizontal turbulent mixing and diffusion}

Horizontal turbulent mixing can be specified directly, or it can be controlled by the method of Smagorinsky (1963). A description of this method follows.

The Smagorinsky method of describing horizontal eddy viscosities and diffusion coefficients is a "tensorially invariant generalization of the mixing length type representation" (Speziale 1998). The Smagorinsky description of the turbulent mixing terms in the Navier-Stokes equations are given as follows. For the $\mathrm{x}$-momentum equation

$$
\rho h \frac{\partial}{\partial x}\left(2 S \frac{\partial u}{\partial x}\right)+\rho h \frac{\partial}{\partial y}\left(S\left(\frac{\partial u}{\partial y}+\frac{\partial v}{\partial x}\right)\right)
$$

For the $y$ momentum equation

$$
\rho h \frac{\partial}{\partial y}\left(2 S \frac{\partial v}{\partial y}\right)+\rho h \frac{\partial}{\partial x}\left(S\left(\frac{\partial u}{\partial y}+\frac{\partial v}{\partial x}\right)\right)
$$

where

$$
S=k A\left[\left(\frac{\partial u}{\partial x}\right)^{2}+\left(\frac{\partial v}{\partial y}\right)^{2}+\frac{1}{2}\left(\frac{\partial u}{\partial y}+\frac{\partial v}{\partial x}\right)^{2}\right]^{\frac{1}{2}}
$$

$k=$ Smagorinsky coefficient, usually given a value ranging from approximately 0.005 for rivers to 0.05 for estuaries and lakes (Speziale 1998; Thomas and Williams 1995)

$A=$ surface area of the element

The Smagorinsky description of the turbulent diffusion terms in the advectiondiffusion equation is given as follows:

$$
h \frac{\partial}{\partial x}\left(2 S \frac{\partial C}{\partial x}\right)+h \frac{\partial}{\partial y}\left(2 S \frac{\partial C}{\partial y}\right)
$$

In order to promote numerical stability, TABS-MDS provides a means of establishing minimum values of turbulent mixing and turbulent diffusion. These values are used in place of the Smagorinsky term $(S)$ when they are found to exceed the value of that term. The minimum turbulent mixing value is given by the following equation: 


$$
S_{E \min }=\mathrm{TBMINF} \times \rho \alpha \sqrt{A}
$$

The minimum turbulent diffusion value is given by the following equation:

$$
S_{D \min }=\mathrm{TBMINFS} \times \alpha \sqrt{A}
$$

where

$$
\begin{aligned}
\text { TBMINF }= & \text { minimum turbulent mixing factor }(\text { default }=1.0) \\
\text { TBMINFS }= & \text { minimum diffusion factor }(\text { default }=1.0) \\
\alpha= & \text { a coefficient, given as } 5.00 \times 10^{-3} \mathrm{ft} / \mathrm{sec} \text { or } 1.52 \times 10^{-3} \mathrm{~m} / \mathrm{s}, \\
& \text { depending on the unit system being used in the simulation. } \\
& \text { This value is an arbitrary estimate of the minimum turbulent } \\
& \text { mixing needed to ensure model stability. It equals the value of } \\
& \text { eddy viscosity } / \text { diffusion which corresponds to a Peclet number } \\
& \text { of } 40 \text { and a velocity magnitude of } 0.2 \mathrm{ft} / \mathrm{sec} .
\end{aligned}
$$

Also, if $|\mathrm{V}|<\mathrm{TBMINF} \times V_{\min }, S_{E \min }$ is applied, regardless of the turbulent mixing as given by the Smagorinsky calculation. This is done to inhibit numerical instability in areas with both extremely small velocities and high velocity gradients.

\section{Vertical turbulent mixing and diffusion}

Vertical turbulent mixing and diffusion are given by the method of MellorYamada (1982) with a modification according to Hendersen-Sellers (1984).

The Mellor-Yamada expressions for vertical eddy viscosity and diffusion are given as follows:

$$
\begin{aligned}
& E_{x z}=E_{y z}=\rho S_{m} l_{m} q \\
& D_{z}=S_{h} l_{m} q
\end{aligned}
$$

where

$$
l_{m}=0.4(z-a)\left|1-\frac{(z-a)}{h}\right|^{\frac{1}{2}}
$$




$$
\begin{aligned}
q & =\left\{b_{1} l_{m}^{2} S_{m}\left[\left|\frac{\partial u}{\partial z}\right|^{2}+\left|\frac{\partial v}{\partial z}\right|^{2}\right]\right\}^{\frac{1}{2}} \\
S_{m} & =0.393 \\
S_{h} & =0.494 \\
b_{1} & =16.6
\end{aligned}
$$

The Henderson-Sellers adjustment is a factor that accounts for the dampening affect on turbulence induced by stable stratification. The factor is expressed in terms of the Richardson number:

$$
R_{i}=\frac{-g(\partial \rho / \partial z)}{\rho\left[\left(\frac{\partial u}{\partial z}\right)^{2}+\left(\frac{\partial v}{\partial z}\right)^{2}\right]}
$$

For vertical diffusion of momentum (i.e., vertical eddy viscosity) the expression is given as follows:

$$
E_{z}=\frac{E_{z o}}{\left(1+0.74 R_{i}\right)}
$$

where $E_{z}$ is the vertical eddy viscosity, and $E_{z o}$ is the vertical eddy viscosity assuming no stratification influence on the turbulence (i.e., the value taken from Mellor-Yamada).

For vertical diffusion of salinity (i.e., vertical diffusion coefficient) the expression is given as follows:

$$
D_{z}=\frac{D_{z o}}{\left(1+37 R_{i}^{2}\right)}
$$

where $D_{z}$ is the vertical diffusion coefficient, and $D_{z o}$ is the vertical diffusion coefficient assuming no stratification influence on the turbulence (i.e., the value taken from Mellor-Yamada). 


\section{REPORT DOCUMENTATION PAGE}

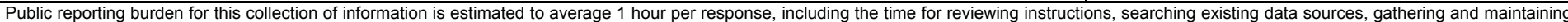

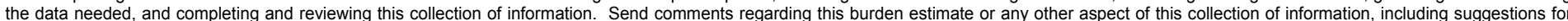

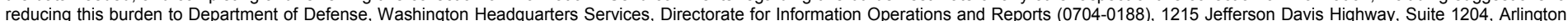

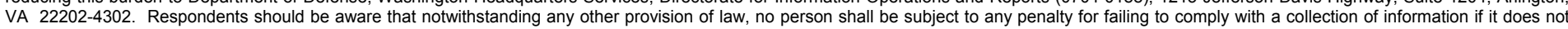
display a currently valid OMB control number. PLEASE DO NOT RETURN YOUR FORM TO THE ABOVE ADDRESS.

\begin{tabular}{l|c}
$\begin{array}{l}\text { 1. REPORT DATE (DD-MM-YYYY) } \\
\text { September } 2003\end{array}$ & $\begin{array}{c}\text { 2. REPORT TYPE } \\
\text { Final report }\end{array}$ \\
\hline
\end{tabular}

\section{TITLE AND SUBTITLE}

Development of Two-Dimensional Numerical Model of Hydrodynamics and Salinity for

Biscayne Bay, Florida

3. DATES COVERED (From - To)

5a. CONTRACT NUMBER

5b. GRANT NUMBER

5c. PROGRAM ELEMENT NUMBER

5d. PROJECT NUMBER

5e. TASK NUMBER

5f. WORK UNIT NUMBER

8. PERFORMING ORGANIZATION REPORT NUMBER

ERDC/CHL TR-03-10

3909 Halls Ferry Road, Vicksburg, MS 39180-6199;

U.S. Army Engineer District, Jacksonville

P.O. Box 4970, Jacksonville, FL 32232-0019

\section{SPONSORING / MONITORING AGENCY NAME(S) AND ADDRESS(ES)}

U.S. Army Corps of Engineers

Washington, DC 20314-1000;

U.S. Army Engineer District, Jacksonville

P.O. Box 4970, Jacksonville, FL 32232-0019

\section{DISTRIBUTION / AVAILABILITY STATEMENT}

Approved for public release; distribution is unlimited.

\section{SUPPLEMENTARY NOTES}

\section{ABSTRACT}

This report documents the development of a verified 2-D numerical model of the hydrodynamics and salinity of Biscayne Bay, FL. The computer code employed for this study was TABS-MDS (multidimensional sediment) (formerly called RMA10-WES). The model was calibrated and verified against an extensive set of hydrodynamic and salinity field data collected in a previous effort performed by the U.S. Army Engineer Research and Development Center, Coastal and Hydraulics Laboratory, in conjunction with the Biscayne National Park. This report discusses general characteristics of the Biscayne Bay system, model development, model boundary condition, and calibration and verification results.

\section{SUBJECT TERMS}

See reverse.

16. SECURITY CLASSIFICATION OF:

a. REPORT

UNCLASSIFIED

b. ABSTRACT
UNCLASSIFIED

c. THIS PAGE

UNCLASSIFIED

\begin{tabular}{l|c|}
$\begin{array}{l}\text { 17. LIMITATION } \\
\text { OF ABSTRACT }\end{array}$ & $\begin{array}{c}\text { 18. NUMBER } \\
\text { OF PAGES } \\
173\end{array}$ \\
\cline { 2 - 3 } &
\end{tabular}

19a. NAME OF RESPONSIBLE PERSON

19b. TELEPHONE NUMBER (include area code) 
15. (Concluded)

Biscayne Bay

Boundary conditions

Calibration

Diffusion coefficient

Eddy Viscosity

Index of Agreement

Initial Conditions

Manning's n

Marsh porosity

Sensitivity tests

Smagorinsky Parameter

Verification

Variance ellipse

Numerical modeling 